UNIVERSIDADE DE SÃO PAULO

ESCOLA DE ENFERMAGEM

GUILHERME CORREA BARBOSA

AVALIAÇÃO DO CENTRO DE ATENÇÃO PSICOSSOCIAL EM ÁLCOOL E OUTRAS DROGAS DO MUNICÍPIO DE BOTUCATU

SÃO PAULO

2013 


\section{AVALIAÇÃO DO CENTRO DE ATENÇÃO PSICOSSOCIAL EM ÁLCOOL E OUTRAS DROGAS DO MUNICÍPIO DE BOTUCATU.}

Tese de Doutorado apresentada ao Programa de Pós-Graduação em Enfermagem da Escola de Enfermagem de São Paulo da Universidade de São Paulo, para obtenção do título de Doutor em Ciências.

Área de Concentração: Ciências da Saúde.

Orientadora: Prof. ${ }^{a}$ Dr. ${ }^{\text {a }}$ Márcia Aparecida Ferreira de Oliveira

Versão corrigida.

\section{SÃO PAULO}

2013 


\begin{abstract}
AUTORIZO A REPRODUÇÃO E DIVULGAÇÃO TOTAL OU PARCIAL DESTE TRABALHO, POR QUALQUER MEIO CONVENCIONAL OU ELETRÔNICO, PARA FINS DE ESTUDO E PESQUISA, DESDE QUE CITADA A FONTE.
\end{abstract}

Assinatura:

Data:

Barbosa, Guilherme Correa

Avaliação do Centro de Atenção Psicossocial em Álcool e Outras Drogas do Município de Botucatu / Guilherme Correa Barbosa. - São Paulo, 2013.

$238 \mathrm{p}$.

Tese (Doutorado) - Escola de Enfermagem da Universidade de São Paulo.

Orientadora: Prof ${ }^{a}$. Dr ${ }^{\mathrm{a}}$. Márcia Aparecida Ferreira de Oliveira

1. Avaliação em Saúde; 2. Serviços de Saúde;

3. Serviços Comunitários de Saúde Mental I. Título. 
NOME: GUILHERME CORREA BARBOSA

TíTULO: Avaliação do Centro de Atenção Psicossocial em Álcool e Outras Drogas do Município de Botucatu

Tese de Doutorado apresentada ao Programa de Pós Graduação em Enfermagem da Escola de Enfermagem de São Paulo da Universidade de São Paulo, para obtenção do título de Doutor em Ciências.

Aprovado em

Banca Examinadora

Prof. Dr. Instituição:

Julgamento: Assinatura:

Prof. Dr. Instituição:

Julgamento: Assinatura:

Prof. Dr. Instituição:

Julgamento: Assinatura:

Prof. Dr. Instituição:

Julgamento: Assinatura:

Prof. Dr. Instituição: Julgamento: Assinatura: 


\section{DEDICATÓRIA}

À Deus, que sempre esteve ao meu lado cuidando de mim incondicionalmente.

À meus pais, Edson e Alinéia, por sempre acreditarem em mim, depositando em mim confiança e segurança para vencer as dificuldades, e pelos valores que sempre passaram a mim, tais como o afeto, a persistência, honestidade e humildade.

À meu irmão que sempre esteve ao meu lado nos momentos de alegria e de dificuldades, um amigo que sempre terei por perto.

À Tatiana e ao Bernardo que estiveram ao meu Cado nas lagrimas e nos sorrisos. Companfia para todos os momentos. 


\section{AGRADECIMMENTOS}

"Cada pessoa que passa em nossa vida, passa sozinha, é porque cada pessoa é única e nenhuma substitui a outra! Cada pessoa que passa em nossa vida passa sozinha e não nos deixa só porque deixa um pouco de si e leva um pouquinho de nós. Essa é a mais bela responsabilidade da vida e a prova de que as pessoas não se encontram por acaso." (Charles Chaplin)

Á Prof. ${ }^{a}$ Dr. ${ }^{a}$ Márcia Aparecida Ferreira de Oliveira por me acolher e por acreditar em minha competência, contribuindo para o meu crescimento científico e intelectual. Tendo paciência em entender e me ajudar a vencer minhas dificuldades e obstáculos com carinho e atenção.

Ao Prof. Dr. Carlos Roberto Padovani que me acolheu em momentos de angustia, me ajudou, apoiou e incentivou em minha pesquisa, podendo me acalmar e mostrar que tudo é possível.

Á Prof. ${ }^{a}$ Dr. ${ }^{a}$ Vânia Moreno, minha companheira na trajetória acadêmica. Aquela amiga para todos os momentos, uma pessoa singular. 
Á Prof. ${ }^{a}$ Dr. ${ }^{a}$ Lislaine, Prof. Dr. Carlos Siqueira, que puderam contribuir no amadurecimento de minha pesquisa durante a caminhada do doutorado, acolhendo e ajudando com carinho e muita humanidade.

Aos professores da Escola de Enfermagem de São Paulo - USP que estiveram presentes nesta fase da minha vida, contribuindo com meu amadurecimento e crescimento intelectual durante as disciplinas.

Ao Mauricio e ao Gilberto pela acolfida, incentivo e carinho de sempre, grandes companheiros nesta caminhada.

À Equipe, aos usuários e familiares do Centro de Atenção Psicossocial em Álcoole Outras Drogas de Botucatu pelo apoio, carinho, e acolhida para obtenção dos dados.

E aos amigos em que tive oportunidade de conhecer em São Paulo durante o curso, Heloísa Veiga, Heloisa Claro, Luciana Cordeiro, Ricardo Soares, Paula Pinho, Rejane, Neuri Pires, Maria Odete, Rosana Tarifa, Marina Bittencourt, Jandro, Gilberto Prates, e a todo o Grupo de Estudos em Álcool e outras Drogas - GEADUSP;

À secretária da Pós-Graduação da Escola de Enfermagem de São Paulo - USP, pelo carinho, atenção a cada atendimento e orientação. 
"Não faças do amanhã o sinônimo de nunca, nem o ontem te seja o mesmo que nunca mais.

Teus passos ficaram. OChes para trás ... mas vá em frente pois há muitos que precisam que chegues para poderem seguir-te."(Charles Chaplin) 
Barbosa GC. Avaliação do centro de atenção psicossocial em álcool e outras drogas do município de Botucatu. [tese]. São Paulo: Escola de Enfermagem, Universidade de São Paulo; 2013.

\section{RESUMO}

Introdução: Com o processo de desinstitucionalização psiquiátrica e a consequente reestruturação dos serviços de assistência em saúde mental, tem sido cada vez mais enfatizada a necessidade de avaliação dos equipamentos que compõem a Rede de Atenção Psicossocial. Diante da complexidade que envolve os sistemas de saúde e saúde mental, a avaliação é considerada como essencial para a garantia de qualidade dos serviços. A Organização Mundial de Saúde (OMS) destaca a necessidade de incorporar a avaliação dos resultados do tratamento como prática contínua e permanente, utilizando os dados da avaliação para melhorar a qualidade da assistência prestada. Objetivo: Este estudo tem por objetivo avaliar quantitativamente a estrutura, o processo de trabalho, a organização da atenção em saúde mental e o resultado da atenção em saúde mental oferecida pelo Centro de Atenção Psicossocial Il em álcool e outras drogas (CAPSad) do município de Botucatu. Método: O estudo foi realizado em um CAPSad do município de Botucatu. Para a coleta dos dados utilizou-se de quatro instrumentos (coordenador, trabalhador, usuário e familiar) compostos pela "Escala de Satisfação - SATIS-Br", Escala de Mudança Percebida (EMP) e Escala de Atitudes Frente ao Álcool, Alcoolismo e Alcoolista (EAFAAA) e questões sobre os dados sociodemográficos, estrutura do serviço, recursos humanos e materiais e uso de álcool e outras drogas. Os dados foram processados de forma descritiva pelo Programa Statistical Package for Social Sciences (SPSS), versão 20,0 para Windows $\AA^{\circledR}$. Resultados: A amostra foi de 01 coordenador, 19 trabalhadores, 25 usuários e 15 familiares. Foram obtidos níveis elevados de satisfação para usuário e familiares, e níveis intermediários de satisfação para trabalhadores com relação aos aspectos avaliados no serviço. Em 
relação à percepção de mudança teve-se percentuais elevados tanto para usuários quanto para familiares. Na questão de melhora global, $100 \%$ dos familiares perceberam a melhora em geral na vida de seu familiar, desde o início do tratamento, sendo que para os usuários $88 \%$ perceberam a ocorrência de melhora em seu tratamento. Evidenciou-se atitudes negativas desses trabalhadores frente ao alcoolismo, ao alcoolista e à bebida alcoólica, pois a maioria das médias dos fatores permaneceu na zona intermediária. Os resultados apontam a necessidade de investimentos em capacitações e cursos de atualização para os profissionais e melhora de pontos específicos em relação a infraestrutura do serviço. Como este estudo foi realizado em um único serviço de saúde mental, não pode ser generalizado para outros serviços.

Descritores: Avaliação em Saúde. Serviços de saúde. Serviços Comunitários de Saúde Mental. 
Barbosa GC Evaluation of the psychosocial care center for alcohol and other drugs from the city of Botucatu - São Paulo 2013. [thesis]. São Paulo (SP), Brasil: Escola de Enfermagem, Universidade de São Paulo; 2013.

\section{ABSTRACT}

Introduction: With the psychiatric deinstitutionalization and consequent restructuring of the mental health services, it is increasingly emphasized the need for evaluating services from the Network for Psychosocial Care. Given the complexity involved in health systems and mental health, evaluation is considered essential for quality assurance of the services. The World Health Organization (WHO ) emphasizes the need to incorporate the assessment of treatment outcomes as a continuous and ongoing practice, using assessment data to improve quality of care. Objective: This study aims to evaluate quantitatively the structure, work process, the organization of mental health care and outcomes of mental health care provided by the Psychosocial Care Center II for alcohol and other drugs (CAPSad) from the city of Botucatu . Method: The study was conducted in a CAPSad in Botucatu. To collect the data four instruments (coordinator, worker, family and user) were administered to the participants. Those instruments were composed by "Satisfaction Scale SATIS - BR " Perceived Change Scale (EMP) and the Scale of Attitudes Towards Alcohol, Alcoholism and alcoholic (EAFAAA). The instruments were also composed by sociodemographic data, service structure, human and material resources and the use of alcohol and other drugs. Descriptive analysis of the data was performed using the software Statistical Package for Social Sciences (SPSS) version 20.0 for Windows ${ }^{\circledR}$. Results: The sample consisted of 01 coordinator, 19 workers, 25 users and 15 relatives. We obtained high levels of users and family satisfaction, and intermediate levels of satisfaction for employees with respect to the evaluated service. Regarding the perceived change, the data showed high percentages of change for both users and for family. 
On a global question about improvements, $100 \%$ of the families noticed an improvement in the overall life of their relatives, when comparing to the beginning of treatment, and $88 \%$ of the users noticed the occurrence of improvement in their treatment. The data showed a tendency toward negative attitudes of these workers towards alcohol, alcoholism and alcoholics because for most means of factors remained in the intermediate zone. The results highlight the need for investment in training and extension courses for professionals and the need to improve specific points regarding the service infrastructure. As this study was conducted in a single mental health service, this results cannot be generalized to other services .

Keywords: Health Evaluation. Health services. Community Mental Health Services. 


\section{LISTA DE QUADROS}

Quadro 1 Definição dos conceitos dos componentes Donabedianos......64

Quadro 2 Descrição da População total, estimativa de usuários de álcool e outras drogas do município de Botucatu. 


\section{LISTA DE FIGURAS}

Figura 1 Modelo lógico para atenção em saúde mental no CAPS.........67

Figura 2 Fluxograma da qualidade da atenção em Saúde Mental do CAPSad do Município de Botucatu..........................................69

Figura 3 Fluxograma do CAPSad do município de Botucatu................ 82 


\section{LISTA DE GRÁFICOS}

Gráfico 1 Descrição da satisfação do ambiente dos trabalhadores do Centro de Atenção Psicossocial Álcool e Outras Drogas em

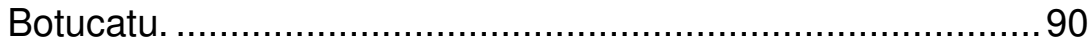

Gráfico 2 Descrição da abordagem terapêutica dos trabalhadores do Centro de Atenção Psicossocial Álcool e Outras Drogas em Botucatu. 


\section{LISTA DE TABELAS}

Tabela 1 Caracterização dos trabalhadores do Centro de Atenção Psicossocial Álcool e Outras Drogas em Botucatu, segundo gênero, etnia, faixa etária, estado civil, escolaridade, tempo de trabalho em CAPSad, tempo de trabalho no CAPSad atual, profissão, salário e carga horária, 2013................................ 88

Tabela 2 Caracterização dos trabalhadores do Centro de Atenção Psicossocial Álcool e Outras Drogas em Botucatu, segundo atendimentos individuais e quantidade, atendimentos grupais e quantidade, reuniões de equipe e quantidades, atividades comunitárias e quantidade, 2013 91

Tabela 3 Caracterização dos trabalhadores do Centro de Atenção Psicossocial Álcool e Outras Drogas em Botucatu, segundo condições de trabalho 93

Tabela 4 Caracterização dos trabalhadores do Centro de Atenção Psicossocial Álcool e Outras Drogas em Botucatu, segundo modalidades de atendimento. 95

Tabela 5 Caracterização das modalidades de atendimento do Centro de Atenção Psicossocial Álcool e Outras Drogas em Botucatu, segundo trabalhadores. 98

Tabela 6 Média e Desvio-padrão da satisfação dos trabalhadores do CAPSad Botucatu- SP, 2013. 100

Tabela 7 Distribuição dos escores observados na EAFAAA pelos trabalhadores do CAPSad Botucatu- SP, 2013. 102

Tabela 8 Supervisão, Apoio e avaliação global do atendimento prestado, segundo os trabalhadores do CAPSad Botucatu- SP, 2013.1033

Tabela 9 Caracterização dos usuários do Centro de Atenção Psicossocial Álcool e Outras Drogas em Botucatu, segundo gênero, etnia, faixa etária, estado civil, escolaridade, fonte de renda, renda familiar no último mês, 2013. 104

Tabela 10 Distribuição de com quem vivem atualmente os usuários do CAPSad Botucatu-SP, 2013. 
Tabela 11 Média e Desvio-padrão da satisfação dos usuários do CAPSad Botucatu- SP, 2013 ......................................................... 107

Tabela 12 Média e Desvio-padrão da da escala de mudança percebida dos usuários na perspectiva dos usuários CAPSad BotucatuSP, 2013. 10909

Tabela 13 Caracterização dos familiares do Centro de Atenção Psicossocial Álcool e Outras Drogas em Botucatu, segundo tipo de vinculo, gênero, etnia, faixa etária, estado civil, escolaridade, trabalho remunerado e renda familiar no último mês, 2013 110

Tabela 14 Média e Desvio-padrão da satisfação dos familiares do CAPSad Botucatu- SP, 2013. 112

Tabela 15 Média e Desvio-padrão da da escala de mudança percebida dos usuários na perspectiva dos familiares CAPSad BotucatuSP, 2013 


\section{SUMÁRIO}

APRESENTAĈAO


APRESENTACÃO 


\section{APRESENTAÇÃO}

Esta tese faz parte dos quesitos para obtenção do título de doutor de um programa de pós-graduação e está inserida em um estudo maior que visa avaliar os Centros de Atenção Psicossocial em Álcool e Outras Drogas (CAPSad) do Estado de São Paulo conduzida pelo Grupo de Estudos de Álcool e outras Drogas da Escola de Enfermagem de São Paulo - GEADUSP. Este estudo busca respostas às inquietações levantadas nas reuniões do GEADUSP. Tendo 12 anos da Lei 10.216 e da criação dos dispositivos extrahospitalares em saúde mental, surge a importância de realizar uma avaliação de como estes dispositivos estão funcionando e contemplando as portarias que os regem.

Com isso, o GEADUSP constrói tal projeto com a preocupação em discutir a avaliação no campo da saúde mental e ao mesmo tempo se fundamentar nas dificuldades encontrados na assistência. 
INTRODUCÃO 


\section{INTRODUÇÃO}

Dada sua complexidade, é indiscutível que o consumo de álcool e outras drogas, particularmente os transtornos decorrentes do uso abusivo, constitui-se um dos maiores desafios contemporâneo à saúde pública mundial. Dados produzidos por estudos epidemiológicos permitem dimensionar a extensão deste desafio no mundo e no Brasil.

A Organização Mundial da Saúde (OMS) afirma que 10\% das populações dos centros urbanos do mundo fazem uso abusivo de substâncias psicoativas, independentemente da idade, sexo, nível de escolaridade e classe social. Sendo, portanto, o enfrentamento desta problemática uma demanda mundial (WHO, 2004).

O álcool passou do uso social ao problemático, sendo a substância química mais consumida no mundo. Segundo a OMS (2004), aproximadamente dois bilhões de pessoas consomem bebidas alcoólicas. Seu uso indevido é um dos principais fatores que contribuem para a diminuição da saúde mundial, sendo responsável por $3,2 \%$ de todas as mortes e por $4 \%$ de todos os anos perdidos de vida útil. Quando esses índices são analisados em relação à América Latina, o álcool assume uma importância ainda maior.

No Brasil, o II Levantamento Domiciliar sobre o Uso de Drogas Psicotrópicas aponta que $12,3 \%$ das pessoas pesquisadas, com idades entre 12 e 65 anos, preenchem critérios para a dependência do álcool e cerca de $75 \%$ já beberam pelo menos uma vez na vida. Os dados também indicam o consumo de álcool em faixas etárias cada vez mais precoces e sugerem a necessidade de revisão das medidas de controle, prevenção e tratamento (Carlini, 2006).

O consumo de álcool é considerado importante causa de adoecimento, mortalidade precoce e incapacidade, sendo apontado 
como fator determinante de mais de $10 \%$ do total dos problemas de saúde no Brasil (Meloni, Laranjeira, 2004).

Em 2002, o Brasil apresentou índices de mortalidade diretamente relacionados ao uso abusivo ou dependência de álcool correspondente a $0,8 \%$ de todas as mortes de homens e $0,1 \%$ de mulheres (Marin-Leon, Oliveira, Botega, 2007). Considerando a população de pessoas com transtorno mental no referido estudo, verificou-se que $83,3 \%$ das mortes de homens e $34,8 \%$ de mulheres estavam relacionadas ao uso abusivo ou dependência de álcool. Em adição, estima-se que pelo menos metade das pessoas que precisam de tratamento para o uso abusivo ou dependência de álcool não recebe assistência de saúde no país (Kohn, Mello, Mello, 2007).

Em um quadro com esta magnitude, a atenção em saúde mental se constitui em uma necessidade crescente, dada a complexidade das necessidades e da população envolvida. Em um diagnóstico realizado pela OMS identifica-se deficiência nas políticas e nos serviços de saúde mental, seja por meio da insuficiência de pessoal especializado ou de distribuição não uniforme (WHO, 2011).

Soma-se a estes dados o aumento progressivo do uso do crack por populações vulneráveis, o que demonstra a necessidade de pesquisas que possam abordar a caracterização destes usuários, bem como a identificação de fatores de vulnerabilidade entre os usuários de crack.

Entretanto, a compreensão do fenômeno da dependência das drogas não pode ser restrita à sua dimensão bioquímica. A discussão acerca dos fatores determinantes das dependências ressalta a confluência de fatores biológicos, psicológicos e sociais, com delineamento de modelos explicativos complexos e não necessariamente consensuais pela comunidade científica.

Para além do discurso científico, a questão da dependência às substâncias psicoativas ainda apresenta-se permeada por discursos de ordem moral, religioso e jurídico-policial. A coexistência 
dessas perspectivas discursivas, muitas vezes estigmatizantes, torna ainda mais complexa não apenas a compreensão da questão das dependências, mas também da adoção de medidas de intervenção e enfrentamento do problema, que nem sempre são convergentes aos objetivos propostos.

Com a implantação e regulamentação do Sistema Único de Saúde - SUS, instituído pela Constituição de 1988, configurado como: um conjunto de ações e serviços de saúde que tem por finalidade a promoção de maior qualidade de vida para toda a população brasileira, cujo objetivo primordial é a garantia do acesso de todos a uma assistência à saúde integral e equitativa; ocorreu uma reformulação profunda da assistência à saúde, visando à consolidação de uma rede de cuidados regionalizada, hierarquizada e integrada (Brasil, 2004).

No campo da assistência à saúde mental, a Reforma Psiquiátrica é atualmente marcada em sua vertente assistencial, pela implantação de serviços substitutivos ao hospital psiquiátrico, com destaque aos Centros de Atenção Psicossocial (CAPS). Essas modalidades de atendimento foram implantadas em muitos municípios brasileiros em oposição ao sistema hospitalocêntrico, constituindo-se em um sistema comunitário de saúde mental, tendo como uma de suas metas a inclusão social do indivíduo com sofrimento psíquico.

Estas transformações tiveram início, no Brasil, a partir da década de 1960, com o Movimento da Reforma Sanitária e, posteriormente, com maior visibilidade no Movimento da Reforma Psiquiátrica brasileira que, no cenário de um País em processo de democratização e reformulação do sistema de saúde, coloca em xeque os saberes e práticas psiquiátricas e o hospital psiquiátrico, como o lócus do tratamento. O Movimento foi protagonizado por diversos atores: usuários e famílias, trabalhadores de saúde mental, políticos, donos de hospitais psiquiátricos, artistas, entre outros, e passou a introduzir questões da esfera político-ideológica tais como 
cidadania, direitos e ética. Essa polifonia tensa, com conflitos e até paradoxos resultou em várias mudanças políticas, na legislação e na organização da atenção em saúde mental, preconizando a necessidade de equipamentos múltiplos para atender à complexidade do sofrimento psíquico.

Nesse contexto, os CAPS assumem especial relevância no cenário das novas práticas em saúde mental no País. Essa mudança paradigmática deve englobar a relação que se estabelece com o usuário, equipe e família, e entre esses e a comunidade. A mudança de papéis, a democratização das Instituições, o envolvimento e responsabilização da comunidade devem somar-se aos objetivos técnicos do tratamento. O objeto de intervenção torna-se mais complexo, interdisciplinar, e as práticas e saberes tradicionais devem ser reconstruídos para responder a esta transformação.

O Ministério da Saúde preconiza que esses serviços tenham o papel articulador, que trabalhem com uma rede estabelecida em várias instâncias como: os cuidados básicos promovidos pela Estratégia da Saúde da Família - ESF; serviços ambulatoriais; leitos de hospitais gerais e iniciativas de suporte e reabilitação psicossocial como os serviços residenciais terapêuticos e trabalho protegido (Onocko-Campos, Furtado, 2006), ou seja, o ordenador da rede de atenção em saúde mental.

Com a implantação dos CAPSad em 2002, iniciou-se a construção de uma rede de serviços direcionada à população dependente de álcool e outras drogas. De acordo com as propostas do Ministério da Saúde, esses dispositivos devem utilizar como referência a lógica de redução de danos, que busque as necessidades a serem atendidas de forma sistemática e ativa, coadunando com o meio cultural e a comunidade em que os usuários estão inseridos, e de acordo com os princípios da Reforma Psiquiátrica (Brasil, 2003). 
Assim, a partir de 2003 o SUS começou a desenvolver ações sistemáticas e regulares de atenção integral para a população que faz uso abusivo de álcool e outras drogas.

Essa mudança do enfoque exige a implantação de uma diversidade de equipamentos que respondam aos diferentes momentos e necessidades do indivíduo.

Atualmente, tem-se implantados no Brasil 272 CAPSad II e 5 CAPSad III desses, 69 estão instalados no estado de São Paulo, sendo 67 CAPSad II e 2 CAPSad III (Brasil, 2012). Para tanto, o Ministério da Saúde tem investido em metodologias que possam avaliar os CAPS, no sentido de reforçar a sua importância e fortalecer o seu funcionamento. Entre os meses de setembro de 2008 e janeiro de 2009, o Ministério da Saúde fez a terceira edição do Avaliar CAPS. Em setembro, na fase de pré-teste participaram $10 \%$ de todos os serviços brasileiros e na coleta de novembro de 2008 a janeiro de 2009 participaram 78,51\% dos CAPS (Brasil, 2009).

Com o Avaliar CAPS, a área técnica de Saúde Mental do Ministério da Saúde objetiva oferecer um panorama de como está a qualidade da assistência em saúde mental oferecida nos CAPS do território nacional e, estabelecer os indicadores de avaliação dos CAPS (Brasil, 2009). Entretanto, os resultados ainda não foram disponibilizados.

A avaliação é uma necessidade de política pública, pois é fundamental que um programa de saúde possa mostrar para a sociedade o que faz, como funciona, pra que serve. No campo da saúde mental, podemos dizer que esta necessidade é ainda maior, se considerarmos que a constituição dos serviços CAPS parte de um movimento de transformação do modelo tecno-assistencial para os pacientes da psiquiatria.

Portanto, um processo avaliativo de CAPS deve monitorar essas ações acompanhando a construção de um serviço que se proponha a atender a inserção do usuário com maior resolubilidade, 
com uma intervenção pautada na diversidade de saberes de uma equipe multiprofissional e na utilização de múltiplos recursos.

\subsection{UM RESGATE DOS ASPECTOS HISTÓRICOS DA REFORMA PSIQUIÁTRICA NO ÂMBITO DO USO DE ÁLCOOL E OUTRAS DROGAS NO BRASIL}

Torna-se necessário traçar um resgate desta trajetória de como é visto o tema do uso do álcool e de outras drogas. Tal tema sempre foi, historicamente, no Brasil voltado aos aspectos morais, sendo associado à criminalidade e práticas antissociais.

Relembrando o Código Penal de 1940, que trata de forma repressiva a questão do alcoolismo, fundamentando na punição a forma de expiação e recuperação, tratando a questão sob a responsabilidade da justiça que assume a responsabilidade pelo alcoolista e depois pelo usuário de drogas, condicionando-os como "viciados", potencialmente inclinados para o mal e para o crime, devendo ser apartados do convívio social (Brasil, 1940).

A oferta de tratamentos acabava restringindo na exclusão dos usuários do convívio social. Pensando em serviços públicos de saúde para esta demanda, tínhamos disponíveis ambulatoriais e hospitais, e ainda em número muito reduzido. Havia uma necessidade de uma política que contemplasse esta demanda nacionalmente focando no âmbito da saúde pública.

Enquanto faltavam políticas públicas para atender o grave problema da prevenção e tratamento de transtornos associados ao consumo de álcool e outras drogas, outros setores da sociedade se ocuparam dessa problemática, instituições da justiça, segurança pública, pedagogia, benemerência, associações religiosas. Diante desta grande lacuna nas políticas de saúde e com a complexidade da questão, surgem, em todo o território nacional, alternativas de atenção. Estas alternativas, em sua maioria, eram de caráter 
religioso, com perfil de instituições totais, fechadas, baseadas em uma prática predominantemente ao modelo biomédico, focado na medicalização, e tendo como principal objetivo a ser alcançado a abstinência. Esta rede de instituições, que em sua maioria filantrópicas, acabam cumprindo um papel relevante, e apontam a necessidade de assunção pela saúde pública de uma política mais clara e incisiva para o problema (Brasil, 2005; Brasil, 2007).

O uso de álcool e outras drogas não pode ser reduzido a um olhar biomédico centrado apenas nos sintomas, desvinculados do contexto social no qual são produzidas as representações que sustentam e organizam a vida social das pessoas (Pratta, Santos, 2009). Com isso surge a importância de políticas voltadas a esta demanda.

A primeira iniciativa para a assistência a usuários de álcool foi efetivada no Brasil, por meio do Programa Nacional de Controle dos Problemas Relacionados com o Consumo do Álcool (PRONAL) (Brasil, 1987), no qual a atenção à saúde era dirigida de forma específica à problemática, bem como a participação de diversos profissionais da saúde na assistência ao alcoolista e aos seus familiares. Entretanto, esse programa só foi implementado por gestores públicos no Distrito Federal e nos estados do Amazonas, Maranhão, Bahia, São Paulo e Rio Grande do Sul (Fornazier, Siqueira, 2006).

Outras iniciativas para a discussão da assistência à saúde relacionada ao uso de álcool e outras drogas, no setor público, aparecem na trajetória da Reforma Psiquiátrica brasileira.

A Reforma Psiquiátrica brasileira teve seu início no bojo da Reforma Sanitária, porém seu processo intensificou-se no fim da década de 70 , do século passado, e início da década de 80 , do mesmo século e, foi marcado pela redemocratização do país e pela contestação do modelo de atenção psiquiátrica, o que consequentemente, propicia anos depois uma mudança na forma de atenção aos indivíduos portadores de sofrimento psíquico e 
influencia a mudança na atenção aos usuários de álcool e outras drogas.

Em 1986, realizou-se a VIII Conferência Nacional de Saúde, que teve como desdobramento a I Conferência Nacional de Saúde Mental (I CNSM), que contemplou os temas Economia, Sociedade e Estado: impactos sobre saúde e doença mental; Reforma Sanitária e Reorganização da Assistência a Saúde Mental; Cidadania e Doença Mental: direitos, deveres e legislação do doente mental (Amarante, 1995).

Amarante (1995) considera que a I Conferência Nacional de Saúde Mental marca o fim da trajetória sanitarista e o início da trajetória de desinstitucionalização ou da desconstrução/invenção. Em 1987, acontece o II Congresso Nacional dos Trabalhadores em Saúde Mental, em Bauru-SP, que teve a participação não apenas de técnicos, mas também de lideranças municipais, usuários e familiares, que juntos buscaram tornar a opinião pública favorável à luta antimanicomial, que adota o lema: "Por uma sociedade sem manicômios".

A III Conferência Nacional de Saúde Mental de 2002 foi o agente propulsor para que o Ministério da Saúde implementasse o Programa Nacional de Atenção Comunitária Integrada aos Usuários de Álcool e outras Drogas, trazendo à tona o reconhecimento do problema do uso prejudicial de substâncias como importante problema da saúde pública e assim construindo uma política pública específica para a atenção às pessoas que fazem uso de álcool ou outras drogas, situada no campo da saúde mental, e tendo como estratégia a ampliação do acesso ao tratamento, a compreensão integral e dinâmica do problema, a promoção dos direitos e a abordagem de redução de danos" (Brasil, 2005).

Com isso, surge a primeira política com foco no uso de álcool e outras drogas denominada Política Nacional do Ministério da Saúde Brasileiro para a atenção integral aos usuários de álcool e 
outras drogas instituída por meio da Portaria no 2.197/GM, em 14 de outubro de 2004 (Brasil, 2004b).

Antes da criação da lei específica para álcool e outras drogas, a Lei 10.216/01 foi promulgada em 6 de abril de 2001, que dispõe sobre a busca da desconstrução dos hospitais psiquiátricos e a construção de serviços extrahospitalares, surgindo assim os Centros de Atenção Psicossocial em Álcool e outras Drogas (CAPSad), principal estratégia de tratamento para essa demanda. Tem como proposta de tratamento a estratégia de redução de danos, enfatizando também as ações de prevenção e promoção da saúde (Brasil, 2004).

Os serviços extramuros, os CAPSad, têm um papel estratégico na confecção da rede de saúde mental, inicialmente foram implantados em grandes regiões metropolitanas e em regiões ou municípios de fronteira, com indicadores epidemiológicos relevantes. É um serviço que trabalha na lógica do território e rede, bem como também na lógica ampliada de redução de danos. Enfocando uma procura ativa e sistemática das necessidades a serem atendidas de forma integrada ao meio cultural e à comunidade em que estão inseridos, pautando nos princípios da Reforma Psiquiátrica (Brasil, 2005).

De acordo com a política do Ministério da Saúde para atenção integral a usuários de álcool e outras drogas, a assistência aos usuários de álcool deve ser oferecida em todos os níveis de atenção, privilegiando os cuidados em dispositivos extrahospitalares, como os CAPSad, devendo também estar inserida na atuação da Estratégia de Saúde da Família (ESF), programa de Agentes Comunitários de Saúde (PACS), Programas de Redução de Danos e da Rede Básica de Saúde (Brasil, 2003).

Como na assistência aos pacientes com transtornos mentais, a assistência aos usuários de álcool e outras drogas também requer a organização de uma rede diversificada, complexa, com abordagens diversas e na perspectiva da integração social do 
usuário de acordo com o nível de complexidade de cada serviço. Se pensarmos a rede de cuidados, iniciamos com a estratégia de saúde da família como porta de entrada para esses usuários, o CAPSad como suporte especializado e os leitos em hospital geral para os casos de urgência/emergência, e também outros dispositivos sociais como os grupos de ajuda e as comunidades terapêuticas. Vale ressaltar que a rede ainda está se consolidando, com deficiências para as necessidades da demanda.

Em junho de 2009, o Ministério da Saúde lançou o Plano Emergencial de Ampliação de Acesso ao Tratamento e Prevenção em Álcool e outras Drogas (PEAD), por meio da Portaria $\mathrm{n}^{\circ}$ $1.190 / G M / M S$, de 4 de junho de 2009, voltado aos 100 maiores municípios brasileiros (com mais de 250 mil habitantes), todas as capitais e sete municípios de fronteira selecionados, totalizando 108 municípios. Essas cidades somam 77,6 milhões de habitantes, que correspondem a $41,2 \%$ da população nacional (Brasil, 2009b).

O Plano Emergencial busca alcançar, prioritariamente, crianças, adolescentes e jovens em situação de grave vulnerabilidade social, por meio das ações de prevenção, promoção e tratamento dos riscos e danos associados ao consumo prejudicial de substâncias psicoativas. Para atingir os objetivos, foram previstos quatro eixos de atuação: ampliação do acesso, qualificação dos profissionais, articulação intra/intersetorial e promoção da saúde, dos direitos e enfrentamento do estigma.

Em 2010, buscando a intersetorialidade - recomendação da IV Conferência Nacional de Saúde Mental, o Presidente da República lança, por meio do Decreto 7.179 de 20 de maio de 2010, o Plano Integrado de Enfrentamento ao Crack fundamentado na integração e na articulação permanente entre as políticas e ações de saúde, assistência social, segurança pública, educação, desporto, cultura, direitos humanos, juventude, entre outras, em consonância com os pressupostos, diretrizes e objetivos da Política Nacional sobre Drogas (Brasil, 2010). 
Esse decreto também institui a criação de um comitê gestor ao qual compete: estimular a participação dos entes federados na implementação do Plano Integrado de Enfrentamento ao Crack e outras Drogas; acompanhar e avaliar a implementação do Plano Integrado de Enfrentamento ao Crack e outras Drogas; e consolidar em relatório periódico as informações sobre a implementação das ações e os resultados obtidos.

São objetivos do Plano Integrado de Enfrentamento ao Crack e outras Drogas: estruturar, integrar, articular e ampliar as ações voltadas à prevenção do uso, tratamento e reinserção social de usuários de crack e outras drogas, contemplando a participação dos familiares e a atenção aos públicos vulneráveis, entre outros, crianças, adolescentes e população em situação de rua; estruturar, ampliar e fortalecer as redes de atenção à saúde e de assistência social para usuários de crack e outras drogas, por meio da articulação das ações do Sistema Único de Saúde - SUS com as ações do Sistema Único de Assistência Social - SUAS; capacitar, de forma continuada, os atores governamentais e não governamentais envolvidos nas ações voltadas à prevenção do uso, ao tratamento e à reinserção social de usuários de crack e outras drogas e ao enfrentamento do tráfico de drogas ilícitas; promover e ampliar a participação comunitária nas políticas e ações de prevenção do uso, tratamento, reinserção social e ocupacional de usuários de crack e outras drogas e fomentar a multiplicação de boas práticas; disseminar informações qualificadas relativas ao crack e outras drogas; e fortalecer as ações de enfrentamento ao tráfico de crack e outras drogas ilícitas em todo o território nacional, com ênfase nos Municípios de fronteira (Brasil, 2010).

Diante da necessidade da organização da rede de serviços de saúde para uma melhor assistência aos usuários do SUS, a Portaria no 4.279/GM/MS de 30 de dezembro de 2010, trata das diretrizes para a estruturação da Rede de Atenção à Saúde (RAS) como estratégia para superar a fragmentação da atenção e da gestão nas 
Regiões de Saúde e aperfeiçoar o funcionamento políticoinstitucional do SUS, com vistas a assegurar ao usuário o conjunto de ações e serviços, que necessita, com efetividade e eficiência(Brasil, 2010b).

A RAS pode ser definida como arranjos organizativos de ações e serviços de saúde, de diferentes densidades tecnológicas, que integradas por meio de sistemas de apoio técnico, logístico e de gestão, buscam garantir a integralidade do cuidado. Seu objetivo é promover a integração sistêmica, de ações e serviços de saúde com provisão de atenção contínua, integral, de qualidade, responsável e humanizada, bem como incrementar o desempenho do Sistema, em termos de acesso, equidade, eficácia clínica e sanitária; e eficiência econômica.

A RAS caracteriza-se pela formação de relações horizontais entre os pontos de atenção com o centro de comunicação na Atenção Primária à Saúde (APS), pela centralidade nas necessidades em saúde de uma população, pela responsabilização na atenção contínua e integral, pelo cuidado multiprofissional, pelo compartilhamento de objetivos e compromissos com os resultados sanitários e econômicos.

A RAS fundamenta-se na compreensão da APS como primeiro nível de atenção, enfatizando a função resolutiva dos cuidados primários sobre os problemas mais comuns de saúde e a partir do qual se realiza e coordena o cuidado em todos os pontos de atenção.

Especificamente na área da saúde mental, a Portaria $\mathrm{n}^{\circ}$ 3.088/GM/MS, de 23 de dezembro de 2011, institui a Rede de Atenção Psicossocial para atenção às pessoas com sofrimento ou transtorno mental e com necessidades decorrentes do uso de crack, álcool e outras drogas, no âmbito do Sistema Único de Saúde (Brasil, 2011).

Os objetivos gerais da Rede de Atenção Psicossocial são: ampliar o acesso à atenção psicossocial da população em geral, 
promover a vinculação das pessoas com transtornos mentais e com necessidades decorrentes do uso de crack, álcool e outras drogas e suas famílias aos pontos de atenção e garantir a articulação e integração dos pontos de atenção das redes de saúde no território, qualificando o cuidado por meio do acolhimento, do acompanhamento contínuo e da atenção às urgências.

Em relação aos objetivos específicos, destacamos: prevenir o consumo e a dependência de crack, álcool e outras drogas, reduzir danos provocados pelo consumo de crack, álcool e outras drogas, promover a reabilitação e a reinserção das pessoas com transtorno mental e com necessidades decorrentes do uso de crack, álcool e outras drogas na sociedade, por meio do acesso ao trabalho, renda e moradia solidária. Há também objetivos relacionados à: promoção de mecanismos de formação permanente aos profissionais de saúde; desenvolvimento de ações intersetoriais de prevenção e redução de danos em parceria com organizações governamentais e da sociedade civil; produção e oferta de informações sobre direitos das pessoas, medidas de prevenção e cuidado e os serviços disponíveis na rede; regulação e organização das demandas e dos fluxos assistenciais da Rede de Atenção Psicossocial; e monitoramento e avaliação da qualidade dos serviços por meio de indicadores de efetividade e resolutividade da atenção (Brasil, 2011).

A Rede de Atenção Psicossocial (RAPS) é constituída pelos seguintes componentes: Atenção Básica em Saúde, Atenção Psicossocial Especializada, Atenção de Urgência e Emergência, Atenção Residencial de Caráter Transitório, Atenção Hospitalar, estratégias de Desinstitucionalização e Reabilitação Psicossocial.

Um ponto crítico da RAPS é que os Serviços de Atenção em Regime Residencial inclui as Comunidades Terapêuticas (CT), sendo um serviço de saúde destinado a oferecer cuidados contínuos de saúde, de caráter residencial transitório por até nove (9) meses para adultos com necessidades clínicas estáveis decorrentes do uso de crack, álcool e outras drogas (Brasil, 2011). O autor faz um alerta 
acerca dos $\mathrm{CT}$, pois relata problemas nestes dispositivos em que na maioria das vezes são instituições precárias, com equipes mal preparadas, que utilizam métodos pouco científicos, sem preocupação com avaliação da eficácia das intervenções propostas. São geralmente modelos mistos, com forte viés moralista, sem conhecimento adequado da complexidade do fenômeno dependência. A maioria delas sequer sabe distinguir um usuário de um dependente de drogas (e precisamos lembrar que os estudos epidemiológicos do mundo inteiro nos mostram que mais de $80 \%$ dos usuários de drogas não são dependentes e, portanto, não teriam que ser submetidos a qualquer forma de tratamento). No entanto, algumas delas oferecem um tratamento de qualidade que infelizmente são exceções (Silveira, 2013).

Ainda com o fim de redefinir o Centro de Atenção Psicossocial de Álcool e outras Drogas 24h (CAPSad III) e os respectivos incentivos financeiros, o ministro da saúde divulga a Portaria № 130 GM/MS, de 26 de janeiro de 2012. A Portaria aponta que O CAPSad III é o Ponto de Atenção do Componente da Atenção Especializada da Rede de Atenção Psicossocial destinado a proporcionar a atenção integral e contínua a pessoas com necessidades relacionadas ao consumo de álcool, crack e outras drogas, com funcionamento nas 24 horas do dia e em todos os dias da semana, inclusive finais de semana e feriados (Brasil, 2012b).

Com este novo formato de estratégia de atenção, torna-se relevante uma avaliação dos dispositivos CAPSad para assim visualizar suas potencialidades e fragilidades no atendimento a essa demanda. 


\subsection{O CENTRO DE ATENÇÃO PSICOSSOCIAL (CAPS)}

Os Centros de Atenção Psicossocial - CAPS são instituições destinadas a acolher os pacientes com transtornos mentais, estimular sua integração social e familiar, apoiá-los em suas iniciativas de busca de autonomia, além de lhes oferecer atendimento médico e psicológico. Têm como característica principal a busca para integrá-los a um ambiente social e cultural concreto, o espaço da cidade onde acontece o cotidiano de usuários e familiares, denominado como sendo "seu território". Constituem-se na principal estratégia do processo de Reforma Psiquiátrica Brasileira.

Os CAPS são locais comunitários de referência para o tratamento de pessoas portadoras de transtornos mentais como: psicoses e neuroses graves, entre outros, cuja severidade e/ou persistência justifiquem a sua permanência para cuidados intensivos, personalizados e que promovam a vida.

O objetivo do CAPS é oferecer atendimento à população de sua área de abrangência, realizando o acompanhamento clínico e a reinserção social dos usuários, por meio do acesso ao trabalho, lazer, exercício dos direitos civis e estreitamento dos laços familiares e comunitários.

A primeira definição formal para os CAPS surgiu com a Portaria oㅡ 224 de 29 de janeiro de 1992, do Ministério da Saúde, que definiu os CAPS como unidades locais/regionalizadas com uma população adscrita definida pelo nível local e que oferecem atendimentos de cuidados intermediários entre o regime ambulatorial e a internação hospitalar, em um ou dois turnos de quatro horas, por equipe multiprofissional (Brasil, 2004).

Com o fim de atualização das normas constantes na Portaria 224, a Portaria no 336, de 19 de fevereiro de 2002, acrescenta novos parâmetros para o funcionamento dos CAPS, definindo a sua 
estrutura, o seu funcionamento e seus objetivos principais, a partir de porte/complexidade e abrangência populacional (Brasil, 2004).

Estabelece que os Centros de Atenção Psicossocial podem constituir-se em: CAPS I, CAPS II e CAPS III, definidos por ordem crescente de porte/complexidade e abrangência populacional, capacitadas para realizar prioritariamente 0 atendimento de pacientes com transtornos mentais severos e persistentes em sua área territorial em regime de tratamento intensivo, semi-intensivo e não intensivo. Também define as características de cada modalidade em termos de recursos humanos, atividades, horário de funcionamento, capacidade operacional, funções que desempenha e direciona a criação de serviços específicos para a área de infância e adolescência (CAPSi) e para a área de álcool e outras drogas (CAPSad) (Brasil, 2004).

Descrição dos tipos de CAPS segundo a Portaria 336/02.

Abrangência populacional (habitantes):

- CAPS I- 20.000 a 70.000

- CAPS II - 70.000 a 200.000

- CAPS III - acima de 200.000

- CAPS i II - acima de 200.000, ou a depender do gestor local

- CAPSad II - acima de 200.000

Horário de funcionamento:

- CAPS I- 8 às $18 \mathrm{~h}$, nos 5 dias úteis.

- CAPS II, CAPSad II e CAPS i II - 8 às 18h, nos 5 dias úteis, podendo comportar um 3ํㅡㄴ turno (18 às $21 \mathrm{~h}$ ).

- CAPS III - 24h, incluindo feriados e finais de semana.

Equipe:

- CAPS I - 1 médico com formação em saúde mental; 1 enfermeiro; 3 profissionais de nível superior; 4 profissionais de nível médio. 
- CAPS II - 1 médico psiquiatra; 1 enfermeiro com formação em saúde mental; 4 profissionais de nível superior; 6 profissionais de nível médio.

- CAPS III - 2 médicos psiquiatras; 1 enfermeiro com formação em saúde mental; 5 profissionais de nível superior; 8 profissionais de nível médio

- CAPS i II - 1 médico psiquiatra ou neurologista ou pediatra com formação em saúde mental; 1 enfermeiro; 4 profissionais de nível superior; 5 profissionais de nível médio.

- CAPSad II - 1 médico psiquiatra;1 enfermeiro com formação em saúde mental; 4 profissionais de nível superior;6 profissionais de nível médio.

População atendida:

- CAPS I e CAPS II: São CAPS para o atendimento diário de adultos, em sua população de abrangência, portadoras de transtornos severos e persistentes;

- CAPS III: São CAPS para atendimento diário e noturno de adultos, durante sete dias da semana, atendendo à população de referência com transtornos mentais severos e persistentes;

- CAPS i: São CAPS para atendimento diário de crianças e adolescentes com transtornos mentais;

- CAPSad: São CAPS para atendimento diário de usuários de álcool e outras drogas e pessoas com transtornos mentais decorrentes do uso e dependência dessas substâncias. Esse tipo de CAPS possui leitos de repouso com a finalidade exclusiva de tratamento e desintoxicação.

Cada usuário de CAPS deve ter um projeto terapêutico singular, que corresponde a um conjunto de atendimentos que respeite a sua particularidade, que personalize 0 atendimento de cada pessoa na unidade e fora dela e que de acordo com suas necessidades, proponha atividades durante a sua permanência no serviço. 
Dessa forma, de acordo com as determinações da Portaria GM 336/02, os CAPS podem ter atendimento Intensivo; SemiIntensivo e Não Intensivo.

a. Atendimento Intensivo: Trata-se de atendimento diário, oferecido quando a pessoa se encontra com grave sofrimento psíquico, em situação de crise ou dificuldades intensas no convívio social e familiar, necessitando de atenção contínua. $O$ atendimento pode ser domiciliar, se necessário.

b. Atendimento Semi - Intensivo: Nessa modalidade de atendimento, o usuário pode ser atendido até 12 dias no mês, em momentos em que $o$ sofrimento $e$ desestruturação psíquica da pessoa diminuíram, melhorando as possibilidades de relacionamento, mas a pessoa ainda necessita de atenção direta da equipe para se estruturar e recuperar sua autonomia. $\mathrm{O}$ atendimento pode ser domiciliar ou não.

c. Atendimento Não - Intensivo: Oferecido quando a pessoa não precisa de suporte contínuo da equipe para viver em seu território e realizar suas atividades na família e/ ou no trabalho, sendo atendido pelo serviço em até três dias no mês. $O$ atendimento pode também ser domiciliar ou não.

Cada CAPS deve ter um projeto terapêutico do serviço, que considere as diferentes contribuições técnicas dos profissionais dos CAPS, as iniciativas dos familiares e usuários e o território onde se situa, com sua identidade, sua cultura local e regional.

Os CAPSad II, serviço de atenção psicossocial para atendimento de pacientes com transtornos decorrentes do uso e dependência de substâncias psicoativas, deve ter as seguintes características: 
a) constituir-se em serviço ambulatorial de atenção diária, de referência para área de abrangência populacional definida pelo gestor local.

b) sob coordenação do gestor local, responsabilizar-se pela organização da demanda e da rede de instituições de atenção a usuários de álcool e drogas, no âmbito de seu território.

c) possuir capacidade técnica para desempenhar o papel de regulador da porta de entrada da rede assistencial local no âmbito de seu território e/ou do módulo assistencial, definido na Norma Operacional de Assistência à Saúde (NOAS), de acordo com a determinação do gestor local.

d) coordenar, no âmbito de sua área de abrangência e por delegação do gestor local, as atividades de supervisão de serviços de atenção a usuários de drogas, em articulação com o Conselho Municipal de Entorpecentes.

e) supervisionar e capacitar as equipes de atenção básica, serviços e programas de saúde mental local no âmbito do seu território e/ou do módulo assistencial.

f) realizar, e manter atualizado, o cadastramento dos pacientes que utilizam medicamentos essenciais para a área de saúde mental regulamentados pela Portaria/GM/MS no 1077 de 24 de agosto de 1999 e medicamentos excepcionais, regulamentados pela Portaria/SAS/MS no 341 de 22 de agosto de 2001, dentro de sua área assistencial.

No que se refere à assistência prestada ao paciente no CAPSad II, devem ser desenvolvidas as seguintes atividades:

a) atendimento individual (medicamentoso, psicoterápico, de orientação, entre outros); 
b) atendimento em grupos (psicoterapia, grupo operativo, atividades de suporte social, entre outras);

c) atendimento em oficinas terapêuticas executadas por profissional de nível superior ou nível médio;

d) visitas e atendimentos domiciliares;

e) atendimento à família;

f) atividades comunitárias enfocando a integração do dependente químico na comunidade e sua inserção familiar e social;

g) os pacientes assistidos em um turno (4 horas) receberão uma refeição diária; os assistidos em dois turnos (8 horas) receberão duas refeições diárias.

h) atendimento de desintoxicação.

Segundo os dados do Ministério da Saúde (2012), até dezembro de 2011, contamos com aproximadamente 1742 CAPS funcionando no Brasil, o que aponta uma cobertura muito boa $(0,72)$. Em relação ao número de CAPSad, dispomos de 272 CAPSad II e 05 CAPSad III funcionando no país (Brasil, 2012b).

Em relação aos dados do Estado de São Paulo, contamos com o total de 282 CAPS, apontado como uma boa cobertura $(0,64)$. No que se refere aos CAPSad, o Estado tem 67 CAPSad II e 02 CAPSad III. Já o Departamento Regional de Saúde de Bauru conta com 4 CAPSad II. É uma rede importante, mas que ainda é insuficiente para atender à demanda cada dia mais crescente (Brasil, 2012).

Considerando os pressupostos da Reforma Psiquiátrica Brasileira, a influência deste novo paradigma de atenção em saúde mental, e consequentemente as políticas aos usuários de álcool e outras drogas, torna-se necessário avaliar os Centros de Atenção Psicossocial em Álcool e Outras Drogas. 


\subsection{O CAMPO DE AVALIAÇÃO}

A avaliação em saúde é um procedimento quase tão antigo quanto a própria atividade dos serviços. Já a avaliação sistematizada das práticas e dos serviços de saúde e saúde mental é um procedimento relativamente recente.

Os primeiros estudos no campo da saúde envolvendo avaliação dos serviços de saúde ocorreram por volta de 1910 e foram direcionadas às práticas médicas e ao controle do exercício profissional. Os estudos de avaliação se desenvolveram lentamente, de forma fragmentada, já que não eram considerados como essenciais ao funcionamento dos serviços. A expansão da avaliação dos serviços de saúde ocorreu somente após a Segunda Guerra Mundial, em virtude da necessidade de monitorar a eficácia dos recursos e da tecnologia investidos na área de saúde pelo Estado. É nessa época que se iniciam as auditorias hospitalares com o intuito de avaliar o processo assistencial (Reis et al., 1990; Adami, Maranhão, 1995 ).

Atualmente a busca pela qualidade é de vital importância no mundo globalizado, competitivo e capitalista que vivemos, uma vez que a qualidade dos serviços e produtos é avaliada por meio da satisfação dos usuários, fator fundamental na sobrevivência das organizações. Nos serviços de saúde não é diferente, a qualidade é um elemento diferenciador na prestação de serviços, sendo decisivo o momento em que o usuário recebe a assistência do profissional de saúde, pois este é um dos balizadores para que o usuário defina como percebe e avalia a qualidade do serviço prestado.

A consolidação da avaliação em saúde enquanto objeto de investigação científica, dentro do movimento que estabeleceu as intervenções em saúde como campo científico, teve seu marco inicial na década de 50, do século passado (Nemes, 2001). 
Este campo de estudo teve um grande avanço nos anos $60 \mathrm{e}$ 70 , do século passado. A avaliação de qualidade dos serviços de saúde se sistematiza, nos anos de 1960, nos Estados Unidos, com finalidade quase exclusivamente econômica nos campos médico sanitário, de desenvolver modos de otimizar o enfrentamento de problemas de saúde, com os recursos científicos disponíveis e os recursos efetivamente utilizáveis (Akerman, Nadanovsky, 1985).

A avaliação dos serviços está estreitamente vinculada ao financiamento, à atribuição de recursos e à garantia da qualidade. A avaliação do funcionamento e a eficácia do sistema de saúde tornaram-se relevantes na obtenção de informações que garantissem a qualidade dos serviços (Reis et al., 1990).

O campo da avaliação em saúde pode ser delimitado em três grandes grupos: a avaliação tecnológica que esta ligada na segurança, efetividade e custo de tecnologias de produto ou de processos, a avaliação de programas que está ligada em conjuntos articulados de atividades voltados para uma população alvo, e a avaliação de qualidade que está ligada em serviços assistenciais de saúde (Nemes, 2001).

Há uma diferenciação entre avaliação e pesquisa avaliativa. Avaliar consiste em fazer um julgamento a respeito de uma intervenção ou sobre qualquer um de seus componentes, tendo como meta o auxílio na tomada de decisões em relação aos serviços. Tal julgamento pode ser resultado da aplicação de critérios e normas, tratando-se de uma avaliação normativa, ou construído com base nos procedimentos científicos, caracterizando uma pesquisa avaliativa (Contandriopoulos, 2006).

A avaliação é um julgamento de valor, em que se parte do bom, do esperado de um serviço ou programa em relação a um contexto cultural e político específico. Esse julgamento de valor não apresenta neutralidade técnica, pois sofre a influência da visão de mundo dos que exercem essa ação. Quando olhamos pesquisas avaliativas de cunho médico, são utilizados indicadores diretos de 
qualidade como, por exemplo, taxa de mortalidade ou remissão dos sintomas. (Adami, Maranhão, 1995; Schmidt, 2007).

O julgamento acontecerá a partir da confrontação entre 0 objeto da avaliação e um referencial que poderá ser os objetivos iniciais do projeto, as normas profissionais, o desempenho de um programa similar ou outros referenciais não explicitadas por diferentes motivos. As normas e critérios a serem utilizados para conferir um julgamento ao final da avaliação serão influenciados pelos grupos que o definem, sejam, usuários, familiares, profissionais ou gerentes, entre outros (Furtado, 2001).

Um dos grandes desafios da estratégia da avaliação é conseguir incorporar os pontos de vista de atores em diferentes posições, com a intenção de proporcionar às instâncias de decisão as informações de que precisam para fazer um julgamento mais amplo possível (Contandriopoulos, 2006).

O sistema de saúde apresenta atualmente alta complexidade, com isso torna-se importante que qualquer decisão deve ser acompanhada de avaliações sistemáticas. Isso inclui um ciclo de planejar, executar, avaliar e agir, no sentido de readequar os conhecimentos em função dos dados produzidos pela avaliação. Isto deve fazer parte da rotina dos serviços (Contandriopoulos, 2006; Silva, 2011).

Segundo esta lógica, é necessário implantar e institucionalizar as avaliações e que ocorram em todos os níveis do sistema de saúde. E que isto se gere uma verdadeira cultura de avaliação na intenção de verificações continuas da qualidade dos serviços (Contandriopoulos, 2006). Esta prática torna-se importante para melhorar os sistemas de atenção à saúde.

A avaliação no campo da saúde é um instrumento adequado para a crítica das práticas em saúde, um caminho que apresenta a realidade da assistência com o que é proposto pela política de saúde. Tal avaliação possui enfoque especifico, é sempre 
pragmática e são desenvolvidos em contextos históricos particulares (Furtado, 2001; Nemes, 2001).

Com as mudanças ocorridas com a reforma psiquiátrica, surge a necessidade de serviços extrahospitalares no cenário das novas práticas em saúde mental no país, configurando-se como dispositivo estratégico para a reversão do modelo hospitalar. Tendo como dispositivo primordial o Centro de Atenção Psicossocial (CAPS) que tem como uma de suas metas a inserção social do doente mental, a mudança deve englobar a relação que se estabelece com o usuário, equipe e família, e entre esses e a comunidade. E devem responder aos diferentes momentos e necessidades do indivíduo.

Por isso, torna-se importante ter um processo avaliativo de CAPS que monitore as ações e acompanhe a construção de um serviço que se proponha a atender a inserção do usuário, com maior resolubilidade, com uma intervenção pautada na diversidade de saberes de uma equipe multiprofissional e na utilização de recursos múltiplos.

Acompanhar esse processo possibilitará uma interpretação de como este serviço está funcionando e realizando com o que é proposto para tal. Este olhar crítico da prática nestes serviços auxiliará em apontamentos de fragilidades e potencialidades, trazendo reflexão para compreensão e transformações dos mesmos.

\subsection{QUALIDADE E AVALIAÇÃO DE SERVIÇOS DE SAÚDE: O MODELO DONABEDIANO}

A corrente de avaliação da qualidade é representada principalmente pelos trabalhos clássicos de Donabedian. Seus primeiros trabalhos sobre o tema datam dos anos de 1960, mas atingiram notoriedade mundial a partir do final dos anos de 1980 , quando estudou sistematicamente a avaliação da qualidade da 
atenção médica, modelo esse, que posteriormente foi adaptado para a avaliação de serviços de saúde.

Para Donabedian (1984), a qualidade da atenção à saúde é difícil de ser definida e envolve critérios, determinados em forma de juízo de valor, que podem ser aplicados a diferentes aspectos, propriedades, componentes ou alcances desse tipo de atenção.

Assim, a qualidade percebida pode ser considerada a partir das referências dos sujeitos envolvidos que atribuem significados às suas experiências, privilegiando ou excluindo determinados aspectos, de acordo com suas preferências, necessidades e expectativas individuais e sociais (Donabedian, 1984).

Deve-se reconhecer, entretanto, que dadas as características especificas do processo de produção em saúde, nenhuma estrutura adequada garante bons resultados, nenhuma estrutura considerada ruim os impede; nem processos desenvolvidos com o rigor da técnica permitem contar com resultados favoráveis, nem a realização de processos sem qualquer cuidado, necessariamente, inviabiliza os resultados esperados. Trabalha-se no universo das possibilidades: uma boa estrutura favorece processos adequados, que, por sua vez, aumentam a probabilidade de atingir resultados desejados (Malik, 2006).

Nesse sentido, Donabedian (1978) atribuiu três dimensões para a qualidade: o conhecimento técnico-científico, referindo-se à resolução das necessidades do usuário; relações interpessoais, que dizem respeito ao relacionamento que se estabelece entre o prestador de serviços e o usuário e ambientais, relativas às condições do local onde são realizados os cuidados, desde as comodidades oferecidas até a organização dos processos de trabalho.

Há mais de três décadas Donabedian (2003) sugeriu três abordagens para avaliar a qualidade de cuidado, às quais chamou: estrutura, processo e resultados. 
Estrutura é utilizada para designar as condições sob as quais o cuidado é provido. Incluem:

1. Recursos materiais, tais como facilidades e equipamentos.

2. Recursos humanos, tais como número, variedade e qualificação profissional e pessoal de suporte.

3. Características organizacionais, tais como a organização de equipe médica e de enfermagem, a presença de funções de ensino e pesquisa, tipos de surpervisão e avaliação de desempenho, métodos de pagamento pelo cuidado, e assim por diante.

Processo significa as atividades que constituem o cuidado de saúde, incluindo diagnóstico, tratamento, reabilitação, prevenção e educação do paciente, usualmente realizado pelo profissional de referência, mas também incluindo outras contribuições para cuidado, particularmente dadas por pacientes e seus familiares.

Resultados significam mudanças (desejável ou indesejável) em indivíduos ou populações que podem estar sujeitas ao cuidado de saúde.

Os resultados incluem: mudanças no estado de saúde; mudanças em conhecimentos adquiridos por pacientes e familiares que podem influenciar 0 cuidado futuro; mudanças de comportamento de pacientes ou familiares que podem influenciar o cuidado futuro; e satisfação de pacientes e seus familiares com o cuidado recebido e seus resultados.

Para o autor, a qualidade da assistência não é um atributo abstrato, ao se considerar que é construída pela avaliação assistencial, abrangendo a análise dos componentes da estrutura, dos processos de trabalho e dos resultados dos mesmos.

Donabedian (1980) considera ser o processo, o caminho mais direto para a avaliação da qualidade do cuidado. Já os resultados 
possuiriam as características de refletir os efeitos de todos os insumos do cuidado, podendo, servir de indicador para a avaliação indireta da qualidade, tanto da estrutura quanto do processo.

Donabedian (2003) definiu a avaliação de qualidade como sendo toda ação realizada para estabelecer, proteger, promover e incrementar a qualidade do cuidado em saúde.

Segundo o autor, os principais itens no circulo de monitorizarão são:

1. Obtenção de dados ou performance (estrutura, processo, resultados).

2. Padrões de análise (tempo, lugar, pessoa, função). Uma atividade que seja natural e essencialmente epidemiológica.

3. Interpretação, a qual dá significado às hipóteses causais, que podem explicar o padrão observado.

4. Fazer prevenção, correção ou ações de promoção à saúde, baseadas em hipóteses causais que tem foram avançadas.

5. Obter dados sobre performance subsequente para determinar as consequências das ações realizadas.

Ampliando o conceito de qualidade, Donabedian (2003) descreveu os sete pilares da qualidade: eficácia, efetividade, eficiência, otimização, aceitabilidade, legitimidade e equidade, descritos a seguir:

Eficácia é a habilidade da ciência e tecnologia de cuidado em saúde para trazer melhorias na saúde quando usadas sob circunstâncias mais favoráveis .

Efetividade é o grau ao qual a melhoria da saúde possível de ser atingida, é de fato, alcançada.

Eficiência é a habilidade de se ter menor custo do cuidado de saúde sem diminuir as melhorias alcançáveis. 
Eficiência $=$ melhorias esperadas na saúde $/$ o custo do cuidado

Otimização é o balanço entre as melhorias em saúde e o custo de tais melhorias. Esta definição implica que há o melhor ou ótimo relacionamento entre custos e benefícios de cuidados de saúde, considerando um ponto abaixo ao qual mais benefícios poderiam ser obtidos com custos menores, comparados aos benefícios e acima ao qual benefícios adicionais podem ser obtidos de custos também largo relacionado aos benefícios correspondentes.

Aceitabilidade é definida como conformidade para os desejos e expectativas de pacientes e responsabilidade dos membros de suas famílias.

Donabedian (2003) desenvolveu esta definição em cinco partes:

1. Acessibilidade.

2. O relacionamento médico-paciente.

3. As amenidades do cuidado.

4. O que os pacientes consideram ser justo e equitativo.

5. Preferências do paciente quanto aos efeitos, riscos e custos dos cuidados.

No setor da saúde, a qualidade é definida como um conjunto de atributos que inclui nível de excelência profissional, uso eficiente de recursos, mínimo risco ao paciente e alto grau de satisfação por parte do usuário, considerando os valores sociais existentes (Donabedian, 2003).

Novaes (2000) afirma que cada um desses pilares pode ser específico para contextos diferenciados por meio da identificação de critérios adequados para cada situação, valorizando as particularidades e mantendo uma coerência entre si, porque apresentam uma interdependência e um movimento, do específico 
para o geral. Acrescenta, ainda, que as dimensões consideradas técnicas, condicionam as dimensões interpessoais, mas ao mesmo tempo, dependem dessas para realizarem seu potencial.

\subsection{AVALIAÇÃO DE SERVIÇOS EM SAÚDE MENTAL}

Apesar da tendência internacional de incorporação de avaliação ao campo da Saúde Mental, sobretudo relacionada à questão de redução de custos, de uma maneira geral essa área não possui tradição em avaliação, em comparação com outras de atenção à saúde. Mesmo os procedimentos clássicos de avaliação baseados em análise de eficácia, efetividade e eficiência, são pouco utilizados (Giordano, Pereira, 2000).

A avaliação da qualidade em Saúde Mental parece ser conduzida por características peculiares à área, quando comparadas às demais áreas de saúde. A avaliação de extensão de cobertura e de números de consultas, internações e procedimentos laboratoriais, por si só, não parece satisfazer critérios de boa qualidade em Saúde Mental. Todos os aspectos objetivos e materiais, mais que em outras áreas, são perpassados pela intersubjetividade das relações entre usuários e trabalhadores, enfim, de todos os envolvidos nesse processo de trabalho, aumentando as dificuldades já presumíveis nos processos de avaliação em serviços de saúde (Carvalho, Amarante, 1996).

O desafio técnico-metodológico é o de construir desenhos de pesquisa, técnicas e instrumentos que não sejam artificiais, de modo a descaracterizarem as práticas e os serviços que se pretende estudar.

Um programa ou serviço é entendido como um processo que possui movimento, uma dinâmica própria. É levada em conta a ação de atores distintos que se aliam e se contrapõem, tratando-se de uma busca hermenêutica por compreender antagonismos e 
consensos. Dessa forma, avaliar é também decodificar conflitos visando ao entendimento da cultura institucional e das práticas dos agentes que o serviço ou programa envolve. As análises dos sujeitos sociais acerca dessas experiências não podem ser ignoradas, mas reconhecidas como portadoras de racionalidade e analisadas sob a luz das conexões histórico-sociais que conformam tais discursos. A análise de serviços envolve também a da consciência histórica de seus agentes e de suas representações sociais, que por sua vez estão contidas nas práticas que os mesmos desenvolvem (Deslandes, 1997).

A avaliação de serviços e programas de saúde tem sido tema de diversas publicações, embora a produção de pesquisas referentes à avaliação dos serviços de saúde mental ainda se apresente escassa.

Para buscarmos uma qualidade dos cuidados de saúde prestados, é necessário definir o objeto que será avaliado, e sempre esclarecer o porquê avaliar, qual é a finalidade de tal avaliação, qual o caminho metodológico que será utilizado e também apresentar como serão aplicadas as medidas corretivas das deficiências, que irão ser identificadas por estudos desta natureza (Adami, Maranhão, 1995).

Quando falamos em avaliação em saúde mental, as pesquisas que utilizam instrumental padronizado, sempre utilizam como resultado uma boa pratica com indicadores indiretos que tenham como mensuração as medidas de qualidade de vida, autonomia e satisfação, com o intuito de ir além dos indicadores epidemiológicos. Podemos reunir, a partir do conjunto da literatura sobre a área, que a avaliação apresenta três objetivos gerais:

1) produzir conhecimento e reflexão sobre as práticas, os serviços, os programas;

2) produzir conhecimento sobre a própria avaliação e avançar em termos metodológicos; 
3) fornecer subsídios ao planejamento, gestão e administração dos serviços, quiçá ao ordenamento político dos programas de saúde pública (Schmidt, 2007).

Para pensar em avaliação na área da saúde mental os pesquisadores envolvidos precisam ter um certo compromisso, ideológico e ético, com a Reforma Psiquiátrica. Tendo em vista que participaram ativamente deste movimento e que foi a partir dele que houve a possibilidade do surgimento da nova política de saúde mental e a criação dos dispositivos extrahospitalares, foco desta investigação. Este campo de avaliação tem sido entendido como uma estratégia de reflexão sobre os novos serviços de saúde mental.

Um dos pilares deste movimento é a desinstitucionalização, ou seja, é a desconstrução de todo esse aparato manicomial, e a (re)construção de serviços substitutivos localizados na comunidade, com o intuito da reinserção social e a garantia de cidadania e melhor qualidade de vida.

Este é um momento de incentivo ao aprofundamento do conhecimento destes novos dispositivos de cuidado e à busca de mecanismos adequados para acompanhar estes dispositivos. Portanto, realizar avaliações da qualidade torna-se útil no sentido de apresentar as experiências cotidianas ocorridas nestes serviços substitutos ao manicômio para possibilitar lançar um olhar crítico sobre a assistência. Cabe salientar que já estamos na etapa posterior de denúncia aos horrores do hospício e da batalha por uma legislação que dê suporte às novas formas do cuidar em saúde mental. Este é o momento de conhecer o que tem sido realizado e avaliar seus efeitos.

No município de São Paulo, foi realizada uma pesquisa, publicada em 2009, com o objetivo de descrever a estrutura física, recursos humanos e modalidades de atenção existentes nos CAPS. Foram incluídos no estudo 21 serviços para atendimento de adultos, 
vinculados à Secretaria Municipal de Saúde de São Paulo. Os resultados mostraram que 10 dos serviços estudados iniciaram as atividades funcionando como ambulatórios e, posteriormente foram transformados em CAPS. Nenhum serviço funcionava diariamente durante 24 horas. Cinquenta por cento deles funcionavam em imóveis alugados, com instalações físicas inadequadas, especialmente, para atendimentos grupais. A composição das equipes dos serviços estudados foi bastante diversa. As atividades desempenhadas nos CAPS foram heterogêneas, com maior valorização das atividades grupais desenvolvidas com usuários dentro dos CAPS e pouca integração aos outros equipamentos de saúde. As atividades grupais de arte e cultura foram as mais frequentes em todos os serviços, no entanto, os serviços que tinham a origem ambulatorial apresentavam atividades artesanais e os que haviam sido hospitais-dia realizavam mais atividades de integração psicofísica. O perfil de atividades relacionou-se à distribuição regional dos serviços (Nascimento, Galvanese, 2009).

$\mathrm{O}$ referido estudo concluiu que a heterogeneidade dos CAPS parece se relacionar à história dos programas de saúde mental implementados no município desde a década de 1980 e à diversidade socioeconômica e cultural das regiões da cidade, bem como às diferentes composições das equipes observadas. Diferentes modelos de atenção psicossocial foram encontrados no estudo, desde a constituição de "equipamentos-síntese" (cunho dos autores) dos quais os usuários não recebem alta, até aqueles serviços que encaminham ou que dão alta após a estabilização dos sintomas dos usuários, no entanto, não viu nenhuma tentativa de construção de uma rede de cuidados (Nascimento, Galvanese, 2009).

Corroborando com os achados da pesquisa acima, em outra pesquisa as autoras afirmam que há uma grande diferenciação entre os CAPS existentes, sobretudo, na diversificada realidade brasileira. Nessas instituições, há histórias, compromissos e dificuldades 
específicas e distintas que as impedem de serem concebidas como instituições homogêneas. Assim, pensam que essas diferenças são dadas pelas subjetividades e intersubjetividades que nelas coexistem (Sobrinho, 2000).

A padronização de indicadores exclusiva e dominantemente quantitativos em um processo avaliativo não leva em conta essa questão e tem conduzido às noções e julgamentos equivocados de eficiência. No caso de serviços de saúde mental, indicadores quantitativos não avaliam se os serviços estão reproduzindo ou não a lógica manicomial, que é contrária aos princípios da reforma psiquiátrica brasileira. Essa questão passa pela forma como se conformam as relações entre os diferentes atores, no cotidiano do serviço (Sobrinho, 2000).

As críticas a esses serviços têm tido, com frequência, a influência do modelo de avaliação da caixa preta, em que as limitações em relação aos resultados inicialmente esperados são tomadas como um fracasso do dispositivo sem, contudo, analisar a influência de sua origem e do contexto. Muitas vezes, fatores político-administrativos locais e interesses econômicos na manutenção do sistema centrado no modelo hospitalocêntrico têm sido dificultadores para um avanço maior (Wetzel, Kantorski, 2004).

Com o objetivo de avaliar os modelos assistenciais, de gestão e de formação de trabalhadores de uma rede de CAPS, autores realizaram uma pesquisa avaliativa qualitativa, em 2006 e 2007, coletando dados por meio de grupos focais, em CAPS III, com diferentes grupos de interesse (trabalhadores, gestores municipais, usuários, familiares e gestores locais). Os autores identificaram pontos fortes e fracos relativos à atenção durante a crise psíquica; articulação com rede básica; formulação de projetos terapêuticos; gestão e organização em equipes de referência; formação educacional e sofrimento psíquico (Onocko-Campos et al., 2009).

Assim, como o observado no trabalho descrito anteriormente, outra pesquisa desenvolvida também realizou uma avaliação 
qualitativa, no ano de 2006 em Porto Alegre, com o objetivo de apreender a dinâmica de funcionamento de um CAPS, a forma como os atores interagem e os sentidos que eles constroem em relação à sua prática. Para os autores, a avaliação permitiu problematizar a atenção em saúde mental naquele CAPS e contribuiu para o processo emancipatório dos sujeitos envolvidos (Schneider et al., 2009).

Nesse sentido, entendemos que a proposta da Reforma Psiquiátrica não se restringe à criação de serviços extrahospitalares, mas que esses dispositivos sejam substitutivos não apenas às internações, mas ao modelo manicomial e hospitalocêntrico, de modo a incorporar novas tecnologias de intervenção no sofrimento psíquico.

Acerca dessa temática, em um estudo realizado num CAPS, os pesquisadores identificaram como premissas do serviço a liberdade de ir e vir e a reabilitação psicossocial, considerando como principais características das novas tecnologias estudadas: o acolhimento; a escuta; o responsabilizar-se pela trajetória do indivíduo; e o plano terapêutico, que deve considerar a individualidade do sujeito e a inserção da família/comunidade (Kantorski, Machado, Oliveira, 2000).

$\mathrm{Na}$ mesma direção, o estudo de caso de cunho avaliativo realizado num CAPS no Rio de Janeiro-RJ, no ano de 2006, utilizando como material os relatos gravados em uma reunião de supervisão de equipe no próprio serviço; propõem os eixos acesso, acolhimento e acompanhamento como elementos fundamentais para a análise da assistência e para a qualificação permanente dos serviços. Ressaltam ainda, que o acompanhamento se reafirma como um importante indicador em avaliação de qualidade de CAPS, ao mesmo tempo em que é um balizador no cotidiano do trabalho em equipe (Schmidt, Figueiredo, 2009).

Outros estudos, ainda, avaliam as práticas de cuidar com a utilização de recursos de artes no CAPS, indicando que a avaliação 
em saúde apresenta-se como um dos processos capazes de fornecer subsídios à tomada de decisão no setor com maior responsabilidade, eficácia e adequação (Tavares, Sobral, 2005).

A satisfação dos usuários é considerada aspecto fundamental na avaliação da qualidade dos cuidados prestados nos serviços de saúde mental. Essa avaliação é especialmente importante na medida em que se vivencia atualmente a transição do modelo de atenção hospitalar para o de assistência na comunidade.

Sabe-se que o grau de satisfação do trabalhador com a atividade que desenvolve tem influência direta sobre sua produção, que na área de Saúde Mental está relacionada à qualidade de atendimento que o mesmo oferece ao cliente/usuário, assim, estudo acerca da satisfação e impacto do trabalho na vida de 133 profissionais de quatro serviços de saúde mental do Rio de Janeiro, em que foram empregadas as escalas SATIS-BR, IMPACTO-BR e um questionário de caracterização sociodemográfica e das atividades laborais, mostrou que $62,4 \%$ dos profissionais apresentaram um nível intermediário de satisfação (Rebouças et al., 2008).

Uma vez situadas na confluência de diversas disciplinas, as práticas e pesquisas em saúde coletiva e saúde mental compõem o pano de fundo para o debate de oposição entre abordagens qualitativas e quantitativas. O consenso entre defensores do uso de métodos quantitativos e qualitativos parece situar-se num distante e improvável horizonte, havendo discursos que consideram ser compatíveis as diversas ordens entre os dois referenciais, como autores que advogam a incompatibilidade paradigmática dos mesmos.

"A questão não é só a de definir os parâmetros de qualidade a serem alcançados pelos serviços, seja por meio de métodos quantitativos ou qualitativos ou ambos, mas, mapear as relações e acontecimentos que ocorrem nestes serviços, não considerando 
seus processos [...] como algo dado, único, verdadeiro e natural". (Carvalho, Amarante, 1996).

Em uma pesquisa realizada nos CAPS da Região Sul do Brasil, conhecido como avaliação CAPSUL, de cunho qualitativo e quantitativo, investigou-se aspectos de estrutura, processo de trabalho e resultados dos CAPS, com a participação de usuários, familiares, trabalhadores e coordenadores dos serviços nos três estados da região. No estudo, as diferentes abordagens metodológicas privilegiaram diferentes dimensões do objeto da avaliação que, de forma complementar, disponibilizaram diferentes eixos para os julgamentos (Kantorski et al., 2009).

Não se têm estudos de avaliação de CAPSad publicados, assim sendo, é relevante o desenvolvimento de pesquisas que estabeleçam indicadores para a avaliação desses serviços.

\subsection{JUSTIFICATIVA}

No contexto das discussões de diferentes projetos de reforma do Estado Brasileiro, a busca de evidências nos resultados da implementação do SUS se impõe tanto como necessidade de desenvolvimento tecnológico no campo da avaliação em saúde, quanto para sustentar o debate político.

O efetivo controle da população em relação aos serviços ofertados com base na definição de padrões de boa qualidade de serviços, a fim de que possam ampliar sua capacidade de exercer seus direitos de cidadania advogando suas necessidades, tem justificado algumas iniciativas de estudos que tentam preencher um vazio teórico-técnico de como proceder, na prática, com vistas a incluir usuários e familiares como elementos articulados aos processos de planejamento e avaliação de serviços.

Ajustes no modelo assistencial são necessários para a implementação do SUS, o que justifica a promoção de iniciativas que 
se proponham a investigar e contextualizar as realidades assistenciais dos serviços. Investigações essas que identifiquem os resultados do modelo de gestão descentralizada, incluindo a perspectiva dos usuários. No processo de avaliação de novos modelos de cuidados em saúde mental, tais iniciativas de investigação podem contribuir para o desenvolvimento de conceitos, metodologias e instrumentos culturalmente sensíveis, capazes de operacionalizar mudanças e incluir a participação dos usuários e familiares nas práticas de avaliação, controle e garantia de qualidade dos serviços.

Dimensões como custos, acessibilidade, controle social e qualidade do cuidado prestado nos serviços de saúde, se colocam como prioridades para as políticas de saúde de países desenvolvidos e mais ainda naqueles em desenvolvimento, uma vez que crescem as demandas de saúde da população à medida que a sobrevivência deixa de ser um desafio, e que os indivíduos, se reconhecendo como cidadãos, passam a requerer uma atenção à sua saúde de melhor qualidade.

Proporcionalmente aos recursos humanos e econômicos empregados, é difusamente sentida no campo da atenção psiquiátrica a necessidade de avaliar, exprimir um juízo, acerca da organização dos serviços de saúde mental, definindo sua utilidade, a efetividade e eficácia de suas práticas. Paralelamente, estudos de efetividade de tratamentos, por meio de ensaios clínicos bem conduzidos, têm contribuído para o avanço científico-tecnológico.

No processo de trabalho em saúde, em que se trata de um lado, de usuários, cuidadores e organizações de saúde e, de outro, do resultado dessa equação expresso no cuidado produzido, pressupõe-se a urgência de melhor se conhecer esses componentes para que, munidos desse conhecimento, se possa advogar a potencialização da qualidade social, tecnológica, política e econômica do que é recebido e produzido. 
Atualmente os transtornos mentais associados ao uso prejudicial de álcool e outras drogas tem se agravado, como o do uso de crack que está em ascendência nos estados brasileiros.

Esse fenômeno acontece em um cenário em que as respostas institucionais não se adequaram às problemáticas apresentadas em estudos epidemiológicos existentes: uma precária rede de cuidados primários e intermediários inseridos na comunidade, em contraposição à excessiva oferta de leitos psiquiátricos, particularmente para álcool e outras drogas e que tem crescente implantação, sobretudo, no Estado de São Paulo, concentrando-se em algumas regiões, além de serviços não caracterizados como de saúde, como as chamadas comunidades terapêuticas, mas que são contratados por gestões estaduais e municipais.

Nessa direção, um processo avaliativo dos CAPS deve levar em conta que os mesmos, de forma isolada e fora de uma estrutura em rede, podem dar respostas parciais não apenas devido às suas limitações internas, mas também por não estarem inseridos em uma proposta política mais ampla. $\mathrm{Na}$ revisão da literatura não encontramos estudos avaliativos dos Centros de Atenção Psicossocial em Álcool e outras Drogas.

Diante do exposto, o presente estudo se faz necessário, pela premência de se olhar para essas novas modalidades públicas de atenção, que estão sendo implantadas no País há 10 anos, a fim de monitorar essas ações e aferir a sua validade. Avaliar um CAPS implica acompanhar o funcionamento de um serviço que se propõe a atender e a inserir socialmente o usuário, com maior resolubilidade, com uma intervenção pautada na diversidade de saberes de uma equipe multiprofissional e na utilização de múltiplos recursos.

Entendemos que a avaliação de serviços, por si só, assim como a gestão, as políticas e a prática, não são suficientes para alavancar alguma mudança. Entretanto, compreendendo a capacidade de análise como fundamento para a construção de 
sujeitos de mudança, o presente projeto pode inserir a avaliação como o dispositivo que os analistas institucionais definem como: "uma montagem ou artifício produtor de inovações que gera acontecimentos, atualiza virtualidades e inventa o Novo Radical" (Baremblitt, 1996).

Na perspectiva hermenêutica de Santos (2006), as políticas de saúde ou estratégias que contribuam para a sua elaboração, não devem partir verticalmente do setor Público, representado pelo Ministério da Saúde, mas de discussões, estudos e iniciativas que devem emergir de outros setores da sociedade, e nesse projeto, da Instituição de Ensino. Assim, os proponentes consideram que estes dois pontos, acrescidos dos outros já apresentados anteriormente, tornam o projeto em questão relevante e premente.

O que se pretende com esta investigação, privilegiando a construção de metodologias avaliativas de serviços e tratamentos em Saúde Mental é:

1) avaliar a rede de atenção aos usuários de álcool e outras drogas: acesso, infraestrutura, processo de trabalho e recursos humanos, do CAPSad do município de Botucatu.

2) avaliar o modelo de assistência prestado pela equipe técnica do CAPSad do município de Botucatu, caracterizando o modelo de atenção que está sendo oferecido aos usuários de álcool e outras drogas.

3) avaliar a repercussão da atenção oferecida nos CAPSad, nos níveis de satisfação de usuários e familiares.

As perguntas que fazemos inicialmente são: "Os CAPSad são efetivos na intervenção com usuários de álcool e outras drogas? $O$ tratamento no CAPSad está promovendo melhor qualidade de vida aos usuários de álcool e outras drogas? 
OBJETIVOS 


\section{OBJETIVOS}

\subsection{OBJETVO GERAL}

- Descrever e analisar o Centro de Atenção Psicossocial II ad (CAPSad) do município de Botucatu;

\subsection{OBJETVOS ESPECÍFICOS}

- Descrever e analisar a estrutura do CAPSad do município de Botucatu;

- Descrever e analisar o processo de trabalho e a organização da atenção em saúde mental oferecida pelo CAPSad do município de Botucatu;

- Descrever e analisar o resultado da atenção em saúde mental oferecida pelo CAPSad do município de Botucatu. 
METODOLOGIA 


\section{METODOLOGIA}

\subsection{MÉTODO}

O presente estudo é uma pesquisa avaliativa, descritiva, exploratória e transversal.

O referencial teórico-metodológico adotado para 0 desenvolvimento da pesquisa é a abordagem proposta por Donabedian (2003), acreditando-se que esse referencial teórico por abarcar as dimensões de estrutura, de processo e de resultado, propiciem que sejam explicitadas questões referentes à satisfação dos usuários e familiares articulando a tríade citada acima.

Quadro 1 Definição dos conceitos dos componentes Donabedianos.

\begin{tabular}{|l|l|}
\hline COMPONENTES & CONCEITO \\
\hline ESTRUTURA & $\begin{array}{l}\text { Compreende os recursos físicos, } \\
\text { humanos materiais e } \\
\text { financeiros, necessários para a } \\
\text { assistência em saúde mental. }\end{array}$ \\
\hline PROCESSO & $\begin{array}{l}\text { Atividades envolvendo } \\
\text { profissionais de saúde e } \\
\text { usuários com base em padrões } \\
\text { aceitos. A análise pode ser sob o } \\
\text { ponto de vista técnico e/ou } \\
\text { administrativo. }\end{array}$ \\
\hline RESULTADO & $\begin{array}{l}\text { Produto final da assistência } \\
\text { prestada considerando saúde, } \\
\text { satisfação de padrões e } \\
\text { expectativas }\end{array}$ \\
\hline
\end{tabular}

Fonte: Donabedian A. The definition of quality and approaches to it assessment: explorations in quality: explorations in quality assessment and monitoring. Chicago: Health Administration Press; 1980; v.1 


\subsection{MODELO LÓGICO}

O desenho do modelo lógico é o primeiro passo no planejamento de uma avaliação de programa, sendo muitos os caminhos que podem ser utilizados em sua construção (Rowan, 2000).

Construir o desenho lógico de um programa significa esquadrinhá-lo em termos da constituição de seus componentes e da sua forma de operacionalização, discriminando todas as etapas necessárias à transformação de seus objetivos em metas, abstraindo-se aqui suas determinações contextuais (Medina et al., 2005).

O modelo lógico é utilizado para explicitar a teoria de um programa, por meio de um esquema visual, que parte da descrição de recursos e atividades do programa e da forma como esses elementos se concretizam em resultados esperados. O modelo lógico compreende, então, a definição de elementos descritivos, que especificam os processos causais supostamente capazes de responder ao problema enfocado, e de elementos prescritivos, relativos aos componentes e atividades necessários à implementação efetiva do programa (Chen, 2005).

O processo para a construção da representação visual permite que a racionalidade implícita dos Programas, percebidas pelos gerentes e demais grupos implicados, seja manifestada por especialistas e inclusões de informações de pesquisas, levando-se a uma maior possibilidade de construção de acordos entre os componentes do programa e os resultados da avaliação (Rowan, 2000; Renger, Titcomb, 2002).

Apresentar e discutir o modelo lógico de um programa é o que permite definir com exatidão o que deve ser medido e qual a contribuição deste nos resultados esperados. Tornar explícito o modelo lógico consiste em descortinar quais são os limites ou 
debilidades de seus pressupostos, possibilitando identificar onde melhores evidências devem ser buscadas (Mayne, 2000).

Segundo Rossi e colaboradores (1999) em um modelo lógico de um Programa devem constar: Os seguintes componentes:

a. Os componentes: essenciais e secundários - do Programa.

b. Os serviços relacionados e as práticas requeridas para execução dos seus componentes.

c. Os resultados esperados, suas metas e efeitos na situação de saúde da população e organização de serviços.

O modelo lógico deste estudo foi estruturado da seguinte maneira: 


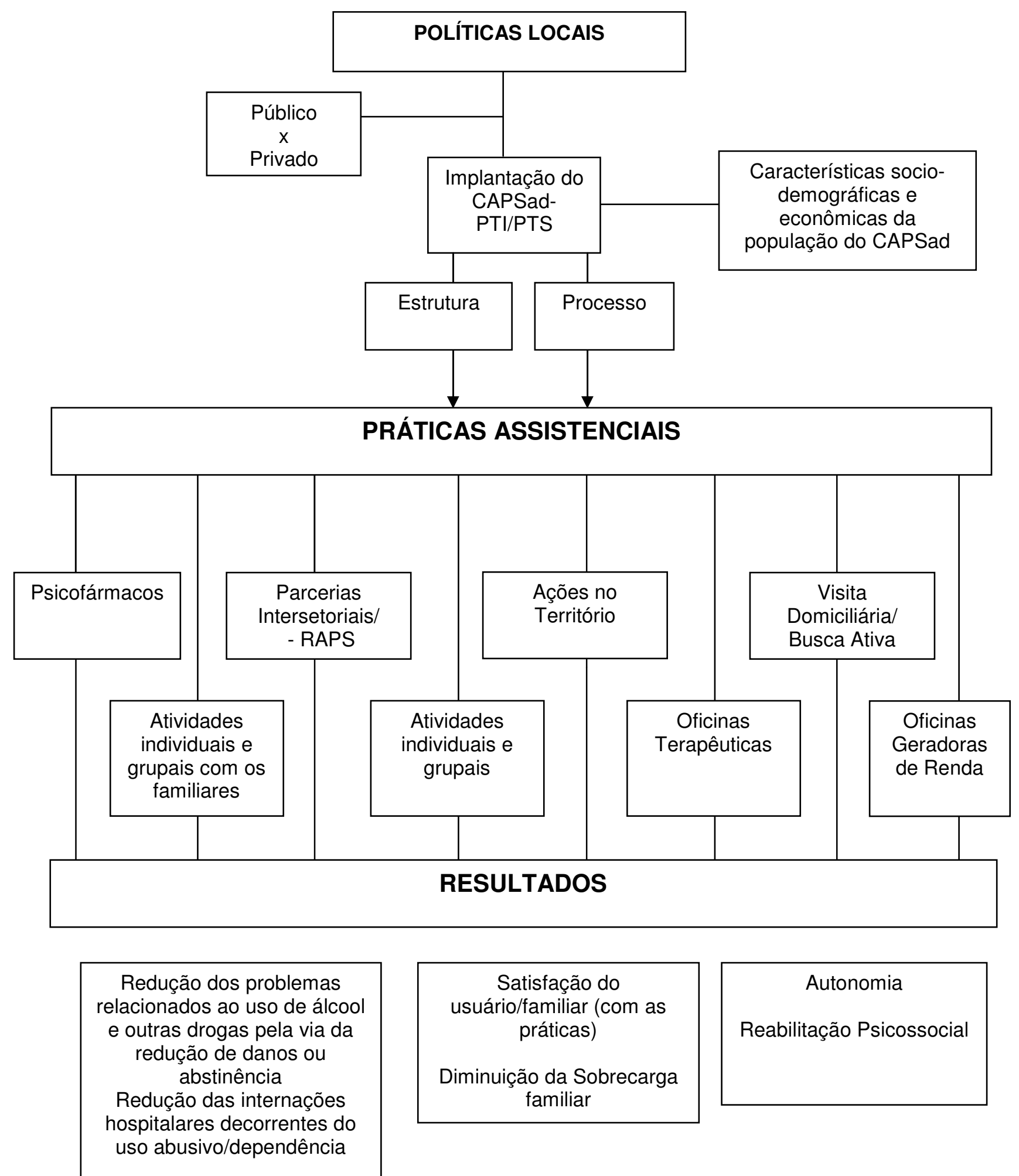

Figura 1 Modelo lógico para atenção em saúde mental no CAPS. 


\subsection{DESCRIÇÃO DO MODELO LÓGICO}

No plano de organização do Programa, ressaltamos a necessidade de se conhecer as políticas públicas locais para o CAPSad.

Neste plano de organização, incluímos as relações e a articulação do CAPS com os serviços de referência e contrarreferência, na rede.

No plano de organização, temos que considerar ainda o processo de implantação do serviço. Para avaliar esse processo de implantação, analisaremos, em auditoria, o Projeto Terapêutico Institucional e o Plano Terapêutico Singular de cada usuário. Se os mesmos foram construídos e estão sendo implementados.

No plano de utilização do serviço, serão avaliadas a estrutura e processo de trabalho, necessários para as práticas assistenciais dos CAPSad do município de Botucatu.

No plano de utilização do serviço, a dimensão que será avaliada é a de práticas assistenciais do CAPSad do município de Botucatu.

As práticas assistenciais desenvolvidas no CAPSad são:

- tratamento psicofarmacológico;

- visitas domiciliárias e/ou buscas ativas, de usuários que evadiram do serviço;

- as psicoterapias grupais e individuais;

- ações no território;

- atendimento familiar individual e participação em grupos de família;

- parcerias intersetoriais que possibilitem aos usuários a satisfação de necessidades nas dimensões do morar, do habitar, do trabalho e das relações sociais;

- oficinas terapêuticas e de geração de renda. 
No plano de impacto do Programa, os objetivos em curto prazo serão a remissão dos sintomas do transtorno psíquico, decorrente do uso de álcool e outras drogas. Os objetivos, em longo prazo, serão a percepção do usuário e do familiar, a respeito das intervenções realizadas pelo serviço, além da autonomia e a reabilitação psicossocial do usuário.

O modelo de forma sintética deve ser desenvolvido a partir da lógica do modelo de Donabedian (1984), conforme o modelo a seguir:

Estrutura da Atenção em Saúde Mental
Estrutura Física;
Recursos Materiais
Recursos Humanos
Recurso Técnico
$\quad$ Normas
$\quad$ Sistema de Referência
Alimentação
Medicamentos

Adequação da Atenção

\section{Processo}

Território

Práticas Assistenciais (Atividades Diversas)

Frequência das Atividades

Assembléias

\section{Satisfação e sobrecarga dos} Trabalhadores

\section{Características Individuais}

Figura 2 Fluxograma da qualidade da atenção em Saúde Mental do CAPSad do Município de Botucatu. 


\subsection{CENÁRIO DA PESQUISA}

\section{Breve Contextualização do CAPSad do município de Botucatu.}

Para apreender o fenômeno na especificidade da proposta desta investigação, realizou-se a coleta de dados em uma realidade específica: no Centro de Atenção Psicossocial em álcool e outras drogas (CAPSad), localizado no município de Botucatu-SP.

Essa escolha foi intencional, pois o objetivo não era o de confrontar realidades, mas buscar uma instituição na qual houvesse a possibilidade de explorar as questões para além da aparência. A ênfase em determinado serviço procura tomá-lo como parte de um conjunto mais amplo e abrangente de práticas assistenciais no campo da saúde mental, o que permite maior aproximação da realidade. Botucatu está localizado na região centro-oeste do Estado Brasileiro de São Paulo e possui uma população de aproximadamente 131.723 habitantes (2013), uma área demográfica de $1.482,642 \mathrm{~km}^{2}$ com uma densidade demográfica de 88,84 $\mathrm{hab} / \mathrm{km}^{2}$ (Brasil, 2013).

Em termos de serviços de saúde, o município apresenta: O CAIS "Professor Cantídio"; Centro de Saúde Escola (CSE) vinculado à UNESP; Pronto- Socorro Municipal; 18 Unidades de Atenção Primária à Saúde, sendo 11 Estratégias de Saúde da Família (ESF) e sete Unidades Básicas de Saúde (UBS); três hospitais, sendo dois secundários e um terciário, totalizando 721 leitos hospitalares, que prestam assistência para o município e região (Brasil, 2013b).

No que se refere às condições de vida (Índice Paulista de Responsabilidade Social - IPRS), o município de Botucatu, em 2010, situava-se no Grupo 2 -, ou seja é um município que, embora com níveis de riqueza elevados, não exibe bons indicadores sociais. Dados da Fundação Sistema Estadual de Análise de dados SEADE mostram que o Índice de Desenvolvimento Humano no 
município - IDHM é de 0,822 , no ano de 2000. A renda per capita é de 1,32 salários mínimos, sendo 5,22\% dos domicílios possuem renda per capita de ate $1 / 4$ do salário mínimo e 15,25\% têm renda per capita de 1/2 salário mínimo, no ano de 2010 (Brasil, 2013).

Considerando a população do município de Botucatu, tentaremos estimar o perfil epidemiológico utilizando o procedimento de estimativa. Dados disponíveis no portal da OBID (2013) e relativos à pesquisa do CEBRID nos informam prevalência de 5,0\% para problemas severos relativos ao consumo de outras drogas, contando com a baixa precisão de dados de algumas das substâncias de uso menos prevalente e $12 \%$ da população brasileira apresentam algum problema com álcool. Portanto, estes dados serão utilizados para fins de identificação da população com problemas severos relativos ao consumo de outras drogas e com problemas com o álcool, bem como para verificação da necessidade de redimensionamento da rede de cuidados:

- $5 \%$ da população brasileira têm problemas severos relativos ao consumo de outras drogas (à exceção de álcool e tabaco) - Será a prevalência referencial para as projeções relativas à população circunscrita do município de Botucatu.

- $12 \%$ da população brasileira têm problemas mais severos relativos ao consumo de álcool - Será a prevalência referencial para as projeções relativas à população circunscrita do município de Botucatu. 
Quadro 2 Descrição da População total, estimativa de usuários de álcool e outras drogas do município de Botucatu.

\begin{tabular}{|c|c|c|c|}
\hline DRS-VI & $\begin{array}{c}\text { População } \\
\text { Total }\end{array}$ & $\begin{array}{c}\text { Estimativa } \\
\text { Outras Drogas }\end{array}$ & $\begin{array}{c}\text { Estimativa } \\
\text { Álcool }\end{array}$ \\
\hline Botucatu & 127.328 & $6.366,4$ & $15.279,4$ \\
\hline
\end{tabular}

O município faz parte do 6을 Departamento Regional de Saúde - DRSVI, e a rede de atenção em saúde mental estruturada há 10 anos vem adaptando-se às novas políticas nacionais de saúde mental pautadas na Reforma Psiquiátrica, priorizando o atendimento extra-hospitalar.

A atenção em Saúde Mental em Botucatu inicia-se com o Hospital Professor "Cantídio de Moura Campos" - HPCMC, unidade de internação Estadual, no final da década de 60. No espaço hospitalar, funcionava ainda o Ambulatório de Saúde Mental, o que acabava favorecendo o encaminhando dos usuários para internação.

No início da década de 70 , do século passado, criou-se o serviço ambulatorial de Psiquiatria da Faculdade de Medicina de Botucatu - UNESP. Logo após, foram implantados o Hospital-Dia e o serviço de Saúde Mental do Centro de Saúde Escola (início da década de 80 , do século passado), ambos ligados à Faculdade de Medicina de Botucatu - UNESP.

Em 1992, houve a transferência do Ambulatório de Saúde Mental do HPCMC, para o NGA-11 de Botucatu, onde é uma das especialidades do mesmo.

Atualmente, a Emergência Psiquiátrica do município de Botucatu e região (31 municípios) é realizada no Pronto-Socorro do Hospital das Clínicas da Faculdade de Medicina de Botucatu UNESP.

O Hospital "Professor Cantídio de Moura Campos (HPCMC) era o único hospital psiquiátrico da região, que dispunha de 180 leitos SUS, dos quais 126 erram destinados a usuários moradores, 10 para usuários dependentes químicos e 44 em casos de quadro 
agudo. O HPCMC, em 2007, foi transformado em um Centro de Atenção Integral à Saúde (CAIS). O CAIS é intitulado CAIS "Professor Cantídio"

O CAIS hoje gerencia as seguintes unidades:

- Unidade de Internação de Agudos "InterAgir" com 60 leitos.

- Serviço Residencial Terapêutico (SRT) "Recanto das Flores" com duas residências na cidade e outras oito residências nas dependências do CAIS em que vivem 56 pacientes.

- Ambulatório de Saúde Mental, que atende em média 700 pacientes.

- Oficina Terapêutica Girassol que atende em média 70 pacientes.

- Dois Centros de Atenção Psicossocial (CAPS): um CAPSII "Espaço Vivo" que atende em média 320 pacientes, e um CAPSad "Renascer" que atende em média 300 pacientes.

A rede de saúde mental da cidade fica composta por um CAPSII, um CAPSIlad cadastrados de acordo com a portaria 336/2002 do Ministério da Saúde; dois Ambulatórios de Saúde Mental, um vinculado ao CAIS e outro vinculado a UNESP; uma oficina terapêutica vinculada ao CAIS; dois Prontos-Socorros, um vinculado ao município e outro ao Hospital das Clínicas sendo que apenas o vinculado ao Hospital das Clínicas possui médico psiquiatra de plantão. $O$ atendimento em saúde mental está regionalizado por meio dos Distritos Sanitários, com serviços de referência que são responsáveis pela cobertura assistencial de cada região. Há também uma organização não governamental voltada a pacientes com transtorno mental intitulada de Arte Convívio. 
O CAPSad do município de Botucatu é gerenciado pelo Centro de Atenção Integral à Saúde "Professor Cantídio" que é gestado pela Secretaria Estadual de Saúde, ou seja, é um dos CAPSad do Estado de São Paulo que é estadual. Com isso, ele é responsável por atender toda a demanda regional de Botucatu que engloba 31 municípios.

Torna-se importante relatar que antes do surgimento do CAPSIlad do município de Botucatu, para o tratamento e reabilitação dos usuários com transtorno por uso indevido de substâncias o município tinha: dois ambulatórios de saúde mental, sendo o ambulatório de Psiquiatria da Faculdade de Medicina e o ambulatório do Núcleo de Gestão Assistencial (NGA-11), o Centro de Saúde Escola e a unidade de desintoxicação (UDQ) do HPCMC. Em 2007, é (des)construído a UDQ e a equipe desta unidade é direcionada para o funcionamento do CAPSad.

\subsection{POPULAÇÃO/AMOSTRA DE PARTICIPANTES}

A população deste estudo é constituída pelo coordenador do CAPSad, pela equipe multiprofissional do serviço, e pelos usuários e familiares atendidos no serviço.

A equipe está assim configurada: dois médicos generalistas, dois médicos psiquiatras, duas psicólogas, três enfermeiras, duas assistentes sociais, uma terapeuta ocupacional, um farmacêutico, nove técnicos/auxiliares de enfermagem, quatro técnicos administrativos, um funcionário de limpeza, uma funcionária de cozinha. O farmacêutico não fica lotado no CAPSad, ele apenas presta assistência ao CAPS, pois é responsável por todos os serviços do CAIS "Professor Cantídio".

Para a amostra de usuários, foi realizado um sorteio aleatório de 30 usuários inscritos no serviço. 
No momento da coleta, o número de usuários cadastrados ativos no serviço foi de 182 usuários.

\subsection{CRITÉRIOS DE INCLUSÃO DOS PARTICIPANTES}

Os critérios de inclusão para participar da pesquisa foram:

1. O coordenador e membros da equipe técnica dos CAPS participantes deveriam ter no mínimo um ano de trabalho no serviço.

2. Para os usuários do CAPS, os critérios de inclusão foram os seguintes:

$\checkmark \quad$ Indivíduos com idades entre 18 e 70 anos.

$\checkmark$ Estarem cadastrados e participando das atividades dos CAPS há no mínimo seis meses.

$\checkmark$ Serem portadores de transtornos mentais graves e persistentes decorrentes do uso e da dependência ao álcool e outras drogas.

Foram incluídos no estudo o coordenador, membros das equipes técnicas e usuários do CAPS que preencherem os requisitos acima e concordarem em participar da pesquisa, assinando o Termo de Consentimento Livre e Esclarecido.

\subsection{ESTUDO PILOTO}

Foi aplicado um estudo piloto nos quatros segmentos: usuários (incluindo auditoria de prontuários), familiares, trabalhadores e coordenador. O piloto foi realizado por meio da coleta de dados com todos os instrumentos, que produziu um 
relatório para apresentação e discussão das dificuldades encontradas.

O estudo piloto foi necessário para testarmos os instrumentos e adequá-los às necessidades e contrastes dos campos de atuação, pois apesar de estarmos utilizando os instrumentos propostos pelo estudo de avaliação dos CAPS da região Sul do Brasil, os instrumentos não abarcaram a especificidade do CAPSad. Com isso, nos ajudou a chegar a pontos específicos, que indicaram caminhos para adaptar e/ou melhorar os questionários, para assim contemplarmos cada questão proposta no estudo. O estudo piloto também serviu como treinamento dos entrevistadores.

\subsection{PROCEDIMENTOS ÉTICOS}

O projeto foi submetido ao Comitê de Ética em Pesquisa da Escola de Enfermagem da Universidade de São Paulo, seguindo as determinações da Resolução 196/96, do Conselho Nacional de Ética em Pesquisa - CONEP/CNS e aprovado com o no 1001/2011 (Anexo 1).

Foi pedida autorização para o Comitê de Pesquisa do CAIS "Professor Cantídio" e para coordenação do CAPSad (Apêndice 1).

Alguns procedimentos éticos que antecedem à coleta de dados foram cumpridos, como se segue:

Contato por meio telefônico com a coordenação do CAPSad, para o agendamento de uma reunião com a finalidade de apresentar o projeto e entregar a carta explicativa. Após esse primeiro contato, as visitas foram agendadas em dias e horários que eram mais convenientes ao funcionamento do serviço.

A carta explicativa acerca do estudo continha: título e objetivos do mesmo; relevância para sua execução; isenção de ônus financeiro ou sanções a quem não desejar participar ou que desistir de participar, durante sua execução (Apêndice 3). 
Em seguida, os membros das equipes técnicas, usuários e familiares dos CAPS foram informados acerca da realização da pesquisa, sendo-Ihes entregue uma carta-convite (Apêndice 3) com os itens, citados acima, para participar da pesquisa, e todos igualmente assinaram os TCLE (Apêndices 2 e 4).

Com a obtenção dos TCLE dos participantes, deu-se início à coleta de dados.

\subsection{COLETA DE DADOS}

A coleta de dados ocorreu por meio de instrumentos designados para cada grupo de participantes: coordenador, membros da equipe técnica, usuários e familiares.

Para os coordenadores, membros da equipe técnica, usuários e familiares, na coleta dos dados foi empregada a técnica de entrevista com instrumento estruturado.

A coleta ocorreu no período de maio a julho de 2013.

\subsection{OS INSTRUMENTOS DE COLETA DE DADOS}

Os instrumentos (Anexos 2, 3, 4 e 5) foram cedidos por Kantorski (2006) (Anexo 6) e, após o estudo piloto foram adaptados pelos pesquisadores do GEADUSP.

Os instrumentos tem como base a Portaria $n^{\circ} .336 / 2002$ do Ministério da Saúde, tendo incluído as Escalas de Satisfação SATISBR (Bandeira, Pitta, Mercier, 2000; Bandeira et al., 2002; Bandeira, Silva, 2012), da Escala de Avaliação da Percepção de Mudança (EMP) (Bandeira, Felicio, Cesari, 2010; Bandeira et al., 2011) e pela Escala de Atitudes frente ao álcool, alcoolismo e alcoolista EAFAAA (Vargas, 2011). 
O instrumento do coordenador serviu para descrever como o serviço está constituído e funcionando.

As Escalas de Satisfação SATIS-BR integram um conjunto de três escalas para avaliação de Serviços de Saúde Mental: Escalas de Avaliação da Satisfação dos usuários e familiares com os Serviços de Saúde Mental - SATIS-BR (Bandeira, Silva, 2012; Bandeira et al., 2002) e a Escala de Avaliação da Satisfação de Profissionais em Serviços de Saúde Mental - SATIS-BR (Bandeira, Pitta, Mercier, 2000).

Essas escalas foram elaboradas pela Divisão de Saúde Mental da Organização Mundial de Saúde (OMS) e, posteriormente foram validadas para o Brasil por Bandeira e colaboradores entre 2000 e 2002 e atualizadas em 2012.

A Escala de Avaliação da Percepção de Mudança (EMP) foi elaborada por Mercier e colaboradores, no Canadá e validada para o Brasil (Mercier et al., 2004; Bandeira et al., 2009).

A Escala de Atitudes frente ao álcool, alcoolismo e alcoolista EAFAAA, foi construída em sua primeira versão em 2005 (Vargas, 2005), com o objetivo de avaliar os principais grupos de atitudes dos profissionais de saúde frente ao álcool e ao alcoolismo (fator moral, fator doença, fator etiológico, fator profissional e fator humano) (Pillon, Dum, Laranjeiras, 1999).

Diversos estudos de validação da escala mostraram valores elevados de consistência interna e validade, permitindo afirmar que o instrumento apresenta bons parâmetros psicométricos (Vargas, 2011).

\subsection{TRATAMENTO E ANÁLISE DOS DADOS}

O banco de dados foi construído por meio da codificação dos dados pelo pesquisador, em seguida, processados no software 
Microsoft Excel® 2010, por meio de dupla digitação, com a finalidade de minimizar os possíveis erros.

O controle de qualidade foi realizado nos seguintes momentos:

- Na aplicação dos instrumentos de coleta, por meio da checagem de cada entrevistador ao final da entrevista; na revisão realizada pelos supervisores ao receberem o questionário; na replicação de $5 \%$ das entrevistas realizadas e na correção da codificação.

- Na entrada de dados, por meio da dupla digitação, checagem e mapa de consistência.

Os dados foram processados no Programa Statistical Package for Social Sciences (SPSS), versão 20,0 para Windows®. Tanto o desenho amostral, como a elaboração do banco de dados e as análises estatísticas foram realizadas com assessoria do estatístico da EEUSP.

Foi realizada uma análise descritiva dos dados. Com o objetivo de verificar se os CAPS são bem avaliados pelos usuários e seus familiares, utilizamos a escala SATIS-BR e testamos as médias de respostas do serviço. O escore é dado por meio das médias das respostas, e quanto mais próximo este valor de 5, melhor é a satisfação (Bandeira e Silva, 2012).

Com o objetivo de analisar se os usuários e familiares percebem mudanças após o tratamento no serviço, o autor empregou a escala de mudanças percebidas e testou as médias das respostas do serviço. O escore é dado por meio das médias das respostas, e quanto mais próximo este valor de 3 , melhor é a percepção de mudança (Bandeira et al., 2011). 
RESULTADOS 


\section{RESULTADOS}

\subsection{DESCRIÇÃO DOS SUJEITOS DO ESTUDO}

Fizeram parte deste estudo um coordenador, 19 trabalhadores, 25 usuários e 15 familiares.

Entre os 30 usuários do CAPSad selecionados, 25 (83,3\%) participaram do estudo, dois $(6,6 \%)$ não aceitaram, dois $(6,6 \%)$ abandonaram e um $(3,3 \%)$ estava internado em uma Comunidade Terapêutica no período da coleta.

Entre os 30 familiares do CAPSad selecionados, 15 (50\%) participaram do estudo, sendo a percentagem que acompanha e tem algum contato com o CAPSad. $O$ restante nunca frequentou 0 serviço.

Os trabalhadores selecionados para a coleta foram os profissionais de saúde de nível médio e superior que estão relacionados com as práticas assistenciais, dos 22 selecionados, 19 $(86,3 \%)$ participaram do estudo, tendo duas $(9,1 \%)$ recusas.

\subsection{CENTRO DE ATENÇÃO PSICOSSOCIAL DE ÁLCOOL E OUTRAS DROGAS: DESCRIÇÃO DO SERVIÇO}

O Centro de Atenção Psicossocial de álcool e outras drogas de Botucatu é intitulado de CAPSad "RENASCER". Possui natureza jurídica pública com administração direta, cadastrado e funcionando como CAPSad II em regime ambulatorial. É um serviço estadual administrado pelo Centro de Atenção Integral à Saúde "Professor Cantídio" (CAIS "Professor Cantídio). Teve seu início em 10 de janeiro de 2007 funcionando apenas em turno diurno de segunda a sexta da $8 \mathrm{~h}$ às $18 \mathrm{~h}$. O serviço está alocado em uma casa alugada e 
adaptada para o funcionamento do CAPS. O serviço possui projeto terapêutico institucional (Anexo 7).

O fluxograma do CAPSad do município de Botucatu está apresentado na figura abaixo:

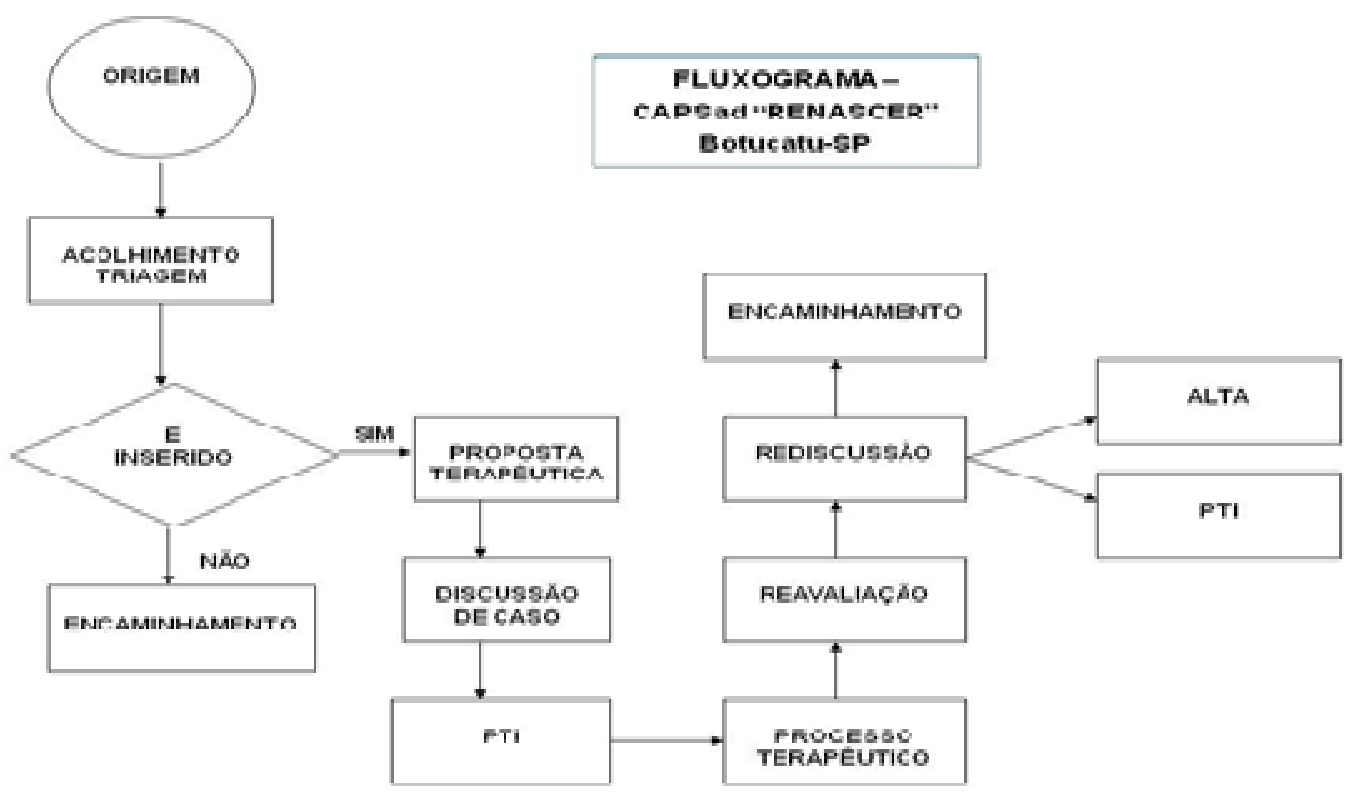

Figura 3 - Fluxograma do CAPSad do município de Botucatu.

Contempla acolhimento diurno, acesso livre dos usuários, ou com hora marcada. Os técnicos que fazem acolhimento são: enfermeiro, psicólogo, médico psiquiatra, assistente social, terapeuta ocupacional, técnico/auxiliar de enfermagem e técnico administrativo. O serviço também realiza triagem.

A coordenação do serviço é de caráter formal sendo escolhido por indicação da Diretoria da Divisão do CAIS "Professor Cantídio". A coordenadora está na função há 48 meses, tendo formação em psicologia, com especialização na área de saúde mental, especialização em saúde pública e mestrado na área de saúde mental. Seu turno de trabalho é de 30 horas semanais com vínculo estatutário.

Segundo a coordenadora, suas funções no serviço são as seguintes: "responsável pelos bens móveis e imóveis do serviço; 
responsável pela gestão dos funcionários; representante técnica dos casos acompanhados; representa o CAIS "Professor Cantídio" nos espaços públicos e privados referentes às questões de álcool e outras drogas; direcionamento de ensino e pesquisa com os funcionários".

A equipe está assim configurada: dois médicos generalistas, dois médicos psiquiatras, duas psicólogas, três enfermeiras, duas assistentes sociais, uma terapeuta ocupacional, um farmacêutico, nove técnicos/auxiliares de enfermagem, quatro técnicos administrativos, uma funcionária de cozinha e um funcionário de limpeza. O farmacêutico não fica lotado no CAPSad, ele apenas presta assistência ao CAPS, pois é responsável por todos os serviços do CAIS "Professor Cantídio".

O financiamento dos CAPS está regulamentado pela portaria ministerial 189/2002 como atendimento a pacientes de alta complexidade, como uma estratégia do Ministério da Saúde na consolidação da implantação do CAPS nos municípios, por meio de um maior aporte de recursos para esses serviços. Os recursos são utilizados mediante um planejamento que leva em consideração as demandas e necessidades do CAPS e são utilizados para o CAPS, tendo o conhecimento da procedência desses recursos.

O número de pacientes inscritos no serviço no período da coleta de dados foi de 182. Foram atendidos 155 usuários acima de 18 anos e 27 usuários acima de 60 no último mês. E utilizando dados da RAPS foram: 35 procedimentos de acolhimento diurno, 208 procedimentos de atendimento individual, 26 procedimentos de atendimento familiar, 14 procedimentos de acolhimento inicial e 26 procedimentos de atenção à situação de crise. 


\subsubsection{Infraestrutura do serviço}

A estrutura física do CAPSad estudado se configura numa casa ampla, de apenas um piso, com aproximadamente $500 \mathrm{~m}^{2}$ de área construída tendo: dois leitos de desintoxicação, dois leitos de acolhimento máximo, uma sala de desintoxicação, uma sala de acolhimento máximo, três salas de atendimento individual, três salas para atividades coletivas, duas salas para oficinas, uma sala para enfermagem e procedimentos, sete banheiros, duas cozinhas, um refeitório, três salas de depósitos de materiais (limpeza, enfermagem, terapia ocupacional), uma sala de recepção, uma sala de equipe, uma sala de administração e uma sala de biblioteca. O espaço do serviço ainda possui jardim, quintal, praça, varanda e piscina.

A avaliação da coordenadora é que o serviço não possui número de salas adequadas para a demanda de atendimento. Possui oficinas estruturadas e equipadas, mas a sala de desintoxicação ainda não está em funcionamento por falta de adequações na estrutura física.

O serviço disponibiliza café da manhã, almoço e lanche da tarde, com cardápio especial para hipertenso e diabético.

Os prontuários de registro ficam arquivados no CAIS, ou seja, quando o usuário é admitido no serviço, a equipe requer o prontuário ao SAME (Serviço de Arquivo Médico e Estatístico) do CAIS, isso se este já tiver prontuário aberto no CAIS.

O serviço possui farmácia no local em que o próprio CAPS dispensa as medicações em que são provenientes da cesta básica das secretarias municipal e estadual de saúde. Há medicação para urgência/emergência no serviço. As medicações são dispensadas conforme discutido no projeto terapêutico singular de cada paciente, podendo ser por medicação supervisionada ou mensal. 


\subsubsection{Atividades de articulação}

O serviço apresenta articulação com os recursos do território sendo alguns citados como: Atenção Básica, Centro de Referência de Assistência Social (Cras-Norte), discussão de penas alternativas com o Centro de Referência Especializado de Assistência Social (Creas) e Conselho Tutelar, participação em diversos Fóruns, Serviço de Assistência Especializada de Infectologia-SAE de Infectologia "Domingos Alves Meira" - Medicina Unesp - Botucatu, Departamento de Psiquiatria da Unesp- Botucatu, Conselho Municipal de Saúde, Conselho Municipal de Direitos Humanos da Criança e do Adolescente.

Está inserido na Rede de Atenção Psicossocial (RAPS), mas com dificuldades em relação ao fluxo de internação no CAPSad, sendo elas: falta de leito desintoxicação de grau moderado e grave; rede de atenção psicossocial falha, falta de casas transitórias.

O tempo de espera para uma vaga na Central de Vagas é em média três dias não havendo outra via de acesso para obtenção de vaga para internação.

Possui sistema de referência e contrarreferência organizado com serviços de atendimento especializado, com serviços de emergência psiquiátrica, com hospital psiquiátrico e com os serviços da atenção básica. $O$ serviço de referência de internação psiquiátrica é normalmente para o CAIS "Professor Cantídio".

O serviço também é campo de ensino e recebe programas de estágios de medicina, enfermagem, psicologia e serviço social e visitas técnica de curso curricular de graduação. Recebe também visitas técnica de cursos de auxiliar e técnico de enfermagem. 


\subsubsection{Práticas assistenciais}

Os critérios de acesso ao CAPS são: ter acima de 17 anos e meio de idade e ter grau de dependência provável. E os critérios de alta geralmente utilizado pelo serviço são: abandono ou alta solicitada, melhora do quadro, transferência para outro serviço, não aderência do usuário/família ao tratamento proposto, mudança de cidade ou aquisição de trabalho.

Dentre as atividades descritas pela coordenadora estão: avaliação clínica, social, psicológica, psiquiátrica e neurológica do usuário. Atendimento individualizado tanto no serviço quanto no domicilio. Pode receber atendimento de orientação e psicoterápico individual e em grupo. Os critérios para a indicação do usuário para a psicoterapia individual são: ter o desejo e passar por avaliação da equipe se o paciente irá ter beneficio em seu tratamento.

Há atendimento à família no serviço sendo ofertados orientação individual e grupal.

O serviço realiza manejo do usuário em situação de crise como surto, agitação psicomotora, risco de agressão a outros e a si mesmo, risco de suicídio. O mecanismo mais utilizado para evitar internação sem situações de crise é a inserção do usuário na modalidade intensivo do serviço. O serviço também não conta com serviços residenciais terapêuticos ou casa transitórias.

Conta, ainda, com oficinas terapêuticas de artes e de música. Possui atividades grupais de caráter: operativo, psicoterapia, psicoeducação, recreativos e prevenção de recaídas. Realizam visitas domiciliares com objetivo de busca ativa, acompanhamento da situação e acompanhamento de situações agudas, sendo realizadas por: médico, psicólogo, enfermeiros, assistente social, terapeuta ocupacional, técnico/auxiliar de enfermagem, ocorrendo conforme necessário. O transporte para as visitas domiciliares está disponível quando solicitado. 
As atividades físicas ofertadas aos pacientes no serviço são: o grupo de caminhada, utilização da academia ao ar livre e prática do Lian Gong, tendo em média 25 pacientes participantes desta atividade e que é realizado por uma enfermeira do serviço em média três vezes por semana. Os usuários também utilizam campo de futebol e espaços do campus da Faculdade de Agronomia da Universidade Estadual Paulista - Unesp.

O serviço possui assembleias semanais com registro em ata tendo como participantes os usuários, familiares, equipe, serviços da CAIS "Professor Cantídio" e da Organização Não Governamental (ONG) "Arte e Convívio". Conta também com reuniões de equipe semanais com a presença de todos os funcionários com duração de $4 \mathrm{~h}$ e 30 minutos.

Nos prontuários, ocorre registro diário da frequência do usuário ao CAPS e de sua participação nas atividades, bem como o relato do primeiro atendimento e conduta, das alterações de projeto terapêutico, das situações de crise, entre outras. Todos os profissionais da equipe fazem anotações nos prontuários. O serviço possui o Projeto Terapêutico Singular e que normalmente é preenchido pelo profissional de referência do usuário.

O serviço não possui projetos de geração de renda e também não possui associação de usuários. Conta com técnico de referência sendo: psicólogo, enfermeiro, assistente social, terapeuta ocupacional e técnico/auxiliar de enfermagem. A equipe é dividida em três miniequipes e cada uma possui um número de pacientes que é dividido entre os profissionais e este fica referência do paciente.

\subsection{TRABALHADORES}

Os dados a seguir correspondem ao perfil sociodemográfico dos trabalhadores do CAPSad. Neste serviço, há um predomínio de 
trabalhadores do sexo feminino, de cor branca, com formação qualificada, casado ou com companheiro, com tempo de trabalho superior a dois anos no CAPS, recebendo salários de um a três salários mínimos, tendo carga horária de 30 horas semanais.

Tabela 1 Caracterização dos trabalhadores do Centro de Atenção Psicossocial Álcool e Outras Drogas em Botucatu, segundo gênero, etnia, faixa etária, estado civil, escolaridade, tempo de trabalho em CAPSad, tempo de trabalho no CAPSad atual, profissão, salário e carga horária, 2013.

\begin{tabular}{|c|c|c|}
\hline Gênero & $\mathbf{N}$ & $\%$ \\
\hline Feminino & 17 & $89,5 \%$ \\
\hline Masculino & 2 & $10,5 \%$ \\
\hline \multicolumn{3}{|l|}{ Etnia } \\
\hline Branca & 18 & $94,7 \%$ \\
\hline Negra & 1 & $5,3 \%$ \\
\hline \multicolumn{3}{|l|}{ Faixa etária } \\
\hline De 30 a 40 & 9 & $47,4 \%$ \\
\hline De 41 a 50 & 6 & $31,6 \%$ \\
\hline De 51 a 60 & 4 & $21,1 \%$ \\
\hline \multicolumn{3}{|l|}{ Estado civil } \\
\hline Casado/Com Companheiro & 11 & $57,9 \%$ \\
\hline Divorciado & 2 & $10,5 \%$ \\
\hline Solteiro & 6 & $31,6 \%$ \\
\hline \multicolumn{3}{|l|}{ Escolaridade } \\
\hline Curso Técnico Completo & 2 & $10,5 \%$ \\
\hline Ensino Médio Completo & 2 & $10,5 \%$ \\
\hline Ensino Médio Incompleto & 1 & $5,3 \%$ \\
\hline Ensino Superior Completo & 3 & $15,8 \%$ \\
\hline Ensino Superior Incompleto & 1 & $5,3 \%$ \\
\hline Pós Graduação Completa & 10 & $52,6 \%$ \\
\hline \multicolumn{3}{|l|}{ Tempo de trabalho em CAPSad } \\
\hline 1 ano & 4 & $21,1 \%$ \\
\hline Entre 2 a 4 anos & 6 & $31,6 \%$ \\
\hline Entre 5 a 7 anos & 9 & $47,4 \%$ \\
\hline \multicolumn{3}{|c|}{ Tempo de trabalho no CAPSad atual } \\
\hline 1 ano & 4 & $21,1 \%$ \\
\hline Entre 2 a 4 anos & 6 & $31,6 \%$ \\
\hline Entre 5 a 7 anos & 9 & $47,4 \%$ \\
\hline \multicolumn{3}{|l|}{ Profissão } \\
\hline Assistente Social & 2 & $10,5 \%$ \\
\hline Enfermeiro & 3 & $15,8 \%$ \\
\hline Médico & 3 & $15,8 \%$ \\
\hline Psicólogo & 2 & $10,5 \%$ \\
\hline Técnico/auxiliar de enfermagem & 8 & $42,1 \%$ \\
\hline Terapeuta Ocupacional & 1 & $5,3 \%$ \\
\hline \multicolumn{3}{|l|}{ Salário } \\
\hline 1 a 3 salários mínimos & 10 & $52,6 \%$ \\
\hline 4 a 7 salários mínimos & 7 & $36,8 \%$ \\
\hline 8 a 11 salários mínimos & 2 & $10,5 \%$ \\
\hline \multicolumn{3}{|l|}{ Carga horária } \\
\hline 20 & 2 & $10,5 \%$ \\
\hline 24 & 1 & $5,3 \%$ \\
\hline 30 & 16 & $84,2 \%$ \\
\hline Total & 19 & $100,0 \%$ \\
\hline
\end{tabular}

Fonte: CAPSad, Botucatu, 2013. 
$\mathrm{Na}$ distribuição dos trabalhadores, há um predomínio do perfil feminino, $89,5 \%$, que se configura normalmente em todas as outras áreas da saúde. A maior parte dos trabalhadores encontra-se na faixa etária dos 30-40 anos com percentual de 47,4\%, sendo que na faixa etária dos 41 a 50 anos é de $31,6 \%$, o que nos indica uma população de meia idade.

Em relação à cor da pele, 94,7\% dos entrevistados se dizem brancos, 57,9\% referiram possuir uma relação estável ou casamento e $31,6 \%$ são solteiros.

Quanto à formação e escolaridade, a maioria dos trabalhadores possui ensino superior, 68,4\%, sendo que cerca de $52,6 \%$ possuem pós-graduação. Temos $36,8 \%$ dos profissionais com especialização na área de saúde mental, $36,8 \%$ dos profissionais com especialização fora da área, 5,2\% dos profissionais com residência fora da área, 10,5\% profissionais cursando mestrado na área de saúde mental. Entre os cursos fora da área de saúde mental, a grande maioria é realizada na área de saúde pública, sendo também referido cursos nas áreas de: geriatria, medicina preventiva social, saúde do escolar, clínica médica, serviço social, administração de serviços de saúde, saúde do trabalhador e enfermagem perioperatória.

Como este CAPSad foi fundado em 2007, uma parcela dos profissionais está desde a sua inauguração, perfazendo 47,4\%. Todos os profissionais iniciaram a experiência de trabalhar em CAPSad neste serviço.

No item salarial, o que destaca é que $52,6 \%$ ganha até três salários mínimos, tendo $84,2 \%$ dos profissionais uma jornada de trabalho de 30 horas semanais.

No vínculo empregatício, temos $73,6 \%$ dos profissionais em regime estatutário e $26,4 \%$ em regime Lei 500 . Apenas $21 \%$ dos profissionais apresentam mais de um vínculo empregatício. 
Quanto à realização de cursos de atualização, 94,7\% afirmaram que realizam, 47,4\% realizam eventualmente e $36,8 \%$ realizaram entre dois e seis meses o último curso.

Gráfico 1 Descrição da satisfação do ambiente dos trabalhadores do Centro de Atenção Psicossocial Álcool e Outras Drogas em Botucatu.

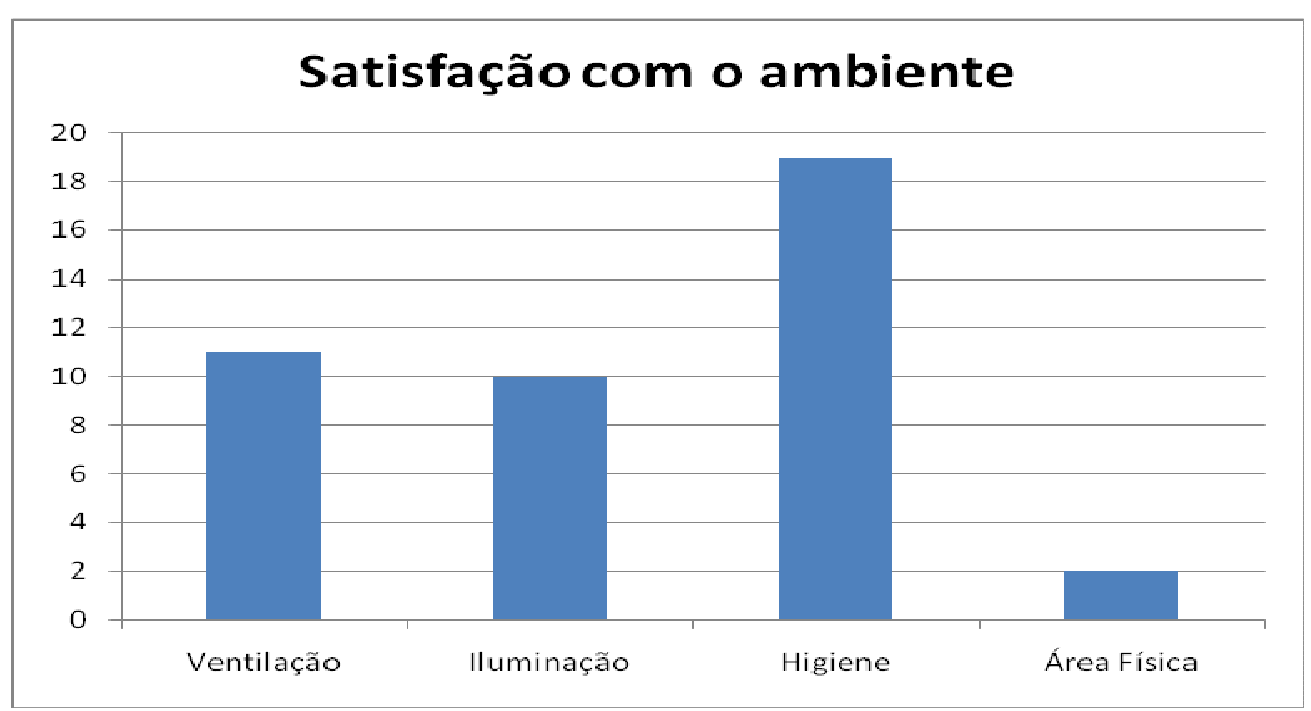

Fonte: CAPSad, Botucatu, 2013.

Em relação à satisfação com o ambiente do CAPSad, 11 profissionais $(57,9 \%)$ referiram problemas quanto à ventilação. As justificativas foram: falta de ventiladores, estrutura inadequada para o serviço, falta melhor climatização, faltam janelas mais amplas. No item iluminação, 10 (52,6\%) profissionais apontaram problemas, tendo como justificativas: pouca luz, salas pouco iluminadas, salas muito escuras, salas escuras, pouca luz nas salas de atendimento.

Em relação a higiene, todos os profissionais consideraram adequada. No item área física, 17 (89,5\%) profissionais referiram problemas, tendo como justificativas: faltam salas de atendimento; salas mais amplas e em maior número; espaço físico; melhor acessibilidade; o serviço está mal localizado; espaço para atendimento; pouco espaço para as atividades existentes; estrutura física; salas pequenas; altura da casa baixa; área para desintoxicação; inadequação das salas de atendimento. 
E em relação a materiais de conforto e segurança, os dados apresentados apontam fragilidades do imóvel utilizado para o CAPSad, especialmente em relação à saída de emergência e extintores de incêndio, em que $100 \%$ dos trabalhadores referem não estar instalados e nem em funcionamento no serviço. Outro dado é que $53 \%$ relatam não ter ventiladores disponíveis para uso no serviço.

Tabela 2 Caracterização dos trabalhadores do Centro de Atenção Psicossocial Álcool e Outras Drogas em Botucatu, segundo atendimentos individuais e quantidade, atendimentos grupais e quantidade, reuniões de equipe e quantidades, atividades comunitárias e quantidade, 2013.

\begin{tabular}{|l|c|c|}
\hline Atendimentos Individuais & $\mathbf{N}$ & $\%$ \\
\hline Sim & 19 & $100,0 \%$ \\
\hline Quantos atendimentos & & \\
\hline 0 & 5 & $5,3 \%$ \\
\hline De 1 a 10 & 3 & $16,3 \%$ \\
\hline De 11 a 40 & 8 & $42,1 \%$ \\
\hline De 41 a 100 & 2 & $10,5 \%$ \\
\hline Mais de 100 & & \\
\hline Atendimentos em grupo & 8 & $42,1 \%$ \\
\hline Não & 11 & $57,9 \%$ \\
\hline Sim & & \\
\hline Quantos atendimentos grupais & 8 & $42,1 \%$ \\
\hline 0 & 5 & $26,3 \%$ \\
\hline De 1 a 10 & 4 & $21,1 \%$ \\
\hline De 11 a 15 & 2 & $10,5 \%$ \\
\hline De 16 a 30 & & \\
\hline Reuniões de equipe & 19 & $100,0 \%$ \\
\hline Sim & & \\
\hline Quantas reuniões de equipe & 3 & $15,8 \%$ \\
\hline De 1 a 5 & 14 & $73,7 \%$ \\
\hline De 6 a 20 & 2 & $10,5 \%$ \\
\hline De 21 a 28 & & \\
\hline Atividades comunitárias & 15 & $78,9 \%$ \\
\hline Não & 4 & $21,1 \%$ \\
\hline Sim & & \\
\hline Quantas atividades comunitárias & 15 & $78,9 \%$ \\
\hline 0 & 2 & $10,5 \%$ \\
\hline 1 & 1 & $5,3 \%$ \\
\hline 2 & 19 & $5,3 \%$ \\
\hline 4 & & \\
\hline Total Geral & $100,0 \%$ \\
\hline Fonte: CAPSad, Botucatu, 2013 & & \\
\hline
\end{tabular}

Fonte: CAPSad, Botucatu, 2013. 
Todos os profissionais realizaram atendimentos individuais no último mês, sendo que o número de atendimentos variou de 5 a 160 . Cinco $(26,3 \%)$ profissionais utilizaram a modalidade consulta em seus atendimentos individuais. Dois (10,5\%) utilizaram a psicoterapia, 18 (94,9\%) utilizaram apenas como orientação, 10 (53\%) utilizaram para procedimentos técnicos, 13 (68\%) para acompanhamento do uso de medicação, cinco (26\%) para intervenção em crise, 14 (74\%) para orientação de atividades da vida diária, cinco (26\%) para intervenção em agitação psicomotora, 12 (63\%) em orientação quanto à redução de danos e 12 em outras atividades sendo elas: avaliação clínica; avaliação medicamentosa e sinais e sintomas; orientação familiar e discussão de casos; atendimento de referência; orientação em oficina terapêutica; medicação supervisionada; recepção; acolhimento; acompanhamento de soropositivos, de gestantes e de homoafetivos; triagem.

Onze (58\%) profissionais realizaram atendimentos em grupo no último mês, sendo que o número de atendimentos variou de 4 a 30 atendimentos. Foram nove $(47,3 \%)$ os que utilizaram a modalidade grupo terapêutico, dois (10,5\%) para grupos de atividades esportivas, três $(15,7 \%)$ para atividades de suporte social, dois $(10,5 \%)$ para grupo de leitura e debate, um $(5,2 \%)$ para grupo de confecção de jornal, oito $(42,1 \%)$ grupo de orientações gerais, oito $(42,1 \%)$ grupos de orientação de redução de danos, três $(15,7 \%)$ para grupo de família e quatro $(44,4 \%)$ para outros grupos sendo: grupo de acolhimento, oficina terapêutica.

Todos participam de reuniões de equipe. Há reuniões diárias de passagem de plantão entre a equipe da manhã e a equipe da tarde e reunião geral com todos os funcionários do CAPSad todas as sextas-feiras.

Quanto às atividades comunitárias, apenas quatro profissionais responderam que participaram no último mês, sendo em participação em eventos, passeios externos com os pacientes, 
participação no conselho municipal de saúde representando o serviço, discussão de casos com o Centro de Referência em Assistência Social (CRAS).

Outras atividades não mencionadas realizadas pelos membros da equipe são: reunião no CRAS, assistência de enfermagem direta, discussão de casos com hospital dia de HIV e supervisão técnica no Hospital Pinel situado no município de São Paulo.

Em relação às visitas domiciliares, 15,8\% dos profissionais realizaram visitas no último mês. Os demais (84,2\%) referem algumas dificuldades como: falta de transporte; de tempo para organizar a visita; outros dizem que não foi preciso realizar visita no último mês.

Tabela 3 Caracterização dos trabalhadores do Centro de Atenção Psicossocial Álcool e Outras Drogas em Botucatu, segundo condições de trabalho.

\begin{tabular}{|c|c|c|c|}
\hline & & $\mathrm{N}$ & $\%$ \\
\hline \multirow{4}{*}{$\begin{array}{l}\text { Desde que você entrou neste emprego, as } \\
\text { condições de trabalho: }\end{array}$} & Melhoraram muito & 8 & $42,1 \%$ \\
\hline & Melhoraram Pouco & 6 & $31,6 \%$ \\
\hline & Não mudaram & 4 & $21,1 \%$ \\
\hline & Pioraram & 1 & $5,3 \%$ \\
\hline \multirow{2}{*}{ Falta de ferramenta adequada para o trabalho } & Não & 8 & $42,1 \%$ \\
\hline & Sim & 11 & $57,9 \%$ \\
\hline \multirow{2}{*}{ Falta de segurança } & Não & 2 & $10,5 \%$ \\
\hline & Sim & 17 & $89,5 \%$ \\
\hline \multirow{2}{*}{ Risco permanente de vida } & Não & 12 & $63,2 \%$ \\
\hline & Sim & 7 & $36,8 \%$ \\
\hline \multirow{2}{*}{ Outras situações que incomodam } & Não & 14 & $73,7 \%$ \\
\hline & Sim & 5 & $26,3 \%$ \\
\hline \multirow{2}{*}{$\begin{array}{l}\text { Escolher individualmente a forma de fazer suas } \\
\text { atividades }\end{array}$} & Não & 6 & $31,6 \%$ \\
\hline & Sim & 13 & $68,4 \%$ \\
\hline \multirow{2}{*}{$\begin{array}{l}\text { Escolher de forma coletiva/em equipe a forma de } \\
\text { fazer suas atividades }\end{array}$} & Não & 1 & $5,3 \%$ \\
\hline & Sim & 18 & $94,7 \%$ \\
\hline \multirow{2}{*}{ Fazer reuniões } & Não & 2 & $10,5 \%$ \\
\hline & Sim & 17 & $89,5 \%$ \\
\hline Fazer cursos & Sim & 19 & $100,0 \%$ \\
\hline Outra atividade de organização & Sim & 19 & $100,0 \%$ \\
\hline Conversar com os colegas & Sim & 19 & $100,0 \%$ \\
\hline Usar suas ideias & Sim & 19 & $100,0 \%$ \\
\hline Discutir casos com os colegas & Sim & 19 & $100,0 \%$ \\
\hline Total & & 19 & $100,0 \%$ \\
\hline
\end{tabular}

Fonte: CAPSad, Botucatu, 2013. 
Quanto às condições de trabalho, desde que o profissional entrou no serviço, $73,7 \%$ referem que houve melhora. Estão satisfeitos nos itens: existência de ferramentas de trabalho e liberdade e autonomia para executar suas funções.

Em relação às ferramentas adequadas para o trabalho, 57,9\% dos trabalhadores do CAPSad referem enfrentar falta de material, sendo que $89,5 \%$ relatam falta de segurança. Já no item risco permanente de vida, $63,2 \%$ referem não enfrentar. Dentre as outras situações que incomodam os profissionais são: falta de recursos humanos, de disponibilidade dos profissionais, pacientes ociosos, espaços inadequados, ruídos de comunicação, demora para o paciente ser atendido na triagem(sala de espera).

No trabalho, $68,4 \%$ dos entrevistados relatam ter liberdade para escolher individualmente a forma de fazer suas atividades, já em escolher de forma coletiva/em equipe a forma de fazer suas atividades, 94,7\% referem liberdade em tal escolha. Se houver necessidade de solicitar uma reunião, $89,5 \%$ relatam ter liberdade para tal atividade. Todos os entrevistados afirmaram positivamente ter liberdade para: fazer cursos, realizar outra atividade de organização, usar suas ideias e discutir casos com os colegas, quando necessário.

Em relação aos acidentes de trabalho, nos últimos seis meses, apenas dois (11\%) profissionais sofreram acidentes e ambos foram por queda. Em relação ao absenteísmo, apenas três (15,7\%) faltaram nos últimos seis meses, sendo dois (10,5\%) por doença, um $(5,2 \%)$ por acidente que culminou em cirurgia eletiva.

Em relação ao principal critério de inclusão de tratamento no CAPSad, cinco (26\%) profissionais referiram o consumo de álcool e outras drogas, $11(58 \%)$ apontaram a gravidade do consumo de álcool e outras drogas, 14 (74\%) relatam o impacto global na vida relacionado ao consumo prejudicial de álcool e outras drogas, e dois (11\%) relatam que é preciso ser dependente de álcool e outras drogas. 
A respeito do modelo de assistência utilizada no serviço que são a redução de danos e a abstinência total, oito (42\%) profissionais relatam utilizar redução de danos, 11 (58\%) relatam utilizar as duas modalidades e nenhum relata utilizar a abstinência total.

Para considerar abandono de tratamento neste CAPSad, 15 (79\%) profissionais referiram que o usuário necessita não comparecer ao serviço por 30 dias consecutivos, sem justificativa.

$\mathrm{Na}$ questão da busca ativa, $16(84,2 \%)$ profissionais referiram que o serviço realiza. Sendo 13 (81\%) relatam que ocorre por contato telefônico, um $(5,2 \%)$ por visita domiciliar e dois (11\%) por ambas as formas. Obtivemos um percentual de três (15,7\%) trabalhadores referindo que o serviço não realiza, sendo que dois (11\%) justificaram não saber o porquê e um (5,2\%) refere por ser demanda espontânea não necessita de busca ativa.

Ao realizar a busca ativa, os profissionais relatam: 11 (57,8\%) referem que deve ser por desistência do tratamento, dois (11\%) deve ser a melhora do usuário, segundo a sua percepção, sete $(36,8 \%)$ deve-se ao retorno às suas atividades sociais (trabalho, lazer), dois (11\%) deve-se a outra modalidade de tratamento (internação).

Tabela 4 Caracterização dos trabalhadores do Centro de Atenção Psicossocial Álcool e Outras Drogas em Botucatu, segundo modalidades de atendimento.

\begin{tabular}{|l|c|c|c|}
\hline \multicolumn{2}{|l|}{$\begin{array}{l}\text { Quais são as oficinas/atividades terapêuticas oferecidas } \\
\text { nesse CAPSad? }\end{array}$} & N & $\%$ \\
\hline Grupos terapêuticos & Sim & 19 & $100,0 \%$ \\
\hline Oficinas terapêuticas & Sim & 19 & $100,0 \%$ \\
\hline Atendimento individual & Sim & 19 & $100,0 \%$ \\
\hline \multirow{2}{*}{ Atividades na comunidade } & Não & 11 & $57,9 \%$ \\
\cline { 2 - 4 } & Sim & 8 & $42,1 \%$ \\
\hline \multirow{2}{*}{ Outras atividades não contempladas acima } & Não & 15 & $78,9 \%$ \\
\cline { 2 - 4 } & Sim & 4 & $21,1 \%$ \\
\hline Total & & 19 & $100,0 \%$ \\
\hline
\end{tabular}

Fonte: CAPSad, Botucatu, 2013. 
Dentre as modalidades de atendimento, $100 \%$ dos entrevistados referem desenvolver grupos terapêuticos, oficinas terapêuticas e atendimento individual, sendo que $42 \%$ relatam a realização de atividades na comunidade.

Analisando os grupos que o serviço disponibiliza, tem-se: grupos de atividades esportivas (74\%), grupos de suporte social (68\%), grupos de leitura e debates (26\%), grupos de confecção de jornal $(5 \%)$, oficinas expressivas $(47 \%)$, oficinas culturais $(53 \%)$, e $100 \%$ de grupos de orientação, grupos de família, grupos de redução de danos e grupos terapêuticos. Analisando as oficinas, temos $100 \%$ de oficinas terapêuticas e oficinas de atividades manuais.

Em relação aos atendimentos individuais, tem-se: consulta de enfermagem (21\%), procedimentos técnicos (95\%), intervenção em crise (84\%), intervenção em agitação psicomotora (84\%), orientação de redução de danos (89\%), e 100\% de atendimentos individuais, consulta médica, psicoterapia, orientação, consulta com outros técnicos, acompanhamento do uso de medicação e orientação em atividades de vida diária.

As atividades na comunidade são realizadas por meio de atividades gerais na comunidade (42\%), festa comunitárias (32\%), participação em eventos e grupos dos centros comunitários (26\%).

Os profissionais relatam ainda, que realizam acompanhamento à internação, assembleias, atendimento de referência, grupo temático, parceria com a organização não governamental - arte convívio, academia ao ar livre e cursos abertos à comunidade.

A estrutura organizacional de trabalho mais citada foi a abordagem interdisciplinar (74\%), sendo a abordagem multiprofissional citada por $26 \%$.

Nas ações intersetoriais do serviço, 53\% dos entrevistados referem que ocorre com: Centro de Referência em Assistência Social (CRAS, Oficina Terapêutica Girassol, Secretaria de Esportes, 
Conselho Tutelar, Hospital-Dia de HIV, ONG-Arte Convívio, Secretaria da Cultura, 37\% referem não ocorrer por falta de recursos humanos e pelas dificuldades de contato com os outros setores; $11 \%$ responderam não saber se ocorrem tais ações.

Nas atividades no campo de geração de renda, $100 \%$ dos entrevistados relatam não existir, tendo como justificativas: por ser um serviço estadual não pode ter ações de geração de renda, alguns não sabem o porquê e outros relataram que está iniciando uma parceria com a ONG-Arte Convívio para iniciar ações de geração de renda via ONG.

Gráfico 2 Descrição da abordagem terapêutica dos trabalhadores do Centro de Atenção Psicossocial Álcool e Outras Drogas em Botucatu.

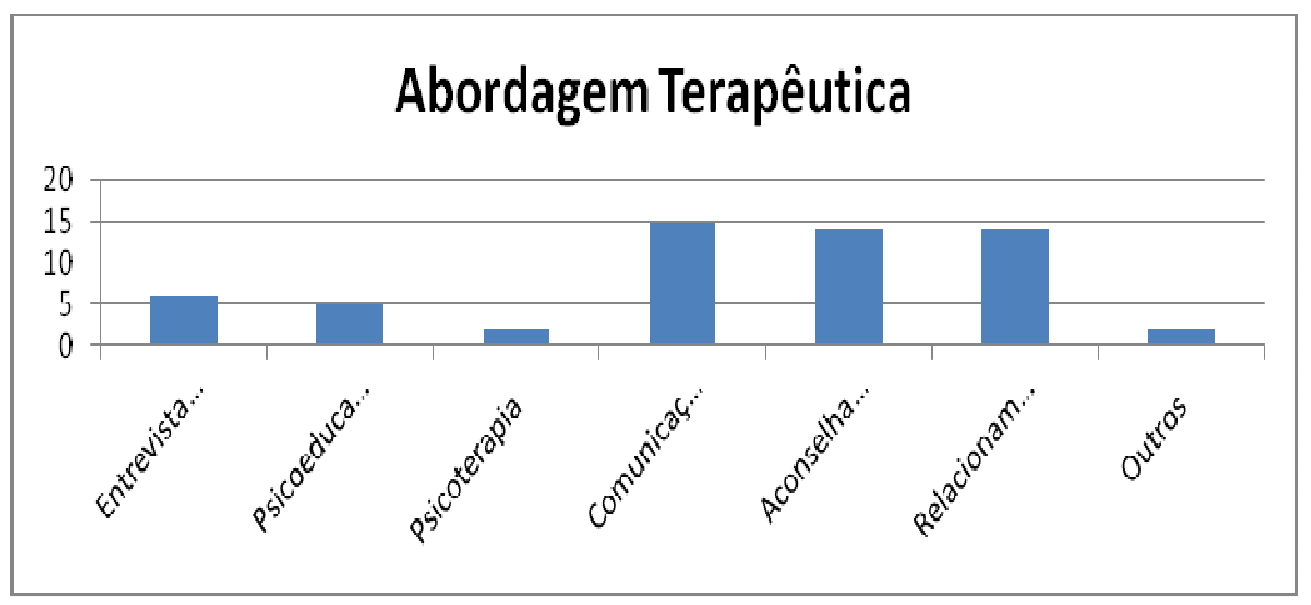

Fonte: CAPSad, Botucatu, 2013.

As abordagens terapêuticas utilizadas pelos profissionais do serviço são: entrevista motivacional (21,5\%), psicoeducação $(26,3 \%)$, psicoterapia (10,5\%), comunicação terapêutica $(79 \%)$, aconselhamento $(73,6 \%)$, relacionamento terapêutico $(73,3 \%)$, outros (10,5\%). As outras abordagens foram descritas como: avaliação clínica, abordagem psicanalítica, escuta social, avaliação medicamentosa e de sinais e sintomas.

Em relação às intervenções terapêuticas, 73,7\% referiram que no serviço as intervenções terapêuticas visam primordialmente que o 
paciente desenvolva consciência crítica acerca dos problemas relacionados para além do consumo de álcool e outras drogas.

\subsubsection{Características do CAPS}

Tabela 5 Caracterização das modalidades de atendimento do Centro de Atenção Psicossocial Álcool e Outras Drogas em Botucatu, segundo trabalhadores.

\begin{tabular}{|c|c|c|c|}
\hline & & $\mathbf{N}$ & $\%$ \\
\hline \multirow{3}{*}{$\begin{array}{l}\text { Retaguarda para urgência } \\
\text { psiquiátrica }\end{array}$} & Não & 4 & $21,1 \%$ \\
\hline & Sim & 14 & $73,7 \%$ \\
\hline & Não sei & 1 & $5,3 \%$ \\
\hline \multirow{2}{*}{$\begin{array}{l}\text { Retaguarda para urgência } \\
\text { clínica }\end{array}$} & Não & 4 & $21,1 \%$ \\
\hline & Sim & 15 & $78,9 \%$ \\
\hline \multirow{6}{*}{$\begin{array}{l}\text { Indicação para internação } \\
\text { dos usuários. }\end{array}$} & A pedido da família & 1 & $5,3 \%$ \\
\hline & $\begin{array}{l}\text { Após discussão de caso em } \\
\text { reunião de equipe }\end{array}$ & 2 & $10,5 \%$ \\
\hline & $\begin{array}{l}\text { Discussão com membros da } \\
\text { equipe }\end{array}$ & 3 & $15,8 \%$ \\
\hline & Discussão em equipe & 1 & $5,3 \%$ \\
\hline & $\begin{array}{l}\text { Discussão entre membros da } \\
\text { equipe }\end{array}$ & 6 & $31,6 \%$ \\
\hline & Pelo médico & 6 & $31,6 \%$ \\
\hline \multicolumn{2}{|l|}{ Total } & 19 & $100 \%$ \\
\hline
\end{tabular}

Fonte: CAPSad, Botucatu, 2013.

Quanto à retaguarda para urgência psiquiátrica, 73,7\% apontam que existe e os serviços citados que dão tal retaguarda são: unidade de internação do CAIS "Professor Cantídio", Hospital Psiquiátrico Tereza Perlate (Jaú-SP) e Pronto-Socorro do Hospital das Clínicas da Unesp de Botucatu.

$\mathrm{Na}$ retaguarda para urgência clínica, 78,9\% afirmam que existe, sendo os serviços citados: Pronto-Socorro Municipal de Botucatu e Pronto-Socorro do Hospital das Clínicas da Unesp de Botucatu.

As indicações para internação dos usuários do serviço são normalmente por indicação médica $(31,6 \%)$ ou por discussão entre membros da equipe $(31,6 \%)$. 
Grande parte dos profissionais (88\%) possui conhecimento dos equipamentos de saúde existentes na área de abrangência do serviço, sendo os serviços listados: Unidade Básica de Saúde (UBS), Estratégia Saúde da Família (ESF), Ambulatório de Saúde Mental, CAIS "Professor Cantídio", Pronto -Socorro do Hospital das Clinicas da Unesp de Botucatu, Pronto-Socorro Municipal, CRASNorte, CAPS II, Núcleo de Apoio à Saúde da Família (NASF), Albergue Municipal, Centro de Saúde Escola (CSE), Espaço Saúde (CAPS I).

No encaminhamento de usuários aos serviços listados acima, 92\% apontam que tanto o entrevistado quanto outros membros do serviço encaminham, sendo os mais utilizados: Unidade Básica de Saúde, Núcleo Saúde da Família, CAPSII, Centro Saúde Escola e Pronto- Socorro Municipal. Mas, 67\% referem não haver algum projeto em parceria com tais serviços.

Quanto à facilidade de diálogo com outros equipamentos de saúde da rede e da área de abrangência do serviço para o tratamento do usuário, $79 \%$ dizem ter facilidade no diálogo. Dos $21 \%$ que refere não ter bom diálogo com outros equipamentos e, justificam: falta conhecimento do trabalho do CAPSad; resistência com outros profissionais de saúde.

Em relação ao conhecimento do trabalho desenvolvido pelo CAPSad, 58\% apontaram que os demais profissionais da saúde desconhecem o trabalho que o CAPSad desenvolve.

\subsubsection{Satisfação do trabalhador}

Para avaliação de satisfação dos trabalhadores utilizou-se a escala SATIS-BR e apresentada na tabela a seguir, seguindo as questões validadas no Brasil por Bandeira, Pitta e Mercier (2000). A aplicação da escala aos trabalhadores permitiu a identificação do quadro global de satisfação, conforme os fatores e escala global 
apresentados abaixo que indica uma avaliação intermediária de todos os itens com média em torno de 3,6 (dp 0,3), em uma escala tipo likert de 1 a 5 .

Tabela 6 Média e Desvio-padrão de satisfação dos trabalhadores do CAPSad Botucatu- SP, 2013.

\begin{tabular}{lccc}
\hline & N & Média & $\begin{array}{c}\text { Desvio- } \\
\text { padrão }\end{array}$ \\
\hline Global do SATIS BR & 19 & 3,6 & 0,3 \\
\hline $\begin{array}{l}\text { Qualidade da assistência prestada } \\
\text { ao usuário }\end{array}$ & 19 & 3,8 & 0,3 \\
\hline $\begin{array}{l}\text { Quanto à sua participação } \\
\text { serviço }\end{array}$ & 19 & 3,6 & 0,5 \\
\hline Condições de trabalho & 19 & 3,5 & 0,4 \\
\hline Relacionamento no serviço & 19 & 3,6 & 0,6 \\
\hline $\mathbf{N}$ & $\mathbf{1 9}$ & & \\
\hline
\end{tabular}

Fonte: CAPSad, Botucatu, 2013.

O escore global do SATIS-BR teve média de 3,6 (dp 0,3), variando de 2,9 a 4,2, tendo um escore intermediário.

As questões quanto à qualidade da assistência prestada ao usuário foram as que receberam melhor avaliação, com uma média de 3,8 (dp 0,3) e as questões referentes à condição de trabalho receberam a pior avaliação com média de 3,5 (dp 0,4), variando entre 2,5 e 4,1 .

A partir da pior avaliação, temos quanto à sua participação no serviço e o relacionamento no serviço, ambas com média de score de 3,6 (dp 0,5).

Em relação à questão de existirem outros cuidados de que o usuário necessita, mas que não recebe no CAPSad, 58\% referiram que com certeza há e especificaram: inserção no mercado de trabalho, reinserção no trabalho formal, reinserção social, demandas sociais (trabalho, moradia, alimentação, família), serviços de geração de renda, lares abrigados, leitos de retaguarda para desintoxicação, assistência social do próprio município, emergência psiquiátrica e trabalho comunitário. 
$\mathrm{Na}$ questão de que se o profissional recomendaria o CAPSad se tivesse um amigo/familiar que estivesse necessitando de ajuda de uma Unidade de Saúde Mental, 68,4\% afirmaram que com certeza indicariam, justificando: o serviço tem um bom atendimento, por obter bons resultados, por ser único na região, ter acolhida e respeito com o usuário, equipe é disponível e responsável, a qualidade do serviço é muito boa, equipe competente para o cuidado, pela estrutura do processo de trabalho, confiança no trabalho prestado, bom empenho dos profissionais no serviço.

Em relação ao que o profissional mais gosta no serviço, nove $(47,3 \%)$ relatam gostar da função que exerce no serviço, seis $(31,6 \%)$ do atendimento prestado ao usuário, um $(5,2 \%)$ dos colegas de trabalho e três $(15,7 \%)$ de outros, sendo: liberdade de expressão dos profissionais e usuários; boa comunicação com a coordenação e diretoria do CAIS; da autonomia enquanto profissional no serviço; possibilidade do profissional em explorar e utilizar suas habilidades pessoais no trabalho.

No que tange ao profissional menos gostar no serviço, sete $(36,8 \%)$ referiram nada e $12(63,2 \%)$ outros, sendo: rigidez da carga horária; falta de estrutura física para desintoxicação; a não adesão dos usuários; conflitos entre paciente e equipe; preconceito da equipe em relação ao usuário; assistencialismo; rede ineficiente; excesso de trabalho; reunião de equipe; falta de rede de atenção; ruídos de comunicação e burocracia; ruídos de comunicação; pacientes ociosos no serviço.

No item de que o serviço poderia ser melhorado, 96\% afirmaram que sim dando as seguintes sugestões: melhora na estrutura e nas instalações físicas; aumento de salas para atendimento; sala específica para as oficinas terapêuticas; utilizar melhor as instalações físicas; apropriação da sala de desintoxicação; tornar CAPSIII; estender o atendimento ao noturno; tornar CAPSad estendido; mais material para as oficinas terapêuticas; aumento de recursos humanos; adequação dos recursos humanos; capacitação 
dos recursos humanos; educação permanente; menos ruídos de comunicação; supervisão institucional; supervisão clínica; melhora de atendimento - inserção social; reinserção social, pois o serviço acaba ficando isolado; atividade comunitária; atividade para reinserção no trabalho formal; parcerias intersetoriais; ampliação das oficinas; aumentar atividades aos pacientes ociosos; grupos terapêuticos e atendimento de desintoxicação.

A Tabela VII apresenta os escores obtidos na EAFAAA como um todo e cada um dos fatores da escala pelos trabalhadores do CAPSad Botucatu- SP que participaram da pesquisa $(n=19)$.

Tabela 7 Distribuição dos escores observados na EAFAAA pelos trabalhadores do CAPSad Botucatu- SP, 2013.

\begin{tabular}{|c|c|c|c|c|c|c|c|}
\hline & $\mathrm{N}$ & $\begin{array}{c}\text { Média } \\
\text { observada } \\
(\mathrm{dp})\end{array}$ & Mediana & $\begin{array}{c}\text { Escore } \\
\text { Mínimo } \\
\text { possível }\end{array}$ & $\begin{array}{c}\text { Escore } \\
\text { Mínimo } \\
\text { observado }\end{array}$ & $\begin{array}{c}\text { Escore } \\
\text { Máximo } \\
\text { possível }\end{array}$ & $\begin{array}{c}\text { Escore } \\
\text { Máximo } \\
\text { observado }\end{array}$ \\
\hline Fator 1 & 19 & $\begin{array}{c}3,78 \\
(0,56)\end{array}$ & 3,8 & 1 & 2,50 & 5 & 4,55 \\
\hline Fator 2 & 19 & $\begin{array}{c}3,88 \\
(0,73)\end{array}$ & 4,1 & 1 & 2,42 & 5 & 4,91 \\
\hline Fator 3 & 19 & $\begin{array}{c}2,98 \\
(0,35)\end{array}$ & 3,0 & 1 & 2,27 & 5 & 3,64 \\
\hline Fator 4 & 19 & $\begin{array}{c}3,35 \\
(0,78)\end{array}$ & 3,3 & 1 & 2,11 & 5 & 4,89 \\
\hline $\begin{array}{c}\text { Atitude } \\
\text { Geral }\end{array}$ & 19 & $\begin{array}{c}\mathbf{3}, \mathbf{5 5} \\
\mathbf{( 0 , 4 6 )}\end{array}$ & $\mathbf{3 , 5}$ & $\mathbf{1}$ & $\mathbf{2 , 5 4}$ & $\mathbf{5}$ & $\mathbf{4 , 1 8}$ \\
\hline
\end{tabular}

Fonte: CAPSad, Botucatu, 2013.

O escore da atitude geral da Escala de Atitudes Frente ao Álcool, ao Alcoolismo e ao Alcoolista (EAFAAA) teve média de 3,5 (dp 0,46) variando de 2,54 a 4,18 .

O escore do fator 1 que avalia a atitude do trabalhar e o relacionar-se com o alcoolista teve uma média de 3,78 (dp 0,563) variando de 2,50 a 4,55 , sendo que $42 \%$ das respostas ficaram em 3,5 a 4,0 . 
O escore do fator 2 que avalia as atitudes frente ao alcoolista foi a que recebeu melhor avaliação, com uma média de 3,88 (dp 0,73 ) e variando de 2,4 a 4,9 , sendo que $52,6 \%$ das respostas ficaram entre 4,0 e 5,0.

O escore do fator 3 que avalia as atitudes frente ao alcoolismo, etiologia teve a pior avaliação, tendo média de 2,98 (dp $0,35)$ e a que menor teve variação de respostas variando de 2,27 a 3,64 , sendo que $52,6 \%$ das respostas ficaram entre 2,5 e 3,0.

O escore do fator 4 que avalia as atitudes frente ao uso do álcool que tiveram uma média $3,35(\mathrm{dp} 0,78)$ a que mais teve variação variando de 2,54 a 4,18 , sendo que $31,6 \%$ das respostas ficaram entre 3,5 e 4,0.

Tabela 8 Supervisão, Apoio e avaliação global do atendimento prestado, segundo os trabalhadores do CAPSad Botucatu- SP, 2013.

\begin{tabular}{|c|c|c|c|c|c|c|}
\hline & $\mathrm{N}$ & Média & Mediana & $\begin{array}{l}\text { Desvio- } \\
\text { padrão }\end{array}$ & Mínimo & Máximo \\
\hline $\begin{array}{l}\text { Supervisão pela secretaria } \\
\text { municipal de saúde }\end{array}$ & 19 & 2,05 & 00 & 2,86 & 0 & 8 \\
\hline $\begin{array}{l}\text { Supervisão pela } \\
\text { coordenação municipal de } \\
\text { saúde mental }\end{array}$ & 19 & 1,47 & 00 & 2,17 & 0 & 8 \\
\hline Supervisão entre equipe: & 19 & 7,63 & 8 & 1,42 & 5 & 10 \\
\hline $\begin{array}{l}\text { Supervisão pela comunidade } \\
\text { em que atua: }\end{array}$ & 19 & 2,11 & 00 & 2,78 & 0 & 8 \\
\hline $\begin{array}{l}\text { Supervisão pela Organização } \\
\text { Social (parceira) }\end{array}$ & 19 & 0 & 00 & 0 & 0 & 0 \\
\hline $\begin{array}{l}\text { Apoio pela coordenação } \\
\text { municipal de saúde mental }\end{array}$ & 19 & 3,11 & 2 & 2,92 & 0 & 8 \\
\hline $\begin{array}{l}\text { Apoio pela secretaria } \\
\text { municipal de saúde }\end{array}$ & 19 & 2,79 & 2 & 2,39 & 0 & 7 \\
\hline Apoio entre equipe & 19 & 7,84 & 8 & 1,71 & 4 & 10 \\
\hline $\begin{array}{c}\text { Apoio pela comunidade em } \\
\text { que atua }\end{array}$ & 19 & 4,63 & 5 & 2,95 & 0 & 10 \\
\hline $\begin{array}{l}\text { De maneira global, qual a } \\
\text { sua avaliação do } \\
\text { atendimento prestado pelo } \\
\text { CAPSad? }\end{array}$ & 19 & 8,05 & 8 & 1,39 & 5 & 10 \\
\hline
\end{tabular}

Fonte: CAPSad, Botucatu, 2013.

Quanto à supervisão no CAPSad, 68,4\% referem que há supervisão. A qualidade da supervisão na entrevista foi mensurada 
de 0 a 10, sendo zero ausência de supervisão e 10 como qualificada. Na qualificação da supervisão exercida pela secretaria municipal de saúde, pela coordenação municipal de saúde mental e pela comunidade em que atua, teve-se uma média muito baixa. Em relação à supervisão entre a equipe, uma média de 7,6 e a maior parte das notas ficaram em 8,0 para qualificação.

Em relação ao apoio exercido, temos: apoio baixo para o coordenador e para a secretaria de saúde tendo uma média perto dos três.

De maneira global, a avaliação do atendimento prestado pelo CAPSad, pelos trabalhadores, teve uma média de oito e a nota mais baixa foi cinco.

\subsection{USUÁRIO}

Nesta etapa, apresentamos os dados com os usuários do CAPad de Botucatu. Em relação às entrevistas, $68 \%$ foram realizadas no serviço e $32 \%$ no domicílio.

Tabela 9 Caracterização dos usuários do Centro de Atenção Psicossocial Álcool e Outras Drogas em Botucatu, segundo gênero, etnia, faixa etária, estado civil, escolaridade, fonte de renda, renda familiar no último mês, 2013.

\begin{tabular}{|l|c|c|}
\hline Gênero & N & $\%$ \\
\hline Feminino & 8 & $32 \%$ \\
\hline Masculino & 17 & $68 \%$ \\
\hline Etnia & & \\
\hline Branca & 22 & $88 \%$ \\
\hline Negra & 3 & $12 \%$ \\
\hline Faixa etária & & \\
\hline de 26 a 30 & 4 & $16 \%$ \\
\hline de 31 a 40 & 9 & $36 \%$ \\
\hline de 41 a 50 & 5 & $20 \%$ \\
\hline de 51 a 69 & 7 & $28 \%$ \\
\hline
\end{tabular}




\begin{tabular}{|l|c|c|}
\hline Estado Civil & & \\
\hline Casado/com companheiro & 9 & $36 \%$ \\
\hline Divorciado/Separado & 2 & $8 \%$ \\
\hline Viúvo & 2 & $8 \%$ \\
\hline Solteiro & 12 & $48 \%$ \\
\hline Escolaridade & & \\
\hline Ensino fundamental Incompleto & 10 & $40 \%$ \\
\hline Ensino Fundamental Completo & 3 & $12 \%$ \\
\hline Ensino Médio Incompleto & 2 & $8 \%$ \\
\hline Ensino Médio Completo & 8 & $32 \%$ \\
\hline Curso Técnico Completo & 1 & $4 \%$ \\
\hline Ensino Superior Incompleto & 1 & $4 \%$ \\
\hline Fonte de Renda & & \\
\hline Emprego & 9 & $36 \%$ \\
\hline Aposentadoria & 3 & $12 \%$ \\
\hline Auxilio-doença & 5 & $20 \%$ \\
\hline LOAS & 1 & $4 \%$ \\
\hline Bolsa Família & 1 & $4 \%$ \\
\hline Não Tem Renda & 6 & $24 \%$ \\
\hline Renda Familiar ultimo mês & & \\
\hline Até 2 salários mínimos & 14 & $56 \%$ \\
\hline Entre 2 a 4 salários mínimos & 9 & $36 \%$ \\
\hline Entre 4 a 10 salários mínimos & 2 & $8 \%$ \\
\hline Total & $\mathbf{2 5}$ & $\mathbf{1 0 0 \%}$ \\
\hline
\end{tabular}

Fonte: CAPSad, Botucatu, 2013.

A média de idade dos usuários é de 43,84 anos, com desvio padrão de 12,42 anos, tendo uma mediana de 39 anos.

Os usuários do CAPSad, em sua maioria são homens, sendo $68 \%$ da amostra. A maioria é de etnia branca, sendo $88 \%$. A idade geral dos usuários variou de 26 a 69 anos, sendo que na faixa etária de 31 a 40 anos, concentram-se nove usuários, o que faz a proporção total de $36 \%$.Temos uma proporção de $48 \%$ solteiros.

Entre os usuários, $96 \%$ afirmam saber ler e $40 \%$ referem possuir ensino fundamental incompleto, enquanto que 32\% detêm ensino médio completo.

Em relação à fonte de renda, $36 \%$ apresentam vínculo empregatício, enquanto $24 \%$ não têm renda. A renda familiar do último mês de $56 \%$ dos usuários foi de até dois salários mínimos. 
A tabela abaixo, mostra com quem os usuários vivem e indica que a maioria, 32\%, vive com cônjuge/companheiro (a) e $40 \%$ vive com familiar, especialmente mãe ou pai. Apenas $8 \%$ vivem sozinhos.

Tabela 10 Distribuição de com quem vivem atualmente os usuários do CAPSad Botucatu-SP, 2013.

\begin{tabular}{|l|c|c|}
\hline Com quem mora & N & $\%$ \\
\hline Sozinho & 2 & $8 \%$ \\
\hline Cônjuge/companheiro e filhos & 8 & $32 \%$ \\
\hline Familiares & 10 & $40 \%$ \\
\hline Mãe e pai & 2 & $8 \%$ \\
\hline Amigo fora do CAPSad & 1 & $4 \%$ \\
\hline Albergue municipal & 1 & $4 \%$ \\
\hline Cuidadora & 1 & $4 \%$ \\
\hline Total & $\mathbf{2 5}$ & $\mathbf{1 0 0} \%$ \\
\hline
\end{tabular}

Fonte: CAPSad, Botucatu, 2013.

Em referência em ser ou não a primeira admissão no serviço, 60\% (15 usuários) afirmam que é sua primeira admissão no serviço. Sendo que 40\% (10 usuários) afirmam que não se trata da primeira internação.

Acerca do tempo que os usuários frequentam este serviço, $48 \%$ (12 usuários) afirmaram que frequentam entre um a dois anos e 24\% (6 usuários) frequentam entre sete a 12 meses.

Quando questionados com que idade o usuário tinha quando percebeu o uso abusivo/dependência de alguma substância, tivemos uma média de 29,8 anos (dp 11,9) e uma mediana de 26 anos, sendo que na faixa de 14 a 30 anos tem-se um percentual de $68 \%$.

Em relação ao diagnóstico, 96\% dos usuários relatam conhecer. Com este dado, podemos identificar que o CAPS, em geral está com uma demanda de usuários em condição mais grave de sofrimento psíquico. Temos $72 \%$ com uso de drogas, $76 \%$ com uso de álcool, 68\% com uso de tabaco, 8\% com esquizofrenia e 4\% com transtorno depressivo maior.

Em relação à internação psiquiátrica antes de iniciar 0 tratamento no CAPSad, $68 \%$ sinalizam que tiveram internações 
nesta modalidade, sendo em hospital psiquiátrico (56\%) e em comunidades terapêuticas (24\%). Já na internação psiquiátrica durante o tratamento no CAPSad, 32\% sinalizam que tiveram internações nesta modalidade, sendo em hospital psiquiátrico (28\%) e em comunidades terapêuticas (8\%).

Quanto ao uso de psicofármacos, 96\% referem que em nenhuma situação precisou comprar a medicação que faz uso. Cerca de $80 \%$ referem "sempre" seguir a prescrição médica, 4\% segue "frequentemente" e 16\% seguem "às vezes".

\subsubsection{Satisfação do usuário}

A avaliação de satisfação dos usuários utilizou a escala SATIS-BR e sistematizada na tabela a seguir, conforme as questões validadas no Brasil por Bandeira e Silva (2012). Os dados permitiram a identificação do quadro global de satisfação, conforme os fatores e escala global apresentados abaixo que indica uma avaliação positiva de todos os itens com média em torno de 4,0 (dp 0,3), que na escala corresponde à satisfação em relação aos itens avaliados, em uma escala tipo likert de 1 a 5.

Tabela 11 Média e Desvio-padrão de satisfação dos usuários do CAPSad Botucatu- SP, 2013

\begin{tabular}{llcc}
\hline & N & Média & Desvio-padrão \\
\hline Global do SATIS BR & 25 & 4,0 & 0,3 \\
\hline Competência e Compreensão & 25 & 4,1 & 0,3 \\
\hline Ajuda recebida e acolhida & 25 & 4,3 & 0,3 \\
\hline Condições físicas e conforto & 25 & 4,2 & 0,5 \\
\hline $\mathbf{N}$ & $\mathbf{2 5}$ & & \\
\hline
\end{tabular}

Fonte: CAPSad, Botucatu, 2013.

A questão de participação, também representa uma limitação quando os usuários são questionados acerca de sua participação no 
processo de avaliação das atividades desenvolvidas no CAPS e apenas $36 \%$ refere participar.

As questões descritivas do instrumento indicaram que $40 \%$ dos usuários consideram que a equipe do CAPS, com certeza está ajudando o usuário e $60 \%$ afirmam que em geral a equipe ajuda. E o CAPS atende às necessidades dos usuários que se dizem satisfeitos, $80 \%$, e muito satisfeitos, $16 \%$. Para os usuários, o tipo de ajuda dada pelo CAPS significou alguma ajuda, $36 \%$, e muita ajuda para $64 \%$. Para $100 \%$ dos usuários, os serviços que recebeu no CAPS o ajudaram a lidar mais eficazmente com seus problemas. $O$ acesso ao CAPS é considerado fácil para $72 \%$ dos usuários e ocorrem através de transporte público, $44 \%$, ou por condução própria, $32 \%$, e para $32 \%$ o deslocamento demora entre 31 a 45 minutos.

Os fatores mais positivos para os usuários são dinâmica dos grupos terapêuticos e regime terapêutico, seguido do ambiente e do relacionamento com os colegas.

A avaliação positiva dos usuários, entretanto, não impede que os $40 \%$ dos usuários considerem que o serviço no CAPS precisa ser melhorado. Os fatores indicados de melhora dos serviços mais frequentemente referidos são: salas de atendimento; recursos humanos; atendimento noturno e alimentação; melhoria da estrutura física; qualificação dos profissionais; material para as oficinas terapêuticas; saco de boxe; atendimento psicológico individual; investimento para o cuidado dos dependentes químicos.

\subsubsection{Escala de mudança percebida na perspectiva do usuário}

A avaliação da percepção de mudança na perspectiva do usuário em seu tratamento utilizou a escala EMP-BR e sistematizada na tabela a seguir, conforme as questões validadas no Brasil Bandeira et al (2011). Os dados permitiram a identificação do quadro 
global de mudança, conforme os fatores e escore total apresentados na tabela abaixo que indica uma melhora em seu tratamento com média em torno de 2,5 (dp 0,4), em uma escala tipo likert de 1 a 3.

Tabela 12 Média e Desvio-padrão da escala de mudança percebida dos usuários na perspectiva dos usuários do CAPSad Botucatu- SP, 2013.

\begin{tabular}{|c|c|c|c|}
\hline & $\mathrm{N}$ & Média & Desvio-padrão \\
\hline Escore total escala EMP & 25 & 2,5 & 0,4 \\
\hline Atividade e Saúde Física & 25 & 2,5 & 0,5 \\
\hline Aspectos Psicológicos e Sono & 25 & 2,6 & 0,4 \\
\hline $\begin{array}{l}\text { Relacionamentos e Estabilidade } \\
\text { Emocional }\end{array}$ & 25 & 2,6 & 0,5 \\
\hline $\mathrm{N}$ & 25 & & \\
\hline
\end{tabular}

Fonte: CAPSad, Botucatu, 2013.

Pode-se observar que o escore médio global de percepção de mudança foi de 2,5 (dp 0,4), tendo uma variação de 2,17 a 3,0 em uma faixa de possíveis variações entre 1 e 3 . Os resultados das subescalas mostraram que as médias obtidas variaram de 2,5 (dp 0,5), na dimensão "Atividade e Saúde Física", a 2,6 (dp 0,4), na dimensão "Aspectos Psicológicos e Sono". Já na dimensão "Relacionamentos e Estabilidade Emocional", o escore foi de 2,6 (dp $0,5)$.

Os dados referentes às porcentagens de pacientes que perceberam melhora com o início do tratamento também mostram um resultado global elevado. Do total de pacientes, $88 \%$ perceberam a ocorrência de melhora, na sua vida em geral, desde o início do tratamento. 


\subsection{FAMILIARES}

Foram entrevistados 15 familiares. A maioria dos entrevistados, 73,4\% foram entrevistados no domicílio.

Tabela 13 Caracterização dos familiares do Centro de Atenção Psicossocial Álcool e Outras Drogas em Botucatu, segundo tipo de vinculo, gênero, etnia, faixa etária, estado civil, escolaridade, trabalho remunerado e renda familiar no último mês, 2013.

\begin{tabular}{|c|c|c|}
\hline Tipo de vinculo & $\mathbf{N}$ & $\%$ \\
\hline Pai/mãe & 7 & $46,7 \%$ \\
\hline Irmão & 1 & $6,7 \%$ \\
\hline Cônjuge & 6 & $40 \%$ \\
\hline Cuidadora & 1 & $6,7 \%$ \\
\hline \multicolumn{3}{|l|}{ Gênero } \\
\hline Feminino & 14 & $93,3 \%$ \\
\hline Masculino & 1 & $6,7 \%$ \\
\hline \multicolumn{3}{|l|}{ Etnia } \\
\hline Branca & 14 & $93,3 \%$ \\
\hline Negra & 1 & $6,7 \%$ \\
\hline \multicolumn{3}{|l|}{ Faixa etária } \\
\hline De 28 a 30 & 2 & $13,3 \%$ \\
\hline De 31 a 40 & 3 & $20 \%$ \\
\hline De 51 a 60 & 5 & $33,3 \%$ \\
\hline De 60 a 74 & 5 & $33,3 \%$ \\
\hline \multicolumn{3}{|l|}{ Estado civil } \\
\hline Casado/com companheiro & 11 & $73,3 \%$ \\
\hline Divorciado/Separado & 2 & $13,3 \%$ \\
\hline Viúvo & 1 & $6,7 \%$ \\
\hline Solteiro & 1 & $6,7 \%$ \\
\hline \multicolumn{3}{|l|}{ Escolaridade } \\
\hline Ensino fundamental Incompleto & 9 & $60 \%$ \\
\hline Ensino Médio Incompleto & 2 & $13,3 \%$ \\
\hline Ensino Médio Completo & 4 & $26,6 \%$ \\
\hline \multicolumn{3}{|l|}{ Trabalho remunerado } \\
\hline Não & 13 & $86,6 \%$ \\
\hline Sim & 2 & $13,3 \%$ \\
\hline \multicolumn{3}{|l|}{ Renda Familiar último mês } \\
\hline Até 2 salários mínimos & 6 & $40 \%$ \\
\hline Entre 2 a 4 salários mínimos & 8 & $53,3 \%$ \\
\hline Entre 4 a 10 salários mínimos & 1 & $6,7 \%$ \\
\hline Total & 15 & $100 \%$ \\
\hline
\end{tabular}

Fonte: CAPSad, Botucatu, 2013. 
A idade média dos familiares é cerca de 52,47 anos sendo a mínima 28 anos e a máxima 74 anos, com mediana de 56 anos e com um desvio padrão de 14,99 anos. Em relação ao vínculo entre os familiares e usuários, $46,7 \%$ dos familiares entrevistados são pai ou mãe dos usuários, seguido de $40 \%$, o familiar cônjuge.

Os familiares entrevistados são em sua maioria do sexo feminino (93,3\%), sendo que $93,3 \%$ se dizem brancos. Quanto ao estado civil desses familiares, $73,3 \%$ são casados ou vivem com um companheiro.

Quanto à escolaridade dos familiares entrevistados, mais da metade, $60 \%$, possuem ensino fundamental incompleto, $26,6 \%$ possuem ensino médio completo.

Em se tratando de trabalho, $86,6 \% \%$ dos familiares não possuem trabalho remunerado e $100 \%$ referiram serem os únicos que cuidam do familiar usuário.

Na renda familiar do último mês, 53,3\% referem ser entre dois a quatro salários mínimos.

O número de pessoas que vivem na casa variou de duas a seis pessoas. Todos os entrevistados responderam que são os únicos no cuidado com o usuário. Todos referem ter filhos e o número de filhos variou de um a cinco. A maioria das casas possuem três dormitórios $(53,3 \%)$, sendo que $86,6 \%$ moram em casa/apartamento próprio.

Em relação aos problemas de saúde, $60 \%$ apresentam algum problema e a maioria faz acompanhamento na atenção básica.

$\mathrm{Na}$ sobrecarga dos cuidados com o familiar, $26,6 \%$ referem sentir-se sobrecarregado. As situações em que se sentem sobrecarregados são: nos momentos de oscilação de humor do usuário, porque estou doente, penso em quem irá cuidar dele quando eu morrer, nos momentos da organização da casa.

$\mathrm{Na}$ questão em que o serviço poderia ser melhorado, apresentam as seguintes sugestões: olhar mais intensivo para pacientes graves; segurança e melhora das oficinas; familiar precisa 
participar mais ativamente dos grupos; repensar o regime terapêutico para fazer sentido para o paciente no tratamento.

\subsubsection{Satisfação do familiar}

A avaliação de satisfação dos familiares utilizou a escala SATIS-BR e sistematizada na tabela a seguir, conforme as questões validadas no Brasil por Bandeira et al (2002) . Os dados indicam que os familiares mostraram satisfeitos com o serviço de saúde mental com uma média geral de 4,3 (dp 0,8), em uma escala tipo likert de 1 a 5 .

Tabela 14 Média e Desvio-padrão de satisfação dos familiares do CAPSad Botucatu- SP, 2013.

\begin{tabular}{lccc}
\hline & $\mathrm{N}$ & Média & Desvio-padrão \\
\hline Global do SATIS BR & 15 & 4,3 & 0,8 \\
\hline Acolhida e Competência da Equipe & 15 & 4,0 & 0,0 \\
\hline $\begin{array}{l}\text { Privacidade e Confiabilidade } \\
\text { Serviço }\end{array}$ & 15 & 4,0 & 0,0 \\
\hline Resultados do Tratamento & 15 & 4,8 & 0,2 \\
\hline $\mathbf{N}$ & $\mathbf{1 5}$ & & \\
\hline
\end{tabular}

Fonte: CAPSad, Botucatu, 2013.

Esta avaliação satisfatória do CAPS implica que $100 \%$ dos familiares voltariam a procurar o CAPS caso o familiar precisasse e $100 \%$ indicariam o serviço para um amigo ou familiar. Entre os itens referidos, o que os familiares mais gostam no CAPS estão: o atendimento, $46,6 \%$, e o regime terapêutico, $20 \%$. No item em que os familiares menos gostam, 73,3\% referem que nada incomoda e o restante, 26,6\% referem que o que menos gostam são: estrutura física; falta de segurança; colegas do grupo de apoio; da abordagem do profissional com o usuário.

Mesmo com esta avaliação, 33,3\% afirmam que o serviço pode ser melhorado. Quando questionados acerca do que precisaria 
ser melhorado no serviço, os familiares referiram como primeira escolha: olhar mais intensivo para pacientes graves; segurança e melhoria das oficinas; familiar participar mais ativamente dos grupos; repensar o regime terapêtico para fazer sentido para o paciente o tratamento.

\subsubsection{Escala de mudança percebida na perspectiva do familiar}

A avaliação da percepção de mudança na perspectiva do familiar no tratamento utilizou a escala EMP-BR e sistematizada na tabela a seguir, conforme as questões validadas no Brasil por Bandeira, Felício e Cesari (2010). Os dados permitiram a identificação do quadro global de mudança, conforme os fatores e escore total apresentados na tabela abaixo que indica uma melhora no tratamento de seu familiar com média em torno de 2,7 (dp 0,2), em uma escala tipo likert de 1 a 3.

Tabela 15 Média e Desvio-padrão da escala de mudança percebida dos familiares na perspectiva dos familiares CAPSad Botucatu- SP, 2013.

\begin{tabular}{lccc}
\hline & $\mathrm{N}$ & Média & Desvio-padrão \\
\hline Escore total escala EMP & 15 & 2,7 & 0,24 \\
\hline Ocupação & 15 & 2,5 & 0,51 \\
\hline Aspectos Psicológica & 15 & 2,8 & 0,13 \\
\hline Relacionamentos & 15 & 2,7 & 0,37 \\
\hline Saúde Física & 15 & 2,7 & 0,23 \\
\hline $\mathbf{N}$ & $\mathbf{1 5}$ & & \\
\hline
\end{tabular}

Fonte: CAPSad, Botucatu, 2013.

Pode-se observar que o escore médio global de percepção de mudança foi de 2,7 (dp 0,24), tendo uma variação de 2,17 a 3,0 em uma faixa de possíveis variações entre um e três. Os resultados das subescalas mostraram que as médias obtidas variaram de 2,5 (dp 0,51), na dimensão "Ocupação", a 2,8 (dp 0,13), na dimensão 
"Aspectos Psicológicos". Já na dimensão "Relacionamentos" o escore médio foi de 2,7 (dp 0,37), tendo na dimensão "Saúde Física" o escore médio de 2,7 (dp 0,23 ).

Os dados referentes às porcentagens de melhora dos usuários sob o olhar dos familiares com o início do tratamento também mostram um resultado global elevado. Do total de familiares, $100 \%$ perceberam a melhora em geral na vida de seu familiar, desde o início do tratamento. 


\section{DISCUSSÃO}




\section{DISCUSSÃo}

O CAPSad estudado possui horário de funcionamento condizente com seu Projeto Terapêutico Institucional e com a portaria GM/MS 336/02, funcionando em turno diurno de segunda a sexta da $8 \mathrm{~h}$ às $18 \mathrm{~h}$. É um serviço relativamente novo com seis anos de existência.

Um dado importante é que o serviço não é gestado pelo município e sim pelo Centro de Atenção Integral a Saúde CAIS "Professor Cantídio", o antigo macro Hospital Psiquiátrico que em 2006 se transformou no CAIS, portanto, de gestão Estadual.

O fluxograma, apresentado na página 81 , nos mostra que são utilizadas as modalidades de triagem e acolhimento como porta de entrada ao usuário. A triagem é definida por Azevedo e Barbosa (2007) como sendo o primeiro atendimento prestado pelo profissional aos usuários dos serviços de saúde que tem por intenção a avaliação inicial, seleção e encaminhamento dos clientes às unidades/especialidades adequadas à sua assistência.

O acolhimento é visto como o atendimento inicial em saúde que busca atender os usuários que procuram os serviços de saúde, realizando a escuta qualificada de seus pedidos e assumindo uma postura capaz de acolher, escutar e dar respostas mais adequadas aos usuários. Esse processo inclui um atendimento com resolutividade e responsabilização, fazendo também as orientações para o paciente e sua família em relação ao atendimento e funcionamento dos demais serviços de saúde, estabelecendo meios para garantir o sucesso desse encaminhamento, se necessário (Azevedo, Barbosa, 2007).

A Política Nacional de Humanização (PNH) preconiza que o acolhimento não precisa ter local e nem hora certa para acontecer, nem um profissional específico para fazê-lo: faz parte de todos os encontros do serviço de saúde. É uma postura ética que implica na 
escuta do usuário em suas queixas, no reconhecimento do seu protagonismo no processo de saúde e adoecimento, e na responsabilização pela resolução, com ativação de redes de compartilhamento de saberes. Acolher é um compromisso de resposta às necessidades dos cidadãos que procuram os serviços de saúde. É importante o serviço garantir privacidade, o respeito aos costumes, às tradições e à diversidade de: ciclos de vida, arranjos, raça/etnia, gênero e orientação sexual (Brasil, 2004c; Brasil, 2013c).

O CAPSad, em estudo, se caracteriza como serviço aberto de base comunitária, recebe usuários por demanda espontânea, e ainda é referência para outros serviços de saúde, assim, fica a inquietação de existir ou não a lógica de triagem em serviços especializados. Porém, todos os profissionais do serviço, em questão, realizam acolhimento seguindo as diretrizes da Política Nacional de Humanização, o que corrobora com o preconizado na Portaria GM/MS 130/2012 em que o acolhimento é uma forma de atendimento inicial ao usuário que chega ao serviço.

Em relação à infraestrutura do serviço, o Ministério da Saúde preconiza que a estrutura física do CAPS seja compreendida por: recepção como espaço de acolhimento; salas de atendimento individualizado; salas de atividades coletivas; espaço que contemple atividades para várias pessoas de forma coletiva; espaço de convivência; banheiros com chuveiro e com sanitário adaptado para pessoas com deficiência; sala de aplicação de medicamentos (sala de medicação) e posto de enfermagem; quarto coletivo com acomodações individuais (para acolhimento noturno com 2 camas) e banheiro (suítes); quarto de plantão (sala de repouso profissional), este ambiente deve ser previsto apenas para CAPS que oferecem atenção contínua 24 horas; sala administrativa: um escritório; sala de reunião; almoxarifado; sala para arquivo; refeitório; copa (cozinha); banheiro com vestiário para funcionários; depósito de material de limpeza (DML); abrigo de recipientes de resíduos (lixo) e abrigo externo de resíduos sólidos; área externa para embarque e 
desembarque de ambulância; área externa de convivência (Brasil, 2013d).

O CAPSad estudado está alocado em uma casa alugada com dimensão territorial ampla, mas com algumas deficiências, tais como: número insuficiente de salas para atender a demanda, falta de salas adequadas para atendimento em grupo e oficinas terapêuticas e, sobretudo a inadequação da sala de desintoxicação, que pode ser considerado como o ponto mais crítico do serviço.

Em relação aos recursos humanos, o serviço segue as normas da portaria GM/MS 336/02, que é: um médico psiquiatra, um enfermeiro com formação em saúde mental, quatro profissionais de nível superior entre psicólogos, assistentes sociais, enfermeiros, terapeutas ocupacionais, pedagogos ou outros profissionais necessários ao processo terapêutico; e seis profissionais de nível médio, dentre técnicos e/ou auxiliares de enfermagem, técnicos administrativos, técnicos educacionais e artesãos. Portanto, observa-se que o número médio de psiquiatras está além do preconizado, bem como o total de técnicos de nível superior existente nos serviços (nos quais os enfermeiros são a categoria profissional mais frequente). O número de técnicos de nível médio também foi superior ao mínimo preconizado pela portaria, que podemos considerar como um ponto forte do serviço.

A Rede de Atenção Psicossocial (RAPS) instituída pela Portaria GM/MS 3.088/2011 preconiza: "respeito aos direitos humanos, garantindo a autonomia e a liberdade das pessoas; promoção da equidade, reconhecendo os determinantes sociais da saúde; combate a estigmas e preconceitos; garantia do acesso e da qualidade dos serviços, ofertando cuidado integral e assistência multiprofissional, sob a lógica interdisciplinar; atenção humanizada e centrada nas necessidades das pessoas; desenvolvimento de atividades no território, que favoreça a inclusão social com vistas à promoção de autonomia e ao exercício da cidadania; desenvolvimento de estratégias de Redução de Danos; ênfase em 
serviços de base territorial e comunitária, com participação e controle social dos usuários e de seus familiares; desenvolvimento da lógica do cuidado para pessoas com sofrimento ou transtorno mental, incluindo aquelas com necessidades decorrentes do uso de crack, álcool e outras drogas, tendo como eixo central a construção do projeto terapêutico singular" (Brasil, 2011).

O serviço, em estudo, apresenta uma ação e participação no território razoável permeando alguns setores como a assistência social, conselhos e serviços especializados. Mas, são citados alguns problemas, tais como a falta de leitos para desintoxicação de grau moderado e grave e casas transitórias. É preconizado pela portaria GM/MS 130/2012 que os CAPSad possuam leitos de acolhimentos para desintoxicação, fato este que o serviço necessita ser adequado às legislações vigentes.

Nas formas de atendimentos, o serviço oferta abordagens psicoterapêuticas (individuais e em grupo), atividades psicofísicas (Lian Gong) e trabalhos manuais (oficina terapêutica). Uma deficiência é a ausência de atividades de geração de trabalho e renda. Tal atividade auxilia na reinserção do usuário na sociedade e é uma das diretrizes da política do ministério da saúde para a atenção integral a usuários de álcool e outras drogas (Brasil, 2003).

As portarias 3088/2011 e a 130/2012 preconizam que os CAPSad realizem atividade de reabilitação psicossocial com 0 objetivo de resgatar e auxiliar a construção da autonomia, alfabetização ou reinserção escolar, acesso à vida cultural, autocuidado, manejo de medicação, inclusão pelo trabalho, ampliação de redes sociais, dentre outros. É de suma importância que o serviço oferte atividades de geração de trabalho e renda, pois é um ponto importante para melhora do usuário em seu tratamento. Se o serviço não pode ofertar, uma alternativa é criar parcerias com outros serviços que possuem tais atividades como, por exemplo, as Organizações não governamentais (ONG), Cooperativas de Trabalho, dentre outros. 
Estudo de Nascimento e Galvanese, (2009) mostra a importância para a diversidade de atividades desenvolvidas pelos CAPS, pois serviços que mantêm muitas atividades de trabalhos manuais (como artesanato) podem não ser atraentes para usuários mais jovens e do sexo masculino, culturalmente são pouco habituados a realizar tal atividade. Mas também, os serviços que optam preferencialmente em abordagens grupais psicoterápicas podem ser decepcionantes para usuários que buscam inserir-se em atividades profissionais ou em outros espaços do cotidiano. É necessário que o serviço apresente uma diversidade em atividades para utilizá-las na melhoria das necessidades de saúde de sua demanda seguindo sempre o Projeto Terapêutico Singular (PTS) de cada usuário.

O projeto terapêutico nos permite pensar e criar novas realidades, novas possibilidades e aos profissionais cabe à coprodução e a cogestão do processo terapêutico que incorpore o olhar aos contextos singulares e que planejem e se organizem nas ações de responsabilidades do cuidado (Oliveira, 2008).

Tal processo agrega ações e intervenções da equipe e também o comprometimento e envolvimento do usuário e está alicerçado em três movimentos sobrepostos e articulados: a coprodução da problematização; a coprodução de projeto e a cogestão/avaliação do processo (Oliveira, 2008). Deve ser dinâmico e requer transformações, adequações e reformulações após sua construção e implementação, baseadas nas necessidades e demandas do usuário do CAPSad.

O projeto terapêutico singular é normativa das portarias 3088/2011 e da 130/2012. Assim, o serviço em questão apresenta o Projeto Terapêutico Singular para todos os usuários, sendo que a responsabilidade de avaliação e adequação regular é realizada pelo técnico de referência (Brasil, 2011; Brasil, 2012)..

A própria Política do Ministério da Saúde para a Atenção Integral a Usuários de Álcool e outras Drogas preconiza que a 
assistência deve ser ofertada em todos os níveis de atenção, privilegiando-se os cuidados em dispositivos extrahospitalares, como - CAPSad, devendo também estar inserida na atuação de uma Rede de Atenção Básica de Saúde (Brasil, 2003).

Nesse sentido, um dos seus objetivos seria estimular a estruturação e fortalecimento de uma rede de assistência e atenção psicossocial centrada na atenção comunitária, associada à rede de serviços de saúde e sociais, que enfatize a reabilitação e reinserção social dos usuários, amparada em dispositivos comunitários, integrados ao meio cultural, articulados à rede de saúde mental e aos princípios da Reforma Psiquiátrica (Brasil, 2003).

É visto que o serviço possui um espectro amplo de fármacos disponível, auxiliando o médico em suas prescrições, pois o serviço conta com a atenção de um farmacêutico e do suporte do CAIS.

\section{TRABALHADOR}

Neste serviço há um predomínio de trabalhadores do sexo feminino, de cor branca, com formação de ensino superior, casado ou com companheiro, com tempo de trabalho superior a dois anos no CAPS, com uma parcela significante recebendo de um a três salários mínimos, e com carga horária de 30 horas semanais.

Estudo quantitativo ocorrido no sul do Brasil também apresenta que 0 perfil dos trabalhadores de CAPS é majoritariamente feminino, $78 \%$, que se mostra igualmente presente em todas as outras áreas da saúde. Sendo que 44,3\% encontram-se na faixa etária dos 36-50 anos, o que nos indica uma população relativamente madura. Quanto à formação e escolaridade a maioria dos trabalhadores possui ensino superior, 55,8\%, sendo que cerca de $40 \%$ possuem pós-graduação (Kantorski et al., 2009).

Outro estudo quantitativo ocorrido no interior de Minas Gerais que também apresenta o perfil dos trabalhadores de CAPS é também majoritariamente feminino $53,3 \%$, tendo uma idade média 
de 38,07 anos variando de 21 a 68 , uma escolaridade de $46,7 \%$ possuía nível superior (Leal, Bandeira, Azevedo, 2012).

Realizando a comparação com os estudos apresentados, é observada uma semelhança nas questões de gênero, idade e escolaridade desses trabalhadores em CAPS.

O número de trabalhadores com nível superior é de $68,4 \%$ e o de pós-graduação $(52,6 \%)$. Tem-se que $36,8 \%$ dos profissionais possui especialização na área de saúde, $36,8 \%$ dos profissionais com especialização fora da área, 5,2\% dos profissionais com residência fora da área, 10,5\% profissionais cursando mestrado na área de saúde mental. Os profissionais deste CAPS apresentam formação que segue as normativas das legislações vigentes (Brasil, 2003; Brasil, 2004).

É digno de nota que $68,4 \%$ dos profissionais possui ensino superior e $52,6 \%$ recebe até três salários mínimos mensais. Pode-se ter uma explicação que independente do mercado, o serviço público não apresenta plano de carreira para os funcionários. Tal constatação também aconteceu em outro estudo (Rebouças, Legay, Abelha, 2007).

Em relação ao tempo de permanência destes profissionais, os resultados mostram que $47,4 \%$ estão no serviço desde a sua inauguração, apontando baixa rotatividade de profissionais no serviço.

Em estudo realizado por Stancato e Zilli (2010) nos mostra a importância das instituições em manterem certo equilíbrio nas taxas de rotatividade, para garantir uma instituição de qualidade e eficácia na sua produção. Ainda propõe que para o serviço adquirir uma maior ênfase nas questões administrativas, deve reforçar que a saúde é um direito inerente à pessoa, garantindo a ela um atendimento humanizado e de uma equipe integrada, além de um serviço equilibrado, que gere condições de trabalho, segurança física, social, financeira e emocional ao profissional. 
Estudos evidenciam que um problema crescente observado em outros países é a alta rotatividade entre os profissionais. Nos Estados Unidos, por exemplo, há pesquisas mostrando que a cada cinco a sete anos muda toda a força de trabalho em saúde mental (Blankertz, Robinson, 1997; Rebouças, Legay, Abelha, 2007).

A satisfação dos trabalhadores em relação ao ambiente nos mostra algumas deficiências relacionadas a ventilação, a iluminação e a área física. No item higiene não houve problemas. $O$ dado que nos chama atenção é em relação à área física em que $89 \%$ referem problemas..

O serviço apresenta uma fragilidade em relação aos materiais de conforto e segurança, especialmente em relação à saída de emergência e extintores de incêndio, em que $100 \%$ dos trabalhadores referem não estarem instalados e nem em funcionamento no serviço. Outro dado é que $53 \%$ relatam não ter ventiladores disponíveis para uso no serviço.

Estudo realizado em um CAPS no Sul Brasil que avaliou a estrutura por meio da ambiência constatou que a falta de recursos humanos e materiais não interferem diretamente na satisfação dos usuários. A estrutura para o CAPS estudado foi um aspecto forte na avaliação da ambiência (Kantorski et al., 2011).

A portaria GM/MS 336/02 institui que a assistência prestada ao paciente no CAPS II inclui as seguintes atividades: atendimento individual (medicamentoso, psicoterápico, de orientação, entre outros); atendimento em grupos (psicoterapia, grupo operativo, atividades de suporte social, entre outras); atendimento em oficinas terapêuticas executadas por profissional de nível superior ou nível médio; visitas domiciliares; atendimento à família; atividades comunitárias enfocando a integração do doente mental na comunidade e sua inserção familiar e social; pacientes assistidos em um turno (04 horas) receberão uma refeição diária: os assistidos em dois turnos (08 horas) receberão duas refeições diárias (Brasil, 2004). 
Comparando-se com os dados da pesquisa, o serviço possui tais atividades elencadas no parágrafo anterior, mas com alguns pontos que necessitam ser discutidos. Sendo eles: o número de profissionais que intervém em situação de crise (26\%); baixa inserção dos profissionais nas atividades junto à comunidade; apenas $15,8 \%$ dos profissionais realizaram visitas domiciliares no último mês.

A intervenção em crise é uma das prerrogativas da portaria 130/2012 em que a equipe precisa ter preparo para tal atendimento, podendo utilizar o acolhimento como uma das ferramentas primordiais na intervenção (Brasil, 2012)..

A abordagem dirigida à crise pode ser um fator de proteção se ajudar o usuário a estabilizar e reajustar sua situação psicopatológica e assim possibilitar uma recuperação de seu nível de funcionamento (Dimenstein et al., 2012).

Com isso, torna-se imprescindível que a rede de atenção psicossocial (RAPS) trabalhe na perspectiva da continuidade de cuidados, gestão integrada de casos e co-responsabilização (Dimenstein et al., 2012).

Quanto à visita domiciliar, 84,2\% refere algumas dificuldades como: falta de transporte; de tempo para organizar a visita e outros dizem que não foi preciso realizar visita no último mês.

A visita domiciliar é o instrumento de realização da assistência domiciliar. É constituída pelo conjunto de ações sistematizadas para viabilizar o cuidado a pessoas com algum nível de alteração no estado de saúde (dependência física ou emocional) ou para realizar atividades vinculadas aos programas de saúde. Tal instrumento auxilia na adesão deste individuo ao serviço que utiliza, indo além do acompanhamento do usuário, pois engloba também a família neste cuidado (Carvalho, Amaral, Magalhães, 2011; Brasil, 2003).

As práticas assistenciais em CAPSad são amplas e envolvem o trabalho da equipe e todos os atendimentos individuais e grupais oferecidos no serviço, as condições de trabalho, o acesso à rede de 
saúde e também a participação dos familiares ou figuras de referência para que os objetivos do processo terapêutico sejam atingidos (Brasil, 2003).

Nas situações de crise é necessária a mobilização dos técnicos de referência dos respectivos usuários, envolvendo geralmente a participação de outros profissionais da equipe. $O$ atendimento de usuários em situação de crise é prioridade no contexto do serviço, em consonância com a proposta de acolhimento com avaliação e classificação de riscos (Brasil, 2004, Brasil, 2004c). É percebida nos dados apresentados uma baixa percentagem de profissionais que utilizam a intervenção em crise, sendo que toda a equipe deveria se empenhar nesta atividade.

A escala SATIS-BR é um importante indicador da qualidade de determinado serviço de saúde mental, uma vez que a satisfação pelos profissionais da equipe de trabalho pode afetar diretamente a qualidade do atendimento prestado aos usuários (Wykes et al., 1997; Bandeira, Ishara, Zuardi, 2007). Baixa satisfação no trabalho pode levar ao aumento da rotatividade de pessoal e aumento dos níveis de absenteísmo, o que pode reduzir a eficiência dos serviços de saúde (Santos et al., 2011).

Para uma instituição atingir seus objetivos de excelência no atendimento e qualidade nos serviços prestados, é necessário ter profissionais satisfeitos e que gozem de boa qualidade de vida (De Marco et al., 2008).

Uma baixa satisfação dos profissionais pode estar relacionada a aspectos como carga horária de trabalho excessiva, baixa remuneração, ausência de lazer, entre outros fatores. Podem também repercutir de forma negativa para 0 bem-estar dos profissionais e também no relacionamento com os pacientes, bem como interferir no próprio tratamento oferecido (Ishara, 2007; Santos et al., 2011). Os trabalhadores, neste estudo, possuem, em média, uma carga horária de 30 horas semanais, perfazendo 6 horas diárias, o que não caracteriza uma sobrecarga de trabalho. 
Com base nas informações apresentadas nos resultados da escala SATIS-BR observa-se que os profissionais deste CAPSad apresentam uma satisfação intermediária em relação ao serviço. Os outros fatores como a qualidade da assistência prestada ao usuário, a sua participação no serviço e as condições de trabalho, também obtiveram escores intermediários de satisfação. Esses resultados corroboram os dados obtidos por Pitta (1996), Ishara (2007), De Marco et al (2008), Ishara, Bandeira e Zuardi (2008), Rebouças et al (2008), Santos et al (2011) e Leal, Bandeira e Azevedo (2012) que também encontraram níveis medianos de satisfação com o trabalho entre profissionais de saúde mental.

No entanto, os resultados obtidos com as respostas às perguntas abertas que estão presentes na escala SATIS-BR demonstram que o nível de satisfação profissional poderia ser maior se existissem mais investimentos para a melhora da estrutura física do serviço, como um local mais apropriado, ou seja, quantidade de salas e tamanhos adequados à demanda de pacientes, mais atividades terapêuticas e na comunidade, entre outros. Tais demandas são similares nos estudos de Rebouças, Legay e Abelha (2007); Ishara (2007); De Marco et al (2008); Kantorski et al (2011); Leal, Bandeira e Azevedo (2012).

A EAFAAA foi aplicada pela primeira vez com profissionais de saúde de um Centro de Atenção de álcool e outras drogas para verificar suas atitudes frente ao álcool, ao alcoolismo e ao alcoolista. Há estudos em que a EAFAAA foi aplicada em estudantes de enfermagem (Vargas, 2011b; Vargas, Luis, 2011; Vargas, Bittencourt, 2013), em enfermeiros de hospital geral (Vargas, Labate, 2006; Vargas, 2010) e em estudantes de psicologia (Merces, 2013).

Observou-se uma tendência de atitude positiva para o fator 1 , que é atribuído à perspectiva "o trabalhar e o relacionar-se com o alcoolista”, que teve uma média de 3,78 (dp 0,563). Para esse fator, conforme preconiza o autor Vargas (2005), verifica-se a percepção, os sentimentos e as atitudes frente ao indivíduo alcoolista, bem 
como o trabalhar e o relacionar-se com o mesmo. Dois estudos com os estudantes de enfermagem apresentaram atitudes negativas para lidar diretamente com o alcoolista, quando comparado aos achados deste estudo, em que os profissionais de saúde do serviço apresentaram uma atitude positiva (Vargas, 2011b; Vargas, Bittencourtt, 2013).

O fator 2 apresentou melhor escore - "as atitudes frente ao alcoolista". Vargas (2005) descreve esse fator como o que está relacionado com o envolvimento de opiniões, sentimentos e percepções frente ao indivíduo alcoolista, destacando principalmente suas características físicas e psíquicas, bem como comportamentos e atitudes atribuídas a esse usuário. Estudo feito com estudantes de enfermagem contrapõe os achados deste, pois se constatou que os estudantes tinham atitudes negativas ao se relacionar com 0 alcoolista. Relataram ter medo do comportamento agressivo, sendo que metade dos entrevistados disse não saber como conduzir o atendimento a um usuário de álcool, caso fosse preciso (Vargas, 2011b).

O fator 3 teve o pior escore nos resultados desta pesquisa com média de 2,98 (dp 0,35) tendendo à atitude negativa frente ao álcool, ao alcoolismo e alcoolista. Esse fator refere-se à "atitude frente ao alcoolismo, à etiologia". Em estudo anterior, os participantes disseram ter conhecimento dos fatores etiológicos para o alcoolismo causado por fatores sociais (desemprego, dificuldade financeira, problemas familiares, depressão), da falta de autocontrole dos pacientes e de que se trata de uma doença genética (Vargas, 2011b). Observam-se atitudes negativas quanto à etiologia e este déficit pode comprometer o manejo com esses usuários. Outros estudos também tiveram tendências para atitudes negativas sobre os fatores associados ao alcoolismo, o que pode estar relacionado à falta de preparo referida, reforçando o que os pesquisadores têm criticado quanto à ausência de qualificação e capacitação tanto para os estudantes quanto para os profissionais da área da saúde (Lopes, 
Luis, 2005; Vargas, 2011b; Merces, 2013; Vargas, Bittencourt, 2013).

O fator 4, "atitudes frente ao uso de álcool" que diz respeito às opiniões, aos sentimentos e às predisposições do profissional de saúde quanto aos custos psíquicos e sociais acarretados pelo uso/abuso do álcool envolvendo o indivíduo, a família e outras esferas de relacionamento pessoal, como trabalho, amigos e outros, estiveram na faixa intermediária com uma média de 3,35 (dp 0,783), mediana de 3,3 e foi o fator que obteve maior variância (Vargas, 2005).

Em estudo realizado com enfermeiros de um hospital, revelou-se dificuldade na aceitação do beber como um direito da pessoa, em que identificam na bebida alcoólica um perigo à saúde, independente da quantidade ingerida (Vargas, Labate, 2006). Outro estudo com enfermeiros de unidades básicas de saúde demonstraram melhor aceitação em relação ao beber (Vargas, Luis, 2008).

\section{USUÁRIO}

Os usuários do CAPSad, em sua maioria são homens, sendo $68 \%$ da amostra. A maioria é de etnia branca (88\%). A idade dos usuários variou de 26 a 69 anos, sendo que na faixa etária de 31 a 40 anos, concentram-se 9 usuários, o que faz a proporção total de $36 \%$. Temos uma proporção de $48 \%$ solteiros.

Dados da pesquisa e estudos evidenciam que a população masculina é a mais atingida pelo problema da dependência de drogas, levando à consequente procura de tratamento. Sabe-se, no entanto, que questões culturais, baseadas em preconceitos, tem sido constatadas no decorrer das atividades de atendimento ao usuário de drogas, principalmente em relação à mulher, o que pode ajudar a compreender a significativa diferença numérica no total de usuários (Passos, Camacho, 1998; Ferreira Filho et al., 2003 Pelisoli, Moreira, 2005; Faria, Schneider, 2009; Marini, 2011; 
Monteiro et al., 2011; Pereira et al., 2012). Corroborando com estudo que evidenciou a questão de gênero para a busca do tratamento, indicando que as mulheres sentem vergonha da doença, resultando em afastamento do tratamento (Monteiro et al., 2011).

Um estudo realizado por Cesar (2006) nos mostra que grupos de tratamento compostos apenas por mulheres apresentam melhor adesão do sexo feminino que em grupos mistos. Neste CAPSad em que foi coletado os dados, o atendimento grupal e outras atividades são compostos por ambos os sexos.

O consumo de álcool e outras drogas aparece socialmente mais marcante quando o dependente é do sexo feminino, e esse preconceito sobre a drogadição pode constituir, nesse caso, um viés epidemiológico, já que tal demanda não chega ao serviço (Ferreira Filho et al., 2003; Pereira et al., 2012). Quando é avaliado o perfil dos usuários em outros serviços de saúde mental, temos a maioria do sexo feminino (Silva et al., 1996; Kantorski et al., 2009).

A idade dos usuários variou de 26 a 69 anos, sendo que na faixa etária de 31 a 40 anos estão concentrados $36 \%$ dos usuários. Temos uma proporção de $48 \%$ solteiros. Em relação à fonte de renda, 36\% apresentam vínculo empregatício, enquanto $24 \%$ não possuem renda. Entre os usuários 96\% afirmam saber ler e $40 \%$ destes referem possuir ensino fundamental incompleto, enquanto que $32 \%$ detêm ensino médio completo.

Comparando dados desta pesquisa com outros estudos é notada similaridade nas questões de faixa etária, estado civil e situação ocupacional (Passos, Camacho, 1998; Monteiro et al., 2011).

A média de idade dos usuários neste estudo foi de 43,8 anos, semelhante ao observado na população estudada em Lorena-SP (41 anos) e maior que o observado em população estudada no Rio Grande do Sul que apresentou a média de 30,3 anos (Pereira et al., 2012; Kantorski et al., 2009). 
Também houve a predominância da baixa escolaridade, a questão de estar fora do mercado de trabalho e a de não ter companheiro foi similar às características da amostra de estudos em CAPSad (Peixoto et al., 2010; Marini, 2011).

No que se refere a vínculo empregatício dos usuários, temos uma percentagem de $52 \%$ que não estava trabalhando no momento em que foram entrevistados. A problemática do desemprego é uma questão de ordem estrutural e conjuntural; entretanto, essa questão torna-se mais significante nos usuários abusivos de álcool e outras drogas, visto que estes "representam um segmento marginalizado dentro do conjunto dos socialmente excluídos" (Brites, 1995, p. 103). Tal fato torna sua inserção e permanência no mercado de trabalho ainda mais restrita, em virtude de apresentarem dificuldades em desempenhar satisfatoriamente suas funções, devido aos efeitos e consequências biopsicossociais específicas de cada tipo de uso abusivo de drogas, caso não estejam em abstinência.

Outro dado interessante é com quem os usuários vivem, a maioria vive com algum familiar sendo que $32 \%$, com cônjuge/companheiro (a) e 40\% com familiar, especialmente mãe ou pai.

Em referência à adesão ao serviço, 60\% afirmou ser sua primeira admissão no serviço. Sendo então que $40 \%$ são reincidentes. Acerca do tempo que os usuários frequentam este serviço, $48 \%$ afirmaram que frequentam entre um a dois anos e $24 \%$ frequenta entre sete a 12 meses.

Comparando os dados com outras pesquisas, temos que os usuários deste serviço apresentam uma melhor adesão do que em outros estudos, pois neste serviço $48 \%$ frequenta o CAPS há mais de seis meses, já em outras investigações mais de 50\% dos usuários não permanecem em tratamento na instituição (Pelisoli, Moreira, 2005; Monteiro et al., 2011).

A adesão ao tratamento é considerada a partir do terceiro mês e a permanência do usuário no serviço por um período mínimo 
de seis meses é avaliada como uma forma positiva de adesão (Monteiro et al., 2011). À aderência ou adesão ao tratamento pode ser entendida como o grau em que o paciente segue as recomendações médicas, ou de outro profissional de saúde, e é entendida como o retorno e a manutenção do tratamento indicado. Pode ser também chamada de obediência e permanência ao tratamento e inclui a frequência até o momento de sua alta (Kaplan, Sadock, Grebb, 1997; Monteiro et al., 2011).

Mesmo os serviços mais efetivos, ainda deparam com as maiores taxas de abandono e menor sucesso terapêutico em comparação com os tratamentos para transtorno mental (Pinsky et al., 1995; Raupp, Milnitsky-Sapiro, 2005).

A respeito do diagnóstico, $96 \%$ dos usuários relatam conhecer. Tem-se $72 \%$ com uso de drogas, $76 \%$ com uso de álcool, $68 \%$ com uso de tabaco, $8 \%$ com esquizofrenia e $4 \%$ com transtorno depressivo maior.

Em relação à internação psiquiátrica antes de iniciar o tratamento no CAPSad $68 \%$ sinalizam que tiveram internações nesta modalidade, sendo em hospital psiquiátrico (56\%) e em comunidades terapêuticas (24\%). Já na internação psiquiátrica durante 0 tratamento no CAPSad $32 \%$ sinalizam que tiveram internações nesta modalidade, sendo em hospital psiquiátrico (28\%) e em comunidades terapêuticas (8\%).

O CAPSad é um serviço alternativo, substitutivo ao processo de reclusão como forma de tratamento. No entanto, como o município não possui um serviço de internação em hospital geral, para tratamento da síndrome de abstinência por uso de substâncias psicoativas, preconizado na Política de Atenção ao Usuário de Álcool e outras Drogas (Brasil, 2004), faz do hospital psiquiátrico umas das opções para os encaminhamentos nesses casos. Como já referido acima, o serviço não possui sala adequada para realizar acolhimento em intervenção à crise moderada e grave. 
Pode existir a necessidade de internação quando o paciente se apresenta em síndrome de abstinência (conjunto de sintomas desenvolvidos em função da abstinência ou redução da substância no organismo), devido a necessidade de monitoramento constante de seu quadro clínico. Entretanto, o pico dos sintomas ocorre entre 24 e 48 horas, desaparecendo, na maioria dos casos, após sete dias. Após 15 dias há remissão dos sintomas da síndrome de abstinência (Laranjeira et al., 2000).

Quanto ao uso de psicofármacos, 96\% referem que em nenhuma situação precisou comprar a medicação que faz uso. Temos que $80 \%$ dos entrevistados seguem sempre as prescrições médicas.

A satisfação dos pacientes vem sendo atrelada há varias questões, entre elas: adesão ao tratamento, características do atendimento, variáveis sociodemográficas e clínicas dos pacientes, redução da sintomatologia, competência da equipe, qualidade do relacionamento profissional e paciente, acessibilidade ao serviço, qualidade das instalações, continuidade dos cuidados e também a informação recebida (Silva et al, 2012).

Os resultados indicaram um bom grau de satisfação dos usuários com o CAPSad, tanto na escala global, como nos fatores: competência e compreensão, ajuda recebida e acolhida e condições físicas e conforto. Estes dados são corroborados com outros estudos a respeito da satisfação do usuário (Teixeira, Trindade, 2006; Heckert, Kantorski et al., 2009; Jaegger et al., 2009; Camilo et al., 2012; Silva et al., 2012).

Mesmo com uma significativa avaliação positiva, os usuários indicam maior investimento de readequação nos aspectos de estrutura e recurso material. A maior dificuldade dos serviços está nas condições de infraestrutura, aspecto presente em outros estudos (Silva et al., 1996; Bandeira, Pitta, Mercier, 1999; Kantorski et al., 2009). 
Outra medida de resultados, na perspectiva dos usuários, que tem tido destaque na avaliação dos serviços é a percepção de mudanças pelos usuários em função do tratamento recebido. Esta escala mensura a percepção de mudanças no que se refere aos efeitos do tratamento na saúde física e psicológica, na vida social e nas atividades, tal como percebido pelo próprio usuário.

Os dados deste estudo nos mostram que os usuários perceberam melhora com o início do tratamento e também mostram um resultado global elevado. Do total de pacientes, $88 \%$ perceberam a ocorrência de melhora, na sua vida em geral, desde o início do tratamento. Comparando com os resultados de outra pesquisa realizada em um serviço de saúde mental é observada uma similaridade nos resultados (Costa et al., 2011). Há um número incipiente de estudos avaliando a percepção de mudança percebida pelos usuários no campo da saúde mental.

\section{FAMILIAR}

Os dados nos mostram que os familiares que acompanham seus parentes no serviço apresentam em média meia idade, e que $90 \%$ do vínculo dos usuários estão na família nuclear, sendo que os pais/mães foram identificados como os principais cuidadores dos usuários $(46,7 \%)$. Isto nos mostra que a família é muito presente no cotidiano do usuário de álcool e outras drogas.

Há a predominância do sexo feminino nos familiares e a maioria casada. Apresentam baixa escolaridade e fora do mercado de trabalho. A renda familiar é de até 4 salários mínimos para mais de $90 \%$ dos entrevistados.

Outro estudo quantitativo ocorrido em Minas Gerais apresenta um perfil de familiares de usuários de serviços comunitários de saúde mental majoritariamente feminino, $78 \%$, tendo uma idade média de 49,74 anos variando de 18 a 78, casado (51\%), com primeiro grau incompleto (63\%) (Costa et al., 2011). 
A presença do gênero feminino no tratamento $e$ no acompanhamento do usuário de drogas nos serviços de saúde mental é frequente nos vários estudos correlatos sobre participação familiar (Filizola et al., 2006; Vargas, Zago, 2008; Azevedo, Miranda, 2010).

Outro dado relevante é que $86,6 \%$ moram em casa/apartamento próprio. Tal dado evidencia que os usuários apresentam boas condições de moradia.

A literatura apresenta pouco destaque na avaliação da satisfação dos familiares em relação aos serviços de saúde mental, apesar da necessidade da inclusão dos familiares no monitoramento e avaliação dos serviços (Gigantesco et al., 2002; Bandeira et al., 2011).

No contexto brasileiro dois estudos são emblemáticos sobre a satisfação dos familiares em serviços de saúde mental, sendo que um teve como objetivo realizar a validação de uma escala de medida, e o outro foi realizado no interior de Minas Gerais (Bandeira et al., 2002; Bandeira et al., 2011).

A satisfação dos familiares (SATIS-BR) indicaram um bom grau de satisfação em relação ao CAPSad, tanto na escala global, como nos fatores: competência e compreensão, ajuda recebida e acolhida e condições físicas e conforto. Estes dados corroboram com estudo de outra pesquisa a respeito da satisfação dos familiares em relação a serviços de saúde mental (Bandeira et al., 2011).

Mesmo com uma significativa avaliação positiva, os familiares apontam aspectos que merecem investimento e readequação no serviço em relação aos aspectos de segurança, das oficinas terapêuticas, do processo terapêutico dos usuários e de uma participação mais efetiva dos familiares nos grupos.

Não há estudos avaliando a satisfação e a percepção de mudança no tratamento dos familiares em relação ao CAPSad.

Finalmente, a principal limitação do presente estudo foi a realização do mesmo em um único serviço de saúde mental, assim, 
não pode ser generalizado para outros serviços, ou seja, não é possível que sejam feitas extrapolações dos resultados obtidos. 
CONCLUSÃO 


\section{CONCLUSÃO}

O serviço prestado pelo CAPSad avaliado no presente estudo foi considerado muito bom pelos pacientes, existindo concordância por parte dos profissionais e dos familiares como sendo uma modalidade de tratamento eficaz para os pacientes dependentes de álcool e drogas.

Em termos de estrutura é apontado pelos profissionais que 0 serviço necessita de algumas adequações para melhora da qualidade da assistência do usuário, sobretudo nos casos de desintoxicação aguda.

Os resultados apontam para a integração da rede de atenção primária à saúde, de acordo com que é preconizado pelo Sistema Único de Saúde, em que a atenção básica à saúde deve ser resultado da integração entre os diferentes serviços, seja ele a Unidade Básica de Saúde, a Estratégia de Saúde da Família (ESF), ou os serviços especializados (hospitais, ambulatórios de especialidades, CAPS, e outros).

Assim sendo, o serviço necessita criar ações que visem capacitar os trabalhadores para atuarem no fortalecimento das relações intersetoriais, como uma possibilidade de melhora na atenção aos usuários de substâncias psicoativas, o que passa pela realização da detecção precoce e intervenção breve e, consequentemente, redução do agravamento do quadro de dependência e das comorbidades associadas.

Quase todas as atividades dos CAPSad são realizadas em grupo, inclusive as psicoterapias. A terapia em grupo apresenta alguns fatores importantes como o altruísmo, a compreensão de si mesmo, o entendimento da importância da família e a coesão grupal.

Os profissionais do CAPSad acreditam que a adoção do modelo de redução de danos possibilita uma melhor eficiência do serviço. A participação dos pacientes em atividades comunitárias 
não está acontecendo, visto a não existência de parcerias para tal. Os programas de geração de renda inexistem no serviço o que representa uma dificuldade no que tange a reinserção social dos pacientes.

No entanto, tem que se considerar que os profissionais do CAPSad devam ter um papel de articuladores no território, desempenhando uma articulação com outras áreas da sociedade para efetivar um verdadeiro projeto de reinserção social do paciente. Finalmente, podemos considerar a necessidade de investimentos em capacitações e cursos de atualização para os profissionais, no intuito de se desenvolver de fato a articulação de vários segmentos da sociedade e, assim construir a verdadeira Rede de Atenção Psicossocial.

Deste modo, espera-se que os resultados apresentados orientem a política local na elaboração de novas ações que ampliem a atenção aos usuários de substâncias psicoativas, bem como a sua permanência em tratamento, no sentido de promover a sua reinserção social. 
REFERÊNCIAS 


\section{REFERÊNCIAS}

Adami NP, Maranhão AMSA. Qualidade dos serviços de saúde: conceitos e métodos avaliativos. Acta Paul Enferm. 1995; 8(4).

Akerman M, Nadanovsky P. Avaliação dos serviços de saúde: avaliar o quê? Cad Saúde Pública [periódico na Internet]. 1992 [citado 2011 Jan 09]:8(4):361-65. Disponível em: http://www.scielosp.org/pdf/csp/v8n4/v8n4a02.pdf

Amarante $\mathrm{P}$, coordenador. Loucos pela vida: a trajetória da reforma psiquiátrica no Brasil. Rio de Janeiro: Fiocruz; 1995.

Azevedo JMR, Barbosa MA. Triagem nos serviços de saúde. Rev Enferm UERJ. 2007; 15(1):33-9.

Azevedo DM, Miranda FAN. Práticas profissionais e tratamento ofertado nos CAPSad do município de Natal-RN: com a palavra a família. Esc Anna Nery. 2010; 14(1):56-63.

Bandeira M, Pitta AMF, Mercier C. Escala de avaliação da satisfação dos usuários em serviços de saúde mental: SATIS-BR. J Bras Psiquiatr. 2000. 49(8):293-300.

Bandeira M, Mercier C, Perreault M, Libério MMA, Pitta, AMF Escala Brasileira de Avaliação da Satisfação dos Familiares em Serviços de Saúde Mental: SATIS-BR. J Bras Psiquiatr. 2002; 51(1):31-8.

Bandeira M, Ishara S, Zuardi AW. Satisfação e sobrecarga de profissionais de saúde mental: validade de construto das escalas SATIS-BR e IMPACTO-BR. J Bras Psiquiatr. 2007; 56(4): 280-86.

Bandeira M, Calsavara MGP, Costa CS. Cesari, L. Avaliação de serviços de saúde mental: adaptação transcultural de uma medida da percepção dos usuários sobre os resultados do tratamento. J Bras Psiquiatr. 2009; 58(2):107-14.

Bandeira M, Felício CM, Cesari L. Validation of the Perception of Change Scale - Family version (EMP-F) as a treatment outcome measure in mental health services. Rev Bras Psiquiatr. 2010; 32(3):283-7.

Bandeira MB, Andrade MCR, Costa CS, Silva MA. Percepção dos pacientes sobre o tratamento em serviços de saúde mental: validação da Escala de Mudança Percebida. Psicol Reflex Crit. 2011; 24(2):236-44. 
Bandeira M, Silva MA. Escala de satisfação dos pacientes com os serviços de saúde mental (SATIS-BR): estudo de validação. J Bras Psiquiatr. 2012;61(3): 124-32.

Baremblitt G. Compêndio de análise institucional e outras correntes: teoria e prática. $3^{\circ}$ ed. Rio de Janeiro: Editora Rosa dos Tempos; 1996.

Blankertz LE, Robinson SE. Turnover intentions of community mental health workers in psychosocial rehabilitation services. Community Ment Health J. 1997; 33:517-29.

Brasil. Decreto-lei n. 2.848, de 7 de dezembro de 1940. Presidência da República. Casa Civil. Subchefia para Assuntos Jurídicos decreta a seguinte Lei do Código Penal. [legislação na Internet]. Brasília; 1940. Disponível em: http://www.planalto.gov.br/CCIVIL/DecretoLei/Del2848.htm.

Brasil. Ministério da Saúde. Programa Nacional de Controle dos Problemas relacionados com o Consumo do Álcool (PRONAL). Brasília, 1987.

Brasil. Ministério da Saúde. Secretaria Executiva. Coordenação Nacional de DST/Aids. A Política do Ministério da Saúde para atenção integral a usuários de álcool e outras drogas / Ministério da Saúde, Secretaria Executiva, Coordenação Nacional de DST e Aids. - Brasília: Ministério da Saúde, 2003.

Brasil. Ministério da Saúde. Secretaria-Executiva. Secretaria de Atenção à Saúde. Legislação em saúde mental: 1990-2004 / Ministério da Saúde, Secretaria-Executiva, Secretaria de Atenção à Saúde. - 5. ed. ampl. - Brasília: Ministério da Saúde, 2004.

Brasil. Ministério da Saúde. Portaria № 2.197/GM de 14 de outubro de 2004b. Dispõe sobre a Política Nacional de atenção aos usuários de álcool e outras drogas. [legislação na internet]. Brasília; 2004b. Disponível

em: http://dtr2001.saude.gov.br/sas/PORTARIAS/Port2004/GM/GM2197.htm

Brasil. Ministério da Saúde. Secretaria-Executiva. Núcleo Técnico da Política Nacional de Humanização. HumanizaSUS: acolhimento com avaliação e classificação de risco - um paradigma ético-estético no fazer em saúde. Brasília: Ministério da Saúde, 2004c.

Brasil. Ministério da Saúde. Secretaria de Atenção à Saúde. Coordenação Geral de Saúde Mental. Reforma psiquiátrica e políticas de saúde mental no Brasil. Documento apresentado à Conferência Regional de Reforma dos Serviços de Saúde Mental: 15 anos depois de Caracas. OPAS. Brasília; 2005 
Brasil. Ministério da Saúde. Secretaria de Atenção à Saúde. Relatório de Gestão 2003-2006: saúde mental no SUS: acesso ao tratamento e mudança do modelo de atenção. Brasília: Ministério da Saúde; 2007.

Brasil. Coordenação de Saúde Mental. Ministério da Saúde. Avaliar CAPS faz um retrato do trabalho dos CAPS [periódico na Internet]. 2009 fev. 19 [citado 2011 jan 11]. Disponível em: http://www.ccs.saude.gov.br/saude_mental/pdf/Not\%C3\%ADciaAvali arCAPSparaBVS19fev09.pdf

Brasil. Ministério da Saúde. Portaria № 1.190/GM de 4 de junho de 2009. Institui o Plano Emergencial de Ampliação do Acesso ao Tratamento e Prevenção em Álcool e outras Drogas no Sistema Único de Saúde - SUS (PEAD 2009-2010) e define suas diretrizes gerais, ações e metas. [legislação na Internet]. Brasília; 2009b. Disponível

em:

http://bvsms.saude.gov.br/bvs/saudelegis/gm/2009/prt1190_04_06_2 009.html

Brasil. Ministério da Saúde. Decreto № 7.179, de 20 de maio de 2010. Institui o Plano Integrado de Enfrentamento ao Crack e outras Drogas, cria o seu Comitê Gestor, e dá outras providências. [legislação na Internet]. Brasília; 2010. Disponível em: http://www.planalto.gov.br/ccivil_03/_Ato2007-

2010/2010/Decreto/D7179.htm

Brasil. Ministério da Saúde. Portaria n 4.279, de 30 de dezembro de 2010. Estabelece diretrizes para a organização da Rede de Atenção à Saúde no âmbito do Sistema Único de Saúde. [legislação na Internet]. Brasília; 2010b. Disponível em: http://www.brasilsus.com.br/legislacoes/gm/107038-4279.html

Brasil. Ministério da Saúde. Portaria nํㅜ 3.088, de 23 de dezembro de 2011. Institui a Rede de Atenção Psicossocial para pessoas com sofrimento ou transtorno mental e com necessidades decorrentes do uso de crack, álcool e outras drogas, no âmbito do Sistema Único de Saúde. [legislação na Internet]. Brasília; 2011. Disponível em: http://www.brasilsus.com.br/legislacoes/gm/111276-3088.html

Brasil. Ministério da Saúde. Saúde Mental em Dados - 10, ano VII, no 10. Informativo eletrônico. Brasília: março de 2012 (acesso em 29 abr. 2013). Disponível em: http://portal.saude.gov.br/portal/arquivos/pdf/mentaldados10.pdf

Brasil. Ministério da Saúde. Portaria no 130, de 26 de janeiro de 2012. Redefine o Centro de Atenção Psicossocial de Álcool e outras Drogas $24 \mathrm{~h}$ (CAPSAD III) e os respectivos incentivos financeiros. [legislação na Internet]. Brasília; 2012b. Disponível em: 
http://bvsms.saude.gov.br/bvs/saudelegis/gm/2012/prt0130_26_01_2 012.html

Brasil. Fundação Sistema Estadual de Analise de Dados (SEADE). [site na Internet]. 2013 [acessado 2013 jan10]. Disponível em: http://www.seade.gov.br/produtos/perfil/perfilMunEstado.php

Brasil. Instituto Brasileiro de Geografia e Estatística (IBGE). [site na Internet]. 2013b [acessado 2013 jan10]. Disponível em: http://www.ibge.gov.br/

Brasil. Ministério da Saúde. Acolhimento. [Internet]. Brasília; 2013c. Disponível em: http://bvsms.saude.gov.br/bvs/dicas/167acolhimento.html.

Brasil. Ministério da Saúde. Secretaria de Atenção à Saúde. Departamento de Ações Programáticas Estratégicas. Manual de Estrutura Física dos Centros de Atenção Psicossocial e Unidades de Acolhimento: Orientações para Elaboração de Projetos de Construção de CAPS e de UA como lugares da Atenção Psicossocial nos territórios. - Brasília: Ministério da Saúde, 2013d.

Brites, Cristina Maria. Serviço Social, drogas e Aids: questões para debate. Caderno de Comunicação do $8^{\circ}$ Congresso Brasileiro de Assistentes Sociais. Brasília; [s.d.], [s.e.], 1995.

Camilo CA, Bandeira M, Leal RMAC, Scalon JD. Avaliação da satisfação e sobrecarga em um serviço de saúde mental. Cien Saúde Colet. 2012; 20(1):82-92.

Carlini EA, supervisão, et al. II Levantamento domiciliar sobre uso de drogas no Brasil: Estudo envolvendo as 108 maiores cidades do país em 2005. São Paulo: Centro Brasileiro de Informações sobre Drogas Psicotrópicas, Departamento de Psicobiologia da Escola Paulista de Medicina; 2006.

Carvalho ALL, Amarante P. Avaliação de qualidade dos novos serviços de saúde mental: em busca de novos parâmetros. Saúde em Debate, 1996; 52:74-82.

Carvalho CG, Amaral RMS, Magalhães SR. Assistência de enfermagem ao portador de transtorno psíquico: visita domiciliar. eScientia, Belo Horizonte. 2011;4(1):31-38.

Cesar BAL. Alcoolismo feminino: um estudo de suas peculiaridades. J.Bras Psiquiatr. 2006 out; 55(3):208-2011.

Chen HT. Practical program evaluation: assessing and improving planning implementation and effectiveness. London: Sage 
Contandriopoulos, AP. Avaliando a Institucionalização da Avaliação. Cien \& Saude Coletiva. 2006;11(3):705-712.

Costa CS, Bandeira M, Cavalcanti RLA, Scalon JD. A percepção de pacientes e familiares sobre os resultados do tratamento em serviços de saúde mental. Cad Saúde Públic. 2011; 27(5):995-1007.

Deslandes SF. Concepções em pesquisa social: articulações com o campo da avaliação em serviços de saúde. Cad Saúde Públic. 1997; 13(1):103-7.

De Marco PF, Cítero VA, Moraes E, Nogueira-Martins LA.O impacto do trabalho em saúde mental: transtornos psiquiátricos menores, qualidade de vida e satisfação profissional. J Bras Psiquiatr. 2008; 57(3):178-83.

Dimenstein M, Amorim AKA, Leite J, Siqueira K, Gruska V, Vieira C, Brito $\mathrm{C}$, Medeiros I, Bezerril MC O atendimento da crise nos diversos componentes da rede de atenção psicossocial em Natal/RN. Polis e Psique. 2012; 2(número temático):95-127.

Donabedian A. The quality of medical care. Science. 1978; 200(4344): 856-64.

Donabedian A. Basic approaches to assessment: structure, process and outcome. In: Explorations in Quality Assessment and Monitoring. Vol. I, pp77-125, Ann Arbor, Michigan: Health Administration Press 1980.

Donabedian A. La calidad de la atención médica. Definición y métodos de valuación. México: La Prensa Mexicana; 1984.

Donabedian A. An introduction to quality assur-ance in health care. New York: Oxford University Press. 2003.

Faria JG, Schneider DR. O perfil dos usuários do Capsad-Blumenau e as políticas públicas em saúde mental. Psicologia \& Sociedade. 2009; $21(3): 324-33$.

Ferreira Filho OF, Turchi MD, Laranjeira R, Castelo A. Perfil sociodemográfico e de padrões de uso entre dependentes de cocaína hospitalizados. Rev Saúde Públic. 2003; 37(6):751-9.

Filizola CLA, Perón CJ, Nascimento MMA, Pavarini SCI, Petrilli Filho JF. Compreendendo o alcoolismo na família. Esc Anna Nery Rev Enferm. 2006; 10(4):660-70.

Fornazier ML. Siqueira MM. Consulta de enfermagem a pacientes alcoolista em um programa de assistência ao alcoolismo. J Bras Psiquiatr. 2006; 55(4):280-7. 
Furtado JP. A avaliação como dispositivo. Tese. Campinas: Programa de Pós-Graduação em saúde Coletiva da Faculdade de ciências Médicas/Universidade Estadual de Campinas; 2001.

Gigantesco A, Picardi A, Chiaia E, Balbi A, Morosine P. Patients' satisfaction with psychiatric services in a large catchment area in Rome. Eur Psychiatry. 2002; 17:139-47.

Giordano JRS, Pereira LM de F. Saúde mental. In: Schraiber LB, Nemes MIB, Mendes-Gonçalves RB, organizadores. Saúde do adulto: programas e ações na unidade básica. $2^{\circ}$ ed. São Paulo: Editora Hucitec; 2000; p. 133-50.

Heckert U, Teixeira LS, Trindade AS. Avaliação da satisfação dos usuários do Centro Regional de Referência em Saúde Mental (CRRESAM) da região central de Juiz de Fora, MG. HU Revista. 2006; 32(1):15-9.

Ishara S. Equipes de saúde mental: avaliação da satisfação e do impacto do trabalho em hospitalização integral e parcial. [tese]. Ribeirão Preto: Universidade de São Paulo, 2007.

Ishara S, Bandeira M, Zuardi AW. Public psychiatric services: job satisfaction evaluation. Rev Bras Psiquiatr. 2008; 30(1):38-41.

Jaegger RC, Guitton AP, Lyrio JM, Santos MM, Freitas RCO, Gonçalves SR, Lima LAde, Legay LF. A experiência de morar fora: avaliação da satisfação de usuários em um serviço de saúde mental. Cad Saúde Coletiva. 2004; 12(1):27-39.

Kantorski LP, Machado AT, Oliveira CA. Centro de atenção psicossocial - reinventando o cuidado em saúde mental. Texto e Contex Enferm. 2000; 9(1):233-43.

Kantorski LP et al. Avaliação dos CAPS da região sul do Brasil. Universidade Federal de Pelotas [periódico na Internet]. 2006 [citado 2011 jan. 12]. Disponível em http://ufpel.edu.br/feo/capsul/capsul.php

Kantorski LP et al. Contribuições do estudo de avaliação dos centros de atenção psicossocial da região sul do Brasil (CD-ROM). Cad Bras Saúde Mental [periódico na Internet]. 2009 jan-abr [citado em 2011 jan 13]:1(1). Disponível em: http://www.abrasme.org.br/cbsm/artigos/artigos/20_Luciane_Kantors ki.pdf

Kantorski LP, Coimbra VCC, Silva ENFda, Guedes AdaC, Cortes JM, Santos Fdos. Avaliação qualitativa de ambiência num Centro de Atenção Psicossocial. Ciênc saúde coletiva. 2011; 16(4):2059-66. 
Kaplan HI, Sadock BJ, Grebb JA. Compêndio de psiquiatria: ciências do comportamento e psiquiatria clínica. $7^{\underline{a}}$ ed. Porto Alegre: Artmed; 1997.

Kohn R, Mello MF, Mello AAF. O ônus e a carência de atendimento da saúde mental no Brasil. In: Mello MF; Mello AAF; Kohn R, organizadores. Epidemiologia da Saúde Mental no Brasil. Porto Alegre: Artmed; 2007; p. 199-207.

Laranjeira $\mathrm{R}$ et al. Consenso sobre a síndrome de abstinência do álcool (SAA) e o seu tratamento. Rev Bras Psiquiatr. 2000; 22(2):6271.

Leal RMAC, Bandeira MB, Azevedo KRN. Avaliação da qualidade de um serviço de saúde mental na perspectiva do trabalhador: satisfação, sobrecarga e condições de trabalho dos profissionais. Psicologia: teoria e prática. 2012; 14(1):15-25.

Lopes GT, Luis MAV. A formação do enfermeiro e o fenômeno no estado do Rio de Janeiro - Brasil: atitudes e crenças. Rev Latino-am Enferm. 2005; 13(número especial);872-9.

Malik AM. Qualidade e avaliação nos serviços de saúde: uma introdução. In: D' Innocenzo M, coordenador. Indicadores, auditorias, certificações: ferramentas de qualidade para gestão em saúde. São Paulo: Martinari; 2006, p 21-35.

Marin-Léon L, Oliveira HB, Botega NJ. Mortalidade por dependência de álcool no Brasil:1998-2002. Psicologia em Estudos. 2007; 12(1):115-21.

Marini M. Preditores de adesão ao projeto terapêutico em Centro de Atenção Psicossocial álcool e outras drogas. Dissertação [Mestrado] - Universidade Federal do Rio Grande do Sul, Escola de Enfermagem, Programa de Pós-Graduação em Enfermagem, Porto Alegre, Br-Rs, $2011.89 \mathrm{f}$.

Mayne J. Addressing atribuition through contribution analysis: using performance measures sensibly. Canadian Journal of Program Evaluation. 2000; 16(1): 124.

Meloni JN; Laranjeira R. Custo social e de saúde do consumo do álcool. Rev Brasil Psiquiatr. 2004; 26(1):7-10.

Medina MG, Silva GAP, Aquino R, Hartz ZMA. Uso de modelos teóricos na avaliação em saúde: aspectos conceituais e operacionais. In: Hartz ZMA, Silva LMV organizadoras. Avaliação em saúde, dos modelos teóricos à prática na avaliação de programas e sistemas de saúde. Salvador: EDUFBA; Rio de Janeiro: Fiocruz; 2005; p. 41-64. 
Merces, NPdas Atitudes de estudantes de psicologia acerca do álcool, do alcoolismo e do alcoolista. 2013. [dissertação]. São Paulo: Escola de Enfermagem de São Paulo, Universidade de São Paulo, São Paulo. [Citado 2013 out, 06].

Mercier L, Landry $M$, Corbière $M$, Perreault $M$. Measuring clients perception as outcome measurement. In: Roberts AR, Yeager KR, editors. Evidence-based Practice Manual: Research an outcome Measures in Health and Human Services. New York: Oxford University Press; 2004. p. 904-9.

Monteiro CFS, Fé LCM, Moreira MAC, Albuquerque IEM, Silva MG, Passamani MC. Perfil sociodemográfico e adesão ao tratamento de dependentes de álcool em CAPS-ad do Piauí. Esc Anna Nery. 2011; 15(1):90-5.

Nascimento AF, Galvanese ATC. Avaliação da estrutura dos Centros de Atenção Psicossocial do município de São Paulo. Rev Saúde Pública. 2009; 43(1):8-15.

Nemes MIB. Avaliação em saúde: questões para o programa de DST/AIDS no Brasil. Rio de Janeiro: Associação Brasileira Interdisciplinar de AIDS; 2001.

Novaes HMD. Avaliação de programas, serviços e tecnologias em saúde. Rev Saúde Pública. 2000; 34(5):547-9.

Obid - Observatório Brasileiro de Informações sobre Droga. [Internet]. 2013. [citado em jun 2013]. Disponível em: http://www.obid.senad.gov.br/portais/OBID/index.php

Oliveira GN. O projeto terapêutico singular. IN: Campos GWS; Guerrero AVP (Org.). Manual de práticas na atenção básica: saúde ampliada e compartilhada. São Paulo: Aderaldo \& Rothschild, 2008. p. 283-97.

Onocko-Campos RT, Furtado JP. Entre a saúde coletiva e a saúde mental: um instrumental metodológico para avaliação da rede de Centros de Atenção Psicossocial (CAPS) do Sistema Único de Saúde. Cad Saúde Pública. 2006; 22(5):1053-62.

Onocko-Campos RT, Furtado JP, Passos E, Ferrer AL, Miranda L, Gama CAP. Avaliação da rede de centros de atenção psicossocial: entre a saúde coletiva e a saúde mental. Rev Saúde Pública. 2009; 43(Supl.1):16-22.

Passos SRL, Camacho LAB. Características da clientela de um centro de tratamento para dependência de drogas. Rev Saúde Pública, 1998;32(1): 64-71. 
Peixoto C, Pradol CHO, Rodrigues CP, Cheda JND, Mota LBT, Veras AB. Impacto do perfil clínico e sociodemográfico na adesão ao tratamento de pacientes de um Centro de Atenção Psicossocial a Usuários de Álcool e Drogas (CAPSad). J Bras Psiquiatr. 2010; 59:317-1.

Pelisoli CdaL, Moreira AK. Caracterização epidemiológica dos usuários do Centro de Atenção Psicossocial Casa Aberta. Rev Psiquiatr. 2005; 27(3):270-77.

Pereira MO, Souza JM, Costa AM, Vargas D, Oliveira MAF, Moura WN Perfil dos usuários dos serviços de saúde mental do município de Lorena - São Paulo. Acta Paul Enferm. 2012; 25(1):48-54.

Pillon SC, Dunn J, Laranjeira RR. Nurses Attitudes Towards Alcoholism: factor analysis of three commonly used scales. São Paulo Med J. 1999; 116(2):1661-6.

Pinsky I, Silva EA, Marques, AC, Formigoni ML. Abandono de tratamento por dependentes de álcool e drogas: um estudo qualitativo do motivo. Revista ABP-APAL. 1995; 17(4):150-4.

Pitta AM. Qualidade de serviços de saúde mental: desafios para a epidemiologia. J Bras Psiquiatr. 1996; 45(6):313-21.

Pratta EMM, Santos MA. O processo saúde-doença e a dependência química: interfaces e evolução. Psicol Teoria e Pesqui. 2009; 25(2):203-11.

Raupp L, Milnitsky-Sapiro C. Reflexões sobre concepções e práticas contemporâneas das políticas públicas para adolescentes: o caso da drogadição. Saude Soc. 2005; 14(2):60-8.

Rebouças D, Legay LF, Abelha L. Satisfação com o trabalho e impacto causado nos profissionais de serviços de saúde mental. Rev Saude Pública. 2007; 41(2):244-50.

Rebouças D, Abelha L, Legay LF, Lovisi GM. O trabalho em saúde mental: um estudo de satisfação e impacto. Cad Saúde Pública. 2008; 24(3):624-32.

Reis, EJFB et al. Avaliação da qualidade dos serviços de saúde: notas bibliográficas. Cad Saúde Pública. 1990; 6(1):50-61.

Renger R, Titcomb AA. Three-Step approach to teaching logic models. American J Evaluation. 2002; 23(4):493-503.

Rossi PH, Freeman HE, Lipsey MW. Evaluation: a systematic approach. Thousand Oaks: Sage Publications, 1999. 
Rowan MS. Logic models in primary care reform: navigating the evaluation. Canadian J Program Evaluation. 2000; 15(2):81-92.

Santos KBO. Estresse ocupacional e saúde mental: desempenho de instrumentos de avaliação em populações de trabalhadores da Bahia, Brasil. [dissertação]. Feira de Santana: Universidade Estadual de Feira de Santana; 2006.

Santos AM, Cardoso DAJ, Vieira DPB, Araújo FC, Farias HS, Mota SP, Monteiro JCMS, ET al. Análise dos níveis de satisfação de trabalhadores de saúde mental de um Hospital público de referência psiquiátrica em Belém (PA) Rev Baiana saúde pública. 2011;35(4):813-25.

Schmidt MB. Avaliação da qualidade de serviços de saúde mental um estudo de caso do CAPS Profeta Gentileza. Tese. Rio de Janeiro: Instituto de Medicina Social da Universidade do Estado do Rio de Janeiro; 2007.

Schmidt MB, Figueiredo AC. Acesso, acolhimento e acompanhamento: três desafios para o cotidiano da clínica em saúde mental. Rev Lat-Am Psicopat Fund. 2009; 12(1):130-40.

Schneider JF, Camatta MW, Nasi C, Kantorski LP, Wetzel C. Utilização da avaliação de quarta geração em um Centro de Atenção Psicossocial. Rev Gaúcha Enferm. 2009; 30(1):131-5.

Silva Filho JF, Cavalcanti MT, Cadilhe GM, Vilaça AT, Avancini E, Machado HO. Avaliação da qualidade de serviços de saúde mental no município de Niterói - RJ. A satisfação dos usuários como critério avaliador. J Bras Psiquiatr.1996; 45(7):393-402.

Silva MA, Bandeira M, Scalon JD, Quaglia MAC. Satisfação dos pacientes com os serviços de saúde mental: a percepção de mudanças como preditora. J Bras Psiquiatr. 2012;61(2):64-71.

Silva, MA, Percepção de mudança em função do tratamento e satisfação dos pacientes psiquiátricos em serviços de saúde mental. [Dissertação]. São João Del Rey: Departamento de Psicologia da Universidade Federal de São João del Rei, 2011.

Silveira DX. Drogas: "Fizemos a guerra contra o inimigo errado". Revista Fórum. [Internet]. 2013 [citado 2013 set 28]. Disponível em: http://revistaforum.com.br/blog/2013/09/drogas-fizemos-a-guerracontra-o-inimigo-errado/

Sobrinho JD. Avaliação institucional, instrumento da qualidade educativa: a experiência da Unicamp. In: Balzan NC, Sobrinho JD, organizadores. Avaliação institucional: teorias e experiências. $2^{\circ}$ ed. São Paulo: Cortez; 2000. p. 53-86. 
Stancato K, Zilli PT Fatores geradores da rotatividade dos profissionais de saúde: uma revisão da literatura. Rev Adm Saúde. 2010;12(47):87-99.

Tavares CMM, Sobral VRS. Avaliação das práticas de cuidar envolvendo arte no âmbito do Centro de Atenção Psicossocial (CAPS). Rev Min Enferm. 2005;9(2):121-25.

Vargas D. A construção de uma escala de atitudes frente ao álcool, ao alcoolismo e ao alcoolista: um estudo psicométrico. 2005. [tese]. Ribeirão Preto: Escola de Enfermagem de Ribeirão Preto, Universidade de São Paulo, Ribeirão Preto. [Citado 2013 jan, 07]. Disponível em: http://www.teses.usp.br/teses/disponiveis/22/22131/tde-25072005090632/

Vargas D, Labate RC. Atitudes de enfermeiros de hospital geral frente ao uso do álcool e alcoolismo. Rev Bras Enferm. 2006; $59(1): 47-51$.

Vargas D, Luis MAV. Construção e validação de uma escala de atitudes frente ao álcool, ao alcoolismo e ao alcoolista. Rev Latinoam Enfermagem. 2008; 16(5):101-8.

Vargas D. Atitudes de enfermeiros frente as habilidades de identificação para ajudar o paciente alcoolista. Rev Bras Enferm. 2010; 63(2):190-5.

Vargas D Versão reduzida da escala de atitudes frente ao álcool, alcoolismo e ao alcoolista: resultados preliminares Rev Esc Enferm USP. 2011; 45(4):918-25.

Vargas D. Atitudes de estudantes de enfermagem frente questões relacionadas ao álcool, alcoolismo e alcoolista. Acta Paul Enferm 2011b; 24(5):638-44.

Vargas D, Bittencourt MN. Álcool e alcoolismo: atitudes de estudantes de Enfermagem. Rev Bras Enferm. 2013; 66(1):84-9.

Vargas NIT, Zago MMF. El sufrimiento de la esposa en la convivência com el consumidor de bebida alcohólicas. Rev Lat-Am Enferm. 2008 13(n. esp):806-12.

Wetzel C, Kantorski LP. Avaliação de serviços em saúde mental no contexto da Reforma Psiquiátrica. Texto Contexto Enferm. 2004; 13(4):593-8. http://dx.doi.org/10.1590/S0104-07072004000400012.

World Health Organization (WHO) - Global Status Report on Alcohol. Geneva: World Health Organization; 2004. 
World Health Organization (WHO). Brazil socioeconomic context. 2011 [Internet].[Accessed 29 abr 2013]. Available in: http://www.who.int/substance_abuse/publications/global_alcohol_rep ort/profiles/bra.pdf

Wykes T, Stevens W, Everitt B. Stress in community care teams: will it affect the sustainability of community care? Soc Psychiatry Psychiatr Epidemiol. 1997; 32:398-407. 
APENNDICES 


\title{
APÊNDICES
}

\section{APÊNDICE 1 - Pedido de autorização institucional}

\author{
São Paulo, de de 2013.
}

Prezado(a) Sr(a):

Venho por meio desta, solicitar autorização para que eu Guilherme Correa Barbosa, doutorando do Programa de Pós-Graduação em Enfermagem da Escola de Enfermagem da Universidade de São Paulo, possa realizar a pesquisa intitulada: "Avaliação do Centro de Atenção Psicossocial Álcool e outras Drogas do município de Botucatu", sob a Coordenação da Prof. ${ }^{a}$ Dr. ${ }^{a}$ Márcia Aparecida Ferreira de Oliveira.

$\mathrm{Na}$ oportunidade, esclareço que a pesquisa será realizada no CAPSad do município de Botucatu, com os coordenadores, membros das equipes técnicas, usuários e familiares. A pesquisa tem por finalidade avaliar a qualidade da atenção em saúde oferecida nos CAPSad.

O objetivo geral da pesquisa é avaliar quantitativamente o Centro de Atenção Psicossocial Álcool e outras Drogas do município de Botucatu; por meio da sua estrutura, processo de trabalho, organização da atenção em saúde mental e resultados atingidos.

Agradeço antecipadamente, e me coloco à disposição para quaisquer esclarecimentos que se fizerem necessários.

Prof. ${ }^{a}$ Dr. ${ }^{\text {a }}$ Márcia Aparecida Ferreira de Oliveira

II. ${ }^{\text {mo }}$ Sr. XXXXX

Coordenador do Centro de Atenção

Psicossocial em Álcool e outras Drogas 
APÊNDICE 2 - Consentimento livre e informado para participação na pesquisa do coordenador e técnicos do CAPS

(Resolução 196/96 do Ministério da Saúde)

Nome do entrevistado

Pesquisadora: Guilherme Correa Barbosa - Doutorando (F: 14 8121-1097 e-mail guilhermebao@usp.br) no Programa de PósGraduação da Escola de Enfermagem da Universidade de São Paulo.

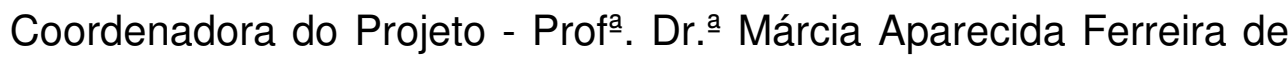
Oliveira - Professora Associada do Departamento de Enfermagem Materno-Infantil e Psiquiátrica da Escola de Enfermagem da Universidade de São Paulo marciaap@usp.br

Estamos apresentando ao Sr. (a) o presente termo de consentimento livre e informado caso queira e concorde em participar de nossa pesquisa, intitulada "Avaliação do Centro de Atenção Psicossocial em Álcool e outras Drogas do município de Botucatu", autorizando a minha observação durante o seu trabalho no CAPS, a aplicação de questionários referentes às etapas de coleta de dados do estudo e a consulta aos prontuários. Esclarecemos que o referido estudo tem como objetivo: avaliar quantitativamente os Centros de Atenção Psicossocial II ad do município de Botucatu.

Garantimos o sigilo e anonimato dos sujeitos desse estudo, o livre acesso aos dados, bem como a opção de não participação em qualquer uma das fases do processo. Caso você tenha disponibilidade e interesse em participar como sujeito deste estudo, autorize e assine o consentimento abaixo:

Pelo presente consentimento livre e informado, declaro que fui informado (a) de forma clara, dos objetivos, da justificativa, dos instrumentos utilizados na presente pesquisa. Declaro que aceito 
voluntariamente participar do estudo e autorizo o uso do gravador nos momentos em que se fizer necessário.

Fui igualmente informado(a) da garantia de: solicitar resposta a qualquer dúvida com relação aos procedimentos; do acesso em qualquer momento às informações sobre riscos e benefícios relacionados à pesquisa; da liberdade de retirar meu consentimento em qualquer momento do estudo sem que isto me traga qualquer prejuízo do meu atendimento; do sigilo e anonimato; e de que não sofrerei qualquer prejuízo, caso me negue a participar do estudo ou interrompa minha participação.

Enfim, foi garantido que todas as determinações ético-legais serão cumpridas antes, durante e após o término desta pesquisa. LOCAL/DATA:

ASSINATURA DO PARTICIPANTE:

Em caso de dúvidas ou denúncias sobre irregularidades éticas, entrar em contato com o Comitê de Ética em Pesquisa da Escola de Enfermagem de São Paulo - CEP/EEUSP através do telefone (11) 3061-7548, ou do e mail: edipesq@usp.br, endereço Av. Dr. Enéas de Carvalho Aguiar, 419 - 05403-000 São Paulo - SP. 


\title{
APÊNDICE 3 - Carta-convite do responsável legal dos participantes da pesquisa
}

\author{
São Paulo, de de 2012.
}

Prezado(a) $\operatorname{Sr}(\mathrm{a})$ :

O convidamos a participar, bem como autorizar a participação de seu familiar, usuário do CAPSad, de uma pesquisa que eu, Guilherme Correa Barbosa - doutorando, vinculado ao Programa de Pós-Graduação em Enfermagem da Escola de Enfermagem da Universidade de São Paulo, realizaremos intitulada: “Avaliação do Centro de Atenção Psicossocial Álcool e outras Drogas do município de Botucatu", sob a Coordenação da Prof. a Dr. a Márcia Aparecida Ferreira de Oliveira.

A pesquisa tem por finalidade avaliar a qualidade da atenção em saúde oferecida nos CAPSad, por meio da sua estrutura, processo de trabalho, organização da atenção em saúde mental e resultados atingidos.

Você e seu familiar, que é usuário do CAPSad, são livres para expressarem suas ideias e poderão fazer questionamentos acerca do estudo e sobre a participação de vocês nele. Se tiverem alguma dúvida procuraremos esclarecê-la em qualquer fase da pesquisa.

A sua participação e de seu familiar, usuário do CAPS, é voluntária, sendo assim vocês não são obrigados (as) a participarem do estudo. Vocês têm o direito de abandonar a pesquisa em qualquer etapa, e em momento algum isto lhes trará prejuízos ou constrangimentos. Se vocês se negarem a participar da pesquisa ou interrompê-la, não sofrerão nenhum prejuízo.

A sua participação na pesquisa, bem como de seu familiar, usuário do CAPS, não oferece a vocês nenhum risco e o benefício que ela trará a você, seu familiar e trabalhadores do CAPSad está relacionado à melhoria do atendimento e tratamento no CAPS, uma vez que os resultados do estudo ajudarão a melhorar o trabalho que 
é realizado no CAPS, no sentido de melhorar a qualidade de vida de todos os envolvidos.

Os dados da presente pesquisa serão registrados e analisados; posteriormente, no momento em que forem publicados, seus nome não constarão nos registros. Assim, a identidade de vocês não será revelada em nenhum momento, nem mesmo na fase de publicação do estudo.

Agradecemos antecipadamente, e nos colocamos à disposição para quaisquer esclarecimentos que se fizerem necessários.

Guilherme Correa Barbosa

Doutorando

Contatos do Comitê de Ética em Pesquisa da Escola de

Enfermagem de São Paulo - CEP/EEUSP - Av. Dr. Enéas de

Carvalho Aguiar, 419 - 05403-000 - São Paulo - SP. Informações/

dúvidas: Fone: (11) 3061-7548, e-mail: edipesq@usp.br 


\section{APÊNDICE 4 - Consentimento livre e informado para participação na pesquisa do participante ou do representante legal do participante (Resolução 196/96 do Ministério da Saúde)}

Nome do entrevistado

Pesquisador: Guilherme Correa Barbosa - Doutorando (F: 14 8121-1097 e-mail guilhermebao@usp.br) no Programa de PósGraduação da Escola de Enfermagem da Universidade de São Paulo.

Coordenadora do Projeto - Profạ. Dr. ․ㅡ Márcia Aparecida Ferreira de Oliveira - Professora Associada do Departamento de Enfermagem Materno-Infantil e Psiquiátrica da Escola de Enfermagem da Universidade de São Paulo marciaap@usp.br

Estamos apresentando ao Sr. (a) o presente termo de consentimento livre e informado caso queira e concorde em participar de nossa pesquisa, intitulada "Avaliação do Centro de Atenção Psicossocial em Álcool e outras Drogas do município de Botucatu", autorizando a minha observação durante a sua permanência no CAPS, a realização de uma entrevista por meio da aplicação de questionários referentes às etapas de coleta de dados do estudo e à consulta aos prontuários. Esclarecemos que o referido estudo tem como objetivo: avaliar o Centro de Atenção Psicossocial Il ad do município de Botucatu.

Garantimos o sigilo e anonimato dos sujeitos desse estudo, o livre acesso aos dados, bem como a opção de não participação em qualquer uma das fases do processo. Caso você tenha disponibilidade e interesse em participar como sujeito deste estudo, autorize e assine o consentimento abaixo:

Pelo presente consentimento livre e informado, declaro que fui informado (a) de forma clara, dos objetivos, da justificativa, dos 
instrumentos utilizados na presente pesquisa. Declaro que aceito voluntariamente participar do estudo e autorizo o uso do gravador nos momentos em que se fizer necessário.

Fui igualmente informado(a) da garantia de: solicitar resposta a qualquer dúvida com relação aos procedimentos; do acesso em qualquer momento às informações sobre procedimentos, riscos e benefícios relacionados à pesquisa; da liberdade de retirar meu consentimento em qualquer momento do estudo sem que isto me traga qualquer prejuízo do meu atendimento; do sigilo e anonimato; e de que não sofrerei qualquer prejuízo, caso me negue a participar do estudo ou interrompa minha participação.

Enfim, foi garantido que todas as determinações ético-legais serão cumpridas antes, durante e após o término desta pesquisa. LOCAL/DATA:

ASSINATURA DO PARTICIPANTE:

Em caso de dúvidas ou denúncias sobre irregularidades éticas, entrar em contato com o Comitê de Ética em Pesquisa da Escola de Enfermagem de São Paulo - CEP/EEUSP através do telefone (11) 3061-7548, ou do e mail: edipesq@usp.br, endereço Av. Dr. Enéas de Carvalho Aguiar, 419 - 05403-000 São Paulo - SP. 
ANEXOS 


\title{
ANEXOS
}

\section{ANEXO 1 - Parecer do Comitê de Ética em Pesquisa.}

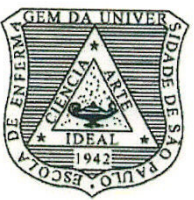

\author{
UNIVERSIDADE DE SÃO PAULO \\ ESCOLA DE ENFERMAGEM \\ Av. Dr. Enéas de Carvalho Aguiar, 419 - CEP 05403-000 \\ Tel.: (011) 3061-7548/8858 - Fax: (011) 3061-7548 - \\ Såo Paulo - SP - Brasi
}

São Paulo, 24 de maio de 2011.

Ilm. ${ }^{a}$ Sr. ${ }^{a}$

Maria Odete Pereira

Ref.: Processo n 1001/2011/CEP-EEUSP - - SISNEP - CAAE: 0005.0.196.000-11

Prezada Senhora,

Em atenção à solicitação referente à análise do projeto "Metodologias de avaliação e medidas políticas de impacto para ações em álcool e outras drogas", a ser desenvolvido no Departamento de Enfermagem Materno-Infantil e Psiquiátrico desta Instituição, sob a responsabilidade da Professora Doutora Márcia Aparecida Ferreira de Oliveira, foi considerado aprovado pelo Comitê de Ética em Pesquisa da Escola de Enfermagem da Universidade de São Paulo (CEP/EEUSP).

Analisado sob o aspecto ético-legal, atende às exigências da Resolução $n^{\circ}$ 196/96 do Conselho Nacional de Saúde.

Esclarecemos que após o término da pesquisa, os resultados obtidos deverão ser encaminhados ao CEP/EEUSP, para serem anexados ao processo.

Atenciosamente,

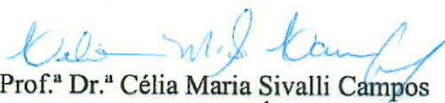

Coordenadora do Comitê de Ética em Pesquisa da

Escola de Enfermagem da Universidade de São Paulo 


\section{ANEXO 2 - Instrumento para o coordenador do serviço.}

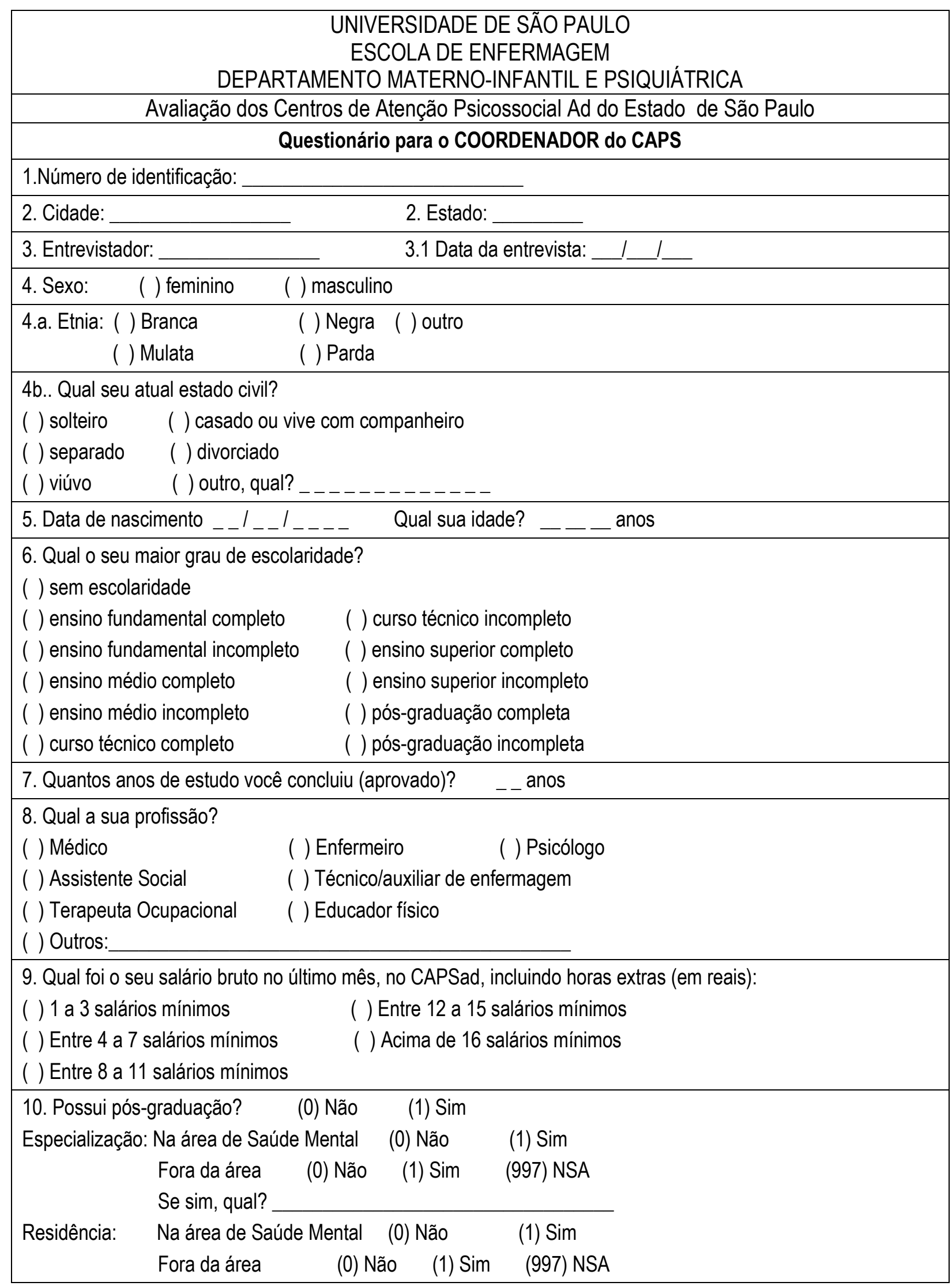




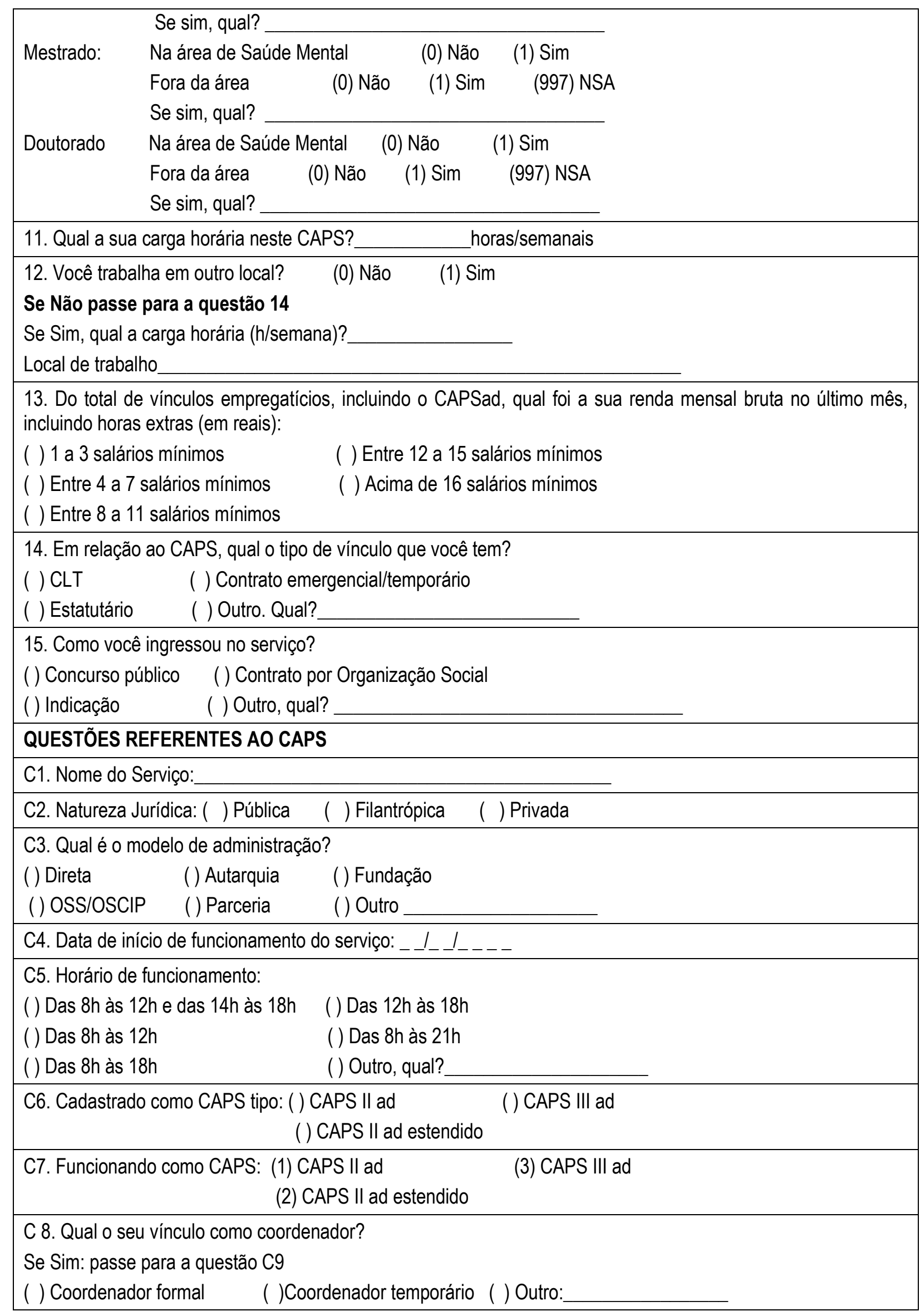




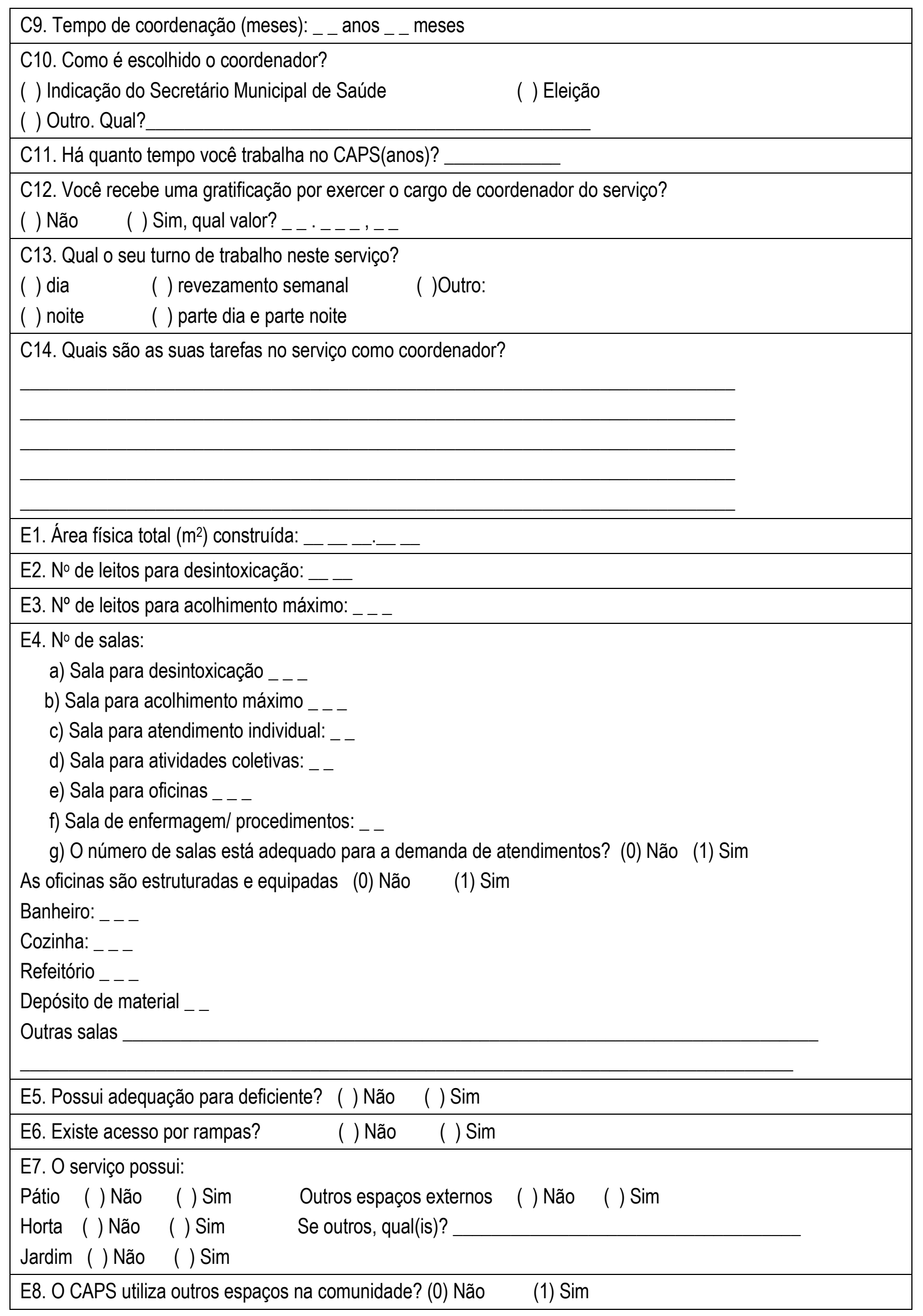




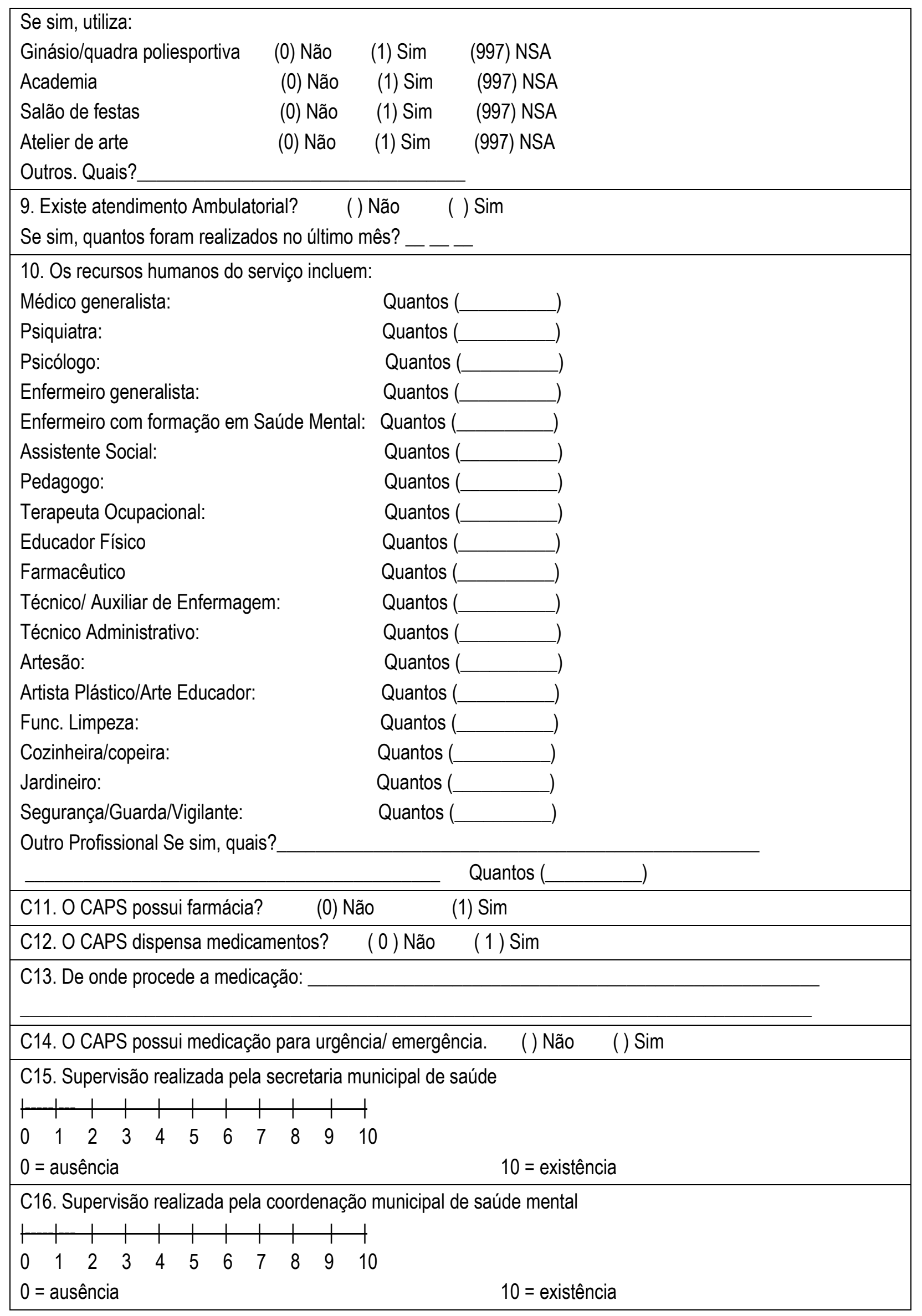




\begin{tabular}{|c|}
\hline 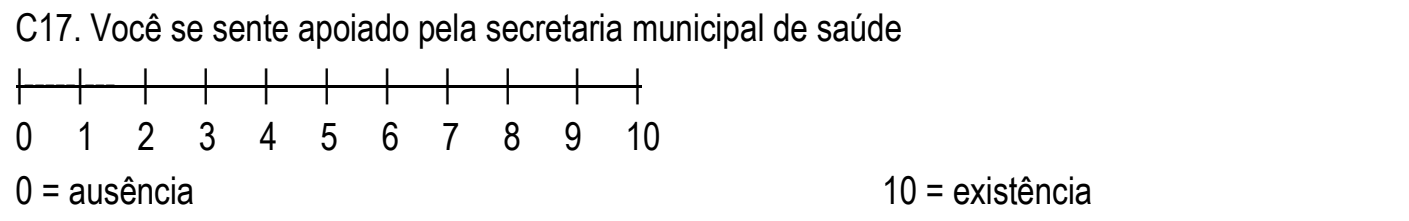 \\
\hline 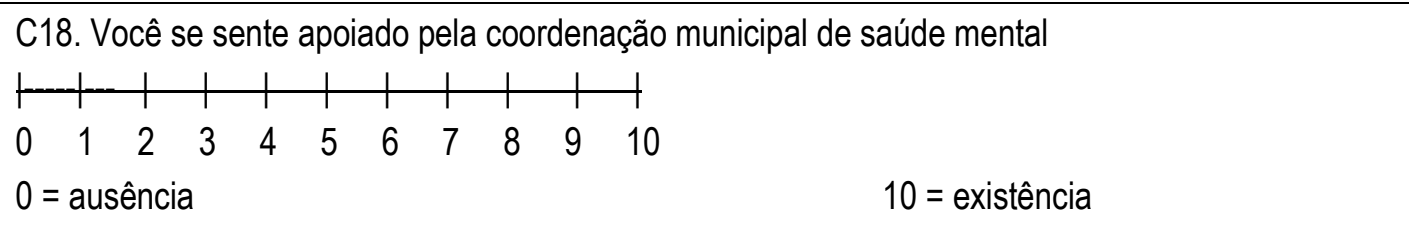 \\
\hline 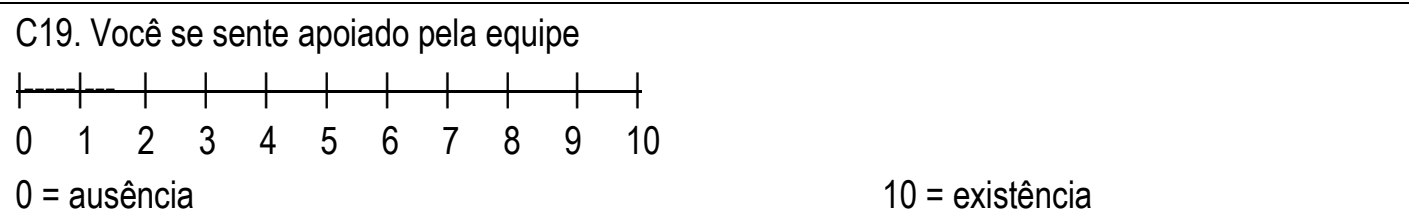 \\
\hline 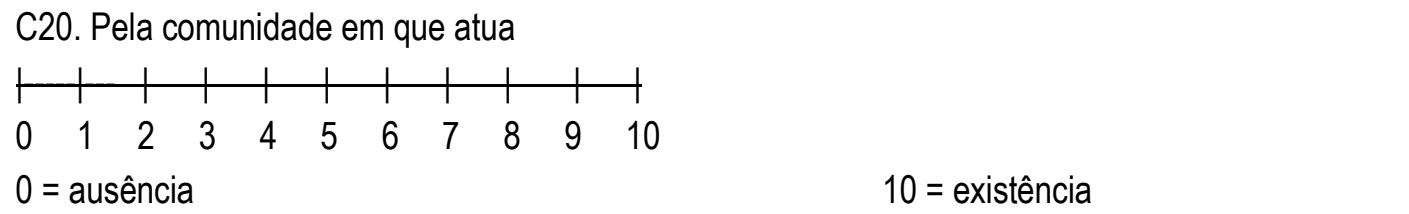 \\
\hline $\begin{array}{l}\text { P1. Existe articulação com recursos do território? (0) Não (1) Sim } \\
\text { Se sim, quais? }\end{array}$ \\
\hline $\begin{array}{lll}\text { P2. Existe articulação com rede básica? } & \text { (0) Não } & \text { (1) Sim }\end{array}$ \\
\hline $\begin{array}{l}\text { P3. Existe outras instâncias de articulação } \quad \text { (0) Não } \\
\text { Se sim, quais? }\end{array}$ \\
\hline $\begin{array}{l}\text { P4. Esse serviço esta inserido na Rede de Atenção Psicossocial (RAPS)? } \\
\begin{array}{ll}\text { (0) Não } & \text { (1) Sim }\end{array}\end{array}$ \\
\hline $\begin{array}{l}\text { P5. Possui avaliação do usuário? } \\
\begin{array}{lllllll}\text { Clínica } & \text { ( ) Não } & \text { ( ) Sim } & & & & \\
\text { Psicológica } & \text { ( ) Não } & \text { ( ) Sim } & & \text { Outras } & & \\
\end{array}\end{array}$ \\
\hline P6. Oferecem atendimento individualizado no serviço? () Não () Sim \\
\hline P7. Oferecem atendimento individualizado no domicílio? () Não () Sim \\
\hline 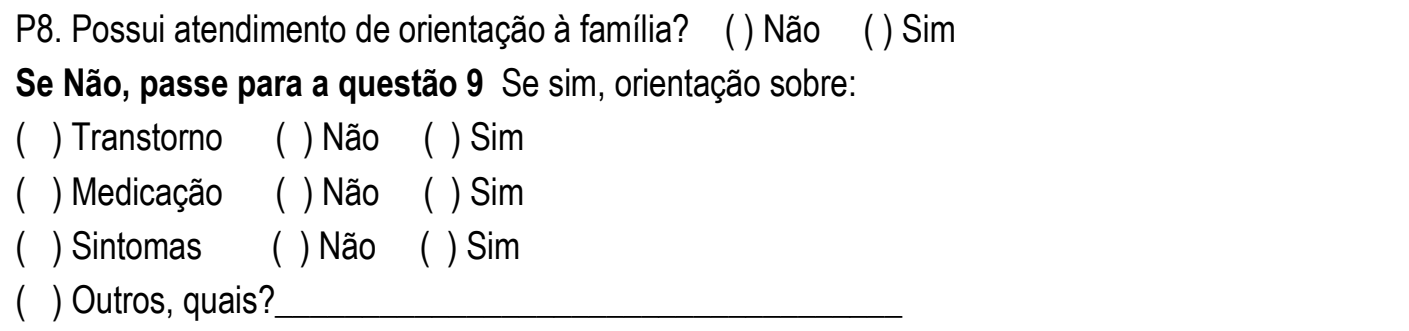 \\
\hline P9. Existe grupo de familiares no serviço? ( ) Não ( ) Sim Se "Não", passe para a questão 11 \\
\hline $\begin{array}{l}\text { P10. Se sim, qual a abordagem desses grupos de família? } \\
\begin{array}{lllll}\text { Manejo } & \text { ( ) Não } & \text { ( ) Sim } & & \\
\text { Apoio psicológico estimulando interação da família e usuário } & \text { ( ) Não } & \text { ( ) Sim } \\
\text { Espaço aberto para sugestões sobre o serviço } & \text { ( ) Não } & \text { ( ) Sim }\end{array} \\
\begin{array}{lllll}\text { Patologia } & \text { ( ) Não } & \text { ( ) Sim } & & \end{array} \\
\begin{array}{lllll}\text { Tratamento } & \text { ( ) Não } & \text { ( ) Sim } & & \end{array}\end{array}$ \\
\hline
\end{tabular}




\begin{tabular}{|c|c|c|}
\hline \multicolumn{3}{|c|}{$\begin{array}{lll}\text { Outros } & \text { ( ) Não ( ) Sim }\end{array}$} \\
\hline \multicolumn{3}{|c|}{ 'P11. A secretaria de Saúde / CAPS fornece as medicações prescritas? ( 0 ) Não ( 1 ) Sim } \\
\hline \multicolumn{3}{|c|}{ Se Não, passe para a questão 12} \\
\hline \multicolumn{3}{|c|}{ Se sim, quais? } \\
\hline Estimulantes: & Dextro-anfetamina & ( 0 ) Não (1) Sim \\
\hline \multirow[t]{8}{*}{ Antipsicóticos: } & Clorpromazina (amplictil) & (1) $\operatorname{Sim}$ \\
\hline & Flufenzaina (prolixin) & ( 0 ) Não (1) Sim \\
\hline & Haloperidol (haldol) & ( 0 ) Não (1) Sim \\
\hline & Clozapina (clozaril) & ( 0 ) Não (1) Sim \\
\hline & Risperidona (risperdal) & ( 0 ) Não (1) Sim \\
\hline & Olanzapina (ziprexa) & ( 0 ) Não (1) Sim \\
\hline & Ziprazidona (abilify) & ( 0 ) Não (1) Sim \\
\hline & _evopromazepina (Neozine) & ( 0 ) Não \\
\hline \multicolumn{3}{|c|}{ Antiparkinsonianos ou medicamentos extrapiramidais: } \\
\hline & Biperideno (akineton) & ( 0 ) Não (1) Sim \\
\hline & Propranolol & ( 0 ) Não (1) Sim \\
\hline & Prometazina (fenergan) & ( 0 ) Não (1) Sim \\
\hline \multirow[t]{9}{*}{ Antidepressivos } & Amitriptilina (tryptanol) & ( 0 ) Não (1) Sim \\
\hline & Imipramina (tofranil) & ( 0 ) Não (1) Sim \\
\hline & Nortriptilina (pamelor) & ( 0 ) Não (1) Sim \\
\hline & Fluoxetina (prozac) & ( 0 ) Não (1) Sim \\
\hline & Paroxetina (aropax) & ( 0 ) Não (1) Sim \\
\hline & Sertralina (zoloft) & ( 0 ) Não (1) Sim \\
\hline & Donaren & ( 0 ) Não (1) Sim \\
\hline & Citalopram & ( 0 ) Não (1) Sim \\
\hline & Venlafaxina & ( 0 ) Não (1) Sim \\
\hline \multicolumn{3}{|c|}{ Reguladores de humor: } \\
\hline & Carbonato de lítio (carbolitium) & ( 0 ) Não (1) Sim \\
\hline & Ácido valpróico & ( 0 ) Não (1) Sim \\
\hline & _amotrigina & ( 0 ) Não (1) Sim \\
\hline & Topiramato & ( 0 ) Não (1) Sim \\
\hline \multirow[t]{3}{*}{ Anticonvulsivantes: } & : Carbamazepina (tegretol) & ( 0 ) Não (1) Sim \\
\hline & Fenobarbital (gardenal) & ( 0 ) Não (1) Sim \\
\hline & Fenitoína (hidantal) & ( 0 ) Não \\
\hline
\end{tabular}




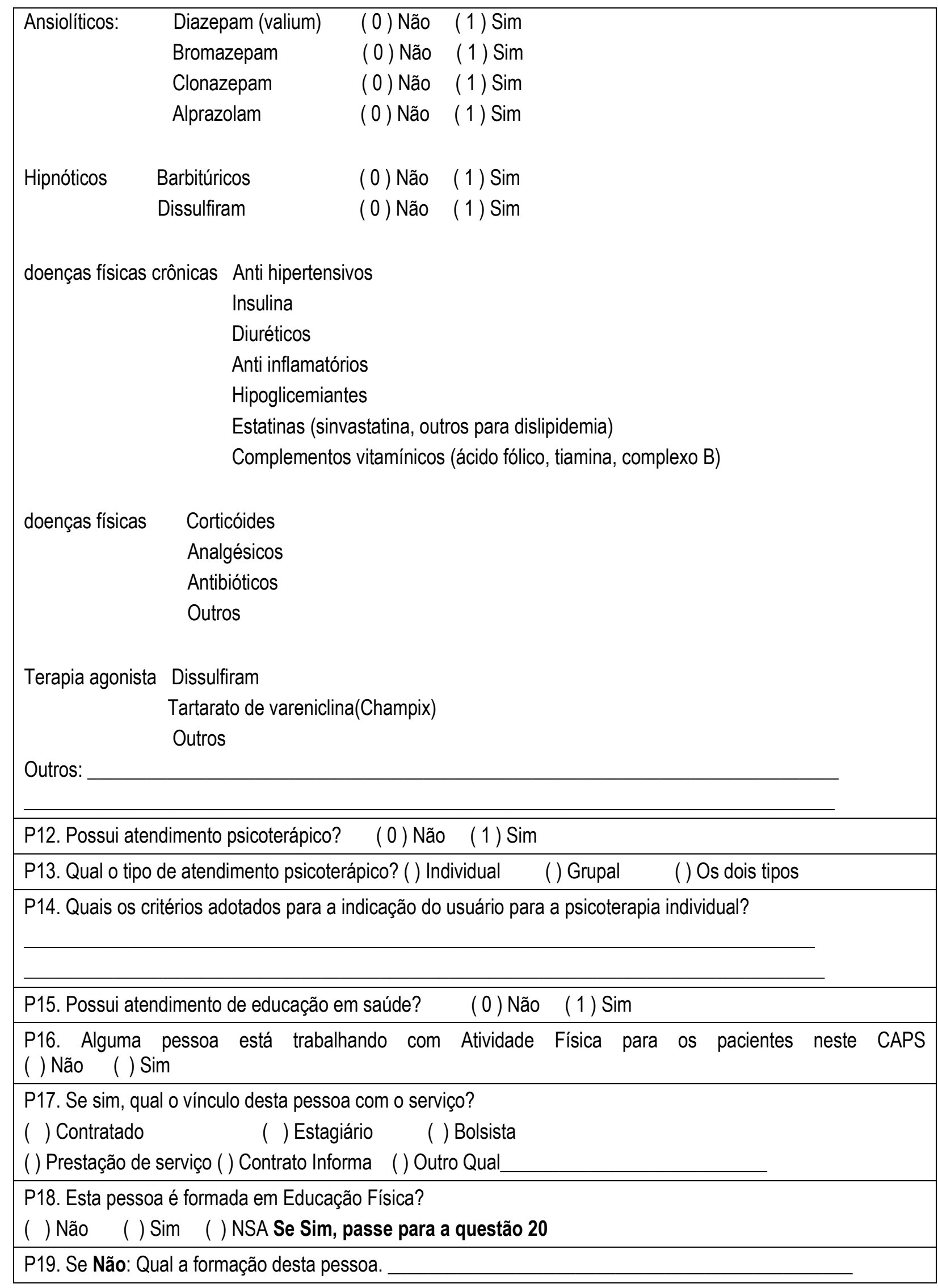


P20. Quais atividades relacionadas à Atividade Física são oferecidas? (cite todas as que forem oferecidas)

P21. Em média, quantas vezes por semana as atividades físicas são oferecidas?
(1) Uma vez por semana
( 2 ) Duas vezes por semana
( 3 ) Três vezes por semana
( 4 ) Quatro vezes por semana
( 5 ) Cinco vezes por semana
(997) NSA

P22. Na última semana, quantos pacientes foram atendidos por este CAPS pacientes

Dos pacientes que foram atendidos na última semana, quantos participaram das atividades físicas oferecidas? _ _ pacientes

P23. Realiza assembleias? $\quad$ ( 0 ) Não $\quad$ (1) Sim Se Não, passe para a questão 27

P24. Há registro formal das assembleias? ( 0 ) Não (1) Sim

P25. Se o CAPS realizar assembleias, qual a periodicidade? (1) Semanal

( ) Quinzenal ( ) Mensal ( )Bimestral ( ) Outra. Qual?

P26. Quem participa das assembleias?
(1) Usuário
( 0 ) Não
(1) Sim
( 2 ) Familiares
( 0 ) Não
(1) $\operatorname{Sim}$
(3) Equipe
( 0 ) Não
(1) Sim
( 4 ) Comunidade
( 0 ) Não
(1) $\operatorname{Sim}$
(999) Outros
( 0 ) Não
(1) Sim Quais?

P27. O serviço realiza projetos de geração de renda? ( )Não

Se Não, porque?

P28. Qual é a regulamentação dessa atividade ( )Cooperativas ( ) ONGS ( ) Outro

P29. Possui abordagem interdisciplinar? ( 0 ) Não (1) Sim

P30. O serviço possui algum mecanismo para evitar internações em situações de crise ( ) Não ( ) Sim

Se SIM, quais mecanismos? Cite pelo menos 3

\section{Se NÃO, para onde encaminha? ( ) Pronto Socorro}

( ) Emergência Psiquiátrica （ ) Internação em Hospital Geral

( ) Internação em Hospital Psiquiátrico ( ) Outro

P31. Como são indicadas as internações. ( )Em reunião de equipe $\quad$ (2) Pelo médico

( ) Outros, quais?

P32. Excluindo as situações de emergências clínicas e psquiátricas, quais são os critério para internação em AOD neste caps?

() A voluntariedade do usuário

( ) $O$ esgotamento todas as possibilidades de tratamento no CAPS

(3) Outro, quais?

P33. Para onde são encaminhadas as internações em AOD?

Enfermaria especializada em AOD em hospital geral ( ) Não ( ) Sim 


\begin{tabular}{|lcc}
\hline Comunidade terapêutica & ( ) Não & ( ) Sim \\
Hospital Psiquiátrico & ( ) Não & ( ) Sim \\
Outros, quais? & & \\
\hline
\end{tabular}

P34. Cite as 3 principais dificuldades em relação ao fluxo de internação neste CAPS?

P35. Quanto tempo se espera pela vaga fornecida pela central de vagas?
() Até 3 dias
() Até 1 semana
() Até 2 semanas
() Mais que 2 semanas
() outros,

36. Há outra via de acesso, não citada, para a obtenção de vaga de internação （） Não （） Sim

Se SIM, quais

37. Quem participa das reuniões de equipe?
Médico:
( 0 ) Não (1) Sim
Psiquiatra:
( 0 ) Não (1) Sim
Psicólogo:
( 0 ) Não (1) Sim
Enfermeiro:
( 0 ) Não (1) Sim
Assistente Social:
( 0 ) Não (1) Sim
Terapeuta ocupacional:
( 0 ) Não (1) Sim
Técnico ou Auxiliar de Enfermagem:
( 0 ) Não (1) Sim
Técnico Administrativo:
( 0 ) Não (1) Sim
Artista Plástico:
( 0 ) Não (1) Sim

Se existir outro profissional, liste-os

P38. Qual a periodicidade das reuniões de equipe?
(1) Semanal
( 2 ) Quinzenal
( 3 ) Mensal
( 4 ) Bimestral
( 5 ) Conforme a necessidade
( 6 ) Não realiza

P39. Qual a duração dessas reuniões? (tempo médio em minutos)

P40. Abordam questões administrativas? ( 0 ) Não (1) Sim

Se Não, passe para a questão 42

P41. Se sim com que frequência?
(1) Semanal
( 2 ) Quinzenal
( 3 ) Mensal
( 4 ) Bimestral
(999) Outro (especificar):

P42. Abordam questões técnicas (discussões de Projetos Terapêuticos Singulares (PTS) discussões de casos, discussões sobre medicações)?
( 0 ) Não
(1) $\mathrm{Sim}$
(997) NSA

Se Não, passe para a questão 44

P43. Com qual frequência?
(1) Semanal
( 2 ) Quinzenal
( 3 ) Mensal
(4) Bimestral
(999) Outro (997) NSA 


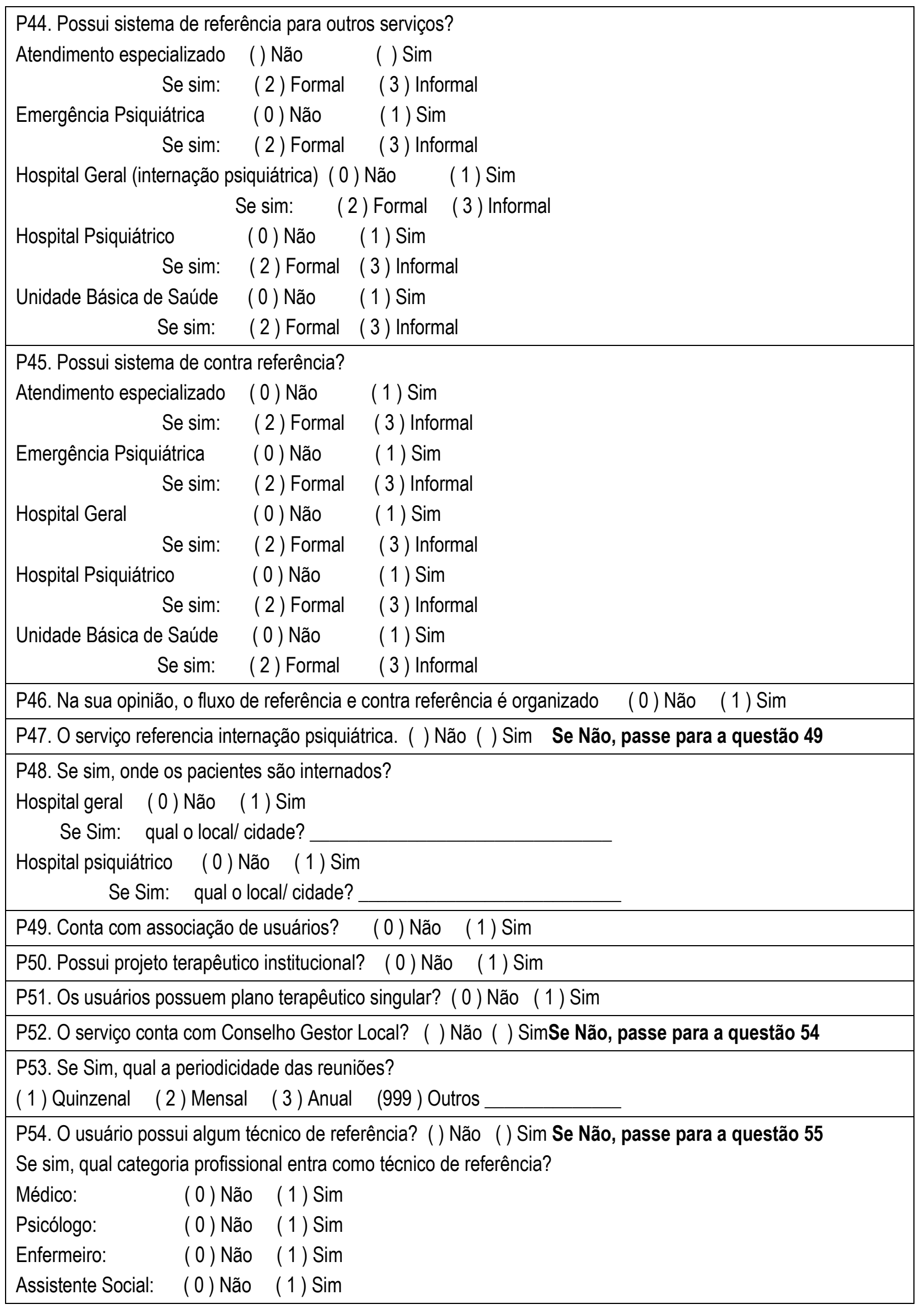




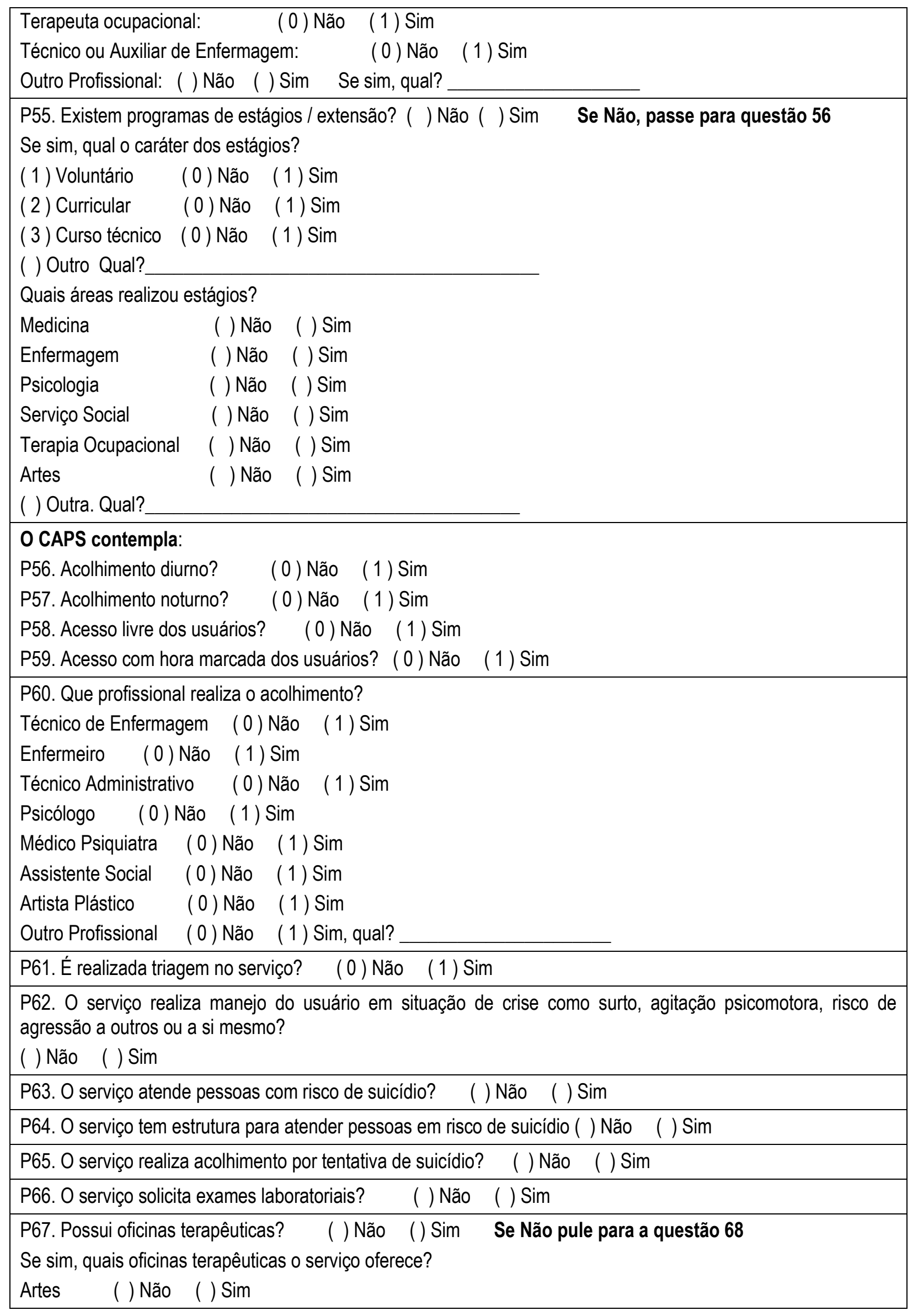




\begin{tabular}{|c|c|}
\hline & $\begin{array}{llll}\text { Música } & \text { ( ) Não } & \text { ( ) Sim } \\
\text { Dança } & \text { ( ) Não } & \text { ( ) Sim } \\
\text { Geração de renda } & \text { ( ) Não ( ) Sim } \\
\text { Higiene e cuidados pessoais ( ) Não ( ) Sim } \\
\text { Outra ( ) Não } & \text { (1) Sim, especificar_ }\end{array}$ \\
\hline & 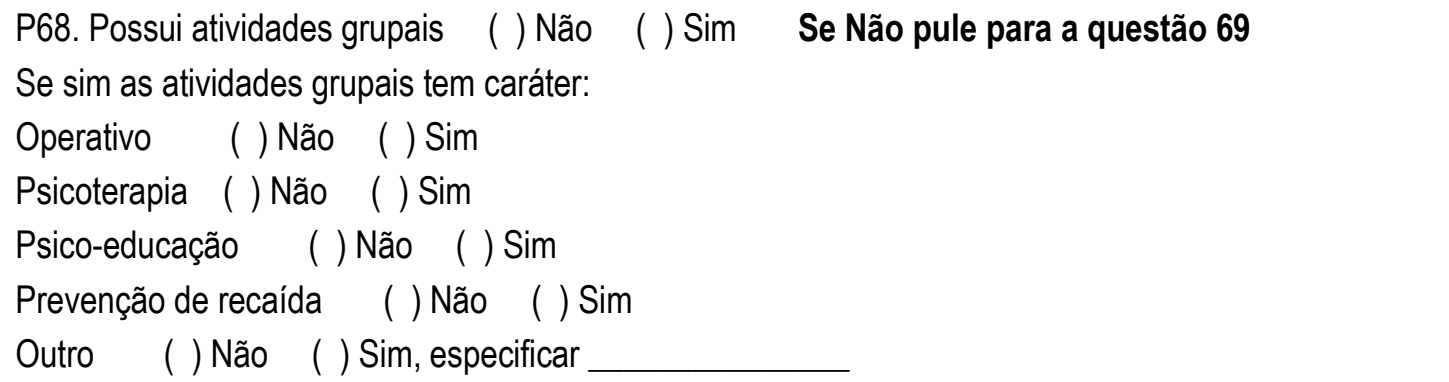 \\
\hline & 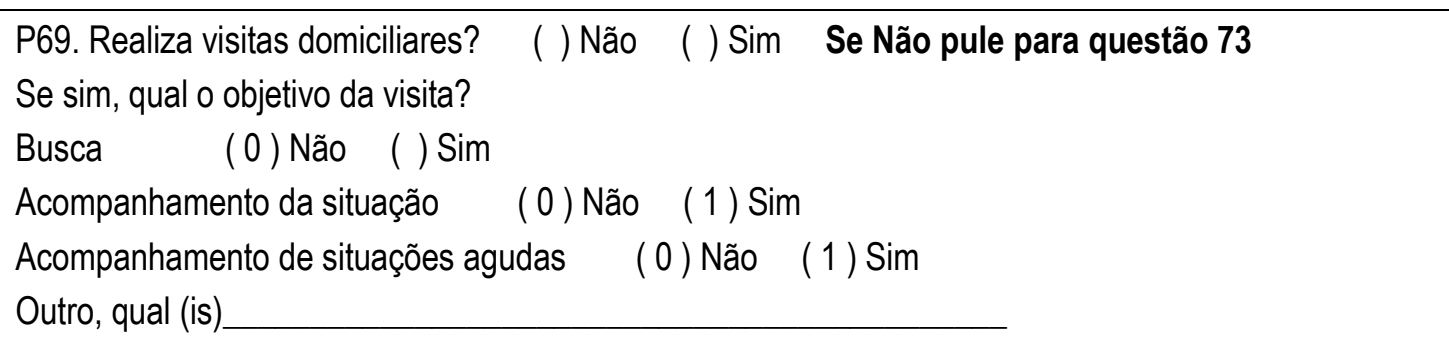 \\
\hline & $\begin{array}{lll}\text { P70. Qual profissional realiza visitas domiciliares? } \\
\text { Médico } & \text { ( ) Não } & \text { ( ) Sim } \\
\text { Psicólogo } & \text { ( ) Não } & \text { ( ) Sim } \\
\text { Enfermeiro } & \text { ( ) Não } & \text { ( ) Sim } \\
\text { Assistente Social } & \text { ( ) Não } & \text { ( ) Sim } \\
\text { Terapeuta Ocupacional } & \text { ( ) Não } & \text { ( ) Sim } \\
\text { Técnico ou Auxiliar de Enfermagem } & \text { ( ) Não } & \text { ( ) Sim } \\
\text { Outro profissional, qual(is)? } & & \\
\end{array}$ \\
\hline & $\begin{array}{l}\text { P71. Com que frequência são realizadas? } \\
\begin{array}{llll}\text { ( ) Semanal } \quad \text { ( ) Quinzenal } & \text { ( ) Mensal } & \text { ( ) Bimestral } \\
\text { ( ) Conforme a necessidade } & \text { ( ) Outro. Qual? } & \end{array}\end{array}$ \\
\hline & $\begin{array}{l}\text { P72. O serviço possui transporte para a realização das visitas domiciliares. ( ) Não ( ) Sim } \\
\text { Se sim: com que frequência o transporte está disponível para uso do serviço? } \\
\begin{array}{lll}\text { ( ) Todos os dias } & \text { ( ) Duas vezes por semana } & \text { ( ) Três vezes por semana } \\
\text { () Outro Qual? } & \end{array}\end{array}$ \\
\hline & 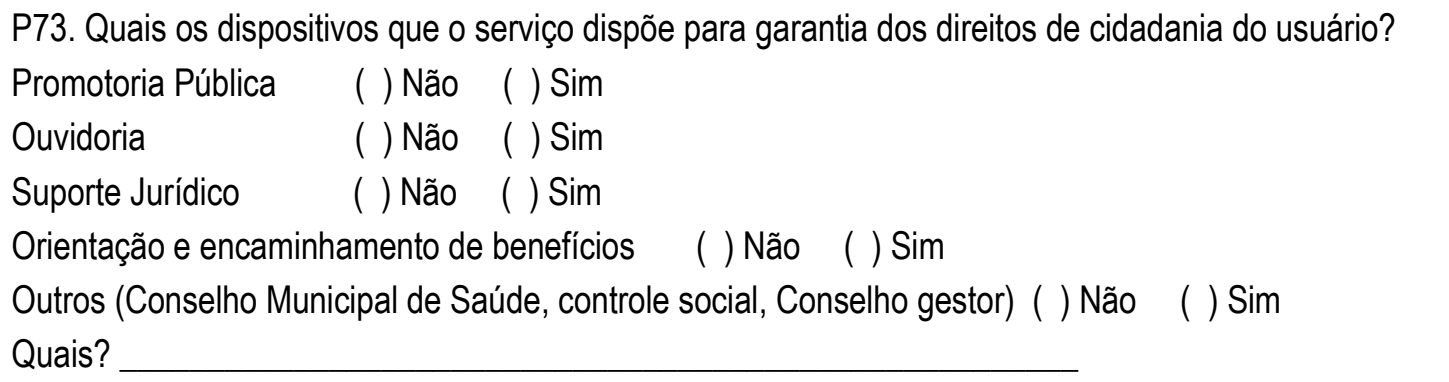 \\
\hline
\end{tabular}


P74. A equipe recebe:

Supervisão Técnica ( ) Não ( ) Mensalmente ( ) Raramente

( ) Outro Qual?

Supervisão Administrativa ( ) Não ( ) Mensalmente ( ) Raramente

( ) Outro Qual?

Consultoria ( ) Não ( ) Mensalmente ( ) Raramente

( ) Outro Qual?

Orientação Técnica ( ) Não (1) Mensalmente ( ) Raramente

( ) Outro Qual?

Orientação Administrativa ( ) Não ( ) Mensalmente ( ) Raramente

( ) Outro Qual?

P75. O serviço conta com algum mecanismo de avaliação sistemática. ( ) Não ( ) Sim

Se sim, quais mecanismos são utilizados.

P76. Há vínculo com Serviços Residenciais Terapêuticos ou Casa de Acolhimento Transitória?

$$
\text { ( ) Não ( ) Sim }
$$

P77. Há critérios de acesso ao CAPS como encaminhamento, faixa etária, diagnóstico, território, gravidade?

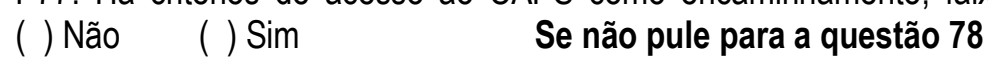

Se sim, quais são os critérios de acesso ao CAPS.

P78. Os usuários recebem alta do serviço? ( ) Não ( ) Sim Se Não, passe para a questão 79

Se sim, quais os critérios para alta?

$\begin{array}{lll}\text { Abandono ou Alta solicitada } & \text { ( ) Não } & \text { ( ) Sim } \\ \text { Melhora } & \text { ( ) Não } & \text { ( ) Sim } \\ \text { Transferência para outro serviço } & \text { ( ) Não } & \text { ( ) Sim }\end{array}$

Não aderência do usuário/família ao tratamento Proposto

Outros, quais

( ) Não ( ) Sim

P79. O serviço disponibiliza refeições? ( ) Não ( ) Sim Se Não, passe para questão 80

$\begin{array}{lll}\text { Café da Manhã } & \text { ( ) Não } & \text { ( ) Sim } \\ \text { Lanche da Manhã } & \text { ( ) Não } & \text { ( ) Sim } \\ \text { Almoço } & \text { ( ) Não } & \text { ( ) Sim } \\ \text { Lanche da Tarde } & \text { ( ) Não } & \text { ( ) Sim } \\ \text { Jantar } & \text { ( ) Não } & \text { ( ) Sim } \\ \text { Lanche Noturno } & \text { ( ) Não } & \text { ( ) Sim }\end{array}$

Tem cardápio especial para:

Diabético (0) Não (1) Sim

Hipertenso ( 0 ) Não (1) Sim

Outro (0) Não (1) Sim Qual?

P80. Registra-se em prontuário único? ( ) Não ( ) Sim 


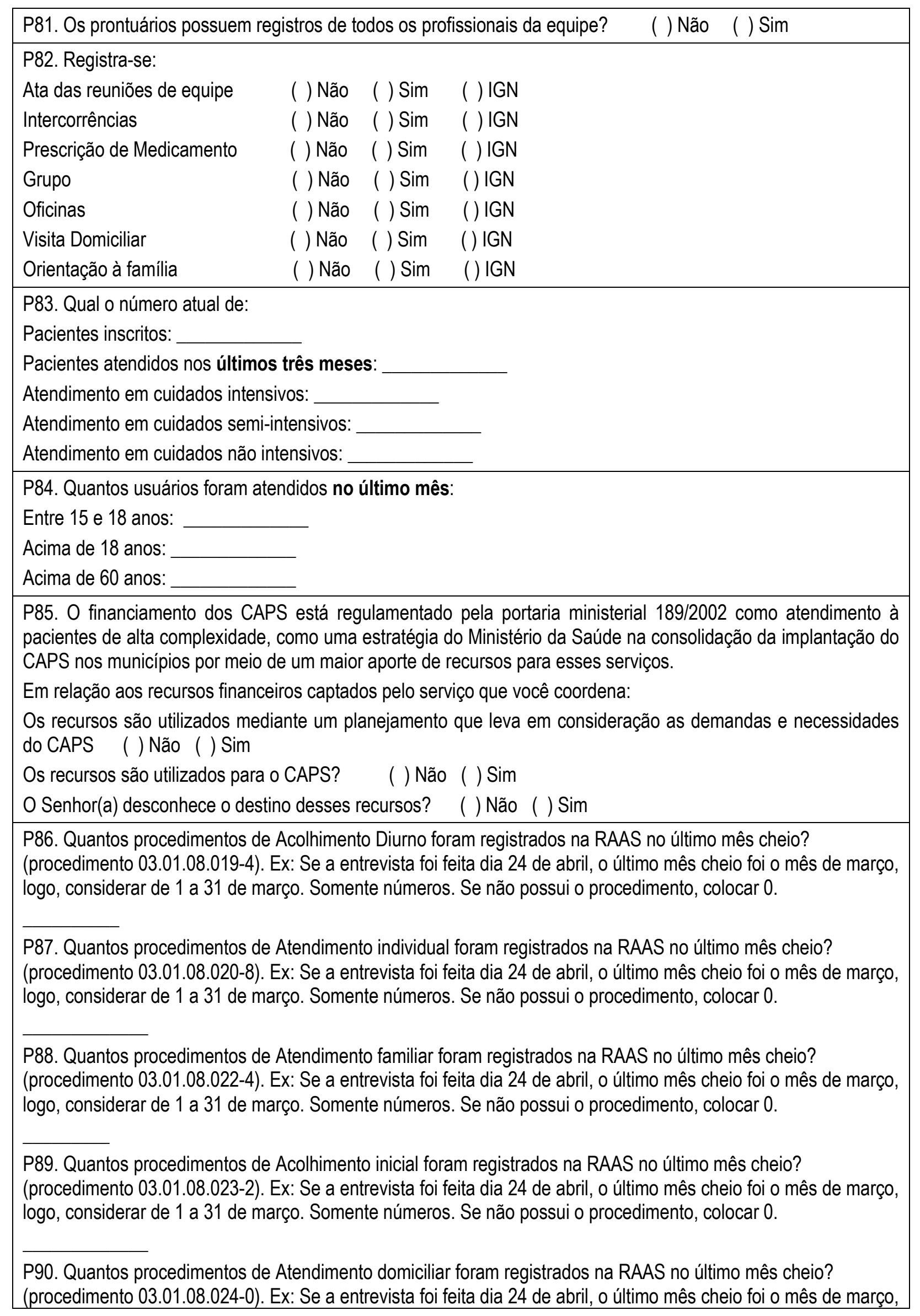


logo, considerar de 1 a 31 de março. Somente números. Se não possui o procedimento, colocar 0.

P91. Quantos procedimentos de Ações de articulação foram registrados na RAAS no último mês cheio? (procedimento 03.01.08.025-9). Ex: Se a entrevista foi feita dia 24 de abril, o último mês cheio foi o mês de março, logo, considerar de 1 a 31 de março. Somente números. Se não possui o procedimento, colocar 0.

P92. Quantos procedimentos de fortalecimento do protagonismo foram registrados na RAAS no último mês cheio? (procedimento 03.01.08.026-7). Ex: Se a entrevista foi feita dia 24 de abril, o último mês cheio foi o mês de março, logo, considerar de 1 a 31 de março. Somente números. Se não possui o procedimento, colocar 0.

P93. Quantos procedimentos de atenção a situações de crise foram registrados na RAAS no último mês cheio? (procedimento 03.01.08.029-1). Ex: Se a entrevista foi feita dia 24 de abril, o último mês cheio foi o mês de março, logo, considerar de 1 a 31 de março. Somente números. Se não possui o procedimento, colocar 0.

P94. Quantos procedimentos de matriciamento de equipe de saúde básica foram registrados na RAAS no último mês cheio? (procedimento 03.01.08.030-5). Ex: Se a entrevista foi feita dia 24 de abril, o último mês cheio foi 0 mês de março, logo, considerar de 1 a 31 de março. Somente números. Se não possui o procedimento, colocar 0.

P95. Quantos procedimentos de matriciamento de equipe de urgência foram registrados na RAAS no último mês cheio? (procedimento 03.01.08.039-9). Ex: Se a entrevista foi feita dia 24 de abril, o último mês cheio foi o mês de março, logo, considerar de 1 a 31 de março. Somente números. Se não possui o procedimento, colocar 0.

P96. Quantos procedimentos de ações de redução de danos foram registrados na RAAS no último mês cheio? (procedimento 03.01.08.031-3). Ex: Se a entrevista foi feita dia 24 de abril, o último mês cheio foi o mês de março, logo, considerar de 1 a 31 de março. Somente números. Se não possui o procedimento, colocar 0.

P97. Quantos procedimentos de acompanhamento de serviço residencial terapêutico foram registrados na RAAS no último mês cheio? (procedimento 03.01.08.032-1). Ex: Se a entrevista foi feita dia 24 de abril, o último mês cheio foi o mês de março, logo, considerar de 1 a 31 de março. Somente números. Se não possui o procedimento, colocar 0 .

P98. Quantos procedimentos de apoio à serviço residencial transitório foram registrados na RAAS no último mês cheio? (procedimento 03.01.08.033-0). Ex: Se a entrevista foi feita dia 24 de abril, o último mês cheio foi o mês de março, logo, considerar de 1 a 31 de março. Somente números. Se não possui o procedimento, colocar 0.

P99. Quantos procedimentos de ações de reabilitação psicossocial foram registrados na RAAS no último mês cheio? (procedimento 03.01.08.034-8).Ex: Se a entrevista foi feita dia 24 de abril, o último mês cheio foi o mês de março, logo, considerar de 1 a 31 de março. Somente números. Se não possui o procedimento, colocar 0.

P100. Quantos procedimentos de promoção da contratualidade foram registrados na RAAS no último mês cheio? (procedimento 03.01.08.035-6). Ex: Se a entrevista foi feita dia 24 de abril, o último mês cheio foi o mês de março, logo, considerar de 1 a 31 de março. Somente números. Se não possui o procedimento, colocar 0.

P101. Quantos procedimentos de acolhimento noturno foram registrados na RAAS no último mês cheio? (procedimento 03.01.08.002-0). Ex: Se a entrevista foi feita dia 24 de abril, o último mês cheio foi o mês de março, logo, considerar de 1 a 31 de março. Somente números. Se não possui o procedimento, colocar 0.

P102. Quantos procedimentos de acolhimento em terceiro turno foram registrados na RAAS no último mês cheio? 
(procedimento 03.01.08.003-8). Ex: Se a entrevista foi feita dia 24 de abril, o último mês cheio foi o mês de março, logo, considerar de 1 a 31 de março. Somente números. Se não possui o procedimento, colocar 0.

Por favor, responda, para cada uma das frases:

(1) para discordo totalmente,

(2) para discordo em parte,

(3) para estou em dúvida,

(4) para concordo em parte,

(5) para concordo totalmente

\section{Fator 1}

\begin{tabular}{|l|l|l|l|l|l|}
\hline A equipe precisa de treinamento para trabalhar com o alcoolista & 1 & 2 & 3 & 4 & 5 \\
\hline E preciso tomar cuidado ao trabalhar com o paciente alcoolista & 1 & 2 & 3 & 4 & 5 \\
\hline Não se deve confiar em alcoolistas & 1 & 2 & 3 & 4 & 5 \\
\hline O paciente alcoolista acaba sempre voltando ao serviço com o mesmo problema. & 1 & 2 & 3 & 4 & 5 \\
\hline Considero paciente alcoolista o mais difícil de lidar. & 1 & 2 & 3 & 4 & 5 \\
\hline O alcoolista é um paciente que nunca dá retorno do cuidado. & 1 & 2 & 3 & 4 & 5 \\
\hline O alcoolista é uma pessoa de difícil contato. & 1 & 2 & 3 & 4 & 5 \\
\hline Eu tenho medo de abordar o problema do alcoolismo com o paciente. & 1 & 2 & 3 & 4 & 5 \\
\hline Eu tenho medo da agressividade do alcoolista. & 1 & 2 & 3 & 4 & 5 \\
\hline Sinto-me frustrado quando trabalho com alcoolistas. & 1 & 2 & 3 & 4 & 5 \\
\hline Quando o paciente não quer colaborar, o melhor é desistir de ajudar. & 1 & 2 & 3 & 4 & 5 \\
\hline Quando trabalho com o alcoolista, não sei como conduzir a situação. & 1 & 2 & 3 & 4 & 5 \\
\hline Para atender o alcoolista, é preciso contê-lo. & 1 & 2 & 3 & 4 & 5 \\
\hline Penso que alcoolistas dão muito trabalho para a equipe de saúde. & 1 & 2 & 3 & 4 & 5 \\
\hline Devo cuidar do alcoolista, mesmo que ele não queira. & 1 & 2 & 3 & 4 & 5 \\
\hline Mesmo consciente o alcoolista desrespeita a equipe. & 1 & 2 & 3 & 4 & 5 \\
\hline Sinto raiva ao trabalhar com alcoolistas. & 1 & 2 & 3 & 4 & 5 \\
\hline O paciente alcoolista não aceita o que eu falo. & 1 & 2 & 3 & 4 & 5 \\
\hline Alcoolistas são pacientes difíceis porque não colaboram com o tratamento. & 1 & 2 & 3 & 4 & 5 \\
\hline Eu prefiro trabalhar com pacientes alcoolistas a trabalhar com outros pacientes. & 1 & 2 & 3 & 4 & 5 \\
\hline
\end{tabular}

\section{Fator 2}

\begin{tabular}{|l|l|l|l|l|l|}
\hline Alcoolistas são revoltados. & 1 & 2 & 3 & 4 & 5 \\
\hline O alcoolista é um doente. & 1 & 2 & 3 & 4 & 5 \\
\hline Alcoolistas não têm bom senso. & 1 & 2 & 3 & 4 & 5 \\
\hline O alcoolista é agressivo e mal educado. & 1 & 2 & 3 & 4 & 5 \\
\hline O alcoolista é um irresponsável. & 1 & 2 & 3 & 4 & 5 \\
\hline Os alcoolistas são pacientes violentos. & 1 & 2 & 3 & 4 & 5 \\
\hline Penso que pessoas que desenvolvem o alcoolismo são fracas. & 1 & 2 & 3 & 4 & 5 \\
\hline O alcoolista não quer se cuidar. & 1 & 2 & 3 & 4 & 5 \\
\hline Penso que o alcoolista é culpado por seus problemas de saúde. & 1 & 2 & 3 & 4 & 5 \\
\hline O alcoolista não leva o tratamento a sério. & 1 & 2 & 3 & 4 & 5 \\
\hline
\end{tabular}


Fator 3

\begin{tabular}{|l|l|l|l|l|l|}
\hline Percebo que o alcoolista tem baixa auto-estima. & 1 & 2 & 3 & 4 & 5 \\
\hline Penso que passar por um desajuste familiar leva ao alcoolismo. & 1 & 2 & 3 & 4 & 5 \\
\hline O alcoolista é um individuo que não consegue controlar sua ingestão alcoólica. & 1 & 2 & 3 & 4 & 5 \\
\hline O álcool é usado como fuga. & 1 & 2 & 3 & 4 & 5 \\
\hline Penso que todo o alcoolista tem algo mal resolvido. & 1 & 2 & 3 & 4 & 5 \\
\hline A falta de autocontrole leva ao alcoolismo. & 1 & 2 & 3 & 4 & 5 \\
\hline Penso que a depressão leva ao alcoolismo. & 1 & 2 & 3 & 4 & 5 \\
\hline O alcoolismo está relacionado ao nível de instrução do individuo. & 1 & 2 & 3 & 4 & 5 \\
\hline O alcoolista bebe para fugir da realidade. & 1 & 2 & 3 & 4 & 5 \\
\hline O que falta no alcoolista é força de vontade. & 1 & 2 & 3 & 4 & 5 \\
\hline As questões sociais levam o individuo a beber. & 1 & 2 & 3 & 4 & 5 \\
\hline
\end{tabular}

Fator4

\begin{tabular}{|l|l|l|l|l|l|}
\hline Penso que as pessoas têm o direito de beber se elas quiserem. & 1 & 2 & 3 & 4 & 5 \\
\hline A bebida alcoólica é agradável e traz bem-estar. & 1 & 2 & 3 & 4 & 5 \\
\hline O uso de bebida alcoólica é um comportamento normal. & 1 & 2 & 3 & 4 & 5 \\
\hline Beber com moderação não é prejudicial. & 1 & 2 & 3 & 4 & 5 \\
\hline Eu sou contra o uso de álcool em qualquer momento. & 1 & 2 & 3 & 4 & 5 \\
\hline O álcool em quantidades reduzidas é benéfico. & 1 & 2 & 3 & 4 & 5 \\
\hline Eu sou a favor do beber moderado. & 1 & 2 & 3 & 4 & 5 \\
\hline Doses pequenas de álcool são capazes de causar dependência. & 1 & 2 & 3 & 4 & 5 \\
\hline As pessoas podem beber desde que saibam se controlar. & 1 & 2 & 3 & 4 & 5 \\
\hline
\end{tabular}




\section{ANEXO 3 - Instrumento para os trabalhadores do serviço.}

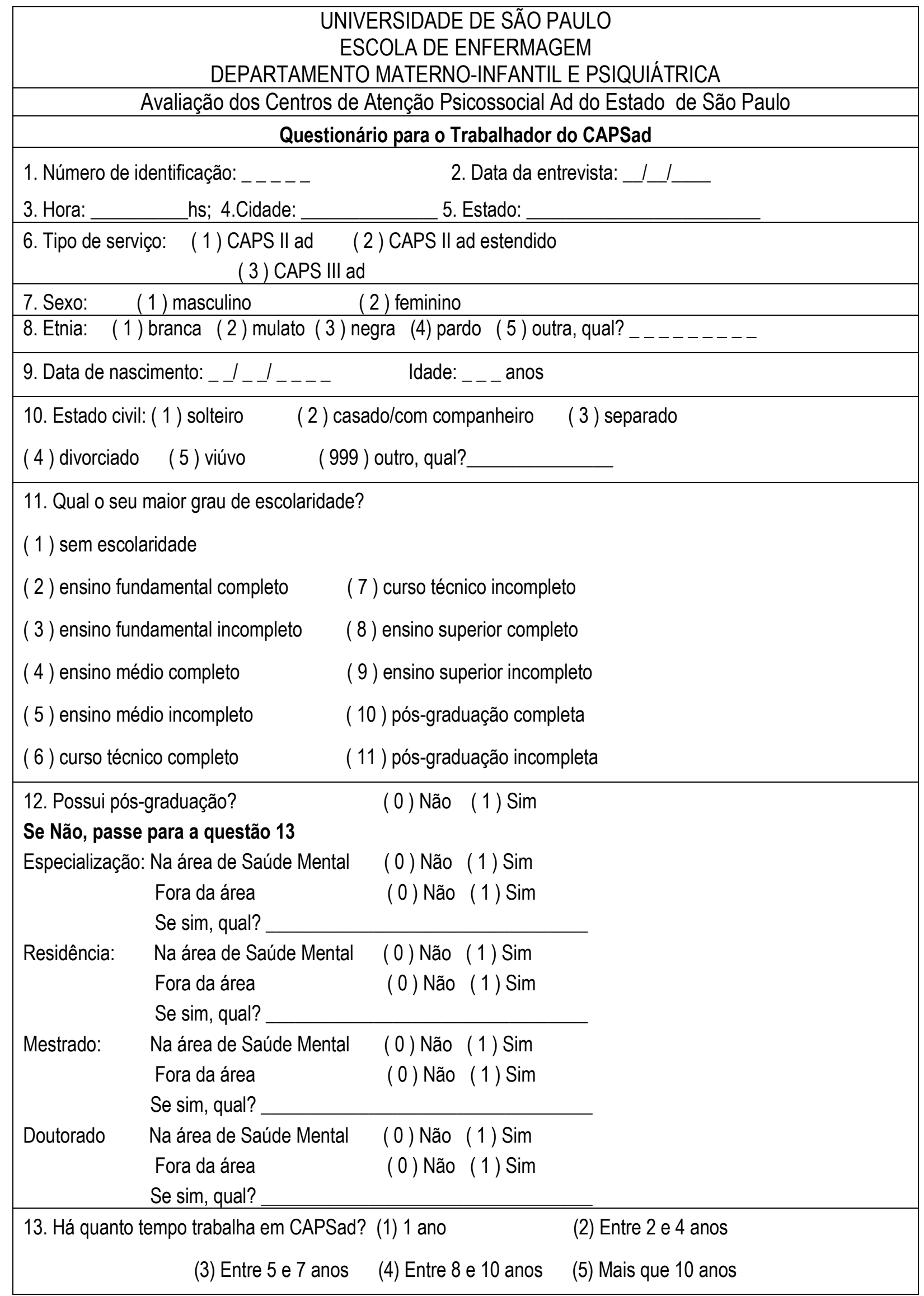




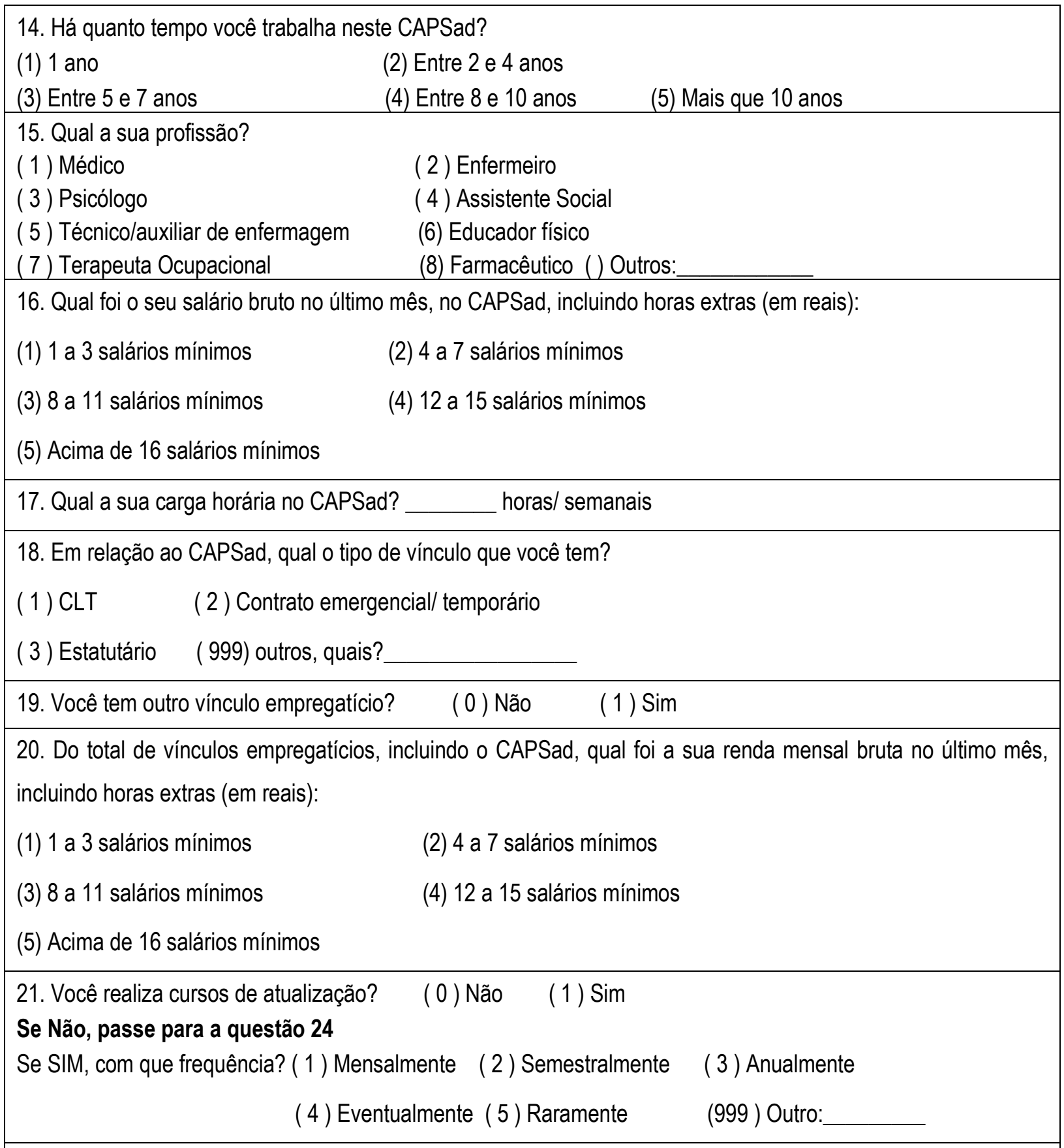

22. Quando foi o último curso de atualização que você participou?
(1) Neste mês
( 3 ) Há 6 meses a 1 ano
( 2 ) Há 2 a 6 meses
( 4 ) mais de 1 ano
( 5 ) nunca participou

23. Quando foi o penúltimo curso de atualização que você participou?
(1) Neste mês
( 3 ) Há 6 meses a 1 ano
( 2 ) Há 2 a 6 meses
( 4 ) mais de 1 ano
( 5 ) nunca participou

24. Qual o seu turno de trabalho neste serviço?
(1) dia
( 2 ) noite
(3) revezamento semanal
( 4 ) parte de dia e parte de noite
(999) outro: 
25. Este turno de trabalho traz problemas para você?

$$
\text { ( } 0 \text { ) Não (1) Sim }
$$

Se sim, quais problemas?
(1) fadiga
( 0 ) Não (1) Sim
( 2 ) choque de horário
( 0 ) Não (1) Sim
( 3 ) organização de vida
( 0 ) Não (1) Sim
(4) estresse
( 0 ) Não (1) Sim
(5) Sinais e sintomas físicos
( 0 ) Não (1) Sim
(999) outros
( 0 ) Não (1) Sim

Outros, se sim, quais?

\section{ESTRUTURA E PROCESSO DAS PRÁTICAS ASSISTÊNCIAIS}

E1. Você considera que o CAPSad é adequado em relação:
a) Ventilação
(0) Não
(1) $\operatorname{Sim}$

Justifique

b) Iluminação

(0) Não

(1) $\operatorname{Sim}$

Justifique

c) Higiene

(0) Não

(1) $\mathrm{Sim}$

Justifique
d) Área física
(0) Não
(1) Sim

Justifique

E2. Você considera que os equipamentos de proteção coletiva estão instalados e funcionando em seu local de trabalho:
(1) exaustores para ventilação
( 0 ) Não (1) Sim
(2) saída de emergência
( 0 ) Não (1) Sim
(3) mangueira p/ incêndio
( 0 ) Não (1) Sim
(4) proteção nas máquinas
( 0 ) Não (1) Sim
(5) extintor de incêndio
( 0 ) Não (1) Sim
(6) ar condicionado
( 0 ) Não (1) Sim
(7) ventilador
( 0 ) Não (1) Sim
(999) outros

Considerando o seu último mês de trabalho, responda as questões de número 3 até 8 :

$\begin{array}{llll}\text { E3. Você realizou visitas domiciliárias } & \text { (0) Não } & \text { (1) Sim }\end{array}$ 


\begin{tabular}{|c|c|}
\hline $\begin{array}{l}\text { Quantas visitas domiciliárias você realizou: _- } \\
\text { Se Não, porque? }\end{array}$ & \\
\hline E4. Você realizou atendimentos individuais & 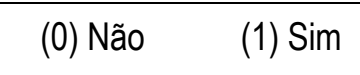 \\
\hline Quantos atendimentos individuais você realizou: & --- \\
\hline Consulta & ( )NÃO ( ) SIM \\
\hline Psicoterapia & ( )NÃO ( ) SIM \\
\hline Orientação & ( )NÃO ( ) SIM \\
\hline Procedimentos técnicos & ( )NÃO ( ) SIM \\
\hline Acompanhamento do uso de medicação & ( )NÃO ( ) SIM \\
\hline Intervenção em crise & ( )NÃO ( ) SIM \\
\hline Orientação de atividades da vida diária & ( )NÃO ( ) SIM \\
\hline Intervenção em agitação psicomotora & ( )NÃO ( ) SIM \\
\hline Orientação quanto a redução de danos & ( )NÃO ( ) SIM \\
\hline Outras atividades de atendimento individual? & ( )NÃO ( ) SIM \\
\hline Qual? & \\
\hline E5. Você realizou atendimentos grupais & (0) Não $\quad$ (1) Sim \\
\hline Quantos atendimentos em grupo você realizou: & \\
\hline Grupos terapêuticos & ( )NÃO ( ) SIM \\
\hline Atividades esportivas & ( )NÃO ( ) SIM \\
\hline Atividades de suporte social & ( )NÃO ( ) SIM \\
\hline Grupo de leitura e debate & ( )NÃO ( ) SIM \\
\hline Grupo de confecção de jornal & ( )NÃO ( ) SIM \\
\hline Grupo de orientações gerais & ( )NÃO ( ) SIM \\
\hline Grupo de orientações para redução de danos & ( )NÃO ( ) SIM \\
\hline Grupos de família & ( )NÃO ( ) SIM \\
\hline Outros grupos & ( )NÃO ( ) SIM \\
\hline Quais? & \\
\hline $\begin{array}{l}\text { E6. Você participou de reuniões de equipe } \\
\text { Quantas reuniões de equipe você participou:_-_ }\end{array}$ & (0) Não (1) Sim \\
\hline $\begin{array}{l}\text { E7. Você participou de atividades comunitárias? } \\
\text { Quantas atividades comunitárias você participou: }\end{array}$ & (0) Não (1) Sim \\
\hline
\end{tabular}




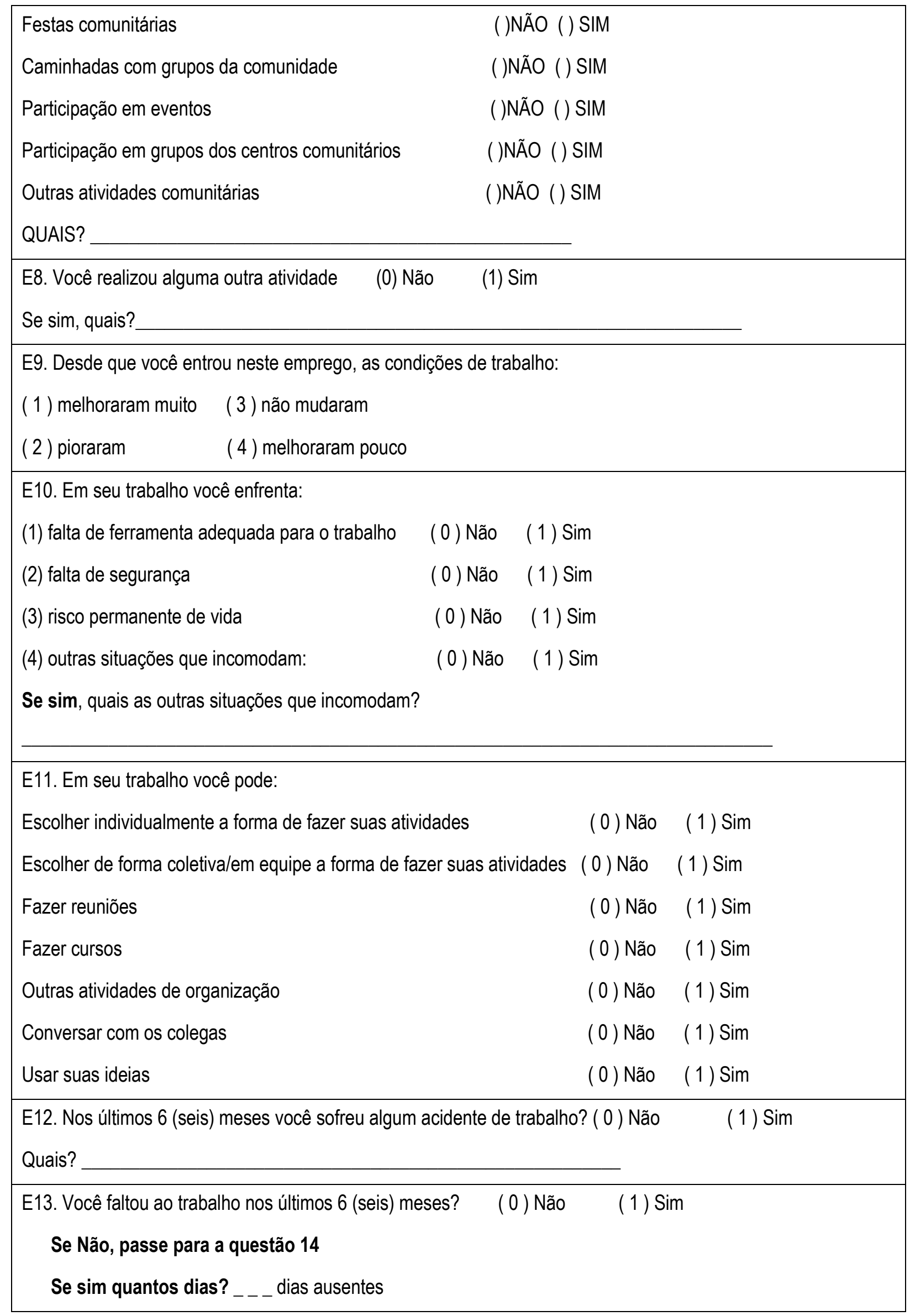


Quais os Motivos:
(1) doença
( 0 ) Não
(1) Sim
(2) acidente
( 0 ) Não
(1) Sim
( 3 ) problema familiar
( 0 ) Não
(1) Sim
( 4 ) problema administrativo
( 0 ) Não
(1) Sim
(999) outros
( 0 ) Não
(1) $\mathrm{Sim}$

Justifique:

E14. Qual o principal critério de inclusão no tratamento CAPSad para as pessoas que procuram este serviço?

(1) O consumo de álcool e outras drogas

(2) A gravidade do consumo de álcool e outras drogas

(3) O impacto global na vida relacionado ao consumo prejudicial de álcool e outras drogas

(4) Outros

E15. Qual o modelo de assistência utilizada neste serviço?
( ) Redução de Danos
( ) Abstinência total
( ) As duas modalidades
() Não sei () Outros

E16. O que é considerado "abandono de tratamento" nesse serviço?

(1) Não comparecimento ao serviço por 30 dias consecutivos, sem justificativa

(2) Não comparecimento ao serviço por 60 dias consecutivos, sem justificativa

(3) Não sei

(4) Outros

E17. É realizada busca ativa nesse serviço?

(0) Não

(1) $\operatorname{Sim}$

Se não, porque?
E18. Se sim, como é realizada:
(1) Contato Telefônico
(2) Visita Domiciliária

(3) Outros

E19. Ao fazer a busca ativa, o que costuma se constatar em relação ao abandono do tratamento?

(1) Deve-se à desistência do tratamento

(2) Deve-se à melhora do usuário, segundo a sua percepção

(3) Deve-se ao retorno do usuário às suas atividades sociais (trabalho, lazer)

(4) Deve-se à outra modalidade de tratamento (internação)

(5) Deve-se à troca por outro serviço

(6) Outro, QUAL: 


\begin{tabular}{|c|c|c|}
\hline \multicolumn{3}{|c|}{ E20. Quais são as oficinas/atividades terapêuticas oferecidas nesse CAPSad? } \\
\hline Grupos Terapêuticos & \multicolumn{2}{|l|}{ 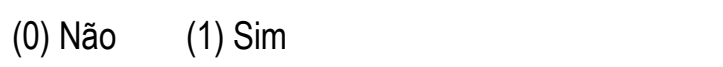 } \\
\hline Atividades Esportivas & \multicolumn{2}{|l|}{ (0) Não (1) Sim } \\
\hline Atividades de Suporte Social & \multicolumn{2}{|l|}{ 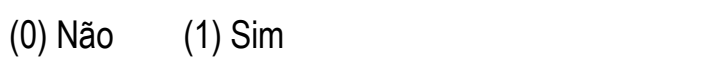 } \\
\hline Grupos de Leitura e Debate & \multicolumn{2}{|l|}{ (0) Não (1) Sim } \\
\hline Grupos de Confecção de Jornal & \multicolumn{2}{|l|}{ (0) Não (1) Sim } \\
\hline Grupos de Orientação & \multicolumn{2}{|l|}{ (0) Não (1) Sim } \\
\hline Grupos de Família & \multicolumn{2}{|l|}{ 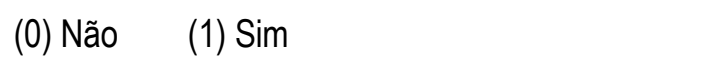 } \\
\hline \multicolumn{3}{|c|}{ Grupos de orientação de redução de danos (0) Não } \\
\hline \multicolumn{3}{|c|}{ Outros $_{------------------------------}$} \\
\hline Oficinas Terapêuticas & \multicolumn{2}{|c|}{ (0) Não (1) Sim } \\
\hline Oficinas Expressivas & \multicolumn{2}{|c|}{ (0) Não (1) Sim } \\
\hline Oficinas Geradoras de Renda & \multicolumn{2}{|c|}{ (0) Não (1) Sim } \\
\hline Oficinas de Alfabetização & \multicolumn{2}{|c|}{ (0) Não (1) Sim } \\
\hline Oficinas Culturais & \multicolumn{2}{|c|}{ (0) Não (1) Sim } \\
\hline Oficinas de atividades manuais & \multicolumn{2}{|c|}{ 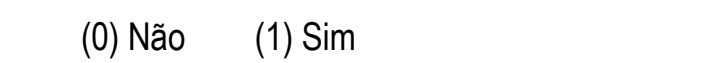 } \\
\hline Oficinas de Trabalho & \multicolumn{2}{|c|}{ (0) Não (1) Sim } \\
\hline \multicolumn{3}{|c|}{ 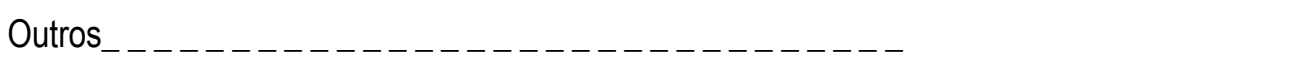 } \\
\hline Atendimento individual & \multicolumn{2}{|c|}{ (0) Não (1) Sim } \\
\hline Consulta médica & \multicolumn{2}{|c|}{ ( 0 ) Não (1) Sim } \\
\hline Psicoterapia & \multicolumn{2}{|c|}{ ( 0 ) Não (1) Sim } \\
\hline Orientação & \multicolumn{2}{|c|}{ ( 0 ) Não (1) Sim } \\
\hline Consulta de enfermagem & \multicolumn{2}{|c|}{ ( 0 ) Não (1) Sim } \\
\hline Consulta com outros técnicos & \multicolumn{2}{|c|}{ ( 0 ) Não (1) Sim } \\
\hline Procedimentos técnicos & \multicolumn{2}{|c|}{ ( 0 ) Não (1) Sim } \\
\hline Acompanhamento do uso de medicação & \multicolumn{2}{|c|}{ ( 0 ) Não （1) Sim } \\
\hline Intervenções em crise & ( 0 ) Não & (1) Sim \\
\hline Intervenções em agitação psicomotora & ( 0 ) Não & (1) Sim \\
\hline Orientação em atividades de vida diária & ( 0 ) Não & (1) Sim \\
\hline Orientação em redução de danos & ( 0 ) Não & (1) Sim \\
\hline Outros $_{------------------1}$ & ----------- & -- \\
\hline Atividades na comunidade & & ( 1) Sim, quais? \\
\hline Festas comunitárias & & ( 0 ) Não \\
\hline Caminhadas com grupos da comunidade & & ( 0 ) Não ( 1 ) Sim \\
\hline Participação em eventos e grupos dos cel & ntros comunitários & ( 0 ) Não ( 1 ) Sim \\
\hline Outros $_{------------------1}$ & ----------- & -- \\
\hline
\end{tabular}




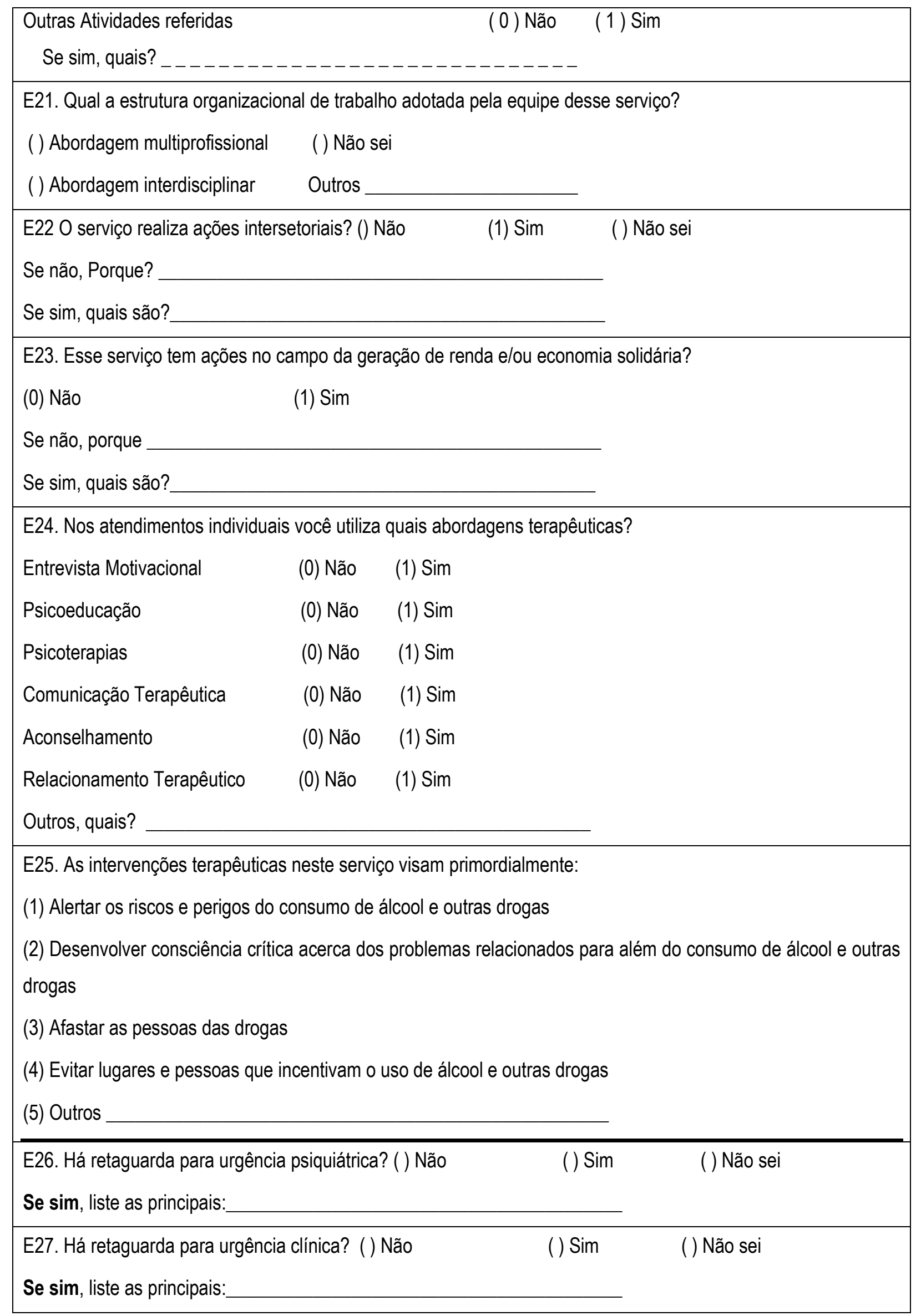


E28 Como são indicadas as internações para a dependência química dos usuários desse serviço?
(1) Após discussão de caso em reunião de equipe
(2) Pelo médico
(3) A pedido do próprio usuário
(4) A pedido da família
(5) Por via judicial
(6) Outros

E29. Você tem conhecimento dos equipamentos de saúde existentes na área de abrangência do CAPSad?
(0) Não
(1) $\operatorname{Sim}$
(998) Não sei

Se sim, liste os principais:

E30. a) A equipe do serviço, incluindo você, quando necessário encaminha os usuários para esses serviços?
(0) Não
(1) $\operatorname{Sim}$
(998) Não sei

Se, sim liste os mais utilizados:

E30. b) Há algum projeto/atividade em parceria com esses serviços?
(0) Não
(1) $\operatorname{Sim}$
(998) Não sei

Se, sim liste os mais utilizados:

E31 Você tem facilidade de diálogo com os outros equipamentos de saúde da rede, da área de abrangência do CAPSad para o tratamento do usuário?
(0) Não
(1) $\operatorname{Sim}$

Se não, porque?

32. Em relação aos profissionais da rede que encaminham usuários para os CAPSad, você nota que estes conhecem o trabalho desenvolvido pelo CAPSad?
(0) Não
(1) $\operatorname{Sim}$
(998) Não sei

E33. Algum profissional desse CAPSad realiza o matriciamento das equipes de Atenção Básica da área de abrangência dos serviços? (0) Não

(1) $\operatorname{Sim}$

(998) Não sei

E34. Qual o principal critério de alta do CAPSad?

(1) A interrupção total do consumo de álcool e outras drogas

(2) A inserção e/ ou reinserção no trabalho formal e informal

(3) A retomada dos laços sociais e familiares

(4) A melhora das condições globais de vida do usuário

Outros, quais?

E35. Que tipo de transporte você usa preferencialmente para chegar a este serviço?
( 1 ) Condução própria
( 4 ) Condução de familiares
( 2 ) Condução de amigos
( 5 ) Transporte público
(3) Caminhada
(999) Outro 
E36. Quanto tempo você gasta para vir de sua casa ao CAPSad?
(1) 0 -15minutos
( 2 ) 16-30 minutos
( 4 ) 46-60 minutos
( 3 ) 31-45 minutos
(5) mais que 60 minutos

E37. Você acha que os profissionais deste serviço compreendem os problemas dos usuários?

(1) De forma alguma
( 2 ) Não muito
( 4 ) Bem
( 3 ) Mais ou menos
( 5 ) Muito bem

E38. Você acha que os profissionais deste serviço compreendem o tipo de ajuda de que os usuários necessitam?
( 1 ) Não compreendem
( 2 ) Não compreendem muito
( 4 ) Bem
( 3 ) Mais ou menos
(5) Muito bem

E39. Considerando as necessidades globais dos usuários que procuram este serviço para tratamento, até que ponto este serviço é apropriado para recebê-los aqui?
( 1 ) muito inapropriado
( 2 ) inapropriado
( 4 ) apropriado
(3) mais ou menos
( 5 ) muito apropriado

E40. Você acha que existem outros cuidados de que o usuário necessita, mas que não recebe aqui?
(1) Com certeza há
( 4 ) Acho que não há
( 2 ) Acho que há
( 5 ) Não, certamente que não
( 3 ) Talvez

Se você respondeu 1 ou 2 , especifique quais são estes serviços

E41. Você acha que o CAPSad estimula as famílias a participarem mais ativamente do processo de tratamento de seus familiares?

(1) De forma alguma
( 2 ) Não muito
( 4 ) Muito
( 3 ) Mais ou menos
( 5 ) Extremamente

E42. Você acha a equipe suficientemente competente para lidar com o envolvimento familiar?
( ) Muito incompetente
( ) Competente
( ) Mais ou menos
( ) Incompetente
( ) Muito competente

E43. Como você classificaria a competência geral da equipe?

( ) muito incompetente

( ) incompetente ( ) competente

( ) Mais ou menos ( ) Muito competente 
E44. Para você realizar as atividades assistenciais no CAPSad, você considera que as instalações da unidade são:
(1) Péssimas
( 2 ) Ruins
(4) Boas
(3) Regulares
(5) Excelentes

Você...

(1) nunca

( 2 ) raramente

( 3 ) mais ou menos

( 4 ) frequentemente

(5) sempre

E45. Sente que recebe o apoio de que necessita do seu supervisor

E46. Você participa do processo de tomada de decisões no seu serviço?

E47. Você participa da implementação de programas e/ou atividades novas no serviço?

E48. Você participa do processo de avaliação das atividades e/ou programas do serviço?

E49. Você acha que suas opiniões são levadas em consideração?

E50. Você percebe um bom clima no ambiente de trabalho?

E51 Em geral, como você classificaria o "clima" de amizade no ambiente de trabalho? *
( ) Nada amigável
( ) Amigável
( ) Pouco amigável
( ) Muito amigável
( ) Mais ou menos

E52. Com que frequência você tem reuniões de equipe?
(1) Diária
(2) Mais que uma vez por semana
(3) Uma vez por semana
(4) Entre 1-3 vezes por mês
(5) Menos que uma vez por mês
(6) Nunca

E53 Se um amigo / familiar estivesse necessitando de ajuda de uma unidade de Saúde Mental, você recomendaria este CAPSad?
( 1 ) Não, com certeza que não
( 4 ) Sim, acho que sim
( 2 ) Não, acho que não
( 5 ) Sim, com certeza
(3) Talvez

Se você respondeu 1 ou 2 (não), por quê?

Se você respondeu 4 ou 5 (sim), por quê? .
(1) 0 CAPSad tem um bom atendimento
( 0 ) Não
(1) $\operatorname{Sim}$
(2) Obtém-se bons resultados no CAPSad
( 0 ) Não
(1) $\operatorname{Sim}$
(3) Outros motivos
( 0 ) Não
(1) Sim, quais? 
E54.1 De que você mais gosta neste serviço?
( ) Da minha função
( ) Dos usuários
( ) Do atendimento prestado aos usuários
( ) Nada
( ) Dos colegas de trabalho
() Outros

E54.2 Qual aspecto você menos gosta CAPSad?
( ) Da minha função
( ) Dos usuários
( ) Do atendimento prestado aos usuários
( ) Nada
( ) Dos colegas de trabalho
() Outros

E55. Você acha que o serviço poderia ser melhorado?

( ) Não

( ) $\operatorname{sim}$

Se sim, de que maneira?

E56. Você se sente sobrecarregado no seu serviço?
(1) Nunca
( 4 ) Frequentemente
(2) Raramente
( 5 ) Sempre
( 3 ) As vezes

Se respondeu 4 e 5 (sim), porque?

E57. Em média, qual seria para você a frequência adequada de contato 1/1, entre os membros da equipe e 0 usuário?
(1) Mais que uma vez por dia
(2) Uma vez por dia
(3) $3-6$ vezes por semana
(4) 1 - 2 vezes por semana
(5) 2 - 3 vezes por mês
(6) Aproximadamente uma vez/mês
(7) Menos que uma vez por mês
(8) Nenhuma

Em cada uma das próximas questões, assinale a alternativa que mais se aproxima do seu sentimento em relação a satisfação. Responda fazendo um circulo em torno do numero em cada questão, de acordo com a seguinte escala:
(1) Muito insatisfeito
( 2 ) Insatisfeito
( 3 ) Indiferente
( 4 ) Satisfeito
( 5 ) Muito satisfeito

58. Você está satisfeito com este serviço?

59. Como você se sente com a expectativa de ser promovido?

60 . Você se sente satisfeito com o grau de responsabilidade que você tem no seu serviço?

61 Você se sente satisfeito no relacionamento com seus colegas?

62. Você se sente satisfeito com a frequência das reuniões de equipe?

63. Você se sente satisfeito com a forma que as reuniões de equipe são realizadas?

64. Até que ponto você se sente satisfeito com a eficácia e utilidade destas

\begin{tabular}{|l|l|l|l|l|}
\hline 1 & 2 & 3 & 4 & 5 \\
\hline 1 & 2 & 3 & 4 & 5 \\
1 & 2 & 3 & 4 & 5 \\
\hline 1 & 2 & 3 & 4 & 5 \\
1 & 2 & 3 & 4 & 5 \\
\hline 1 & 2 & 3 & 4 & 5 \\
\hline 1 & 2 & 3 & 4 & 5 \\
\hline
\end{tabular}




\begin{tabular}{|c|c|c|c|c|c|}
\hline reuniões? & & & & & \\
\hline $\begin{array}{l}\text { 65. Você se sente satisfeito com a quantidade de controle exercida por seus } \\
\text { superiores? }\end{array}$ & 1 & 2 & 3 & 4 & 5 \\
\hline $\begin{array}{l}\text { 66. Como você se sente em relação ao grau de autonomia que você tem em } \\
\text { seu serviço? }\end{array}$ & 1 & 2 & 3 & 4 & 5 \\
\hline 67. Você se sente satisfeito com a frequência de discussões de trabalho? & 1 & 2 & 3 & 4 & 5 \\
\hline $\begin{array}{l}\text { 68. Você se sente satisfeito com o seu nível de participação nas decisões de } \\
\text { trabalho? }\end{array}$ & 1 & 2 & 3 & 4 & 5 \\
\hline $\begin{array}{l}\text { 69. Você se sente satisfeito com o seu grau de participação na } \\
\text { implementação de programas e/ou atividades? }\end{array}$ & 1 & 2 & 3 & 4 & 5 \\
\hline $\begin{array}{l}\text { 70. Você se sente satisfeito com sua participação no processo de avaliação } \\
\text { de atividades e programas do serviço? }\end{array}$ & 1 & 2 & 3 & 4 & 5 \\
\hline 71. Você se sente satisfeito com a atenção dada às suas opiniões? & 1 & 2 & 3 & 4 & 5 \\
\hline 72. Você se sente satisfeito com o clima no ambiente de trabalho? & 1 & 2 & 3 & 4 & 5 \\
\hline 73. Até que ponto você se sente satisfeito com seu salário? & 1 & 2 & 3 & 4 & 5 \\
\hline 74. Você está satisfeito com os benefícios que recebe deste trabalho? & 1 & 2 & 3 & 4 & 5 \\
\hline $\begin{array}{l}\text { 75. Você está satisfeito com a atenção e os cuidados que são dados aos } \\
\text { pacientes? }\end{array}$ & 1 & 2 & 3 & 4 & 5 \\
\hline $\begin{array}{l}\text { 76. Você se sente satisfeito com a frequência de contato entre a equipe e os } \\
\text { usuários? }\end{array}$ & 1 & 2 & 3 & 4 & 5 \\
\hline 77. Como você se sente com o atendimento dado às famílias pela equipe? & 1 & 2 & 3 & 4 & 5 \\
\hline $\begin{array}{l}\text { 78. Você se sente satisfeito com o grau de competência profissional da } \\
\text { equipe? }\end{array}$ & 1 & 2 & 3 & 4 & 5 \\
\hline $\begin{array}{l}\text { 79. Você se sente satisfeito em relação às medidas de segurança ao usuário } \\
\text { do CAPSad? }\end{array}$ & 1 & 2 & 3 & 4 & 5 \\
\hline 80. Você está satisfeito com o conforto e aparência do CAPSad? & 1 & 2 & 3 & 4 & 5 \\
\hline $\begin{array}{l}\text { 81. Você esta satisfeito com quantidade de informações dadas aos usuários } \\
\text { sobre seus problemas de saúde neste serviç? }\end{array}$ & 1 & 2 & 3 & 4 & 5 \\
\hline $\begin{array}{l}\text { 82. Você esta satisfeito com a quantidade de informações dada aos usuários } \\
\text { sobre o tratamento oferecido neste serviço? }\end{array}$ & 1 & 2 & 3 & 4 & 5 \\
\hline $\begin{array}{l}\text { 83. Em geral, você se sente satisfeito com a forma como os usuários são } \\
\text { tratados pela equipe? }\end{array}$ & 1 & 2 & 3 & 4 & 5 \\
\hline $\begin{array}{l}\text { 84. Você esta satisfeito com o grau de envolvimento dos familiares no } \\
\text { processo de tratamento dos usuários no CAPSad? }\end{array}$ & 1 & 2 & 3 & 4 & 5 \\
\hline $\begin{array}{l}\text { 85. Como você se sente com a quantidade de ajuda que é dada aos usuários } \\
\text { pelo CAPSad? }\end{array}$ & 1 & 2 & 3 & 4 & 5 \\
\hline $\begin{array}{l}\text { 86. Você se sente satisfeito com as medidas tomadas para assegurar a } \\
\text { privacidade durante } 0 \text { atendimento dos usuários no CAPSad? (ex. portas } \\
\text { fechadas, nenhuma interrupção durante o atendimento com o profissional) }\end{array}$ & 1 & 2 & 3 & 4 & 5 \\
\hline $\begin{array}{l}\text { 87. Você se sente satisfeito com as medidas tomadas para assegurar o sigilo } \\
\text { sobre os problemas dos usuários e os cuidados recebidos no CAPSad? }\end{array}$ & 1 & 2 & 3 & 4 & 5 \\
\hline \multicolumn{6}{|l|}{ SUPERVISÃO NO CAPSad } \\
\hline \multicolumn{6}{|l|}{ E88.. Há supervisão no CAPSad? ～（） Não～（ ) Sim } \\
\hline \multicolumn{3}{|l|}{ Se não vá para a questão $92 \quad 0=$ ausente $\quad 10=$ qualificada } & & & \\
\hline \multicolumn{6}{|l|}{ E89. Supervisão pela secretaria municipal de saúde } \\
\hline \multicolumn{6}{|l|}{$++|+|+|+|+|+|$} \\
\hline $\begin{array}{llllllllll}0 & 1 & 2 & 3 & 4 & 5 & 6 & 7 & 8 & 9\end{array}$ & & & & & \\
\hline
\end{tabular}


E90 Supervisão pela coordenação municipal de saúde mental

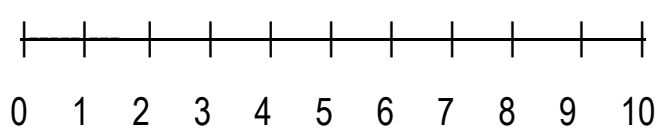

E91. Supervisão entre equipe:

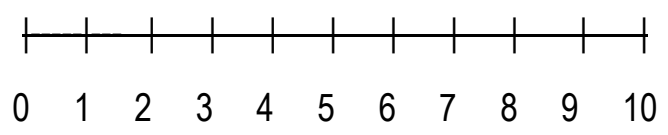

E92. Supervisão pela comunidade em que atua:

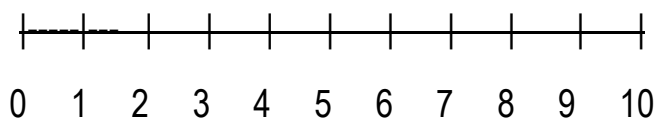

E93. Supervisão pela Organização Social (parceira):

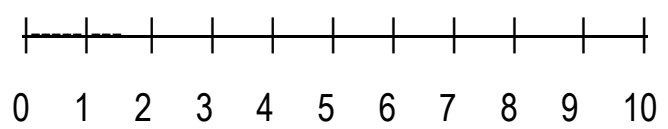

E94. Apoio pela secretaria municipal de saúde

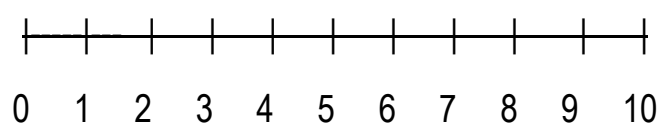

E95. Apoio pela coordenação municipal de saúde mental

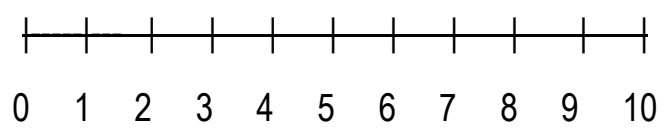

E96. Apoio entre equipe

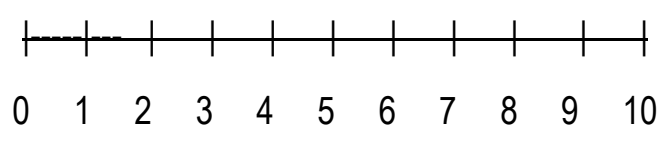

E.97. Apoio pela comunidade em que atua

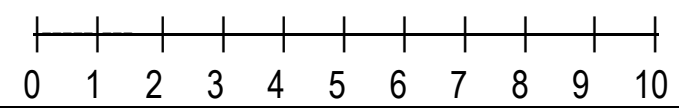

E98. De maneira global, qual a sua avaliação do atendimento prestado pelo CAPSad?

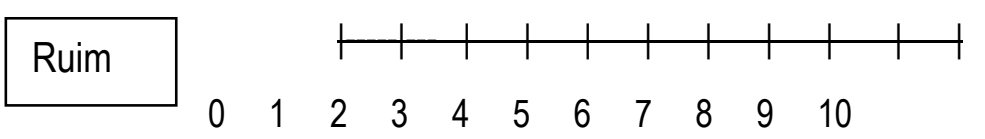

ótimo

97. Com relação à formação profissional e capacitação para trabalhar com álcool e outras drogas, em sua opinião, quais os temas considerados importantes? 
Por favor, responda, para cada uma das frases:

(1) para discordo totalmente,

(2) para discordo em parte,

(3) para estou em dúvida,

(4) para concordo em parte,

(5) para concordo totalmente

Fator 1

\begin{tabular}{|l|l|l|l|l|l|}
\hline A equipe precisa de treinamento para trabalhar com o alcoolista & 1 & 2 & 3 & 4 & 5 \\
\hline E preciso tomar cuidado ao trabalhar com o paciente alcoolista & 1 & 2 & 3 & 4 & 5 \\
\hline Não se deve confiar em alcoolistas & 1 & 2 & 3 & 4 & 5 \\
\hline O paciente alcoolista acaba sempre voltando ao serviço com o mesmo problema. & 1 & 2 & 3 & 4 & 5 \\
\hline Considero paciente alcoolista o mais difícil de lidar. & 1 & 2 & 3 & 4 & 5 \\
\hline O alcoolista é um paciente que nunca dá retorno do cuidado. & 1 & 2 & 3 & 4 & 5 \\
\hline O alcoolista é uma pessoa de difícil contato. & 1 & 2 & 3 & 4 & 5 \\
\hline Eu tenho medo de abordar o problema do alcoolismo com o paciente. & 1 & 2 & 3 & 4 & 5 \\
\hline Eu tenho medo da agressividade do alcoolista. & 1 & 2 & 3 & 4 & 5 \\
\hline Sinto-me frustrado quando trabalho com alcoolistas. & 1 & 2 & 3 & 4 & 5 \\
\hline Quando o paciente não quer colaborar, o melhor é desistir de ajudar. & 1 & 2 & 3 & 4 & 5 \\
\hline Quando trabalho com o alcoolista, não sei como conduzir a situação. & 1 & 2 & 3 & 4 & 5 \\
\hline Para atender o alcoolista, é preciso contê-lo. & 1 & 2 & 3 & 4 & 5 \\
\hline Penso que alcoolistas dão muito trabalho para a equipe de saúde. & 1 & 2 & 3 & 4 & 5 \\
\hline Devo cuidar do alcoolista, mesmo que ele não queira. & 1 & 2 & 3 & 4 & 5 \\
\hline Mesmo consciente o alcoolista desrespeita a equipe. & 1 & 2 & 3 & 4 & 5 \\
\hline Sinto raiva ao trabalhar com alcoolistas. & 1 & 2 & 3 & 4 & 5 \\
\hline O paciente alcoolista não aceita o que eu falo. & 1 & 2 & 3 & 4 & 5 \\
\hline Alcoolistas são pacientes difíceis porque não colaboram com o tratamento. & 1 & 2 & 3 & 4 & 5 \\
\hline Eu prefiro trabalhar com pacientes alcoolistas a trabalhar com outros pacientes. & 1 & 2 & 3 & 4 & 5 \\
\hline
\end{tabular}

Fator 2

\begin{tabular}{|l|l|l|l|l|l|}
\hline Alcoolistas são revoltados. & 1 & 2 & 3 & 4 & 5 \\
\hline O alcoolista é um doente. & 1 & 2 & 3 & 4 & 5 \\
\hline Alcoolistas não têm bom senso. & 1 & 2 & 3 & 4 & 5 \\
\hline O alcoolista é agressivo e mal educado. & 1 & 2 & 3 & 4 & 5 \\
\hline O alcoolista é um irresponsável. & 1 & 2 & 3 & 4 & 5 \\
\hline Os alcoolistas são pacientes violentos. & 1 & 2 & 3 & 4 & 5 \\
\hline Penso que pessoas que desenvolvem o alcoolismo são fracas. & 1 & 2 & 3 & 4 & 5 \\
\hline O alcoolista não quer se cuidar. & 1 & 2 & 3 & 4 & 5 \\
\hline Penso que o alcoolista é culpado por seus problemas de saúde. & 1 & 2 & 3 & 4 & 5 \\
\hline O alcoolista não leva o tratamento a sério. & 1 & 2 & 3 & 4 & 5 \\
\hline
\end{tabular}




\section{Fator 3}

\begin{tabular}{|l|l|l|l|l|l|}
\hline Percebo que o alcoolista tem baixa auto-estima. & 1 & 2 & 3 & 4 & 5 \\
\hline Penso que passar por um desajuste familiar leva ao alcoolismo. & 1 & 2 & 3 & 4 & 5 \\
\hline O alcoolista é um individuo que não consegue controlar sua ingestão alcoólica. & 1 & 2 & 3 & 4 & 5 \\
\hline O álcool é usado como fuga. & 1 & 2 & 3 & 4 & 5 \\
\hline Penso que todo o alcoolista tem algo mal resolvido. & 1 & 2 & 3 & 4 & 5 \\
\hline A falta de autocontrole leva ao alcoolismo. & 1 & 2 & 3 & 4 & 5 \\
\hline Penso que a depressão leva ao alcoolismo. & 1 & 2 & 3 & 4 & 5 \\
\hline O alcoolismo está relacionado ao nível de instrução do individuo. & 1 & 2 & 3 & 4 & 5 \\
\hline O alcoolista bebe para fugir da realidade. & 1 & 2 & 3 & 4 & 5 \\
\hline O que falta no alcoolista é força de vontade. & 1 & 2 & 3 & 4 & 5 \\
\hline As questões sociais levam o individuo a beber. & 1 & 2 & 3 & 4 & 5 \\
\hline
\end{tabular}

\section{Fator4}

\begin{tabular}{|l|l|l|l|l|l|}
\hline Penso que as pessoas têm o direito de beber se elas quiserem. & 1 & 2 & 3 & 4 & 5 \\
\hline A bebida alcoólica é agradável e traz bem-estar. & 1 & 2 & 3 & 4 & 5 \\
\hline O uso de bebida alcoólica é um comportamento normal. & 1 & 2 & 3 & 4 & 5 \\
\hline Beber com moderação não é prejudicial. & 1 & 2 & 3 & 4 & 5 \\
\hline Eu sou contra o uso de álcool em qualquer momento. & 1 & 2 & 3 & 4 & 5 \\
\hline O álcool em quantidades reduzidas é benéfico. & 1 & 2 & 3 & 4 & 5 \\
\hline Eu sou a favor do beber moderado. & 1 & 2 & 3 & 4 & 5 \\
\hline Doses pequenas de álcool são capazes de causar dependência. & 1 & 2 & 3 & 4 & 5 \\
\hline As pessoas podem beber desde que saibam se controlar. & 1 & 2 & 3 & 4 & 5 \\
\hline
\end{tabular}




\section{ANEXO 4 - Instrumento para os usuários do serviço.}

\begin{tabular}{|c|}
\hline $\begin{array}{c}\text { UNIVERSIDADE DE SÃO PAULO } \\
\text { ESCOLA DE ENFERMAGEM } \\
\text { DEPARTAMENTO MATERNO-INFANTIL E PSIQUIÁTRICA }\end{array}$ \\
\hline Questionário para o Usuário do CAPSad \\
\hline Número de identificação: _____ \\
\hline 1a. Cidade: _ 1b. Estado: \\
\hline $\begin{array}{l}\text { 2. Entrevistador: } \\
\text { Data da entrevista: }{ }_{--} I_{--} l_{--\ldots-}\end{array}$ horário de início: \\
\hline $\begin{array}{l}\text { 3. Em que local foi realizada a coleta dos dados? } \\
\begin{array}{ll}\text { (1) No CAPSad } & \text { ( } 2 \text { ) Parte no CAPSad, parte no domicilio } \\
\text { ( } 3 \text { ) No domicilio } & \text { ( } 4 \text { ) outro }\end{array}\end{array}$ \\
\hline 4. Tipo: (1) CAPS II ad $\quad$ (2) CAPS II ad horário estendido $\quad$ (3) CAPS III ad \\
\hline 5. Qual sua data de nascimento? ${ }_{--} I_{--} I_{---} \quad$ Qual sua idade? ${ }_{-\ldots}$ anos \\
\hline $\begin{array}{l}\text { 6.a Naturalidade: } \\
6 \text { b. Cidade onde reside: }\end{array}$ \\
\hline 7. Sexo: $\quad$ (1) feminino $\quad$ (2) masculino \\
\hline 8. Etnia: (1) branca $\quad(2$ ) mulato $\quad$ (3) negra $\quad$ (4) pardo ( 5 ) outra,qual? $\ldots$ \\
\hline 9. Qual é o seu peso (aproximadamente)? ___ kg \\
\hline 10. Qual é a sua altura? (aproximadamente)? ${ }_{-} \mathrm{m}_{-\ldots-} \mathrm{cm}$ \\
\hline 11. Qual seu atual estado civil? \\
\hline 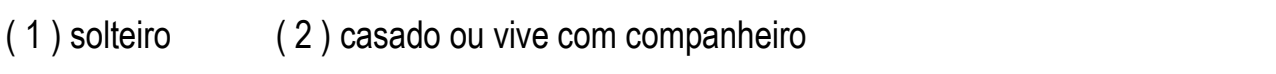 \\
\hline (3) separado (4) divorciado \\
\hline (5) viúvo $\quad$ (999) outro, qual? \\
\hline $\begin{array}{lll}\text { 12. O(a) Sr. (a) sabe ler? } & (0) \text { não } & (1) \text { sim }\end{array}$ \\
\hline Se "Não", passar para questão 14 \\
\hline $\begin{array}{l}\text { 13. Se sim, até que série o(a) Sr. (a) estudou? } \\
\text { (1) sem escolaridade }\end{array}$ \\
\hline $\begin{array}{ll}\text { (2) ensino fundamental completo } & \text { (7) curso técnico incompleto }\end{array}$ \\
\hline $\begin{array}{ll}\text { (3) ensino fundamental incompleto } & \text { (8) ensino superior completo }\end{array}$ \\
\hline (9) ensino superior incompleto \\
\hline (5) ensino médio incompleto \\
\hline $\begin{array}{ll}\text { (6) curso técnico completo } & \text { (11) pós-graduação incompleta }\end{array}$ \\
\hline
\end{tabular}




\begin{tabular}{|c|c|}
\hline \multicolumn{2}{|l|}{ 14. Qual sua principal fonte de renda? } \\
\hline (1) emprego & (6) auxílio-doença \\
\hline (2) seguro-desemprego & (7) pensionista \\
\hline (3) renda do cônjuge & (8) LOAS \\
\hline (4) aposentadoria & (9) Não tem renda \\
\hline (5) renda familiar & (999) outro, qual? _ _-_-_- \\
\hline \multirow{2}{*}{\multicolumn{2}{|c|}{$\begin{array}{l}\text { 15. Se o(a) Sr. (a) atualmente está trabalhando, explique como é sua jornada de trabalho: } \\
\text { (1) jornada integral remunerada }\end{array}$}} \\
\hline & \\
\hline (2) jornada parcial remunerada & (5) não trabalha \\
\hline (3) jornada integral não remunerada & (6) trabalho eventual \\
\hline (4) jornada parcial não remunerada & (999) outro, qual? \\
\hline \multicolumn{2}{|l|}{ 16. Qual sua renda no último mês? } \\
\hline (1) Até 2 salários mínimos & (4) Entre 10 a 20 salários mínimos \\
\hline (2) Entre 2 a 4 salários mínimos & (5) Acima de 20 salários mínimos \\
\hline \multicolumn{2}{|l|}{ (3) Entre 4 a 10 salários mínimos } \\
\hline \multicolumn{2}{|c|}{ 17. Qual a sua renda familiar no último mês? } \\
\hline (1) Até 2 salários mínimos & (4) Entre 10 a 20 salários mínimos \\
\hline (2) Entre 2 a 4 salários mínimos & (5) Acima de 20 salários mínimos \\
\hline \multicolumn{2}{|l|}{ (3) Entre 4 a 10 salários mínimos } \\
\hline \multicolumn{2}{|c|}{ 18. Qual o número de membros/ pessoas na família? _-_ } \\
\hline \multicolumn{2}{|c|}{ 19. Com quem o(a) Sr. (a) vive atualmente? } \\
\hline (1) sozinho (a) & (7) mãe, pai \\
\hline (2) cônjuge/ companheiro (a) & (8) mãe, pai, irmãos \\
\hline (3) com filho (a) & (9) amigo (a) \\
\hline (4) cônjuge/ companheiro (a)/filhos & (999) outro, qual? \\
\hline \multicolumn{2}{|l|}{ (5) outro membro da família } \\
\hline \multicolumn{2}{|c|}{ 6) mãe, pai, irmãos, filhos e companheiro } \\
\hline \multicolumn{2}{|c|}{ 20. Com quem o(a) Sr. (a) gostaria de viver? } \\
\hline (1) sozinho (a) & (6) mãe, pai, irmãos, filhos e companheiro \\
\hline (2) cônjuge/ companheiro (a) & (7) amigo (a) \\
\hline (3) com filho (a) & (8) mãe, pai \\
\hline (4) cônjuge/ companheiro (a)/filhos & (9) mãe, pai, irmãos \\
\hline (5) outro membro da família & (999) outro, qual? $\ldots$ \\
\hline
\end{tabular}




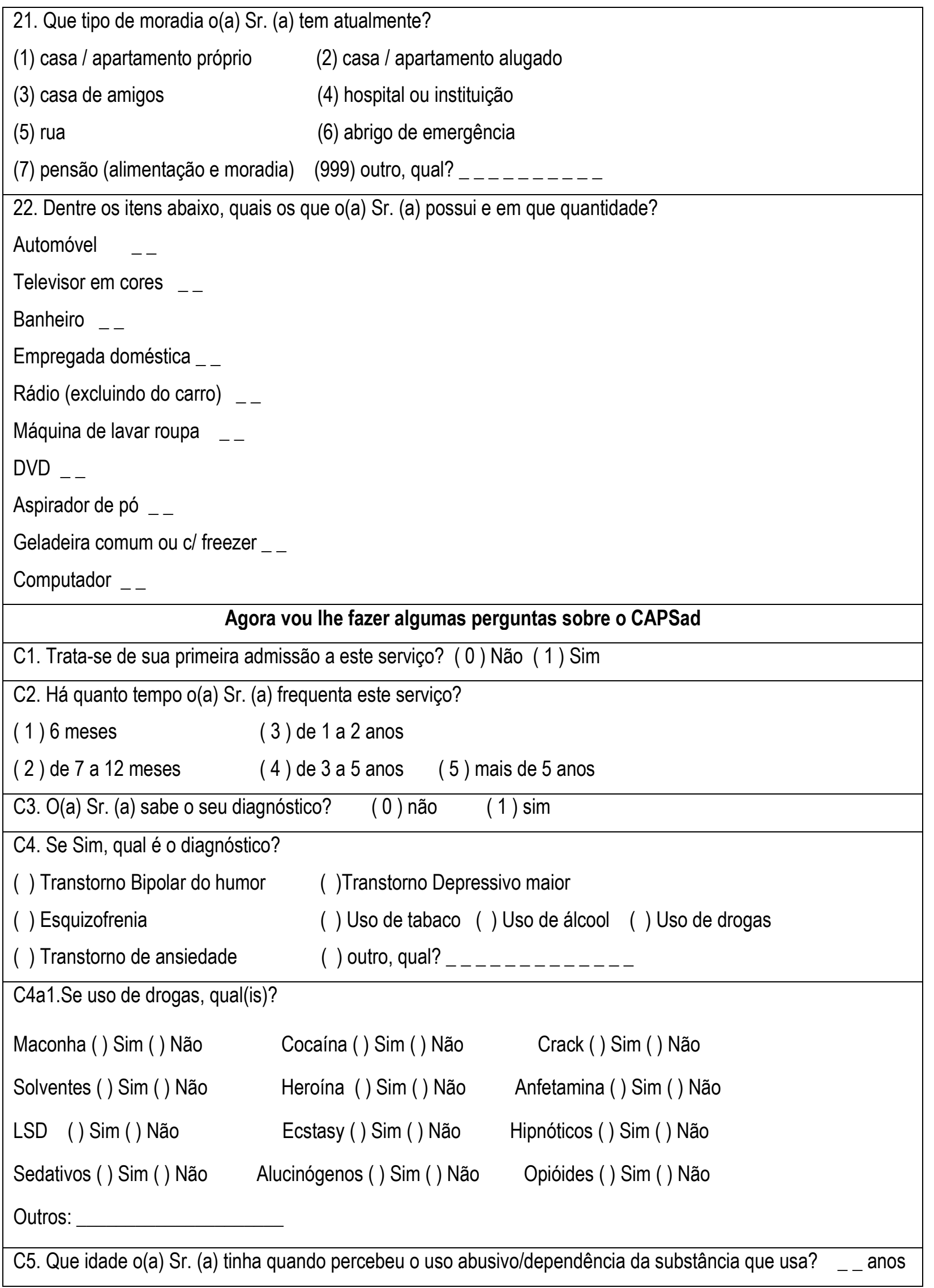




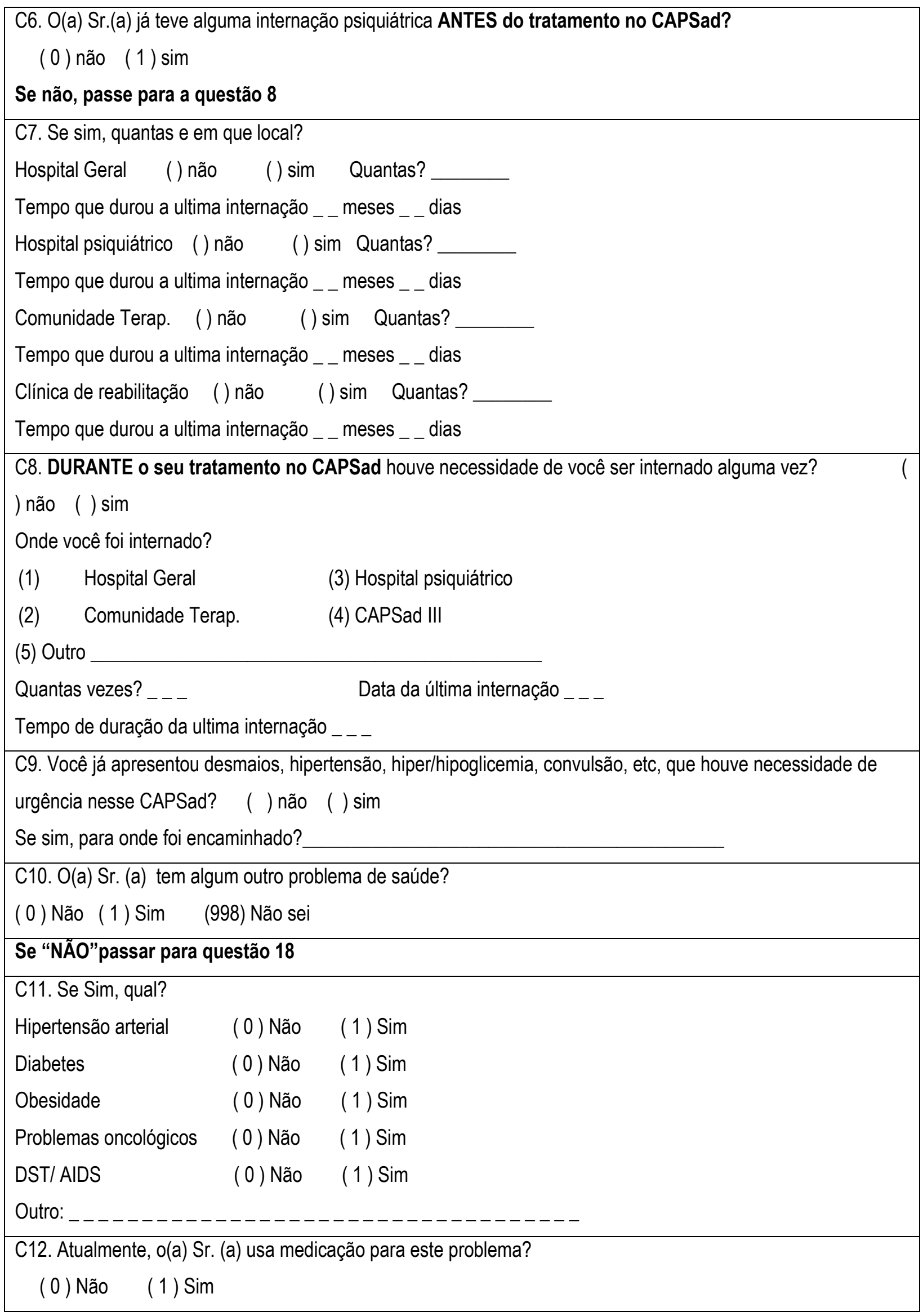




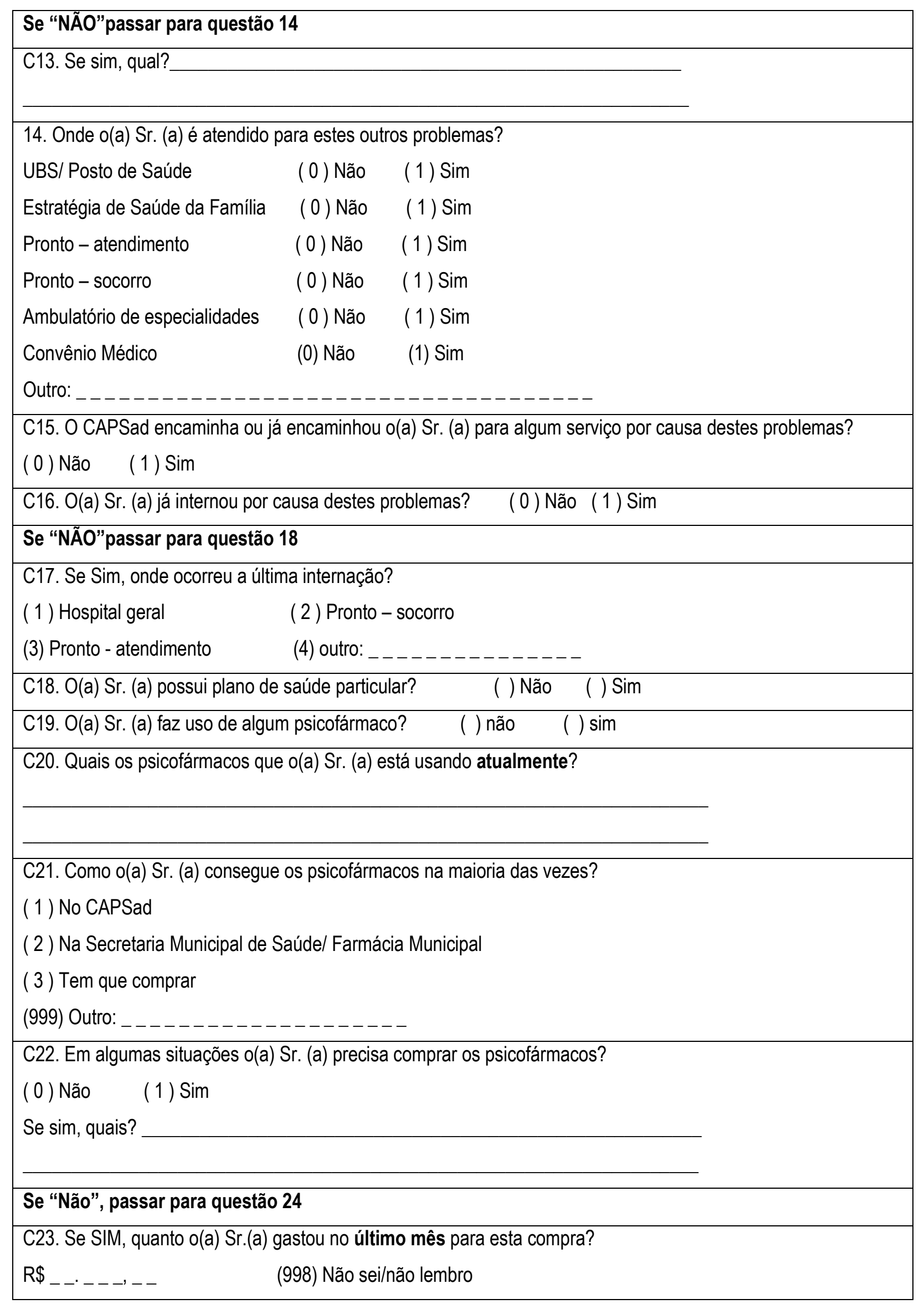




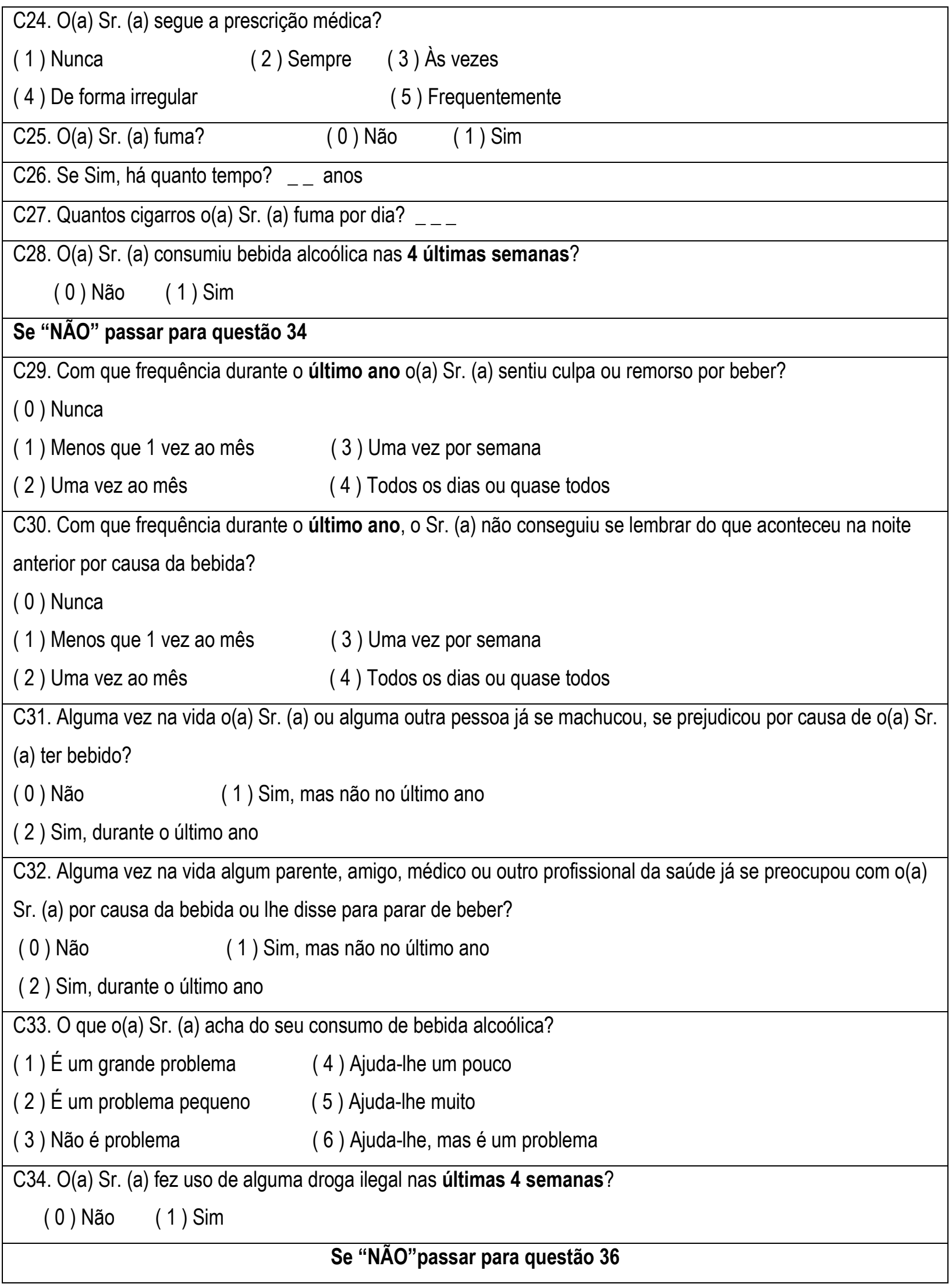




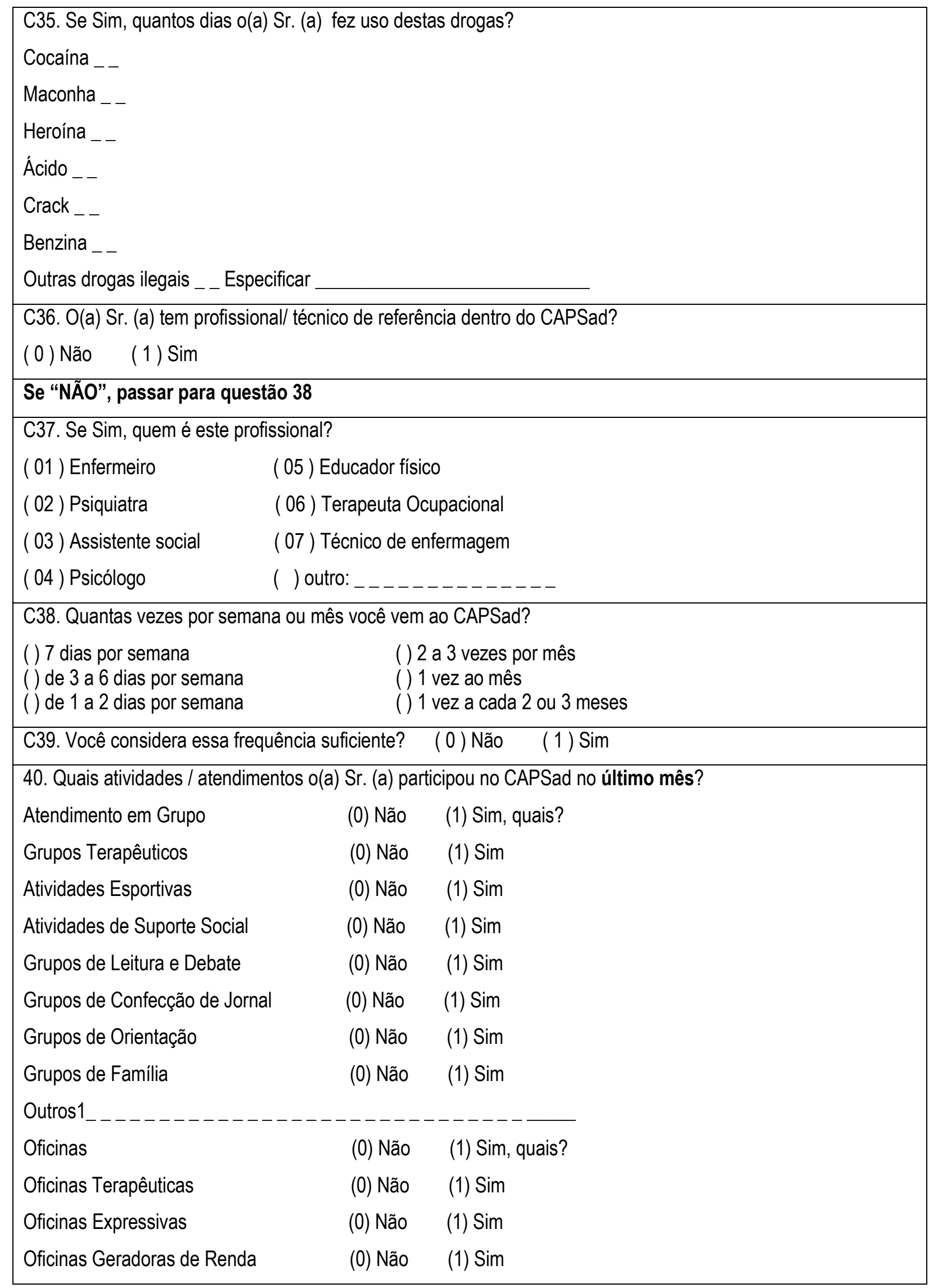




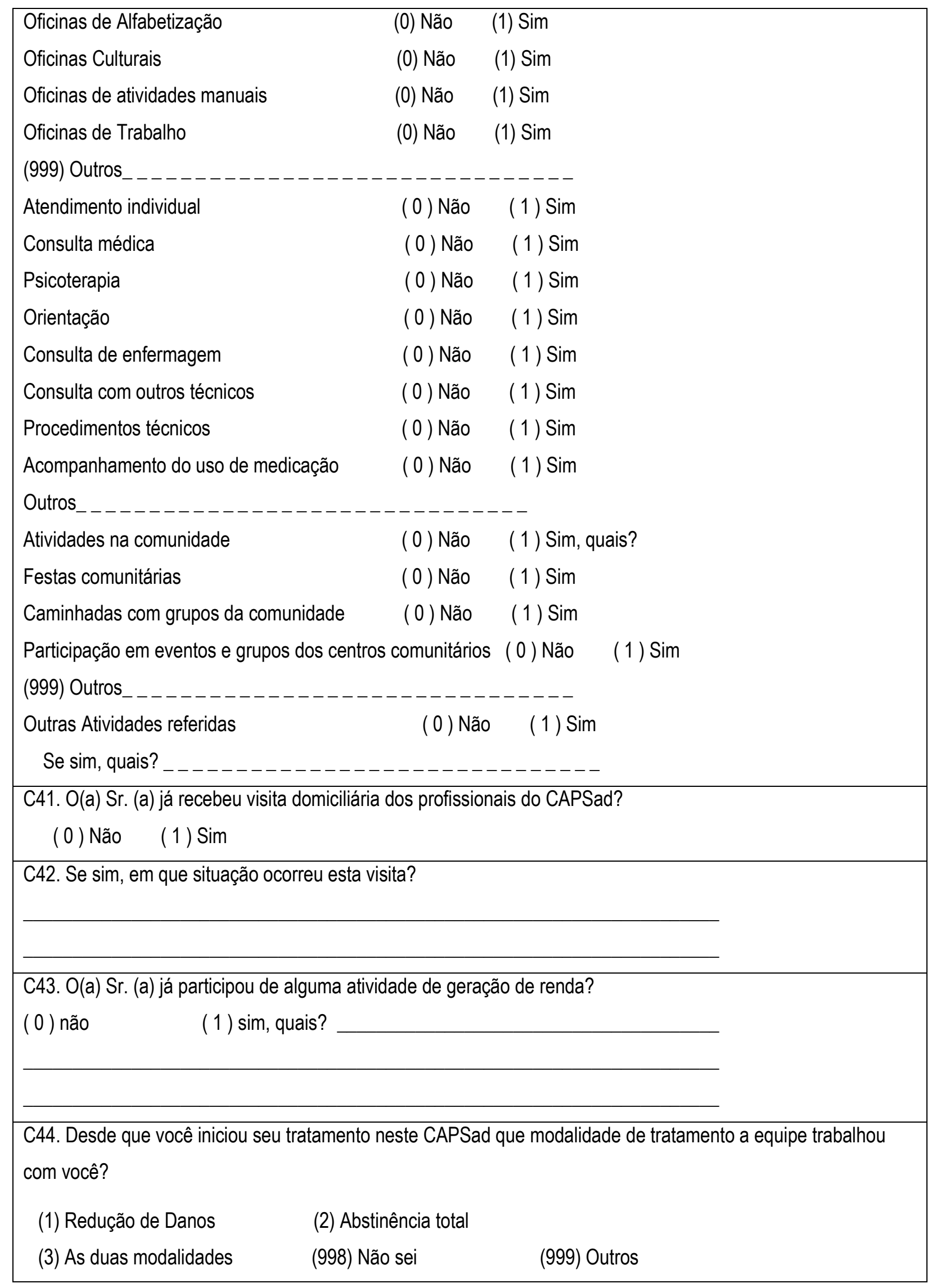


C45. Em outras necessidades, como moradia, educação, lazer, etc, esse serviço lhe ajuda?
(1) $\operatorname{Sim}$
(2) Não
Se sim, como?

C46. Quem encaminhou o(a) Sr. (a) ao CAPSad?
(1) Minha própria decisão
(5) Um médico/ terapeuta/técnico
(2) Uma pessoa da família
(6) Um serviço de referência
(3) Um amigo
(7) A polícia
(4) Ordem judicial
(999) outro

\section{* Nota ao Entrevistador: se foi uma ordem judicial, indicar quem a pediu}

47. Que tipo de transporte o(a) Sr. (a) usa para chegar a este serviço?
(1) Transporte próprio
(4) Transporte público
(2) Transporte da família
(5) Caminhada
(3) Transporte de amigos
(999) Outro

48. Quanto tempo o(a) Sr. (a) gasta para vir de sua casa até o CAPSad?
( 1 ) 0-15 min
( 3 ) $31-45 \mathrm{~min}$
( 2 ) $16-30 \mathrm{~min}$
( 4 ) 46-60 min
( 5 ) mais que $60 \mathrm{~min}$

C49.Como é para o(a) Sr. (a) chegar ao CAPSad?
(1) Muito difícil
( 2 ) Difícil
(3) Mais ou menos
( 4 ) Fácil
( 5 ) Muito fácil

C50. Qual a sua opinião sobre a maneira como o(a) Sr. (a) é tratado, em termos de respeito no CAPSad?
(1) Nunca me senti respeitado
(2) Geralmente não me senti respeitado
(3) Mais ou menos
(4) Geralmente me senti respeitado
(5) Sempre me senti respeitado

C51. Quando o (a) Sr. (a) falou com a pessoa que lhe admitiu/acolheu no CAPSad, ela lhe ouviu?

(1) Não ouviu de forma alguma
(2) Não ouviu
(4) Ouviu
(3) Mais ou menos
(5) Ouviu muito

C52. 0 que o (a) Sr(a) pensava ser o seu problema quando foi admitido/acolhido no CAPSad?
(1) Um problema físico de saúde
(5) Um problema financeiro
(2) Um problema psicológico
(6) Um problema no trabalho
(3) Um problema familiar
(998) Não sei
(4) Um problema social
(999) Outro 


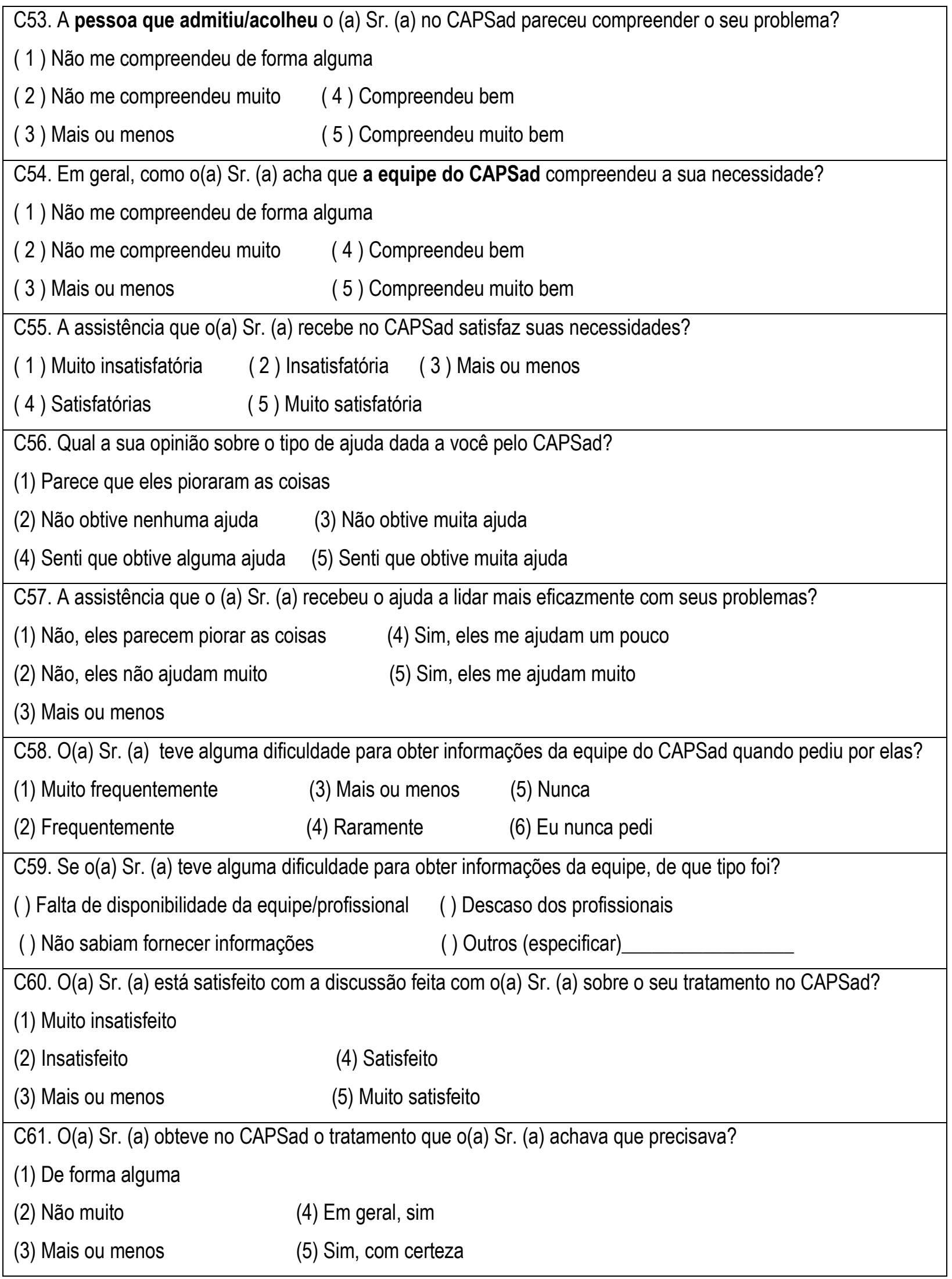


C62. O(a) Sr. (a) considera que a equipe do CAPSad esta lhe ajudando?

(1) Nunca
(2) Raramente
(4) Frequentemente

(3) Mais ou menos

(5) Sempre

C63. Em geral, como o (a) Sr. (a) classificaria a recepção/acolhida dos usuários pelos profissionais do CAPSad?
(1) Nada amigável
(3) Mais ou menos
(5) Muito amigável
(2) Pouco amigável
(4) Amigável

64. Por que o (a) Sr. (a) escolheu o CAPSad? (Marcar até 3 itens)

( ) No passado eu já estive aqui

( ) $O$ serviço foi fortemente recomendado por alguém

( ) Eu conhecia alguém que estava em tratamento aqui

( ) Eu confiei na recomendação de quem me referiu este serviço

( ) A localização é muito conveniente

( ) Estava dentro de minhas possibilidades financeiras

( ) Eu não tive outra escolha

() Outro:

C65. O(a) Sr. (a) está de acordo que sua família ou seus parentes sejam envolvidos no seu tratamento?

(1) Discordo totalmente
(2) Discordo
(4) Concordo
(3) Indiferente/Mais ou menos
(5) Concordo totalmente

C66. Na sua opinião, que grau de competência tem a pessoa que lhe assiste mais de perto (técnico de referência)?
(1) Muito incompetente
(3) Mais ou menos
(5) Muito competente
(2) Incompetente
(4) Competente

C67. Como o(a) Sr. (a) classificaria a competência da equipe do CAPSad?
(1) Muito incompetente
(3) Mais ou menos
(5) Muito competente
(2) Incompetente
(4) Competente

C68. O(a) Sr. (a) participa do processo de avaliação das atividades desenvolvidas no CAPSad?
(0) Não
(1) $\operatorname{Sim}$

C69. 0 que o(a) Sr. (a) acha de participar do processo de avaliação das atividades deste serviço?
(1) Discordo totalmente
(3) Indiferente
(5) Totalmente de acordo
(2) Discordo
(4) De acordo

C70. Como o(a) Sr. (a) classifica a qualidade da assistência que o (a) Sr. (a) recebeu no CAPSad?
( ) Péssima
() Regular
( ) Excelente
( ) Ruim
() Boa 


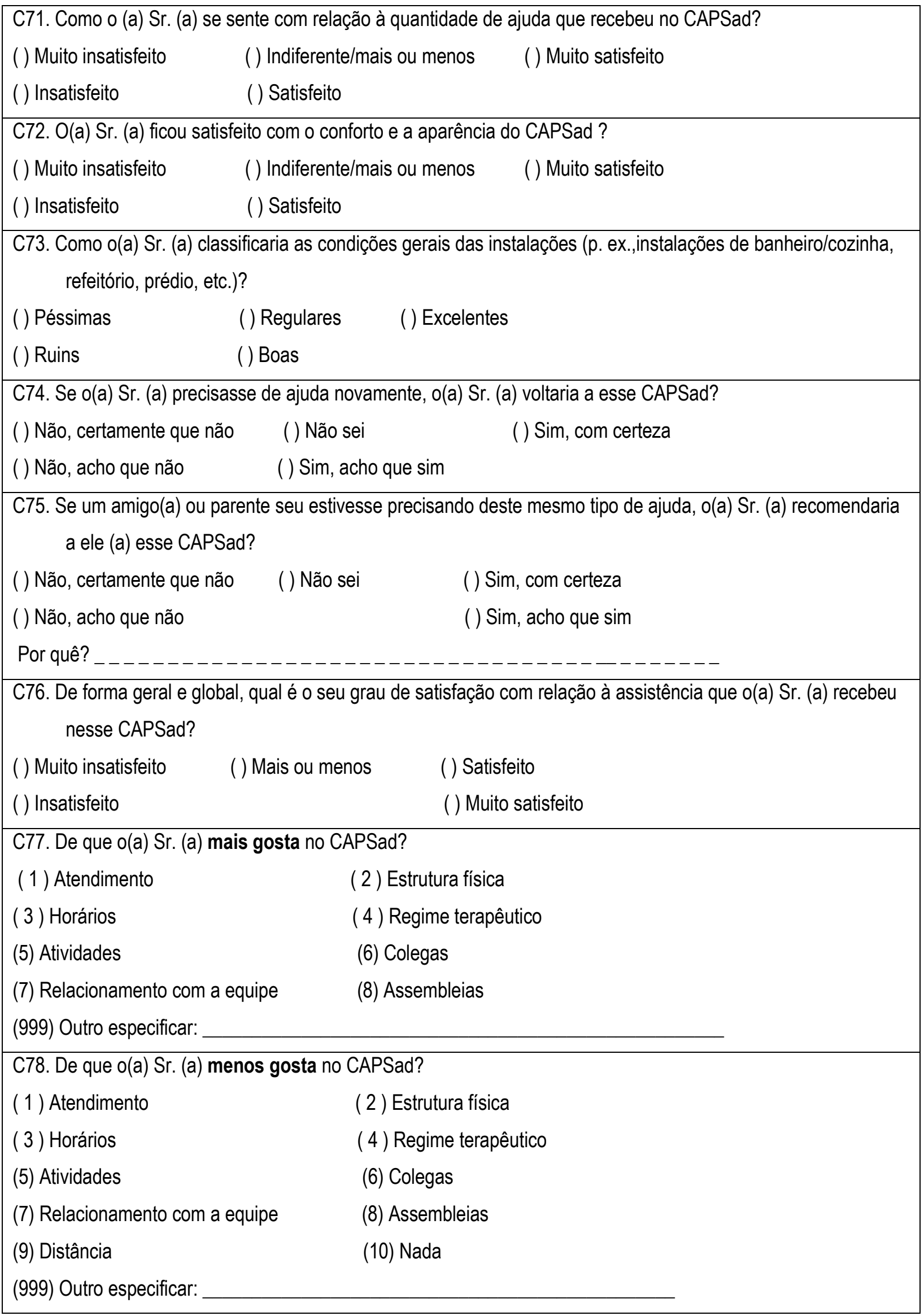


C79. Na sua opinião, o CAPSad poderia ser melhorado?

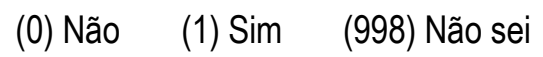

C80. Se Sim, de que maneira?

Agora vou lhe fazer algumas perguntas sobre como você se sente em relação a alguns aspectos de sua vida e você pode responder utilizando as seguintes possibilidades:

$0=$ MUITO INSATISFEITO

$10=$ MUITO SATISFEITO

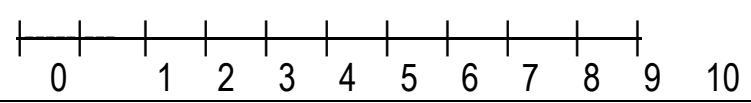

D1. Como o(a) Sr. (a) se sente em relação a maneira com que gasta seu tempo?

Nota:

D2. Como o(a) Sr. (a) se sente quando está sozinho? Nota:

D3. Como o(a) Sr. (a) se sente em relação a sua moradia? Nota:

D4. Como o(a) Sr. (a) se sente em relação à vizinhança do lugar onde o(a) Sr. (a) mora? Nota:

D5. Como o Sr(a). se sente em relação à comida que o(a) Sr. (a) come? Nota:

D6. Como o(a) Sr. (a) se sente em relação à roupa que o(a) Sr. (a) veste? Nota:

D7. Como o(a) Sr. (a) se sente em relação a sua vida afetiva? Nota:

D8. Como o(a) Sr. (a) se sente em relação a sua vida sexual? Nota:

D9. Como o senhor se sente em relação ao seu ciclo de amizades? Nota:

D10. Como o senhor se sente no que se refere ao relacionamento com sua família? Nota:

D11. Como o senhor se sente com relação às pessoas com quem o(a) Sr. (a) mora? Nota:

D12. Como o senhor se sente no que diz respeito ao seu relacionamento com as outras pessoas? Nota:

Agora, eu vou lhe perguntar, para cada aspecto da sua vida, se você acha que você teve mudanças desde que começou a se tratar aqui no CAPSad e se estas mudanças foram para pior ou para melhor.

Nota ao entrevistador: Para os itens abaixo, dizer : "Desde que você começou a se tratar aqui, ........ está(ão)......".

1. Os problemas pessoais

2. O humor

3. A estabilidade das emoções

4. O sentimento de confiança em si próprio

5. O sentimento de interesse pela vida

6. A capacidade de suportar situações difíceis

7. 0 apetite

8. A energia (disposição para fazer as coisas)

9. O sono

10. A saúde física (Dores, tremores)

11. A sexualidade (satisfação sexual)

12. A convivência com a família

13. A convivência com os amigos ou amigas

\begin{tabular}{c|c} 
Pior do \\
que antes
\end{tabular}

(0)

(0)

(0)

(0)

(0)

(0)

(0)

$(0)$

(0)

(0)

(0)

14. A convivência com as outras pessoas

(0)

15. O interesse em trabalhar ou se ocupar com alguma coisa

(0)

Sem
mudanças

Melhor do que antes

\begin{tabular}{|l}
\hline 2$)$ \\
\hline 2$)$ \\
\hline 2$)$ \\
\hline 2$)$ \\
\hline 2$)$ \\
\hline 2$)$ \\
\hline 2$)$ \\
\hline 2$)$ \\
\hline 2$)$ \\
\hline 2$)$ \\
\hline 2$)$ \\
\hline 2$)$ \\
\hline 2$)$ \\
\hline 2$)$ \\
\hline 2 \\
\end{tabular}




\begin{tabular}{|l|l|l|l|}
\hline 16. As atividades de lazer (as coisas que ele gostava de fazer) & $(0)$ & $(1)$ & $(2)$ \\
\hline $\begin{array}{l}\text { 17. As tarefas de casa (ex : cozinhar, fazer compras para a casa, } \\
\text { lavar roupa, arrumar o quarto ou a casa, consertar coisas, etc). }\end{array}$ & $(0)$ & $(1)$ & $(2)$ \\
\hline 18. A capacidade de cumprir as obrigações e tomar decisões & $(0)$ & $(1)$ & $(2)$ \\
\hline $\begin{array}{l}\text { Impressão geral: Finalizando, eu gostaria de saber se, } \\
\text { 19. Desde que você começou a se tratar aqui, em geral, você está }\end{array}$ & $(0)$ & (1) & (2) \\
\hline
\end{tabular}

Instrumento para coletar dados em prontuário

PRONTUÁRIOS

P1. Número de identificação:

P2..Cidade:

P3..Estado:

P4. Data da coleta:_____/2013

P5.Tipo: ( 1 ) CAPS II ad $\quad$ (2) CAPS II ad estendido

(3) CAPS III ad

P6. No do prontuário:

P6.Nome do usuário:

P7. Data de ingresso no serviço $1^{\mathrm{a}}$ vez: ${ }_{-}{ }_{-}{ }_{-}{ }_{-} \ldots \ldots$

P8. Data de ingresso no serviço última vez: ___ $I_{-} I_{\ldots} \ldots$

P9. Modalidade de acompanhamento atual:
() Intensivo
( ) Semi-intensivo
( ) Não intensivo

P10. Essa informação foi buscada na Autorização de Procedimentos Ambulatoriais de Alta Complexidade/Custo (APAC)?
( 0 ) Não
(1) $\operatorname{Sim}$

P11. Ingresso na modalidade atual de atendimento:

$-l_{--} I_{----}$

P12. Data do último registro de atendimento: ${ }_{-} I_{-} /{ }_{-}$

P13. CID:

P14. Essa informação foi buscada na APAC? ( 0 ) Não $\quad$ (1) Sim

$\mathrm{P} 15$. No registro, quem fez acolhimento inicial do usuário?
( 01 ) Enfermeiro
(02) Médico
( 03 ) Psicólogo
( 04 ) Assistente social
(5) Terapeuta Ocupacional
Outro:

P16. Encaminhado por:

$\begin{array}{lcc}\text { Unidade Básica de Saúde } & \text { ( } 0 \text { ) Não } & \text { (1) Sim } \\ \text { Estratégia de Saúde da Família } & \text { ( 0 ) Não } & \text { (1) Sim } \\ \text { Hospital Geral } & \text { ( 0 ) Não } & \text { (1) Sim } \\ \text { Emergência } & \text { ( 0) Não } & \text { (1) Sim } \\ \text { Ambulatório Especializado } & \text { ( 0) Não } & \text { (1) Sim } \\ \text { Hospital Psiquiátrico } & \text { ( } 0 \text { ) Não } & \text { (1) Sim }\end{array}$

Outro:

P17. Internações psiquiátricas: $\quad$ ( 0 ) Não $\quad$ (1) Sim 


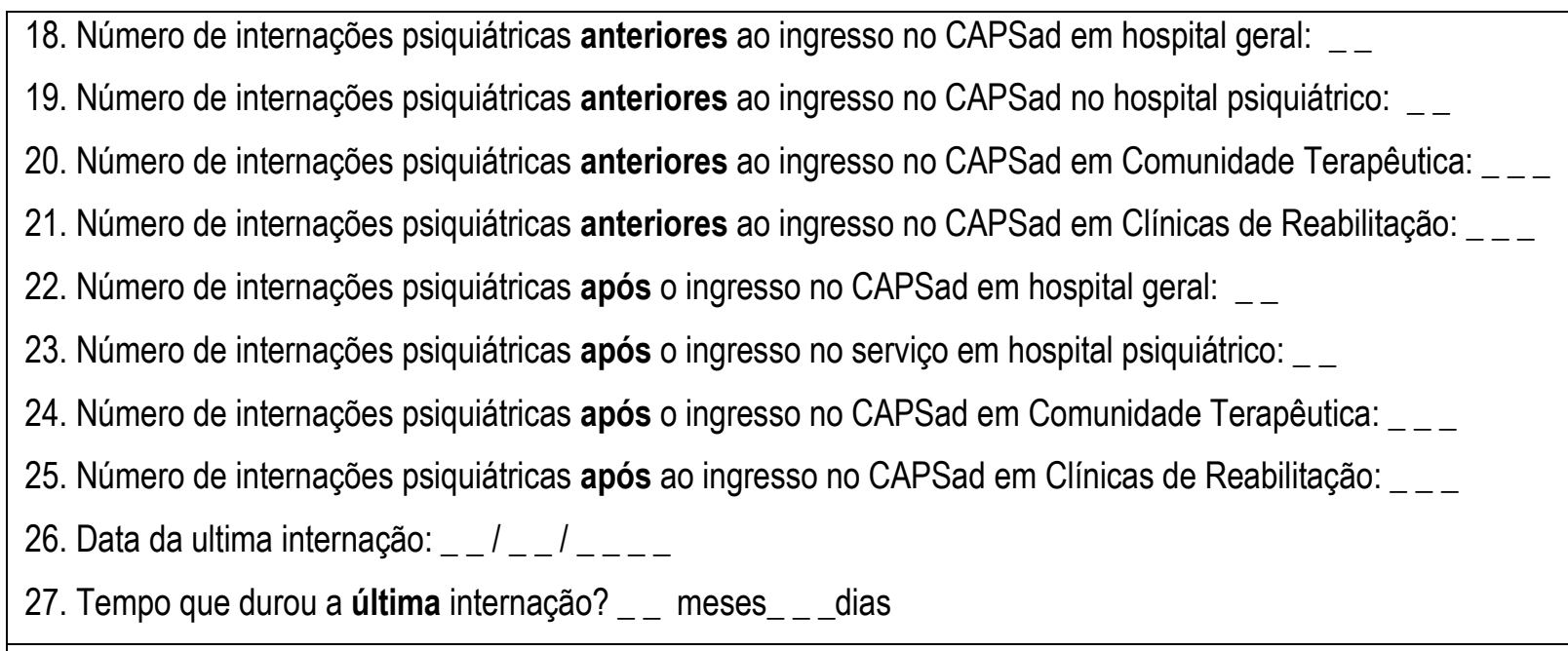

\section{Verifique a existência de registro dos seguintes itens:}
28. Atendimentos individuais:
( 0 ) Não
(1) Sim

Data do último atendimento: Qual atendimento
29. Atendimento grupal
( 0 ) Não
(1) $\operatorname{Sim}$

Data do último atendimento: _ _ $I_{-} I_{\text {_ }} \ldots$ __ Qual atendimento
30. Projeto Terapêutico Singular - PTS:
( 0 ) Não
(1) $\operatorname{Sim}$

Data do último PTS _ _ _ _ _ _ _
31. Intercorrências:
( 0 ) Não
(1) $\operatorname{Sim}$

Data da última intercorrência _ _ _ _ _ _ _ Qual intercorrência
32. Visitas domiciliárias:
( 0 ) Não
(1) $\operatorname{Sim}$

Data da última visita domiciliária _ $\_$_ $\_\ldots$

33. Atendimento / Orientações aos familiares:
( 0 ) Não
(1) $\operatorname{Sim}$
Data da última orientação aos familiares

34. Número de avaliações medicamentosas clínica nos últimos três meses:

Data da última avaliação medicamentosa clínica: _ _ _ _ _ _ _ _

35. Número de avaliações medicamentosas psiquiátrica nos últimos três meses:

Data da última avaliação medicamentosa psiquiátrica: _ _ _ _ _ _-_

36. Número de visitas domiciliárias no último mês:
(01) Enfermeiro: _-
Data da última visita: _ _ _ _ _ _- _
(02) Médico:
Data da última visita _ _ _ _ _ _-
(03) Assistente social:
Data da última visita $\ldots-I_{-} I_{-}-{ }_{-}$
(04) Psicólogo: _ _
Data da última visita _ _ _ I _ _-

Outro 1:__ Especificar:

Data da última visita _ _ _ _ _ _ _ 


\section{Caracterização da última história clínica:}
37. Sinais e sintomas:
( 0 ) Não
(1) $\operatorname{Sim}$
38. Historia familiar:
( 0 ) Não
(1) Sim
39. Uso de medicação:
( 0 ) Não
(1) $\mathrm{Sim}$
40. Avaliação das funções psíquicas:
( 0 ) Não
(1) $\operatorname{Sim}$
41. Apoio familiar:
( 0 ) Não
(1) $\operatorname{Sim}$
42. Adesão às atividades propostas
( 0 ) Não
(1) $\operatorname{Sim}$
43. Perfil sócio econômico
( 0 ) Não
(1) $\operatorname{Sim}$

\section{Caracterização do último PTS}

44. Espaço de definição do PTS:
Reunião de equipe:
( 0 ) Não
(1) Sim
Consulta individual:
( 0 ) Não
(1) Sim
Acolhimento:
( 0 ) Não
(1) $\operatorname{Sim}$
Outro:
( 0 ) Não
(1) $\mathrm{Sim}$

Especificar:

45. Quem participa da definição do PTS?
Enfermeiro:
( 0 ) Não
(1) $\mathrm{Sim}$
Médico:
( 0 ) Não
(1) $\mathrm{Sim}$
Psicólogo:
( 0 ) Não
(1) $\mathrm{Sim}$
Assistente social:
( 0 ) Não
(1) Sim
Terapeuta Ocupacional
(0) Não
(1) $\mathrm{Sim}$
Outro:
( 0 ) Não
(1) $\mathrm{Sim}$

Especificar:
46. Identifique se os seguintes itens fazem parte do PTS
Inserção no trabalho voluntário:
( 0 ) Não
(1) $\operatorname{Sim}$
Inserção no trabalho remunerado:
( 0 ) Não (1) Sim
Iniciativas de geração de renda:
( 0 ) Não
(1) $\mathrm{Sim}$
Inserção comunitária:
( 0 ) Não (1) Sim
Cuidados pessoais com o corpo:
( 0 ) Não (1) Sim
Grupo de conversação:
( 0 ) Não
(1) $\operatorname{Sim}$
Oficinas:
( 0 ) Não
(1) $\operatorname{Sim}$
Acompanhamento aos familiares:
( 0 ) Não
(1) Sim
Atendimento individual:
( 0 ) Não
(1) Sim
Atividades escolares:
( 0 ) Não
(1) Sim 


\begin{tabular}{|lll|}
\hline Prescrição de fármacos: & ( 0 ) Não & (1) Sim \\
Visita domiciliária: & ( 0 ) Não & (1) Sim \\
Assinatura de concordância do usuário & $(0)$ Não & (1) Sim \\
\hline 47. Psicofármacos em uso e / ou indicados na última prescrição: \\
\hline
\end{tabular}




\section{ANEXO 5 - Instrumento para os familiares dos usuários do}

serviço.

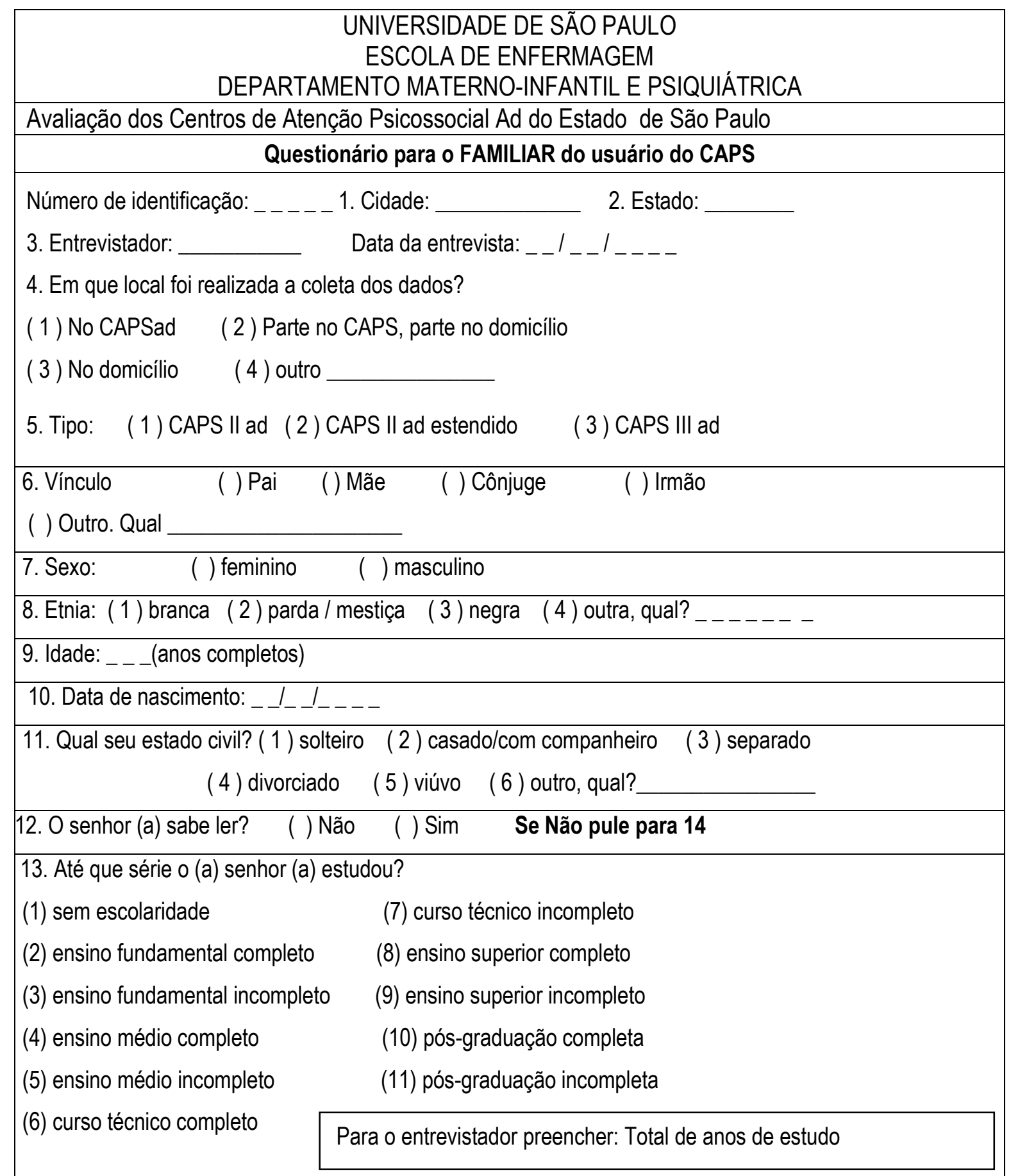

14. 0 (a) senhor (a) tem trabalho remunerado? ( 0 ) Não $\quad$ (1) Sim

Se Não pule para 16

15. Qual sua carga horária semanal de trabalho? _ _ semana 


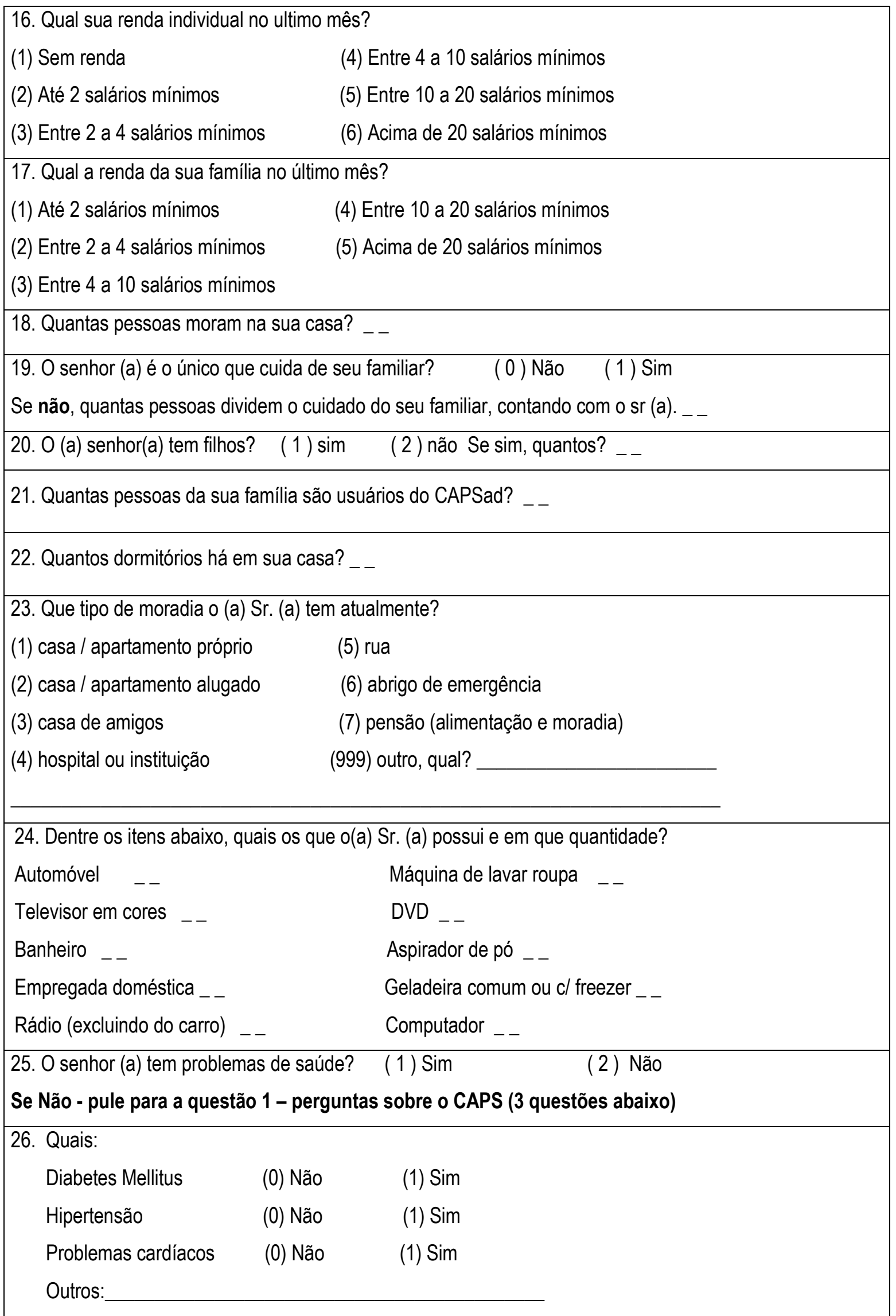




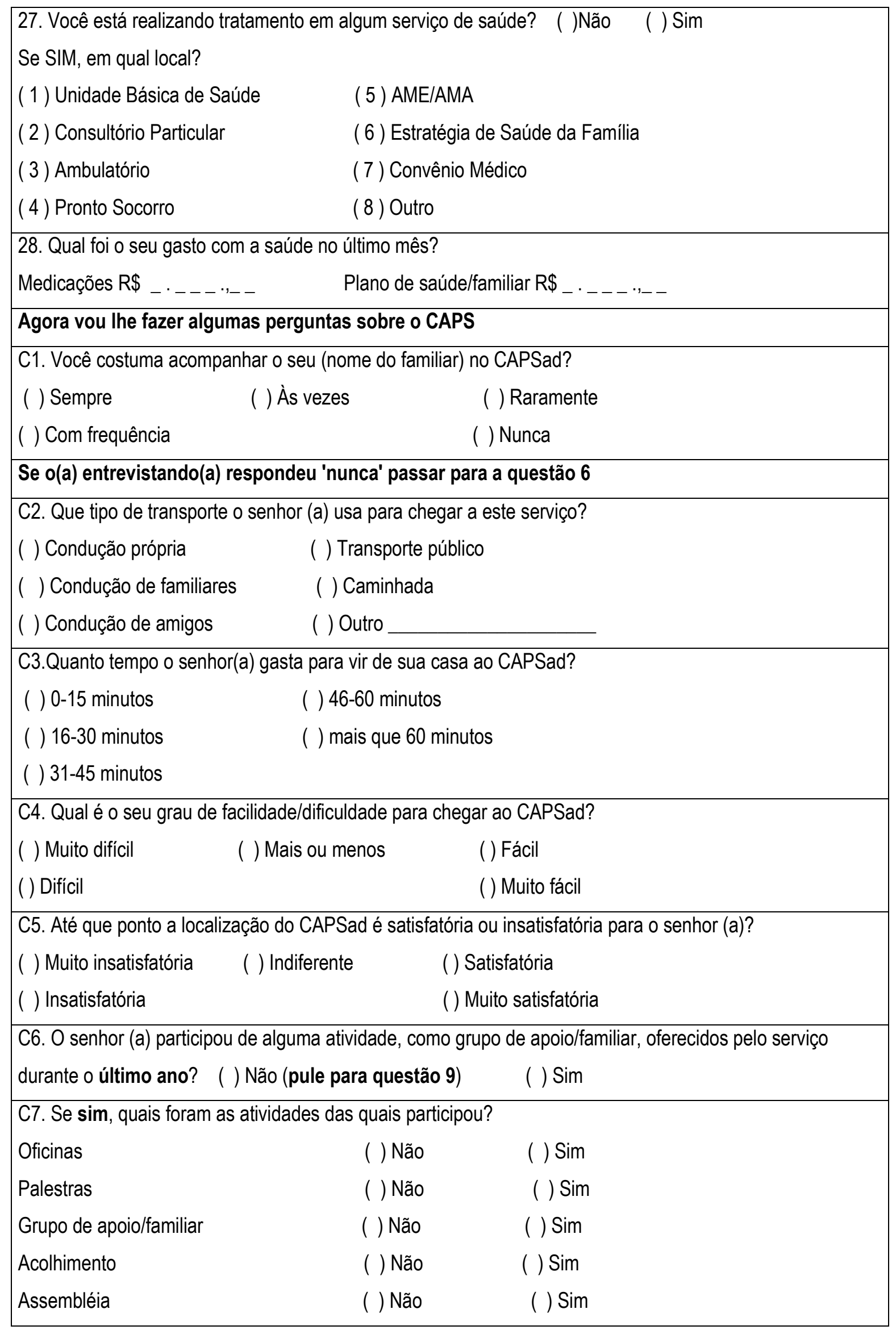




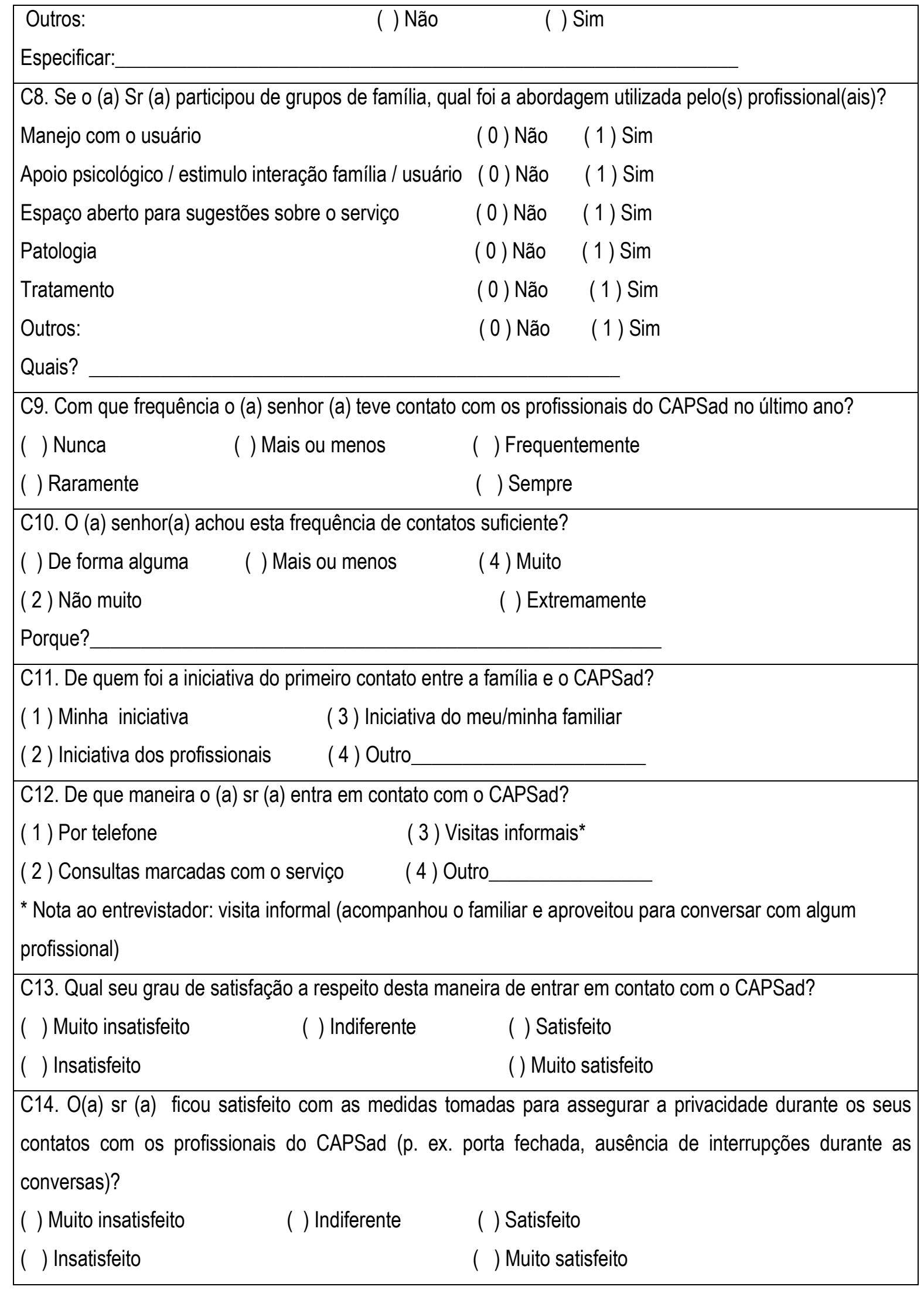


C15. Se o (a) sr (a) solicitou uma consulta com os profissionais do CAPSad, quanto tempo demorou até que fosse atendido?

( ) Não solicitei consulta (Se não solicitou, passar à questão 17)

( 2 ) Fui atendido imediatamente
( ) Menos que 1 dia
( ) Entre 2 semanas e 1 mês
( ) Entre 2 dias e 1 semana
( ) Mais de 1 mês
( ) Entre 1 e 2 semanas
( ) Não fui atendido até agora

C16. O (a) sr (a) achou este período de espera razoável?
( ) Nada razoável
( ) Mais ou menos
( ) Razoável
( ) Não muito razoável
( ) Muito razoável

C17. Em sua opinião, qual foi o grau de flexibilidade do serviço no agendamento de suas visitas, de acordo com sua disponibilidade (dia da semana e horário)?
( 1 ) Muito inflexível
( 3 ) Mais ou menos
( 4 ) Flexível
( 2 ) Inflexivel
( 5 ) Muito flexível

C18. O(a) sr (a) sentiu que foi tratado de forma respeitosa pela equipe do CAPSad?
( 1 ) Nunca me senti respeitado
( 4 ) Frequentemente me senti respeitado
( 2 ) Raramente me senti respeitado
( 5 ) Sempre me senti respeitado
( 3 ) Mais ou menos

C19. Em algum momento, aconteceu alguma violação de seus direitos como pessoa, por algum funcionário do CAPSad?
(1) Muito frequentemente
(3) Mais ou menos
( 4 ) Raramente
( 2 ) Frequentemente
( 5 ) Nunca

C20. Em sua opinião, qual era o principal problema que seu familiar tinha quando ele (a) foi admitido no CAPSad? Marcar apenas UMA resposta
( ) Um problema de saúde física
( ) Um problema financeiro
( ) Um problema de saúde mental
( ) Um problema no trabalho
( ) Um problema familiar
( ) Não sei
( ) Um problema social
( ) Outro (especificar)

C21. Quando o senhor (a) falou com a pessoa que admitiu seu familiar no CAPSad, o senhor (a) sentiu que ele (a) o (a) escutou?
( ) Não me escutou de forma alguma
( ) Me escutou bastante
( ) Não me escutou muito
( ) Me escutou o tempo todo
( ) Mais ou menos
( ) Não se aplica

C22. A pessoa que admitiu o seu familiar no CAPSad pareceu compreender o seu problema (situação).
( ) Não compreendeu de forma alguma
( ) Me compreendeu bem 


\begin{tabular}{|ll|}
\hline $\begin{array}{ll}\text { ( ) Não compreendeu muito } & \text { ( ) Me compreendeu muito bem } \\
\text { ( ) Mais ou menos } & \text { ( ) Não se aplica }\end{array}$ \\
\hline $\begin{array}{lll}\text { C23. O senhor (a) já teve alguma dificuldade para obter informações da equipe do CAPSad quando as } \\
\text { solicitou? }\end{array}$ \\
$\begin{array}{lll}\text { ( } 1 \text { ) Sempre } & \text { (3) Mais ou menos } & \text { ( } 5 \text { ) Nunca } \\
\text { ( } 2 \text { ) Frequentemente } & \text { (4) Raramente } & \text { (6) Nunca pedi }\end{array}$
\end{tabular}

C24. Se sim, que tipo de dificuldade o senhor (a) encontrou?

( 1 ) Falta de disponibilidade da equipe/profissional

( 2 ) Descaso dos profissionais

( 3 ) Não sabiam Ihe informar

(999) Outros (especificar)

C25. Alguma informação foi dada ao senhor (a) sobre a doença de seu familiar?
(1) Sim
( 2 ) Não
( 3 ) Meu parente não permitiu que eu fosse informado

C26. Se sim, estas informações foram claras para o (a) senhor (a)?
( 1 ) Não eram nada claras
( 3 ) Mais ou menos
( 4 ) Informações claras
( 2 ) Não eram muito claras
( 5 ) Informações muito claras

C27. Como o(a) senhor (a) se sente em relação ao tipo de informação que lhe foi dada acerca da doença de seu familiar?
(1) Muito insatisfeito
( 3 ) Mais ou menos
( 4 ) Satisfeito
( 2 ) Insatisfeito
(5) Muito satisfeito

C28. Em relação ao tratamento do seu familiar, alguma informação lhe foi dada?
(1) $\mathrm{Sim}$
( 2 ) Não (passar a questão 31)

( 3 ) Meu parente não permitiu que eu fosse informado (passar a questão 31)

C29. Se sim, estas informações foram claras para o (a) senhor (a)?
( 1 ) Não eram nada claras
( 3 ) Mais ou menos
( 4 ) Informações claras
( 2 ) Não eram muito claras
( 5 ) Informações muito claras

C30. 0 (a) senhor (a) se sente satisfeito em relação ao tipo de informação que the foi dada sobre 0 tratamento de seu familiar?
(1) Muito insatisfeito
(3) Mais ou menos
( 4 ) Satisfeito
( 2 ) Insatisfeito
(5) Muito satisfeito

C31. Alguma vez já foi pedida a sua opinião sobre o tratamento de seu familiar, no CAPSad?

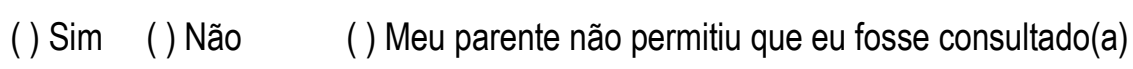


C32. O (a) senhor (a) está satisfeito (a) com as discussões a respeito do tratamento de seu familiar no CAPSad?
(1) Muito insatisfeito
( 3 ) Mais ou menos
( 4 ) Satisfeito
( 2 ) Insatisfeito
( 5 ) Muito satisfeito

C33. $\mathrm{O}$ (a) senhor (a) se sente satisfeito com as medidas tomadas para assegurar o sigilo acerca dos problemas discutidos com a equipe do CAPSad?
( 1 ) Muito insatisfeito
( 3 ) Mais ou menos
( 4 ) Satisfeito
( 2 ) Insatisfeito
(5) Muito satisfeito

C34. Quando o senhor e/ou seu familiar procuraram o CAPSad, qual o profissional que os recebeu?
( ) Terapeuta Ocupacional
() Médico
( ) Enfermeiro
( ) Assistente social
() Psicólogo
( ) Não lembro
()Outro

C35. Quando o (a) senhor (a) falou com a pessoa que admitiu seu familiar no CAPSad, o (a) senhor (a) achou que ele (a) escutou o paciente?
( ) Não escutou nada
( ) Mais ou menos
() Escutou bastante
( ) Não escutou muito
()Escutou o tempo todo

C36. Em geral, como o (a) senhor (a) acha que a equipe do CAPS ad compreendeu o tipo de ajuda que seu familiar necessitava?
( ) Não compreendeu de forma alguma
() Mais ou menos
( ) Compreendeu bem
( ) Não compreendeu muito
( ) Compreendeu muito bem

C37. Você considera os serviços oferecidos pelo CAPSad apropriados?
( ) Muito inapropriados
( ) Mais ou menos
( ) Apropriados
( ) Inapropriados
( ) Muito apropriados

C38. Os cuidados que seu familiar recebeu, o/a ajudaram a lidar mais eficientemente com o problema (situação) dele (a)?
( ) Não, eles pioraram as coisas ( ) Mais ou menos
( ) Sim, eles ajudaram um pouco
( ) Não, eles não ajudaram muito
( ) Sim, eles ajudaram muito

C39. O senhor (a) acha que seu familiar recebeu o tipo de cuidado que o (a) senhor (a) pensa ser o que ele/a necessitava?
( ) Não, de forma alguma
() Mais ou menos
( ) Em geral, sim
( ) Não, não muito
() Sim, com certeza

C40a. O (a) senhor (a) se sente satisfeito (a) com as medidas tomadas para assegurar a privacidade durante o tratamento de seu familiar no CAPSad? (ex: porta fechada, ausência de interrupção durante conversas com 0 profissional.)
( ) Muito insatisfeito
( ) Mais ou menos
() Satisfeito
( ) Insatisfeito
( ) Muito satisfeito 
C40b. O (a) senhor (a) se sente satisfeito (a) com as medidas tomadas para assegurar a confidencialidade dos problemas de seu familiar, e os cuidados que ele/a recebeu no CAPSad?
( ) Muito insatisfeito
() Mais ou menos
() Satisfeito
( ) Insatisfeito
() Muito satisfeito

C41. De maneira geral, como o (a) senhor (a) classificaria a recepção da equipe do CAPSad?
( ) Nada amigável
( ) Mais ou menos amigável
( ) Amigável
( ) Não muito amigável
( ) Muito amigável

C42. No momento em que o (a) senhor (a) e/ou o seu familiar entrou em contato com o CAPSad, tinha conhecimento de outros serviços/atendimentos disponíveis na comunidade?
(1) $\operatorname{Sim}$
( 3 ) Não tenho certeza (pule para 45)
( 2 ) Não (pule para 45)
( 4 ) Não sei (pule para 45)

C43. Se sim, quais eram as opções?
( 1 ) Hospital Psiquiátrico
( 4 ) Hospital geral
( 2 ) Grupo em Posto de Saúde
(5) Comunidade terapêutica
( 3 ) Grupo de apoio
(999) Outros

C44. Existindo outras opções de serviço, por que o (a) senhor (a) e seu familiar escolheram o CAPSad? (Marcar até 3 opções)

( 1 ) Ele/ela já tinha estado lá no passado

( 2 ) 0 serviço foi muito recomendado por alguém

( 3 ) Conheci alguém que fazia tratamento lá

( 4 ) Confiamos na instituição/pessoa de referência

( 5 ) A localização e muito conveniente

( 6 ) Estava dentro de nossas possibilidades financeiras

( 7 ) Não tivemos outra escolha

( 8 ) Serviço mais indicado

(998) Não sei

( ) Outro (especificar)

C45. No seu entendimento, qual a competência e conhecimento da pessoa que 0 atendeu/atende no CAPSad?
( 1 ) Muito incompetente
() Mais ou Menos
(3) Competente
( 2 ) Incompetente
(4) Muito competente

C46. Em geral, como o (a) senhor (a) classificaria o grau de competência da equipe do CAPSad?
( ) Muito incompetente
( ) Mais ou Menos
( ) Competente
( ) Incompetente
( ) Muito competente 
C47. O (a) senhor (a) participou de alguma decisão relacionada ao planejamento e/ou realização de atividades no CAPSad?
( ) Nunca (Pular para 50)
( ) Às vezes
( ) Frequentemente
( ) Raramente
( ) Muito frequentemente

C48. O senhor acha que suas opiniões e pontos de vista acerca do planejamento e/ou realização de atividades no serviço foram levados em consideração?
( ) Nunca
( ) Às vezes
( ) Frequentemente
( ) Raramente
( ) Muito frequentemente

C49. 0 (a) senhor (a) está satisfeito com sua participação no planejamento e/ou realização de atividades no CAPSad?
() Muito insatisfeito
() Mais ou menos
() Satisfeito
( ) Insatisfeito
() Muito satisfeito

C50. 0 (a) senhor (a) participou de alguma decisão relacionada à avaliação das atividades no CAPSad?
( ) Nunca (Pular para 53)
( ) Às vezes
( ) Frequentemente
( ) Raramente
() Muito frequentemente

C51. O senhor (a) sente que suas opiniões e pontos de vista referentes à avaliação das atividades foram levados em consideração?
( 1 ) Nunca (Pular para 53)
( 3 ) Às vezes
( 4 ) Frequentemente
( 2 ) Raramente
( 5 ) Muito frequentemente

C52. O senhor(a) ficou satisfeito com sua participação neste processo de avaliação?
( 1 ) Muito insatisfeito
( 3 ) Mais ou menos
( 4 ) Satisfeito
( 2 ) Insatisfeito
( 5 ) Muito satisfeito

C53. 0 (a) senhor (a) acha que seu familiar se beneficiou com o atendimento no CAPS?
( ) Não, de forma alguma
( ) Mais ou menos
( ) Sim, de alguma forma
( ) Não, não muito
( ) Sim, com certeza

C53a. Como você classificaria, de um modo geral, a qualidade do serviço que seu familiar recebeu?
( ) Péssima
() Mais ou menos
() Boa
( ) Ruim
() Excelente

C54. Como o (a) sr (a) se sente em relação ao tempo dedicado ao seu familiar?

(1) muito insatisfeito

( 2 ) moderadamente insatisfeito (5) um pouco satisfeito

( 3 ) um pouco insatisfeito

(6) moderadamente satisfeito

( 4 ) nem satisfeito nem insatisfeito

( 7 ) muito satisfeito 


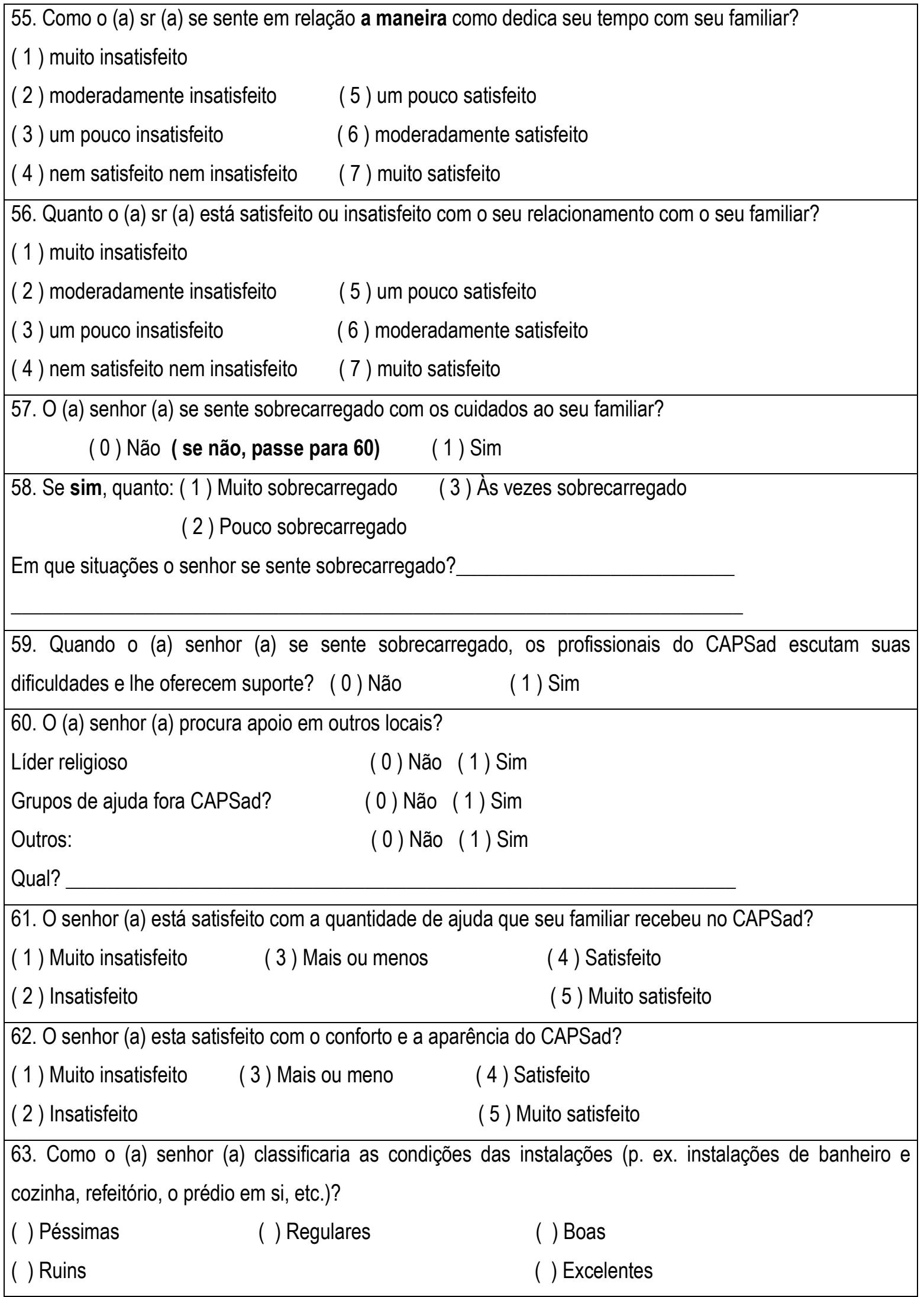


64. Suponhamos que seu familiar precisasse novamente de ajuda, o (a) senhor (a) o traria novamente a este CAPSad?
( 1 ) Não, de forma alguma
( 3 ) Talvez
( 4 ) Sim, acho que sim
( 2 ) Não, acho que não
( 5 ) Sim, com certeza

65. Se um amigo ou familiar estivesse necessitando de ajuda semelhante, o (a) senhor (a) o encaminharia a este CAPSad?
( 1 ) Não, de forma alguma
( 3 ) Talvez
(4) Sim, acho que sim
( 2 ) Não, acho que não
(5) Sim, com certeza

66. De maneira geral, qual é o seu grau de satisfação com relação aos cuidados que seu familiar recebeu no CAPSad?
( ) Muito insatisfeito
( ) Nem satisfeito, nem insatisfeito
() Satisfeito
( ) Insatisfeito
( ) Muito satisfeito

67. Do que o (a) senhor (a) mais gostou neste serviço?
(1) Atendimento
(5) Atividades
( 2 ) Estrutura física
(6) Colegas do grupo
( 3 ) Horários
(7) Relacionamento com a equipe
( 4 ) Regime terapêutico
(8) Assembleias

(999) Outro

68. Qual é o aspecto que o (a) senhor (a) menos gostou neste serviço?
( 1 ) Atendimento
(5) Atividades
( 2 ) Estrutura física
(6) Colegas do grupo
( 3 ) Horários
(7) Relacionamento com a equipe
( 4 ) Regime terapêutico
(8) Assembleias
(999) Outro

69. Em sua opinião, este serviço poderia ser melhorado?
(1) Sim
( 2 )Não
(998) Não sei

70. Se sim, de que forma?

AGORA LHE FAREI ALGUMAS PERGUNTAS ACERCA DE SEU FAMILIAR

Nota ao entrevistador: Para os itens abaixo, dizer:

"Desde que_(Nome) começou a se tratar aqui ......dele(a) está(ão)......"

\begin{tabular}{|l|c|c|c|}
\hline & $\begin{array}{c}\text { Pior do que } \\
\text { antes }\end{array}$ & $\begin{array}{c}\text { Sem } \\
\text { mudanças }\end{array}$ & $\begin{array}{c}\text { Melhor do } \\
\text { que antes }\end{array}$ \\
\hline 1. Os problemas pessoais & $(0)$ & $(1)$ & $(2)$ \\
\hline 2. O humor & $(0)$ & $(1)$ & $(2)$ \\
\hline 3. A estabilidade das emoções & $(0)$ & $(1)$ & $(2)$ \\
\hline 4. O sentimento de confiança em si próprio & $(0)$ & $(1)$ & $(2)$ \\
\hline
\end{tabular}




\begin{tabular}{|l|c|c|c|}
\hline 5. O sentimento de interesse pela vida & $(0)$ & $(1)$ & $(2)$ \\
\hline 6. A capacidade de suportar situações difíceis & $(0)$ & $(1)$ & $(2)$ \\
\hline 7. O apetite & $(0)$ & $(1)$ & $(2)$ \\
\hline 8. A energia (disposição para fazer as coisas) & $(0)$ & $(1)$ & $(2)$ \\
\hline 9. O sono & $(0)$ & $(1)$ & $(2)$ \\
\hline 10. A saúde física (Dores, tremores) & $(0)$ & $(1)$ & $(2)$ \\
\hline 11. A sexualidade (satisfação sexual) & $(0)$ & $(1)$ & $(2)$ \\
\hline 12. A convivência com a família & $(0)$ & $(1)$ & $(2)$ \\
\hline 13. A convivência com os amigos ou amigas & $(0)$ & $(1)$ & $(2)$ \\
\hline $\begin{array}{l}\text { 14. A convivência com as outras pessoas } \\
\text { 15. O interesse em trabalhar ou se ocupar com } \\
\text { alguma atividade }\end{array}$ & $(0)$ & $(1)$ & $(2)$ \\
\hline $\begin{array}{l}\text { 16. As atividades de lazer (as coisas que ele } \\
\text { gostava de fazer) }\end{array}$ & $(0)$ & $(1)$ & $(2)$ \\
\hline $\begin{array}{l}\text { 17. As tarefas de casa (ex: cozinhar, fazer compras } \\
\text { para a casa, lavar roupa, arrumar o quarto ou a } \\
\text { casa, consertar coisas, etc). }\end{array}$ & $(0)$ & $(1)$ & $(2)$ \\
\hline $\begin{array}{l}\text { 18. A capacidade de cumprir as obrigações e tomar } \\
\text { decisões }\end{array}$ & $(0)$ & $(1)$ & $(2)$ \\
\hline $\begin{array}{l}\text { Impressão geral: Finalizando, eu gostaria de saber se: } \\
\text { 19.Desde que_ (Nome) começou a se tratar } \\
\text { no_(Nome do local), em geral, ele(a) está }\end{array}$ & $(0)$ & $(1)$ & $(2)$ \\
\hline
\end{tabular}
Agradecimento ao familiar 


\section{ANEXO 6 - Autorização para utilização dos instrumentos.}

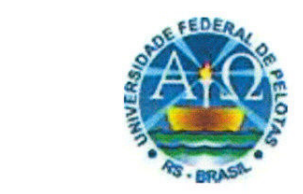

UNIVERSIDADE FEDERAL DE PELOTAS

FACULDADE DE ENFERMAGEM

AUTORIZAÇÃO

Eu, Professora Doutora Luciane Prado Kantorski vinculada a Faculdade de Enfermagem da Universidade Federal de Pelotas, coordenadora do Projeto de Avaliação dos Centros de Atenção Psicossocial do Sul do Brasil - CAPSUL I e II autorizo a Professora Doutora Márcia Aparecida Ferreira de Oliveira, pesquisadora responsável principal pelo projeto intitulado "Avaliação dos CAPS ad do Estado de São Paulo e Minas Gerais", o qual pertence ao Grupo de Estudos em Álcool e outras Drogas, do Departamento de Enfermagem Materno Infantil e Psiquiátrica da Escola de Enfermagem da Universidade de São Paulo (GEADEEUSP), composto por alunos de graduação e pós-graduação, professores e profissionais da área de Saúde, a utilizar os instrumentos de coleta de dados aplicados aos coordenadores, profissionais, usuários e familiares com o objetivo de adaptação e aplicação nessa mesma população do referido projeto. Solicito que nas publicações derivadas do referido projeto quando os resultados forem obtidos a partir dos questionários do CAPSUL (em versão original ou adaptada) seja feita explícita referência a utilização dos instrumentos.

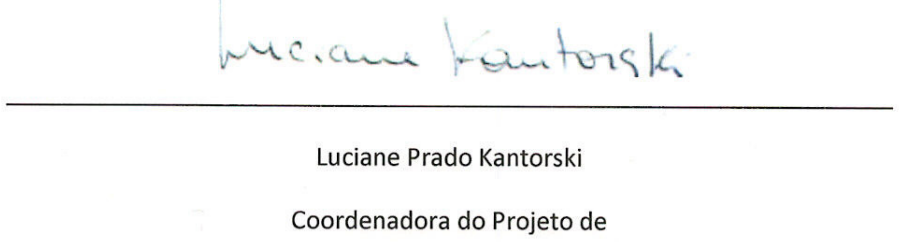

Avaliação dos Centros de Atenção Psicossocial do Sul do Brasil - CAPSUL I e II 
ANEXO 7 - Projeto terapêutico institucional do serviço.

\section{CENTRO DE ATENÇÃO PSICOSSOCIAL - CAPSAD RENASCER}

O Centro de Atenção Psicossocial - CAPSAD RENASCER é um serviço vinculado ao Centro de Atenção Integral à Saúde - CAIS Professor Cantídio de Moura Campos, sob a Gerência do Núcleo de Atenção Integral a Saúde - NAIS.

Localiza-se à Rua Úrsula Camargo de Barros, №265, Jardim Paraíso, local de fácil acesso por transporte coletivo municipal e também, para os pacientes de outros municípios, que são trazidos pelas frotas das diversas Secretarias Municipais de Saúde.

O CAPSAD iniciou seus trabalhos em janeiro de 2007, seguindo as diretrizes da Política Nacional de Saúde Mental expressa na Lei ํo. 10. 216 de 06/04/01, que dispõe sobre a proteção dos direitos das pessoas portadoras de transtornos mentais e regulamentada pela Portaria GM/MS 336/ 2002, que define as normas de funcionamento dos CAPS.

Trata se de um serviço especializado no tratamento de usuários de álcool e outras drogas, de abrangência regional, que disponibiliza assistência preferencialmente aos trinta municípios, das regiões de Avaré e de Botucatu, o que corresponde a aproximadamente 587.655 mil habitantes (IBGE/2007), abrangidos pela Direção Regional de Saúde - DRS VI - Bauru.

\section{Missão}

Ser um serviço de referência regional, que fundamenta sua proposta técnica na implementação de políticas públicas de Saúde Mental vigentes, em consonância com os princípios éticos da Reforma Psiquiátrica Brasileira e de acordo com as diretrizes organizacionais do SUS, oferecendo atendimentos individuais e em grupos, com equipe multiprofissional e abordagem interdisciplinar, para o tratamento de transtornos decorrentes do uso e abuso de álcool e outras drogas, objetivando a reabilitação e a reinserção psicossocial.

\section{Características Gerais}

Serviço ambulatorial de média complexidade da rede SUS, especializado na abordagem e tratamento das dependências químicas, álcool e outras drogas.

O CAPSAD oferece diferentes abordagens terapêuticas, dependendo da avaliação inicial, quando o usuário será admitido em uma das três modalidades de atenção, intensiva, semi-intensivo ou não intensiva, que são distribuídas em turnos de quatro ou de oito horas por dia. A modalidade Intensiva destina-se aos usuários em estado de intenso sofrimento físico e psíquico pelo uso abusivo e sistemático de álcool e/ou outras drogas, graves situações de risco social e com significativas fragilidades nas relações familiares. A 
atenção semi-intensiva é voltada para pacientes em situação de sofrimento físico e psíquico relevante pelo uso e abuso de substâncias psicoativas, em risco social e sérios desgastes das relações familiares. A assistência não intensiva é destinada aos usuários de álcool e/ou outras drogas que apresentam sofrimento psíquico moderado, com alguma preservação de vínculos sociais, familiares, e às vezes laborais. Os usuários do CAPSAD transitam pelas modalidades de atenção supracitadas, de acordo com suas necessidades biopsicossociais e laborais, avaliadas e discutidas pela equipe técnica e pactuadas com eles e seus familiares, sempre que possível. A forma de inclusão no serviço determina a quantidade de refeições que receberá no CAPSAD:

> Turno de quatro horas: uma refeição diária;

$>$ Turno de oito horas: três refeições diárias.

\section{Capacidade}

Modalidade Intensiva: ocorre 04 vezes por semana no mínimo, e no máximo com 22 frequências/mês (procedimentos SIA/SUS), para 40 pacientes/mês;

Modalidade Semi-intensiva: até 3 vezes/semana, máximo de 12 frequências/mês (procedimentos SIA/SUS), para 60 pacientes/mês;

Modalidade não intensiva: a frequência é de 01 vez por semana ou no máximo de 03 frequências/ por mês (procedimentos SIA/SUS), para 90 pacientes/mês.

\section{Horário de Trabalho}

O CAPSAD funciona de segunda a sexta-feira, das 7:30 às 18:00 horas, podendo funcionar até às 21:00 horas, caso haja necessidade. Ass sextas-feiras, acontecem as reuniões de equipe técnica das 8:00 às 14:00 horas, quando ocorrem as discussões dos casos clínicos, atividades de matriciamento interserviços de saúde mental, outros serviços do CAIS Cantídio e os profissionais de referência em Saúde Mental nos 30 municípios das macro regiões de Avaré e de Botucatu. É também, um espaço de integração e de construção coletiva de saberes sobre a atenção integral em álcool e outras drogas com os 30 municípios e a faculdade de Medicina de Botucatu, através do Departamento de Neuropsiquiatria e Psicologia.

\section{Desenvolvimento}

As abordagens terapêuticas oferecidas pelo CAPSAD baseiam-se na estratégia de Redução de Danos e de Abstinência, de acordo com a disponibilidade e as vulnerabilidades do usuário e as possibilidades terapêuticas avaliadas tecnicamente em equipe e em conjunto com o paciente, e que estão integradas aos serviços de saúde municipais e a rede de apoio instalada.

$\mathrm{O}$ inicio do tratamento acontece de forma gradativa, iniciando pelo Grupo de Acolhimento, que consiste em um dispositivo utilizado 
por este serviço para tentar amenizar a falta de adesão dos usuários ao tratamento, bem como ajudá-lo no processo de motivação tendo como facilitador a escuta livre.

Após dois encontros, o paciente que quer se tratar, é encaminhado para Triagem, que através de uma entrevista estruturada e uma escuta individualizada, será avaliado a demanda de cada caso e pactuado com o paciente o seu Projeto Terapêutico Individual, o PTI. Este PTI deverá ser seguido durante o tratamento e poderá ser alterado conforme a evolução do caso.

O projeto terapêutico busca minimizar fatores de risco, reforçando estratégias de autoproteção e fortalecimento pessoal, contemplando atitudes mais proativas e flexíveis frente às recaídas, oferecendo ao usuário e familiares. As seguintes modalidades terapêuticas: Grupo de Acolhimento, Triagem, Grupo de Apoio para Alcoolistas, Grupo de Apoio para Usuários de Drogas, Oficinas de Artesanato, Culinária e de Autocuidados, Assembleia Geral do CAPSAD, Grupo de Ação, Grupo de Manutenção, Grupos Esportivos de Natação e de Caminhada, Terapia Ocupacional, Atendimento Individual, Psicoterapia Individual, Consulta Médica Clínica e Psiquiátrica, Visitas Domiciliares e Atividades Culturais internas como o Grupo Cultural e o Cine Pipoca e de Lazer, além de atividades externas, como passeios e excursões.

Qualquer paciente sob efeito agudo de álcool e/ou drogas será atendido individualmente por um profissional da equipe.

\section{Agendamento}

O CAPSAD - Renascer acolhe a $100 \%$ da demanda, referenciada ou espontânea, certificando-se quanto à natureza da procura, se é um caso novo ou reincidente. Toda procura é acolhida e caso não seja uma urgência, o paciente é agendado para um dos Grupos de Acolhimento.

O agendamento também poderá ser realizado por telefone.

Em casos de urgência, a Triagem acontece no mesmo dia. $\mathrm{O}$ funcionário responsável pela recepção registra as informações sobre a solicitação de tratamento: nome completo, um telefone de contato e município de residência do solicitante, e será agendado dia e horário para comparecimento ao serviço.

Todo paciente recebe um cartão onde é anotado seu nome, a data do retorno e hora, é também orientado quanto à documentação necessária (CIC, RG, CARTÃO SUS e comprovante de endereço) para registro no CAPSAD. Nenhum paciente deixa de ser atendido por falta de documentos, nesse caso é solicitado a ele que os traga no retorno agendado e caso não os tenha, é orientado como e onde tirá-los.

\section{Triagem}

Realizada pela equipe técnica do CAPSAD. 


\section{Do Paciente}

Paciente deve comparecer ao CAPSAD no dia e horário marcados, portando os documentos solicitados.

\section{Do CAPSAD}

- Acolher aos pacientes identificando-se enquanto profissional;

- Fazer o acolhimento humanizado de todos que procuram o serviço;

- Realizar coleta de dados de identificação do paciente;

- Realizar entrevista técnica (triagem ou retriagem) de forma acolhedora;

- Fornecer orientações quanto ao funcionamento do serviço, as modalidades de atenção disponíveis oficinas terapêuticas em funcionamento e as normas gerais do CAPSAD;

- Informar ao NAME os dados de identificação do paciente para fins de recebimento do prontuário e $\mathrm{n}^{0}$ de registro no CAIS Cantídio;

- Preencher identificação no formulário de APAC;

- Realizar avaliação pelo médico clínico;

- Realizar avaliação pelo médico psiquiatra.

- Discutir com o paciente seu Projeto Terapêutico Individual - PTI.

- Informar ao paciente sobre as datas e horários para início da participação nas atividades.

\section{Dos 30 Municípios das Regiões de Avaré e de Botucatu}

- Responsabilizar-se pelo transporte do paciente e familiares até o CAPSAD, e o retorno dos mesmos ao final das atividades.

- Responsabilizar-se pela realização de exames laboratoriais solicitados pelos profissionais médicos, disponibilizando os resultados para o CAPSAD, através do próprio paciente ou da forma que o município achar conveniente.

- Discutir com equipe técnica do CAPSAD casos clínicos em Dependência Química e pactuar ações.

- Disponibilizar serviço de acolhimento e/ou tratamento para contra referência quando da alta do paciente.

\section{Projeto Terapêutico Individual (PTI)}

Elaborado por um dos técnicos da equipe com o paciente, o PTI servirá para nortear o trabalho terapêutico no CAPSAD e deverá ser alterado de acordo com a evolução do caso.

Os técnicos da equipe do CAPSAD estão subdivididos em 3 miniequipes que são referências para um número de pacientes, sendo que cada paciente tem um profissional que é sua referência dentro das miniequipes. Estas miniequipes devem trabalhar de forma intersetorial com os recursos dos municípios atendidos, sendo o apoio matricial um recurso importante do trabalho. 


\section{Rotinas de Enfermagem}

Horário de verificação de PA e HGT ocorrem de acordo com a demanda; 10h - 10:30h ----- 16h às 16:30h. (As intercorrências serão avaliadas.)

\section{Repouso:}

- SSVV (Sinais Vitais) - 1 vez em cada período ou de acordo com a prescrição médica;

- Cuidados de enfermagem com venóclise;

- CCGG (Cuidados Gerias) - higienização;

- Mudança de decúbito;

- Limpeza do leito;

- Retirar roupas sujas e encaminha-las ao expurgo;

\section{Posto de Enfermagem}

- Controle de materiais esterilizados;

- Realização de inalação prescrita;

- Realização de desinfecção de máscaras de inalação;

- Realização de pequenos curativos;

- CCGG (Cuidados gerais);

- Realização de anotações de enfermagem nos prontuários.

- Organizar roupas do quarto de desintoxicação;

\section{Encaminhamentos}

- De acordo com escala estabelecida pela enfermeira;

- Levar carta de encaminhamento;

- Acompanhar o paciente até a chegada de familiares ou a internação;

\section{Roupas sujas}

São retiradas em hamper no final de cada plantão e armazenadas no expurgo, sendo recolhidas e encaminhadas ao CAIS Cantídio sempre que necessário.

\section{Roupas limpas}

- Solicitadas à lavanderia do CAIS Cantídio quando necessário e armazenadas em armário próprio para este fim, no CAPSAD.

\section{Medicação}

- Horário de medicação: 2a à 5 $5^{\text {a }}$ feira - 10:30h, 12:00h, 15:30h e 17:00h. Exceções serão avaliadas.

- Medicação será fornecida de acordo com a demanda do paciente. Fornecida pelo Núcleo de Assistência Farmacêutica do CAIS Cantídio, através do envio de receitas as segundas e quintas-feiras e são armazenadas em um pequeno estoque no CAPS-AD e separadas diária, quinzenal ou mensalmente, conforme PTI do paciente. Os medicamentos de alto custo são fornecidos pela Farmácia de auto custo situada na UNESP, as 
medicações clínicas são fornecidas pelas UBS's e as medicações psicotrópicas fornecidas pela farmácia do CAIS.

- Orientações quanto à posologia das medicações;

- Controle de estoque de medicamentos;

A farmacêutica responsável é lotada na Farmácia do CAIS Cantídio, de onde distribui através de formulários e mapas de controle de medicamentos para cada Núcleo de Atenção Integral a Saúde - NAIS I.

Controle das medicações psicotrópicas e clínicas em estoque.

A separação da medicação é feita de acordo com o PTI do paciente.

Orientação quanto à posologia da medicação.

OBS: Auxiliares de enfermagem executam outras funções que não suas atividades técnicas ex: oficineira, recepção, etc.

\section{Recepção}

- Separar e guardar prontuários para atendimentos médicos;

- Realizar o agendamento;

- Prestar orientações gerais e quando da solicitação de exames de sangue, o pedido - SADT - é entregue ao paciente para que colha em unidade de saúde de referência. Os resultados dos exames deverão ser trazidos ao CAPS-AD pelo paciente.

Colocar data da próxima consulta e PTI dos pacientes na prescrição médica (a lápis);

\section{Material de Consumo}

Fornecido pelo CAIS através de solicitação feita mensalmente via planilha padronizada pelo NGC do CAIS Cantídio. Os materiais ficam armazenados em local específico para cada tipo, tais como escritório, higiene, limpeza e enfermagem, sendo de responsabilidade do Diretor do NAIS.

\section{Alimentação}

A alimentação é integral, fornecida pelo CAIS Cantídio através de solicitação semanal de gêneros alimentícios não perecíveis e perecíveis, a entrega dos pães e refeições é diária, e fica sob a responsabilidade do Núcleo de Nutrição e Dietética - SND.

O CAPSAD oferece aos pacientes o número de refeições previstas na Portaria GM 336/02.

Diariamente todas as refeições são anotadas num livro de controle, que fica na copa sob a responsabilidade da funcionária do setor, que contém as seguintes informações: número de refeições fornecidas no dia, número e nome dos pacientes que almoçaram no CAPSAD, número de refeições que (se) faltaram e que (se) sobraram. Durante a passagem de plantão, a equipe conversa sobre 
as refeições do dia e sobre qualquer alteração no número delas é feita através de contato com o SND do CAIS.

No CAPS, os insumos para a preparação dos lanches também são enviados pelo CAIS Cantídio e o preparo dos mesmos é realizado por funcionária do setor da copa (auxiliar de serviços gerais ou equivalente) e são disponibilizados nos horários previstos.

Quando são programados passeios e algumas comemorações extras, pelos usuários e funcionários, os pedidos específicos são feitos ao SND com antecedência de no mínimo 10 dias, porém todos esses eventos constam do planejamento semestral/anual de festas e passeios elaborados pela equipe técnica do CAPSAD, com as sugestões e aprovação dos pacientes registrada em Ata de Assembleia Semanal de Pacientes e Funcionários do CAPSAD Renascer, e encaminhada para a Gerência do SND do CAIS Cantídio, que avaliará a proposta e retornará ao serviço, com o planejamento final dos variados eventos e o cardápio elaborado.

Qualquer demanda extra é analisada individualmente de acordo com o PTI do paciente, com as possibilidades do serviço e do SND, objetivando o melhor atendimento possível, porém cuidando para que não ocorram desperdícios.

\section{Passagem de Plantão}

Realizada diariamente no horário da troca de funcionários, entre às 12:30 e 13:30 horas, com duração aproximada de uma hora, tendo como objetivo manter a continuidade das atividades assistenciais, assim como a apresentação e a discussão pela equipe, dos casos novos e dos já em acompanhamento que se fizerem necessários. As discussões mais aprofundadas elaboradas pela equipe acontecem às sextas-feiras na Reunião de Equipe Técnica.

\section{Atividades Desenvolvidas}

As atividades que compõem a grade básica do CAPS objetiva possibilitar a reabilitação psicossocial dos pacientes, que consiste na restituição plena dos direitos, das capacidades físicas e psíquicas, das vantagens e responsabilidades, que esses indivíduos tinham ou poderiam ter e para tanto, envolvem uma série de outros desdobramentos necessários, de acordo com o PTI.

- Atendimento Individual: nas diversas especialidades (assistência social, médico, enfermeiro, psicológico.) acolhimento e atendimento referências;

- Atendimento em Grupos: acolhimento, apoio, temático, família, ação, manutenção, oficinas terapêuticas e grupo cultural;

- Atendimento Familiar: em grupo ou individual de acordo com a necessidade do caso;

- Atividades Comunitárias: enfocando a integração do usuário na comunidade e sua inserção social, através do trabalho Inter 
setorial do CAPSAD com outros setores parceiros: esportes, cultura, SENAI, SENAC, ONGs, etc;

- Discussão de Casos: tem como objetivo aprofundar a compreensão dos casos discutindo e avaliando o projeto terapêutico de cada paciente. Deverá acontecer semanalmente em dia e horário pré-agendado, com a participação de toda a Equipe.

- Visita Domiciliar: ocorre mediante necessidade do caso, objetivando ampliar a compreensão dinâmica e qualificar as ações da equipe.

- Atividade de Supervisão/Ensino e Pesquisa: é um serviço aberto para realização de estágios de alunos de graduação, pósgraduação e pesquisa.

- Reunião de Equipe: objetiva planejar e avaliar os trabalhos realizados quanto à dinâmica e rotina. Deverá acontecer semanalmente, em dia e horário pré-agendado com a participação de toda a Equipe.

- Articulação com Serviços da Comunidade: os contatos com outros serviços serão feitos pelos profissionais do CAPSAD, de acordo com suas referências, nas reuniões de matriciamento com os serviços disponíveis nos municípios de origem, objetivando que o usuário se beneficie dos recursos comunitários.

\section{Atribuições dos Cargos}

Agente Estratégico de Saúde - Programa Municipal de DST/AIDS de Botucatu em parceria com o CAPSAD:

- Abordar questões relativas ao uso e abuso de álcool e outras drogas e a prevenção às DST/AIDS/Hepatites Virais, junto à equipe do CAPSAD, às UBS e PSF e Equipe Municipal de Saúde Mental, considerando as características e os objetivos do trabalho com matriciamento e rede em saúde mental no acompanhamento de indivíduos e grupos sociais;

- Participar de atividades com os usuários do CAPSAD, desenvolvendo ações educativas, visando à promoção da saúde e a prevenção das doenças, de acordo com o planejamento da equipe;

- Orientar famílias quanto à utilização dos serviços de saúde disponíveis;

- Desenvolver atividades de promoção da saúde, de prevenção das doenças, de agravos, de vigilância à saúde, por meio de visitas domiciliares e de ações educativas individuais e coletivas no CAPSAD, nos domicílios e na comunidade, mantendo a equipe informada, principalmente a respeito daquelas em situação de risco;

- Acompanhar famílias e indivíduos, de acordo com as orientações e necessidades definidas pela equipe do CAPSAD. 


\section{Oficineiro - CAPSAD II}

- Manusear materiais expressivos e/ou artísticos;

- Orientar na prática grupos de pacientes, para a realização das diversas atividades de artesanato oferecidas, de acordo com o Projeto Terapêutico Individual - PTI - elaborado pela equipe técnica por cada paciente;

- Realizar Oficinas tendo conhecimento sobre os recursos a serem utilizados para o desenvolvimento das atividades propostas.

\section{Assistente Social - CAPSAD II}

- Acolher aos pacientes identificando-se, apresentar o serviço e orientar sobre os primeiros procedimentos a serem realizados; aplicar questionário de triagem buscando conhecer aspectos principais do caso novo;

- Prestar atendimento individual ou em grupos de tratamento, aplicando os conhecimentos de serviço social, visando discutir demandas que auxiliem na sua reabilitação social;

- Intervir pontualmente conforme demanda do caso, realizando encaminhamento se necessário;

- Visitas domiciliares quando identificado à necessidade;

- Participar nos estudos e discussões de casos junto à equipe da unidade, contribuindo com a elaboração e/ou aprimoramento do PTI.

- Participar com a equipe multiprofissional no processo de alta do paciente, objetivando o retorno do mesmo ao meio familiar em condições adequadas;

- Promover e organizar a atualização do cadastro dos recursos comunitários, com vistas a sua democratização e facilidade de acesso dos pacientes aos mesmos;

- Contribuir nas atividades de recepção e agenda quando necessário e manter contato com serviços da rede de assistência para suporte no tratamento;

- Manter o contato com familiar para suporte no tratamento e realizar atividades de referência terapêutica;

- Coordenar grupos com familiares e/ou acompanhantes, com o objetivo orientar e ajudar a família na sua reestruturação frente a situação do tratamento;

- Prestar orientações a pacientes e familiares quanto aos benefícios assistenciais e de previdência e acompanhar pacientes em atividades recreativas extra CAPS;

- Atuar em equipe multiprofissional no desenvolvimento de projetos terapêuticos, seguindo proposta do serviço;

- Participar na formulação e execução dos programas promovendo e divulgando os meios profiláticos, preventivos e assistenciais;

- Realizar ações individuais e coletivas na vigilância educação e cidadania;

- Participar do planejamento e contribuir com sugestões ao superior, nas atividades desenvolvidas na instituição por 
estagiários e voluntários de acordo com a legislação e normas do conselho de classe;

- Executar outras tarefas de mesma natureza ou nível de complexidade, associadas à sua especialidade e ambiente organizacional;

- Capacitação da equipe;

- Realizar atividades de apoio matricial e discutir coma equipe casos e projetos terapêuticos;

- Atuar como supervisor de campo para graduandos de Serviço Social;

- Buscar estar constantemente em processo de aprimoramento dos seus conhecimentos através de curso, seminários e congressos pertinentes à área de saúde mental e Serviço Social;

\section{Auxiliar de Enfermagem - CAPSAD II}

- Exercer atividades de nível médio, de naturezas repetitivas, envolvendo serviços auxiliares de enfermagem, sob supervisão;

- Participar em nível de execução simples em processos de tratamento, observando, reconhecendo e descrevendo sinais e sintomas;

- Participar de atividades de educação em saúde;

- Auxiliar o enfermeiro na execução deste programa;

- Encaminhar o paciente ao banho ou promover o banho no leito;

- Realizar mudança de cúbito, trocar roupas;

- Realizar anotações no prontuário;

- Acompanhar e transportar pacientes;

- Atendimentos às famílias;

- Integrar e participar de reuniões de equipes;

- Atuar em equipe multiprofissional;

- Executar outras tarefas de mesma natureza ou nível de complexidades, associadas à sua especialidade em ambiente organizacional;

- Participar de grupos terapêuticos;

- Realizar atividades de referência terapêutica;

- Prestar assistência de enfermagem como administração de medicação injetável conforme prescrição médica;

- Supervisão de medicação oral, bem como à administração nos horários em que o paciente encontra-se no serviço;

- Observar o paciente no leito quanto à higiene, venóclise caso esteja instalado, sinais e sintomas de abstinência, agitação, delírios, alucinações; e anotar em prontuário;

- Visitas domiciliares para administração de medicação aos pacientes que no momento não apresente condições de ir ao serviço, a pacientes faltosos, ou que apresentem algum risco de inaderência ou uso abusivo à medicação;

- Orientação familiar quanto a posologia de medicação.

- Acolher o paciente, identificando-o, apresentando-se e explicando os procedimentos a serem realizados; 


\section{Enfermeiro - CAPSAD II}

- Acolher o paciente, identificando-o, apresentando-se e explicando os procedimentos a serem realizados;

- Supervisionar a equipe de enfermagem;

- Participar da elaboração de protocolos de assistência e atuar em equipe multiprofissional;

- Participar do planejamento das atividades a serem desenvolvidas, na instituição;

- Supervisionar, orientar e desenvolver serviços de enfermagem aos pacientes de álcool e drogas;

- Executar tarefas associadas a sua especialidade e ambientes organizacionais;

- Discutir com a equipe casos e projetos terapêuticos;

- Visitas domiciliares;

- Prestar assistência de enfermagem como administração de medicação injetável conforme prescrição médica;

- Realizar encaminhamentos quando não for da competência do CAPSAD;

- Participar de grupos terapêuticos;

- Realizar atividades de referência terapêutica;

- Contribuir nas atividades de recepção e agendamento quando necessário;

- Supervisão de medicação oral, bem como a administração nos horários em que o paciente encontra - se no serviço;

- Observar o paciente no leito quanto à higiene, venóclise caso esteja instalado, sinais e sintomas de abstinência, agitação, delírios e alucinações;

- Orientar quanto à patologia, sinais e sintomas de abstinência, sobre a medicação em uso, efeitos esperados e colaterais;

- Orientação familiar.

- Realizar atendimento, triagem, avaliação e acompanhamento do paciente;

\section{Médico Clínico Geral - CAPSAD II}

- Acolher o usuário, identificando-o, apresentando-se e explicando os procedimentos a serem realizados;

- Atuar em equipe multiprofissional no desenvolvimento de projetos terapêuticos individuais e familiares, realizando clínica ampliada;

- Realizar atendimento, triagem, avaliação e acompanhamento do paciente;

- Emitir atestados;

- Visitas domiciliares;

- Realizar encaminhamentos quando não for da competência do CAPS;

- Articular recursos intersetoriais disponíveis para diminuição dos agravos à saúde dos pacientes; 
- Participar do planejamento das atividades a serem desenvolvidas na instituição;

- Executar outras tarefas de mesma natureza ou nível de complexidade, associadas à sua especialidade e ambiente organizacional;

- Orientação familiar;

- Participar de grupos terapêuticos;

- Triagem, avaliação e acompanhamento nos casos de desintoxicação e tratamento do uso abusivo de substâncias psicoativas bem como comorbidades psiquiátricas;

\section{Médico Psiquiatra - CAPSAD II}

- Acolher os pacientes, identificando-o, apresentando-se e explicando os procedimentos a serem realizados;

- Atuar em equipe multiprofissional no desenvolvimento de projetos terapêuticos individuais e familiares, realizando clínica ampliada;

- Visitas domiciliares;

- Realizar atendimento ao paciente;

- Emitir atestados e laudos;

- Realizar encaminhamentos;

- Articular recursos intersetoriais disponíveis para diminuição dos agravos à saúde dos pacientes;

- Participar do planejamento das atividades a serem desenvolvidas na instituição;

- Executar outras tarefas de mesma natureza ou nível de complexidade, associadas a sua especialidade e ambiente organizacional;

- Triagem, avaliação e acompanhamento nos casos de desintoxicação e tratamento do uso abusivo de substâncias psicoativas bem como co-morbidades psiquiátricas;

- Discutir com a equipe casos e projetos terapêuticos;

- Orientação familiar;

- Visitas domiciliares.

- Participar de grupos terapêuticos;

\section{Psicólogo - CAPSAD II}

- Acolher e escutar o paciente, chamando-o pelo nome, apresentando-se e explicando os procedimentos a serem realizados;

- Planejar, coordenar, executar e avaliar as atividades de assistência do usuário de álcool e outras drogas;

- Elaborar com equipe multiprofissional, ações que visem atender integralmente as necessidades dos usuários;

- Discutir com a equipe casos e projetos, auxiliando na elaboração de projetos terapêuticos singulares, ampliando desta forma, a clínica;

- Intervir terapeuticamente com técnicas específicas nas mais diversas modalidades de atendimento individuais e grupais, 
acompanhamento terapêutico, entre outras, visando sempre o cuidado, a autonomia e a atenção psicossocial aos pacientes;

- Visitas domiciliares;

- Desenvolver projetos no território, buscando outras "settings" para ações terapêuticas, que tenham por objetivo a ampliação da clinica e a (re)inserção familiar , social e laborial do paciente;

- Estimular e auxiliar na criação de espaços de convivência para pacientes e familiares;

- Executar outras tarefas essências ao funcionamento do serviço, associadas à sua especialidade e ambiente organizacional;

- Contribuir nas atividades de recepção e agendamento de consultas quando necessário;

- Capacitação da equipe;

- Realizar atividades de apoio matricial;

- Orientação familiar;

- Participar de grupos terapêuticos;

- Realizar atividades de "referência terapêutica";

\section{Recepcionista - CAPSAD II}

- Atender ao público em geral com presteza, por telefone ou pessoalmente, ouvindo, orientando e encaminhando ao atendimento, por tipo de solicitação;

- Registrar e dar encaminhamento às reclamações;

- Agendar consultas;

- Localizar prontuários e fichas de atendimento atualmente sendo realizado por auxiliares de enfermagem.

\section{Técnico Administrativo - CAPSAD II}

- Orientar os serviços quanto às normas disciplinares e as rotinas de funcionamento da Unidade;

- Executar atividades pertinentes à área de Pessoal (controle de freqüência, férias, folgas e faltas);

- Zelar pela manutenção e conservação e uso adequado dos materiais e equipamentos da secretaria de que faz uso;

- Participar de reuniões de trabalho, alimentar o sistema de informações de saúde;

- Receber e enviar correspondência e documentos;

- Realizar atividades de referência terapêutica;

- Contribuir nas atividades de recepção e agendamento quando necessário;

- Verificar o conteúdo e a finalidade de documentos em geral a fim de organizar informações, protocolar, cadastrar, arquivar, elaborar e digitar textos, correspondências, relatórios e outros documentos;

- Tirar cópias, receber e passar fax;

- Executar outras tarefas de mesma natureza ou nível de complexidade associadas a sua especialidade;

- Realizar todas as tarefas relacionadas ao faturamento. 
- Receber todos os materiais (permanentes ou de consumo) conferir e testar quando for equipamento eletrônico;

\section{Terapeuta Ocupacional - CAPSAD II}

- Acolher o paciente, identificando-o, apresentando-se e explicando os procedimentos a serem realizados;

- Elaborar com a equipe multiprofissional, ações que visem atender integralmente as necessidades dos pacientes;

- Discutir com a equipe casos e projetos terapêuticos;

- Visitas Domiciliares;

- Estimular e auxiliar na criação de espaços de convivência para pacientes e familiares;

- Facilitar o acesso e participação dos pacientes e seus familiares no processo de tratamento, incentivando o auto cuidado e as práticas de educação em saúde;

- Planejar, organizar, coordenar e avaliar oficinas terapêuticas;

- Realizar avaliação terapêutica ocupacional dos pacientes, sempre que necessário;

- Realizar acompanhamento terapêutico, programar, estruturar e direcionar atividades de acordo com o interesse e demanda dos pacientes;

- Estabelecer estratégias de redução de danos voltadas para minimizar as consequências do uso indevido, não somente de drogas lícitas e ilícitas, bem como de outras substâncias.

- Participar de grupos terapêuticos;

- Realizar atendimento de referência terapêutica;

- Realizar assistência com base no conceito da clínica ampliada (equipes de referência e apoio matricial) discutindo com a equipe casos e projetos e auxiliando na elaboração de projetos terapêuticos singulares;

- Contribuir para a integração com a rede de Serviços de Saúde local e regional;

- Contribuir nas atividades de recepção e agendamento de consultas quando necessários. 